RENAN PÍCOLO SALVADOR

\title{
ANÁLISE COMPARATIVA DE MÉTODOS DE ENSAIO PARA CARACTERIZAÇÃO DO COMPORTAMENTO MECÂNICO DE CONCRETO REFORÇADO COM FIBRAS
}

\author{
Dissertação apresentada à Escola \\ Politécnica da Universidade de São Paulo \\ para obtenção do título de Mestre em \\ Engenharia Civil
}


RENAN PÍCOLO SALVADOR

\section{ANÁLISE COMPARATIVA DE MÉTODOS DE ENSAIO PARA CARACTERIZAÇÃO DO COMPORTAMENTO MECÂNICO DE CONCRETO REFORÇADO COM FIBRAS}

Dissertação apresentada à Escola Politécnica da Universidade de São Paulo para obtenção do título de Mestre em Engenharia Civil

Área de Concentração: Engenharia de Construção Civil e Urbana

Orientador: Professor Livre-Docente Antonio Domingues de Figueiredo 
Este exemplar foi revisado e alterado em relação à versão original, sob responsabilidade única do autor e com a anuência de seu orientador.

São Paulo, 14 de fevereiro de 2013.

Assinatura do autor

Assinatura do orientador

FICHA CATALOGRÁFICA

Salvador, Renan Pícolo

Análise comparativa de métodos de ensaio para a caracterização do comportamento mecânico de concreto reforçado com fibras / R.P. Salvador. -- ed.rev. -- São Paulo, 2013. 178 p.

Dissertação (Mestrado) - Escola Politécnica da Universidade de São Paulo. Departamento de Engenharia de Construção Civil.

1. Concreto reforçado com fibras 2. Ensaios dos materiais (Comparação; Métodos) 3. Ensaios mecânicos I. Universidade de São Paulo. Escola Politécnica. Departamento de Engenharia de Construção Civil II. t. 
DEDICATÓRIA

Ao meu amor, Talita. 


\section{AGRADECIMENTOS}

Ao professor doutor Antonio Domingues de Figueiredo, pela orientação, incentivo e acolhimento e participação em minha formação profissional.

Ao Antonio Alexandre de Moraes, diretor da empresa Construquímica, pelo enorme apoio, incentivo e disponibilização de recursos para a realização deste programa de mestrado.

A todos os amigos da empresa Construquímica, que participaram direta ou indiretamente da realização deste trabalho. Em especial, aos técnicos José Maria Pereira Nunes e Valdemir Neri Costa pela enorme colaboração nas etapas de moldagem dos corpos-de-prova.

Aos estatísticos Leandro Ruiz Consentino e Rafael Ribeiro dos Santos e ao professor doutor Alexandre Galvão Patriota, do Instituto de Matemática e Estatística da Universidade de São Paulo, pela amizade e pela grande colaboração na análise estatística dos dados experimentais.

À Geóloga MSc Liz Zanchetta D’Agostino, do Laboratório de Caracterização Tecnológica da Escola Politécnica, pela grande ajuda na realização e na interpretação das fotos por microscopia eletrônica de varredura.

Aos técnicos de laboratório da Escola Politécnica pelo auxílio na realização dos ensaios experimentais.

À Renata Monte, pela contribuição na análise estatística e na revisão desta dissertação.

Ao meu pai, José Salvador, à minha mãe, Vanda Aparecida Pícolo Salvador, e às minhas irmãs, Raquel e Angélica Pícolo Salvador, pelo carinho, apoio e incentivo.

À Talita Pieroni, pelo carinho, apoio e incentivo e compreensão. 


\section{RESUMO}

O emprego de fibras para reforço de concreto é uma técnica bastante conhecida e estudada mundialmente. As mais conhecidas e estudadas são as fibras de aço, embora utilização das macrofibras poliméricas esteja amplamente difundida no mercado brasileiro. Entretanto, a caracterização do comportamento mecânico de concretos reforçados com essas macrofibras ainda deve ser mais bem avaliada. Dentre os diversos métodos utilizados para essa finalidade, os ensaios realizados com sistema fechado de controle de velocidade de deslocamento fornecem resultados mais confiáveis. A principal vantagem conferida por esse sistema está na avaliação desses compósitos em baixo nível de fissuração com maior acurácia. O desempenho desses compósitos foi estudado segundo as normas ASTM C1609 (2010), ASTM C1399 (2010) e EN 14651 (2007) e o método JSE-SF4 (1984). Os quatro procedimentos prescrevem ensaios de flexão de corpos-de-prova prismáticos para determinação da resistência residual pós-fissuração e da tenacidade. Os procedimentos americanos e o método japonês prescrevem configuração de aplicação de carga por dois cutelos superiores, posicionados sobre o terço médio do corpo-de-prova. Já a configuração do método europeu é de aplicação de carga por apenas um cutelo superior, centralizado em relação ao vão de ensaio, com corpos-de-prova com entalhe na face inferior. Foram estudadas uma macrofibra de polipropileno, nas dosagens de $0,22,0,33,0,50,0,66,0,82$ e $1,0 \%$ em volume em três matrizes de concreto, com resistências médias à compressão de 30,35 e 40MPa, e uma fibra de aço, nas dosagens de $0,19,0,32$ e $0,45 \%$ em volume em uma matriz de resistência média à compressão de 35MPa. Foi observado que a utilização da velocidade de deslocamento do corpo-de-prova como parâmetro de controle do ensaio forneceu boas condições de avaliação do compósito, devido à redução da instabilidade pós-pico. Com isso, a determinação da resistência residual do compósito nos níveis iniciais de deslocamento e fissuração da matriz foi mais bem caracterizada. Pela análise e comparação dos resultados, foram formuladas equações para estabelecer correlações entre os diferentes métodos de ensaio. Com o modelo de regressão utilizado na análise estatística foi possível verificar que a resistência à compressão da matriz, o tipo e o teor de fibra são as variáveis independentes que mais influenciam os resultados de resistência residual. Foi necessário estabelecer correlações para cada tipo de fibra separadamente, pois o comportamento de slip-softening ou de slip-hardening influencia as funções obtidas.

Palavras chaves: concreto reforçado com fibras, macrofibra polimérica, tenacidade, sistema fechado de controle de velocidade de deslocamento. 


\begin{abstract}
The use of fibers for concrete reinforcing is a very common practice, used all over the world. Steel fibers are the most common and studied, although synthetic macrofibers are in very common use in the Brazilian market. However, the evaluation of the mechanical behavior of concrete reinforced with this type of fiber must be evaluated. A broad range of tests is available for this purpose. Tests performed under closed-loop displacement control provide more reliable results. The main advantage of that system is in the evaluation of the composite at low levels of crack opening with higher accuracy. In this study, the performance of these composites was examined according to the standard test methods ASTM C1609 (2010), ASTM C1399 (2010), EN 14651 (2007) and JSCE-SF4 (1984). These four methods prescribe flexural tests in prismatic specimens for the determination of post-crack residual strength and toughness. The American and the Japanese test methods prescribe four-point bending tests, while the European test method prescribes three-point bending tests and specimens with a notch in the bottom face. Two fibers were analyzed: a polypropylene macrofiber, used in the dosages of $0.22,0.33,0.50,0.66,0.82$ and 1.0 in volume percentage, in three concrete matrices with average compressive strengths of 30,35 and $40 \mathrm{MPa}$, and a steel fiber, in the dosages of $0.19,0.32$ and 0.45 in volume percentage, in one concrete matrix of average compressive strength of $35 \mathrm{MPa}$. It was observed that the use of the net displacement of the specimen as the parameter to control the load application provided good conditions for the evaluation of the mechanical behavior of the composite, due to the reduction of post-peak instability. Therefore, the determination of the residual strength of the composite in the initial levels of displacement and cracking of the matrix was better achieved. From the comparative analysis of the results, equations were developed to establish a correlation among the test methods. Based on the model used in the statistical analysis, the main independent variables that influence the results of residual strength are the compressive strength of the concrete matrix, the type and the content of the fiber. The equations were obtained separately according to the fiber type, because the behavior of slip-hardening or slip-softening influence the correlations.
\end{abstract}

Keywords:fiber-reinforced concrete, synthetic macrofibers, toughness, closed-loop displacement control. 


\title{
LISTA DE ABREVIATURAS E SIGLAS
}

\author{
Sigla Descrição \\ ABNT Associação Brasileira de Normas Técnicas \\ ASTM American Society for Testing Materials \\ JSCE Japanese Society of Civil Engineers \\ CEN Comitê Europeu de Normalização
}

\section{LISTA DE SÍMBOLOS}

\begin{tabular}{|c|c|c|}
\hline Símbolo & Unidade & Descrição \\
\hline $\mathrm{f}_{150,0.75}$ & $\mathrm{MPa}$ & $\begin{array}{l}\text { Resistência residual quando o deslocamento vertical do corpo-de- } \\
\text { prova for } 0,75 \mathrm{~mm} \text {, segundo ASTM C } 1609\end{array}$ \\
\hline $\mathrm{f}_{150,3.0}$ & $\mathrm{MPa}$ & $\begin{array}{l}\text { Resistência residual quando o deslocamento vertical do corpo-de- } \\
\text { prova for } 3,0 \mathrm{~mm} \text {, segundo ASTM C } 1609\end{array}$ \\
\hline $\mathrm{L}$ & $\mathrm{mm}$ & Vão de ensaio \\
\hline $\mathrm{b}$ & $\mathrm{mm}$ & Largura do corpo-de-prova \\
\hline $\mathrm{d}$ & $\mathrm{mm}$ & Altura do corpo-de-prova \\
\hline $\bar{\sigma}_{\mathrm{b}}$ & $\mathrm{MPa}$ & $\begin{array}{l}\text { Fator de tenacidade à flexão quando o deslocamento vertical do } \\
\text { corpo-de-prova for } \delta_{\mathrm{tb}} \text {, segundo JSCE-SF4 }\end{array}$ \\
\hline $\mathrm{T}_{\mathrm{b}}$ & $\mathrm{J}$ & $\begin{array}{l}\text { Tenacidade à flexão (área abaixo da curva carga por deslocamento } \\
\text { vertical), no intervalo de } 0 \mathrm{a} \delta_{\mathrm{tb}} \text {, segundo JSCE-SF4 }\end{array}$ \\
\hline$\delta_{\mathrm{tb}}$ & $\mathrm{mm}$ & Deslocamento vertical no ponto $\mathrm{L} / 150 \mathrm{~mm}$ \\
\hline$\sigma_{\mathrm{b}}$ & MPa & Resistência à tração por flexão do corpo-de-prova \\
\hline ARS & $\mathrm{MPa}$ & Resistência residual média, segundo ASTM C1399 \\
\hline $\mathrm{f}_{\mathrm{ct}, \mathrm{L}}^{\mathrm{f}}$ & MPa & Limite de proporcionalidade, segundo norma EN 14651 \\
\hline $\mathrm{f}_{\mathrm{R}, 1}$ & MPa & $\begin{array}{l}\text { Resistência residual correspondente à abertura de fissura de } 0,50 \mathrm{~mm} \text {, } \\
\text { segundo norma EN } 14651\end{array}$ \\
\hline$f_{R, 3}$ & $\mathrm{MPa}$ & $\begin{array}{l}\text { Resistência residual correspondente à abertura de fissura de } 2,5 \mathrm{~mm} \text {, } \\
\text { segundo norma EN } 14651\end{array}$ \\
\hline $\mathrm{h}_{\mathrm{sp}}$ & $\mathrm{mm}$ & $\begin{array}{l}\text { Distância entre o topo do entalhe e a face superior do corpo-de- } \\
\text { prova, segundo norma EN } 14651\end{array}$ \\
\hline
\end{tabular}




\section{LISTA DE FIGURAS}

\section{Capítulo 2}

Figura 2.1 - Representação esquemática de copolímeros randômicos (a); alternados (b); em bloco (c); e graftizado (d). .

Figura 2.2 - Distribuição do tamanho da molécula por meio da distribuição da massa molecular ou do número de moléculas de determinado tamanho. 9

Figura 2.3 - Estruturas moleculares de polímeros lineares (a); ramificados (b); e em rede (c).

Figura 2.4 - Representação esquemática do polipropileno com configuração isotática (a);

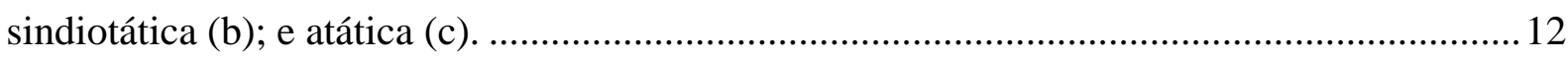

Figura 2.5 - Regiões cristalinas e amorfas de um polímero................................................... 13

Figura 2.6 - Curvas de tensão-deformação de termofixos, termoplásticos e elastômeros....... 15

Figura 2.7 - Curva de tensão-deformação de um termoplástico semicristalino........................ 16

Figura 2.8 - Mecanismos de fratura em materiais poliméricos: quebra de ligações covalentes (a) e escorregamento entre cadeias (b)

Figura 2.9 - Formação de microvazios unidos por regiões fibriladas (a) e a formação de fissuras causada pelo rompimento das regiões fibriladas $(\mathrm{b})$.................................................. 18 Figura 2.10 - Micromecanismos da fratura de um termoplástico: formação de planos de fratura (a); alongamento de segmentos de cadeia (b); alongamento máximo das cadeias (c); ruptura ou arrancamento da cadeia $(\mathrm{d})$.

Figura 2.11 - 1: Estágios na deformação elástica de um polímero semicristalino. 2: Estágios na deformação plástica de um polímero semicristalino

Figura 2.12 - Efeito da massa molecular na resistência à tração do polímero..........................21

Figura 2.13 - Curva tensão-deformação de um fio de polipropileno. 25

\section{Capítulo 3}

Figura 3.1 - Compósitos de cimento vistos como sistemas bicomponentes e suas combinações híbridas 26

Figura 3.2 - Geometria das fissuras e das falhas internas da matriz (a); Perfil de tensão ao longo do eixo X-X', demonstrando a amplificação da tensão na extremidade da fissura (b).. 29 
Figura 3.3 - Características principais das fibras de interesse para matrizes cimentícias........ 31 Figura 3.4 - Diagrama de tensão por deformação elástica de matriz e fibras de alto e baixo módulo de elasticidade trabalhando em conjunto.

Figura 3.5 - Exemplos de macrofibras poliméricas disponíveis no mercado brasileiro: macrofibra flexível na forma torcida (a); macrofibra rígida fornecida solta (b); macrofibra rígida na forma de feixe, envolvida por plástico hidrossolúvel (c).

Figura 3.6 - Interface entre fibra de aço (a) e a microfibra de polipropileno (b) com a matriz.

Figura 3.7 - A interface fibra-matriz

Figura 3.8 - Distribuição de tensões ao longo da fibra interceptando uma fissura: matriz fissurada (a); interface intacta (b); ligação fibra-matriz parcialmente rompida (c).

Figura 3.9 - Esquema de concentração de tensões para um concreto sem fibras (a) e com fibras (b)

Figura 3.10 - Mecanismos de absorção de energia entre a fibra e a matriz 42

Figura 3.11 - Conceitos de softening e hardening para classificação do comportamento de concreto reforçado com fibras

Figura 3.12 - Comportamentos da fibra durante seu arrancamento, mostrando o atrito ideal, slip-hardening e slip-softening.....

Figura 3.13 - Representação da fibra e da matriz na região da fissura: seção fissurada (a); contração da fibra, devido ao efeito de Poisson (b); fibrilação da fibra perante esforço de tração (c) 46

Figura 3.14 - Parâmetros mecânicos que controlam o comportamento do compósito 48

Figura 3.15 - Modelo de distribuição de tensões na seção transversal de um elemento reforçado com fibras durante a flexão.

Figura 3.16 - Distribuições de tensão ao longo da fibra em função de seu comprimento crítico. 52

\section{Capítulo 4}

Figura 4.1 - Configuração de ensaio para flexão em três (a) e quatro pontos (b); distribuição dos momentos para os ensaios em três (c) e quatro pontos (d). 60

Figura 4.2 - Diferença entre sistemas open-loop (a) e closed-loop (b). 
Figura 4.3 - Curvas carga - deslocamento vertical obtidas com sistemas open e closed-loop

Figura 4.4 - Esquema representativo do ensaio segundo JSCE-SF4 (1984). .........................66

Figura 4.5 - Curva carga por deslocamento vertical obtida segundo JSCE-SF4 (1984) .........68

Figura 4.6 - Curvas carga por deslocamento vertical obtidas com sistemas open-loop,

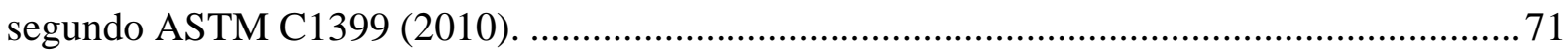

Figura 4.7 - Esquema da realização do ensaio prescrito na norma EN 14651 (2007).............75

Figura 4.8 - Curva carga por abertura de fissura obtida segundo EN 14651 (2007) .............. 75

\section{Capítulo 5}

Figura 5.1 - Coluna de densidade elaborada com soluções de água deionizada e etanol anidro.

Figura 5.2 - Ensaio de tração antes (a) e depois (b) do rompimento do fio.............................92

Figura 5.3 - Amostras do fio após o ensaio: fio desfibrilado (a) e fio rompido(b)................. 92

Figura 5.4 - Esquema da realização do ensaio de dobramento (a) e fibras ensaiadas (b)........96

Figura 5.5 - Fibras utilizadas para verificação de defeitos. …................................................97

Figura 5.6 - Amostra de fibra conforme recebida (a); fotos de um macrofio (b, c); fotos de um

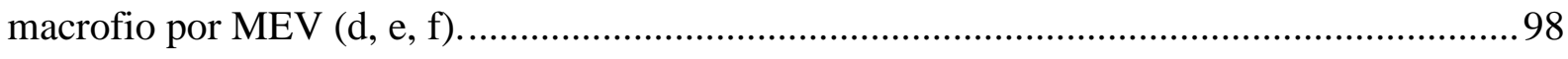

Figura 5.7 - Amostra de macrofibras retiradas do concreto fresco (a, b, c, d)....................... 99

Figura 5.8 - Amostra de macrofibra retirada da seção de ruptura de um corpo-de-prova, com a macrofibra rompida (a); interface da fibra rompida com a matriz (b); amostra retirada da seção de ruptura de um corpo-de-prova, com a macrofibra arrancada (c); vazio deixado na matriz pela fibra arrancada (d); e interface fibra-matriz (e).

Figura 5.9 - Amostra retirada da seção de ruptura de um corpo-de-prova, com a fibra de aço (a); interface da fibra com a matriz (b, c, d).

Figura 5.10 - Determinação do abatimento do tronco de cone com concreto sem fibras (a) e com 7,5kg de fibras por metro cúbico (b); determinação da densidade e do teor de ar

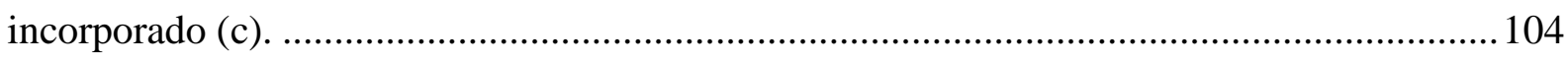

Figura 5.11 - Moldagem dos corpos-de-prova prismáticos (a, b) e cilíndricos (c); adensamento por mesa vibratória (d); corpos-de-prova após moldagem (e)......................... 105

Figura 5.12 - Cura dos corpos-de-prova em câmara úmida............................................... 105 


\section{Capítulo 6}

Figura 6.1 - Informações contidas nos gráficos do tipo boxplot ......................................... 120

Figura 6.2 - Fotografias do terço médio de um corpo-de-prova prismático. ......................... 124 


\section{LISTA DE GRÁFICOS}

\section{Capítulo 5}

Gráfico 5.1 - Curva granulométrica do agregado miúdo. 84

Gráfico 5.2 - Curva granulométrica do agregado graúdo. 85

Gráfico 5.3 - Curvas carga-alongamento obtidas para todos os fios ensaiados (a) e somente para os fios triplos (b). 93

Gráfico 5.4 - Curvas tensão-deformação obtidas para os fios triplos (a) e regressões lineares para essas curvas (b). .94

\section{Capítulo 6}

Gráfico 6.1 - Variação do abatimento dos concretos frescos com o aumento do teor de fibra.

Gráfico 6.2 - Curvas de carga por deslocamento vertical obtidas com o traço CRF 30, utilizando-se a macrofibra polimérica, segundo ASTM C1609: (a) 2,0kg/m $\mathrm{m}^{3}$; (b) $3,0 \mathrm{~kg} / \mathrm{m}^{3}$; (c) $4,5 \mathrm{~kg} / \mathrm{m}^{3}$; (d) $6,0 \mathrm{~kg} / \mathrm{m}^{3}$; (e) $7,5 \mathrm{~kg} / \mathrm{m}^{3}$; (f) $9,0 \mathrm{~kg} / \mathrm{m}^{3}$.

Gráfico 6.3 - Curvas de carga por deslocamento vertical obtidas com o traço CRF 35, utilizando-se a macrofibra polimérica, segundo ASTM C1609: (a) $2,0 \mathrm{~kg} / \mathrm{m}^{3}$; (b) $3,0 \mathrm{~kg} / \mathrm{m}^{3}$; (c) $4,5 \mathrm{~kg} / \mathrm{m}^{3} ;$ (d) $6,0 \mathrm{~kg} / \mathrm{m}^{3}$; (e) $7,5 \mathrm{~kg} / \mathrm{m}^{3}$; (f) $9,0 \mathrm{~kg} / \mathrm{m}^{3}$

Gráfico 6.4 - Curvas de carga por deslocamento vertical obtidas com o traço CRF 40, utilizando-se a macrofibra polimérica, segundo ASTM C1609: (a) 2,0kg/m $\mathrm{m}^{3}$; (b) $3,0 \mathrm{~kg} / \mathrm{m}^{3}$; (c) $4,5 \mathrm{~kg} / \mathrm{m}^{3}$; (d) $6,0 \mathrm{~kg} / \mathrm{m}^{3}$; (e) $7,5 \mathrm{~kg} / \mathrm{m}^{3}$; (f) $9,0 \mathrm{~kg} / \mathrm{m}^{3}$. 115

Gráfico 6.5 - Curvas de carga por deslocamento vertical obtidas com o traço CRF 35, utilizando-se a fibra de aço, segundo ASTM C1609: (a) $15,0 \mathrm{~kg} / \mathrm{m}^{3}$; (b) $25,0 \mathrm{~kg} / \mathrm{m}^{3}$; (c) 35,0 $\mathrm{kg} / \mathrm{m}^{3}$

Gráfico 6.6 - Curvas médias de carga por deslocamento vertical obtidas segundo ASTM C1609: (a) CRF 30, (b) CRF 35 e (c) CRF 40, com a macrofibra polimérica; (d) CRF 35, com a fibra de aço.

Gráfico 6.7 - Fator de tenacidade à flexão para os concretos CRF 30, CRF 35 e CRF 40 reforçados com a macrofibra polimérica, segundo JSCE-SF4. 
Gráfico 6.8 - Resistência residual em 0,75mm para os concretos CRF 30, CRF 35 e CRF 40 reforçados com a macrofibra polimérica, segundo ASTM C1609.

Gráfico 6.9 - Resistência residual em 3,0mm para os concretos CRF 30, CRF 35 e CRF 40 reforçados com a macrofibra polimérica, segundo ASTM C1609.

Gráfico 6.10 - Fator de tenacidade à flexão para o concreto CRF 35 reforçado com a fibra de aço, segundo JSCE-SF4.

Gráfico 6.11 - Resistência residual em $0,75 \mathrm{~mm}$ para o concreto CRF 35 reforçado com a fibra de aço, segundo ASTM C1609.

Gráfico 6.12 - Resistência residual em 3,0mm para o concreto CRF 35 reforçado com a fibra de aço, segundo ASTM C1609.

Gráfico 6.13 - Comparação entre a resistência residual em 0,75mm (a), em 3,0mm (b) e o fator de tenacidade (c) para o para o concreto CRF 35 reforçado com a fibra de aço e com a polimérica. 128

Gráfico 6.14 - Curvas de carga por deslocamento vertical referentes à segunda etapa do ensaio, obtidas com o traço CRF 30, utilizando-se a macrofibra polimérica, segundo ASTM C1399: (a) $2,0 \mathrm{~kg} / \mathrm{m}^{3}$; (b) $3,0 \mathrm{~kg} / \mathrm{m}^{3}$; (c) $4,5 \mathrm{~kg} / \mathrm{m}^{3}$; (d) $6,0 \mathrm{~kg} / \mathrm{m}^{3}$; (e) $7,5 \mathrm{~kg} / \mathrm{m}^{3}$; (f) $9,0 \mathrm{~kg} / \mathrm{m}^{3} .130$ Gráfico 6.15 - Curvas de carga por deslocamento vertical referentes à segunda etapa do ensaio, obtidas com o traço CRF 35, utilizando-se a macrofibra polimérica, segundo ASTM C1399: (a) $2,0 \mathrm{~kg} / \mathrm{m}^{3}$; (b) $3,0 \mathrm{~kg} / \mathrm{m}^{3}$; (c) $4,5 \mathrm{~kg} / \mathrm{m}^{3}$; (d) $6,0 \mathrm{~kg} / \mathrm{m}^{3}$; (e) $7,5 \mathrm{~kg} / \mathrm{m}^{3}$; (f) $9,0 \mathrm{~kg} / \mathrm{m}^{3} .131$ Gráfico 6.16 - Curvas de carga por deslocamento vertical referentes à segunda etapa do ensaio, obtidas com o traço CRF 40, utilizando-se a macrofibra polimérica, segundo ASTM C1399: (a) $2,0 \mathrm{~kg} / \mathrm{m}^{3}$; (b) $3,0 \mathrm{~kg} / \mathrm{m}^{3}$; (c) $4,5 \mathrm{~kg} / \mathrm{m}^{3}$; (d) $6,0 \mathrm{~kg} / \mathrm{m}^{3}$; (e) $7,5 \mathrm{~kg} / \mathrm{m}^{3}$; (f) $9,0 \mathrm{~kg} / \mathrm{m}^{3} .132$ Gráfico 6.17 - Curvas médias obtidas segundo ASTM C1399: (a) CRF 30, (b) CRF 35 e (c) CRF 40, com a macrofibra polimérica.

Gráfico 6.18 - Resistência residual média para os concretos CRF 30, CRF 35 e CRF 40 reforçados com a macrofibra polimérica, segundo ASTM C1399.

Gráfico 6.19 - Curvas de carga por abertura de fissura obtidas com o traço CRF 35, utilizando-se a macrofibra polimérica, segundo EN 14651: (a) $3,0 \mathrm{~kg} / \mathrm{m}^{3}$; (b) $4,5 \mathrm{~kg} / \mathrm{m}^{3}$; (c) $6,0 \mathrm{~kg} / \mathrm{m}^{3}$

Gráfico 6.20 - Curvas de carga por abertura de fissura obtidas com o traço CRF 35, utilizando-se a fibra de aço, segundo EN 14651: (a) $15,0 \mathrm{~kg} / \mathrm{m}^{3}$; (b) $25,0 \mathrm{~kg} / \mathrm{m}^{3}$; (c) $35,0 \mathrm{~kg} / \mathrm{m}^{3}$. 
Gráfico 6.21 - Curvas médias de carga por abertura de fissura, segundo EN 14651, obtidas com o traço CRF 35 reforçado com a macrofibra polimérica (a) e com a fibra de aço (b)....137 Gráfico 6.22 - Resistência residual para abertura de fissura de $0,50 \mathrm{~mm}$, para o concreto CRF 35 reforçado com a macrofibra polimérica e com a fibra de aço, segundo EN 14651 139 Gráfico 6.23 - Resistência residual para abertura de fissura de 2,50mm, para o concreto CRF 35 reforçado com a macrofibra polimérica e com a fibra de aço, segundo EN 14651 139

\section{Capítulo 7}

Gráfico 7.1 - Resistências residuais $\left(\mathrm{f}_{150,3.0}\right.$ e ARS) pelo teor de macrofibra polimérica, obtidas com o traço CRF 30. 144

Gráfico 7.2 - Resistências residuais $\left(\mathrm{f}_{150,3.0}\right.$ e ARS) pelo teor de macrofibra polimérica, obtidas com o traço CRF 35.

Gráfico 7.3 - Resistências residuais $\left(\mathrm{f}_{150,3.0}\right.$ e ARS) pelo teor de macrofibra polimérica, obtidas com o traço CRF 40. 145

Gráfico 7.4 - Gráfico dos resíduos pelos valores preditos (a) e dos resíduos padronizados pelos valores preditos (b). 146

Gráfico 7.5 - Gráfico normal de probabilidades com envelope gerado pelo modelo gama, para a equação (7.3)

Gráfico 7.6 - Curvas de tendência entre os valores médios da resistência residual para os ensaios ASTM C1609 e ASTM C1399, para o traço CRF 30.

Gráfico 7.7 - Curvas de tendência entre os valores médios da resistência residual para os ensaios ASTM C1609 e ASTM C1399, para o traço CRF 35. 151

Gráfico 7.8 - Curvas de tendência entre os valores médios da resistência residual para os ensaios ASTM C1609 e ASTM C1399, para o traço CRF 40. 151

Gráfico 7.9 - Razão entre as funções obtidas para os traços CRF 30, CRF 35 e CRF 40.... 152 Gráfico 7.10 - Gráfico normal de probabilidades com envelope gerado pelo modelo gama, para a equação (7.14) 155

Gráfico 7.11 - Gráfico normal de probabilidades com envelope gerado pelo modelo gama, para a equação (7.15). 156

Gráfico 7.12 - Razão entre as resistências residuais no ELU e no ELS, feita a partir das funções obtidas para as normas ASTM C1609 e EN 14651, para a macrofibra polimérica. . 158 
Gráfico 7.13 - Razão entre os métodos de ensaio, feita a partir das funções obtidas para as normas ASTM C1609 e EN 14651, para a macrofibra polimérica. 158

Gráfico 7.14 - Razão entre as resistências residuais no ELU e no ELS, feita a partir das funções obtidas para as normas ASTM C1609 e EN 14651, para a fibra de aço.

Gráfico 7.15 - Razão entre os métodos de ensaio, feita a partir das funções obtidas para as normas ASTM C1609 e EN 14651, para a fibra de aço.

Gráfico 7.16 - Correlação entre as resistências residuais $f_{R, 1}$ e $f_{150,0.75}$ (EN 14651 e ASTM C1609, respectivamente).

Gráfico 7.17 - Correlação entre as resistências residuais $f_{R, 3}$ e $f_{150,3.0}$ (EN 14651 e ASTM C1609, respectivamente).

Gráfico 7.18 - Correlação entre as resistências residuais médias em 0,75 e 3,0mm (ASTM C1609) e o fator de tenacidade médio (JSCE-SF4). 163

Gráfico 7.19 - Correlação entre a resistência residual média (ASTM C1399) e o fator de tenacidade médio (JSCE-SF4). 164 


\section{LISTA DE TABELAS}

\section{Capítulo 2}

Tabela 2.1 - Propriedades e aplicações de alguns polímeros .7

\section{Capítulo 3}

Tabela 3.1 - Propriedades típicas de fibras sintéticas. 35

Tabela 3.2 - Fator de orientação para elementos restringidos e não restringidos. 49

Tabela 3.3 - Seções possíveis para fibras e os valores correspondentes do FIER, comparados com a fibra circular. 53

\section{Capítulo 4}

Tabela 4.1 - Classes para as resistências residuais $\mathrm{f}_{\mathrm{R}, 3 \mathrm{k}} / \mathrm{f}_{\mathrm{R}, 1 \mathrm{k}}$, obtidas pelo ensaio EN 14651. 77

Tabela 4.2 - Resumo dos principais itens dos cinco procedimentos normalizados. 79

\section{Capítulo 5}

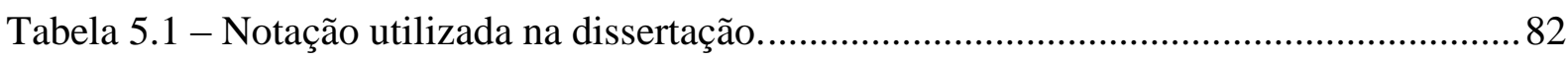

Tabela 5.2 - Ensaios, traços e teores utilizados com a macrofibra polimérica. ........................ 82

Tabela 5.3 - Ensaios, traços e teores utilizados com a fibra de aço ...................................... 82

Tabela 5.4 - Propriedades físicas e mecânicas do cimento...................................................... 83

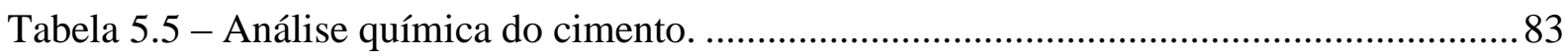

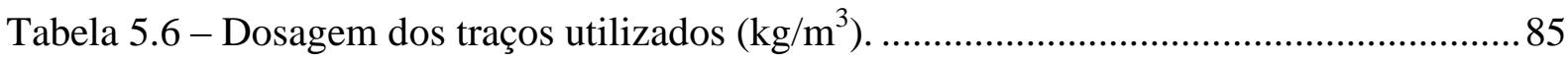

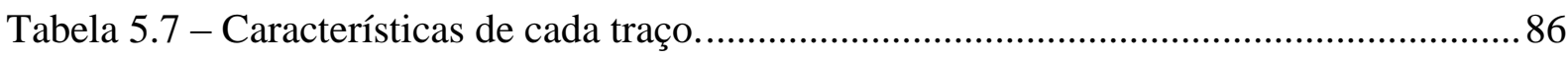

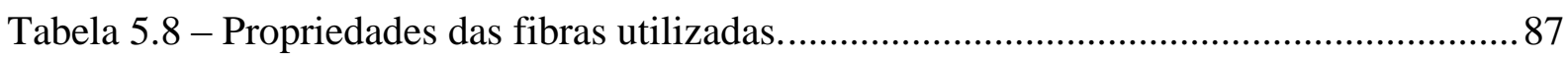

Tabela 5.9 - Parâmetros de conformidade para macrofibras poliméricas, segundo ASTM D7508. 87

Tabela 5.10 - Caracterização dimensional da macrofibra polimérica...................................... 88

Tabela 5.11 - Soluções utilizadas na elaboração da coluna de densidade. ............................. 89 
Tabela 5.12 - Resultados obtidos a partir da análise das curvas carga-alongamento e tensão-

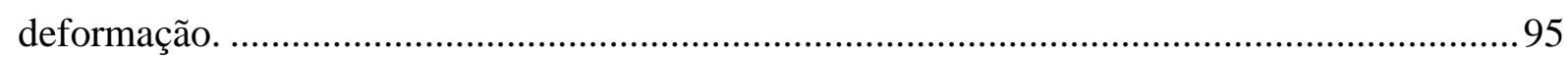

Tabela 5.13 - Ensaios e critérios de aceitação para a fibra de aço ........................................ 95

Tabela 5.14 - Caracterização dimensional da fibra de aço. .................................................... 96

Tabela 5.15 - Parâmetros de ensaio para cada procedimento ............................................... 106

\section{Capítulo 6}

Tabela 6.1 - Características físicas dos concretos frescos. 108

Tabela 6.2 - Resultados de resistência à compressão obtidos com a primeira série de ensaios (ASTM C1609 e ASTM C1399), com os traços CRF 30 / PP, CRF 35 / PP, CRF 40 / PP e CRF 35 / AÇO.

Tabela 6.3 - Resultados de resistência à compressão obtidos com a segunda série de ensaios (EN 14651), com os traços CRF 35 / PP e CRF 35 / AÇO.

Tabela 6.4 - Resultados obtidos segundo ABNT NBR 9778 (2005b). 112

Tabela 6.5 - Resultados obtidos com as curvas carga por deslocamento vertical dos traços CRF 30 / PP, CRF 35 / PP, CRF 40 / PP e CRF 35 / AÇO, segundo ASTM C1609. .119

Tabela 6.6 - Comparação de valores das resistências residuais em 0,75 e 3,0mm de deslocamento vertical com o concreto reforçado com a fibra de aço com os dados publicados por Bernard (2009).

Tabela 6.7 - Resultados obtidos com as curvas carga por deslocamento vertical dos traços CRF 30 / PP, CRF 35 / PP e CRF 40 / PP, segundo ASTM C1399..... 134

Tabela 6.8 - Resultados obtidos com as curvas carga por abertura de fissura dos traços CRF 35 / PP e CRF 35 / AÇO, segundo EN 14651. 138

Tabela 6.9 - Classificação de desempenho segundo critérios apresentados no Model Code fíb 2010. 140

Tabela 6.10 - Comparação de valores de resistência residual obtidos com o concreto reforçado a macrofibra polimérica no teor de $4,8 \mathrm{~kg} / \mathrm{m}^{3}$ com os valores publicados por Buratti, Mazzotti e Savoia (2011).

Tabela 6.11 - Comparação de valores de resistência residual $f_{R, 1}$ obtidos com o concreto reforçado com a fibra de aço nos teores de 15,25 e $35 \mathrm{~kg} / \mathrm{m}^{3}$ publicados por Barros et al (2005). 


\section{Capítulo 7}

Tabela 7.1 - Valores estimados para os parâmetros utilizados na equação (7.1) 149

Tabela 7.2 - Equações para determinação da resistência residual média para os diferentes traços de concreto e ensaios realizados.

Tabela 7.3 - Razões entre as equações dos modelos de resistência residual obtidas para os métodos ASTM C1609 e ASTM C1399.

Tabela 7.4 - Valores estimados para os parâmetros utilizados na equação (7.13), para o concreto reforçado com a macrofibra polimérica.

Tabela 7.5 - Valores estimados para os parâmetros utilizados na equação (7.15), para o concreto reforçado com a fibra de aço. 155

Tabela 7.6 - Equações para determinação da resistência residual para as normas ASTM C1609 e EN 14651.

Tabela 7.7 - Razões entre as equações de determinação da resistência residual para as normas ASTM C1609 e EN 14651.

\section{Apêndice 1}

Tabela A1.1 - Valores de referência, segundo o critério de Chauvenet. 178 


\section{SUMÁRIO}

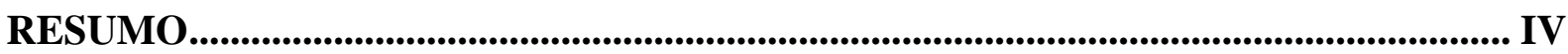

ABSTRACT

LISTA DE ABREVIATURAS E SIGLAS ....................................................................

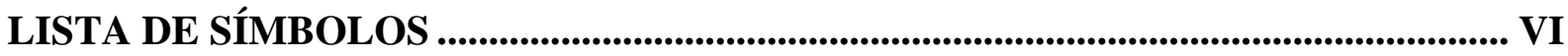

LISTA DE FIGURAS................................................................................................. VII

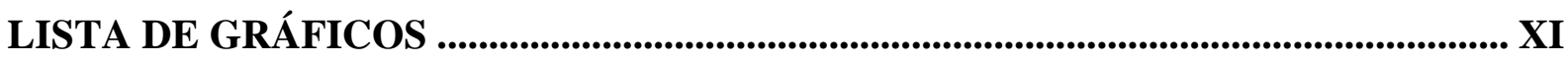

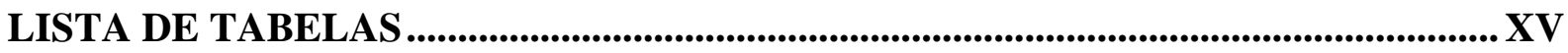

1 Introdução........................................................................................1 1

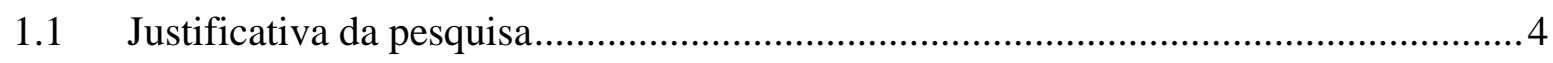

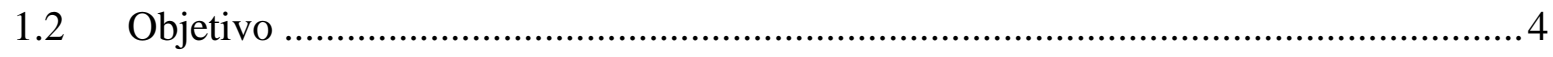

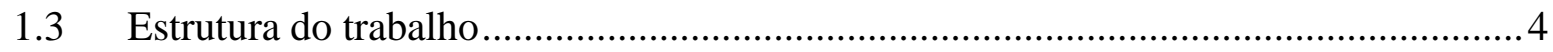

2 Química e propriedades de polímeros ................................................ 6

2.1 Química e microestrutura de polímeros ...............................................................

2.1.1 Composição química e sequencia de distribuição de monômero ...........................

2.1.2 Distribuição de massa molecular ........................................................................

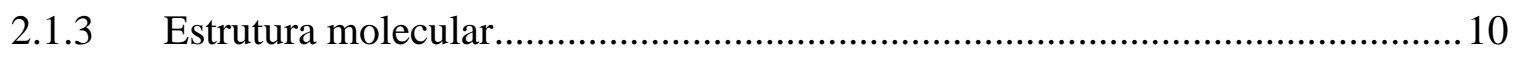

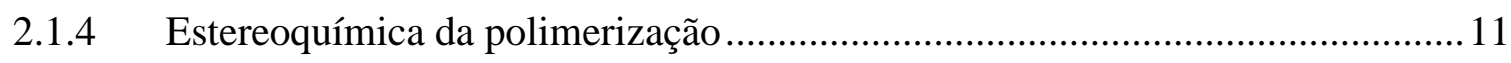

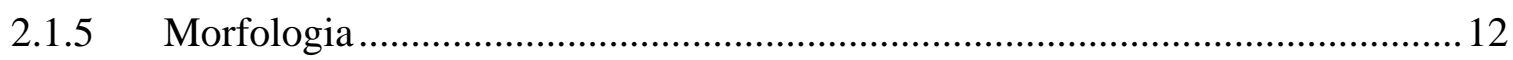

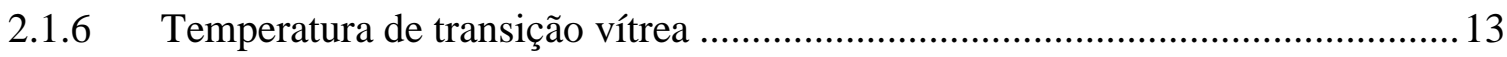

2.2 Comportamento mecânico de polímeros .............................................................. 14

2.2.1 Deformação e viscoelasticidade em polímeros ................................................... 14

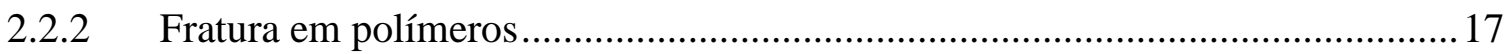

2.2.3 Mecanismo de deformação para aumento da resistência mecânica de polímeros 19

2.2.4 Fatores que influenciam as propriedades mecânicas de polímeros ................... 21

2.3 Superfícies e interfaces de materiais poliméricos ...............................................23

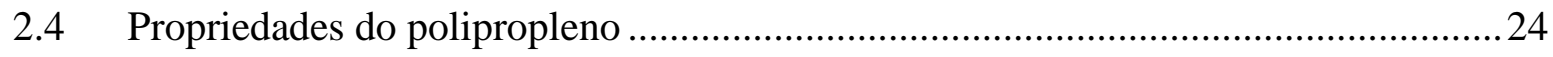


3 Concreto reforçado com fibras ...............................................................26

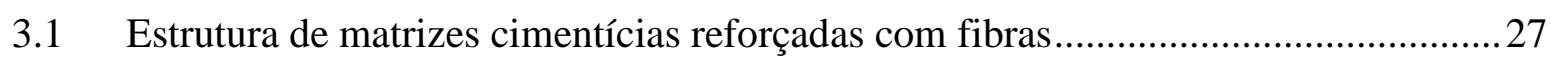

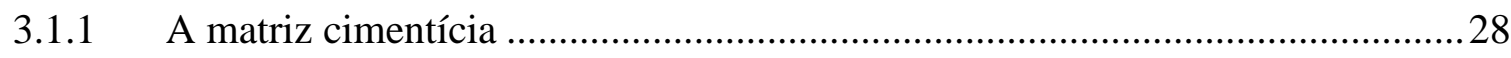

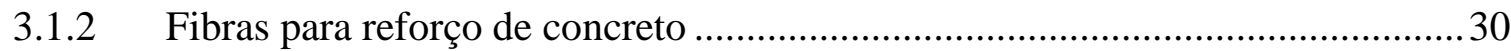

3.1.2.1 Macrofibras poliméricas para reforço de concreto ......................................... 33

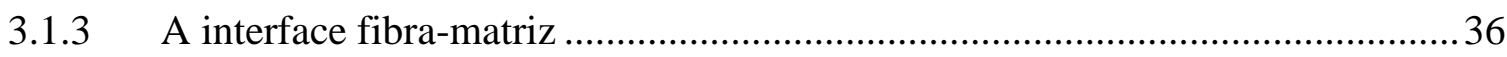

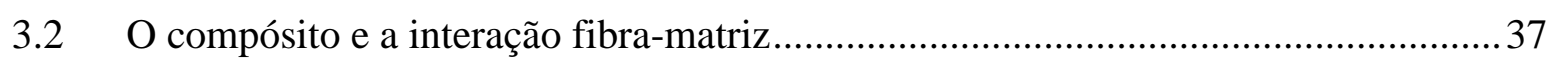

3.3 Comportamento mecânico de concreto reforçado com fibras ................................. 40

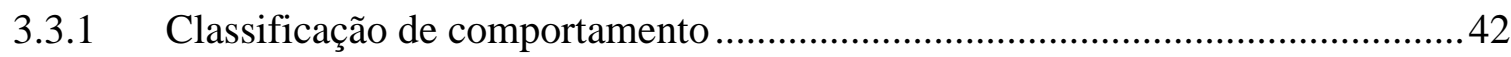

3.3.2 Fatores que influenciam o comportamento mecânico de concreto reforçado com

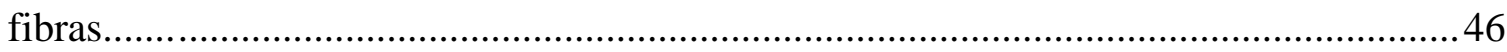

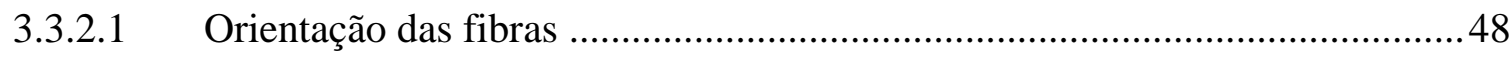

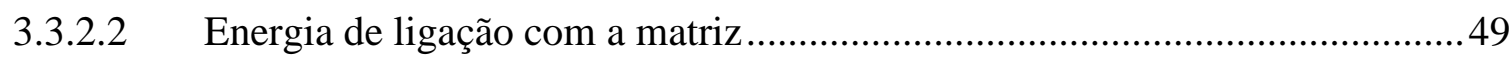

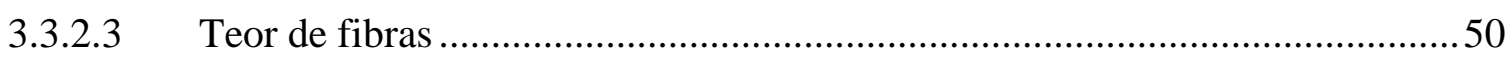

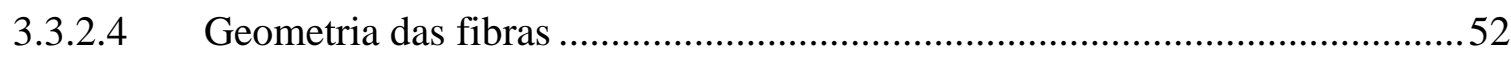

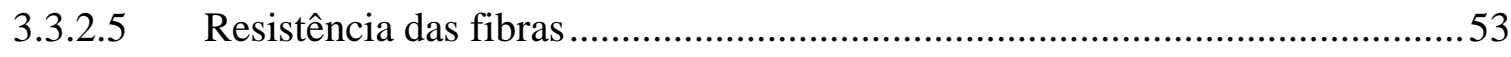

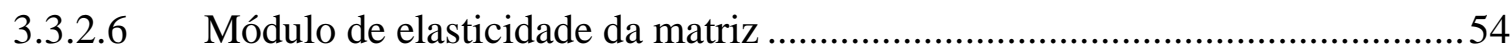

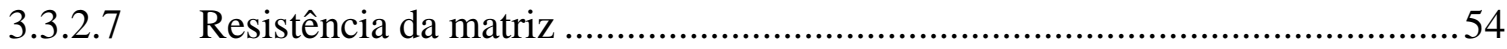

3.4 Propriedades de concreto reforçado com fibras de poliproprileno ............................55

3.5 Aplicações de concreto reforçado com fibras .....................................................57

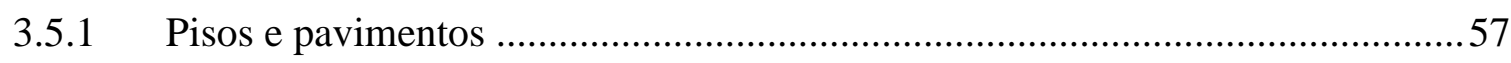

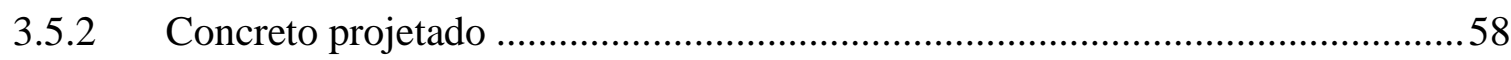

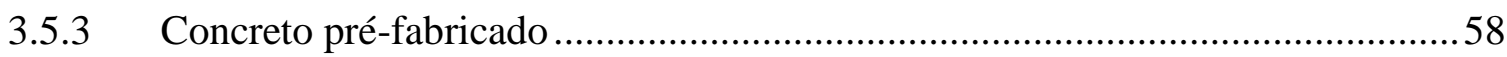

\section{Métodos para avaliação do comportamento mecânico de concreto} reforçado com fibras

4.1 A instabilidade pós-pico e o efeito dos sistemas operacionais na determinação da tenacidade 61

4.2 Procedimentos de ensaio normalizados 65

4.2.1 JSCE-SF4 (1984) - Método de ensaio de resistência e tenacidade à flexão de concreto reforçado com fibras de aço 65

4.2.2 ASTM C1609 (2010) - Método de avaliação do desempenho à flexão de concreto reforçado com fibras 
4.2.3 ASTM C1399 (2010) - Método para obtenção de resistência residual de concreto reforçado com fibras

4.2.4 EN 14651 (2007) - Método de ensaio para concreto reforçado com fibras metálicas - Determinação da resistência à tração por flexão (limite de proporcionalidade

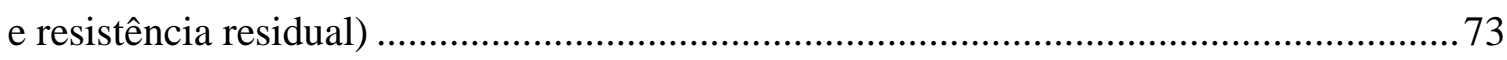

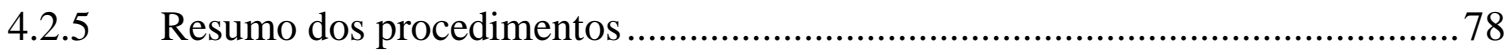

4.3 Determinação da resistência à compressão .............................................................. 80

\section{Metodologia experimental .........................................................................8 81}

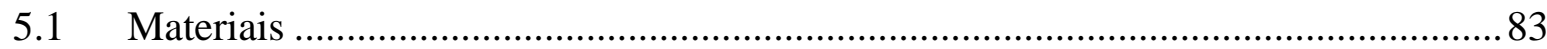

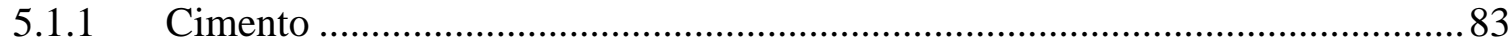

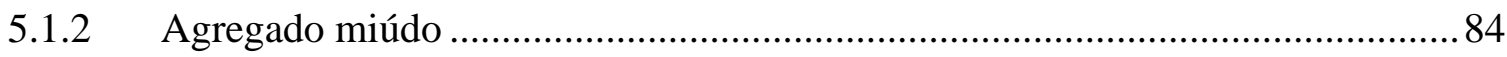

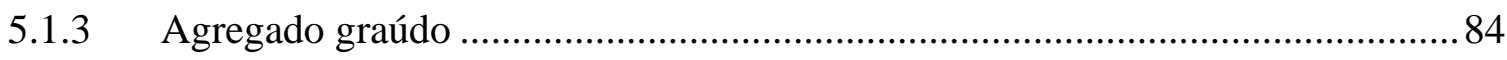

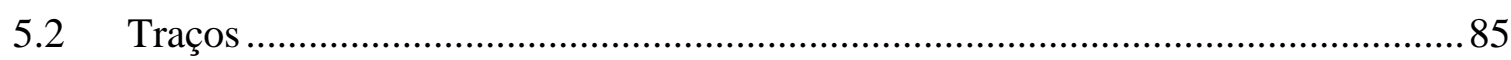

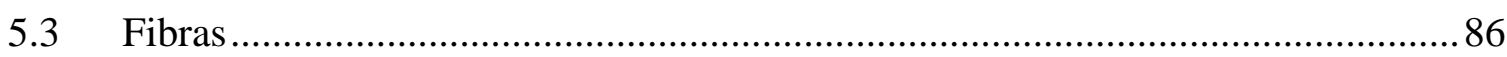

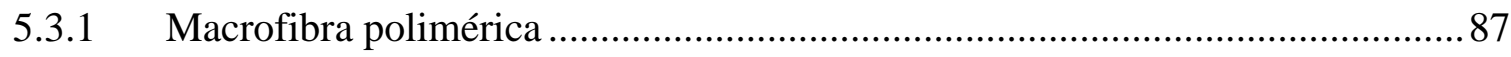

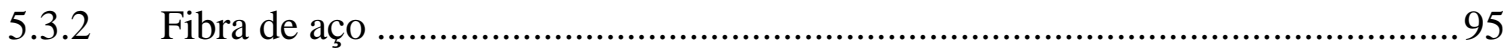

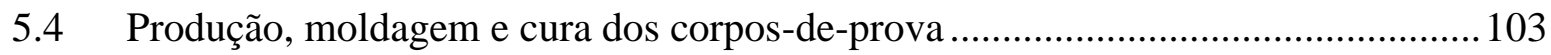

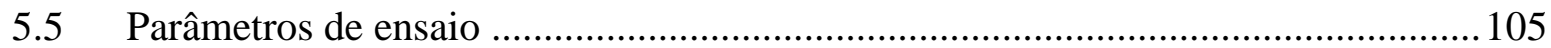

\section{Resultados experimentais ............................................................ 107}

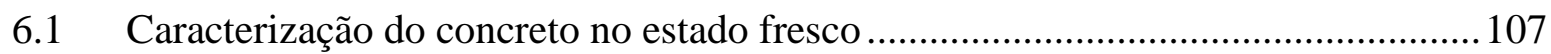

6.2 Determinação da resistência à compressão............................................................ 109

6.3 Determinação da absorção de água, índice de vazios e massa específica ...............111

6.4 Resultados obtidos com o ensaio da norma ASTM C1609 e do método JSCE-

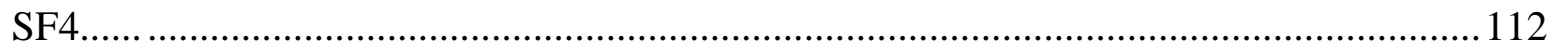

6.5 Resultados obtidos com o ensaio da norma ASTM C1399 …...............................129

6.6 Resultados obtidos com o ensaio da norma EN 14651 ........................................ 135

\section{Comparação de métodos de ensaio.................................................... 142}

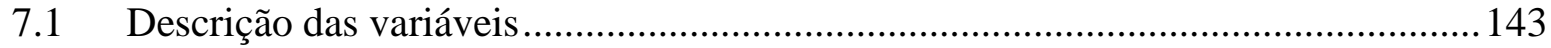

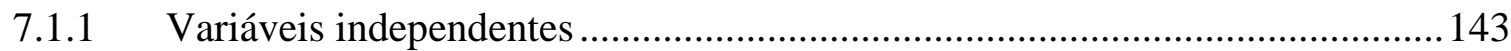

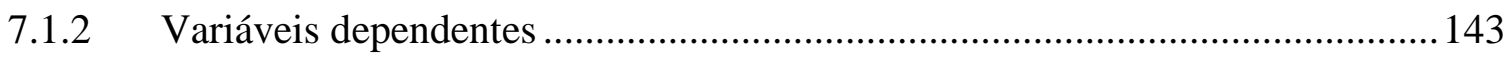


7.2 Comparação entre os métodos ASTM C1609 e ASTM C1399

7.3 Comparação entre os métodos ASTM C1609 e EN 14651

7.4 Comparação entre os métodos JSCE SF4, ASTM C1609 e ASTM C1399 162

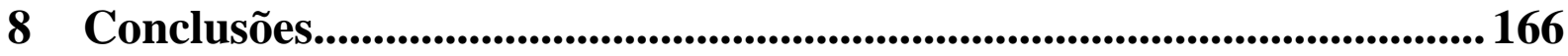

9 Referências bibliográficas ........................................................................ 169

Apêndice 1 - Critério de Chauvenet.............................................................. 178 


\section{Introdução}

Concreto, material estrutural amplamente utilizado em todo o mundo, tem sido assunto de pesquisas contínuas no ramo da construção. Embora esse compósito apresente diversas vantagens, como a alta resistência mecânica, a rapidez na execução, a fácil moldabilidade e o custo relativamente baixo, também apresenta determinadas limitações, como a baixa capacidade de deformação e a rápida propagação de fissuras quando submetido a esforços de tração (BARRAGÁN, 2002; FIGUEIREDO, 2011a).

Com o intuito de minimizar tais limitações, o emprego de fibras para reforço de misturas cimentícias apresentou grande progresso nas últimas décadas. Diferentemente da armadura convencional, que é localizada e necessita prévia montagem, as fibras são misturadas diretamente ao concreto e distribuídas aleatoriamente, reduzindo tempo, mão-deobra e custo de certas aplicações em relação ao processo tradicional (FIGUEIREDO, 2011a).

A incorporação de fibras em misturas cimentícias promove uma melhora significativa em diversas propriedades mecânicas da matriz, com destaque para a tenacidade à flexão, a resistência à fadiga e ao impacto. Proporcionam um grande aumento na capacidade de absorção de energia e transferem tensões através das fissuras, reduzindo sua propagação e expansão (NATARAJA; DHANG; GUPTA, 2000; NUNES, 2006). Além disso, concreto reforçado com fibras apresenta maior ductilidade em relação às matrizes não reforçadas, que se tornam deficientes após a formação de primeira fissura (FIGUEIREDO, 2011a; KIM; NAAMAN; EL-TAWIL, 2008; LIM; OH, 1999).

As propriedades mecânicas de concreto reforçado com fibras são objeto de estudo de muitos pesquisadores, podendo ser citados os trabalhos de Bentur e Mindess (2007), di Prisco, Plizzari e Vandewalle (2009) e Figueiredo (2011b). Entretanto, a comparação dos resultados obtidos por diferentes métodos para análise do comportamento mecânico desse compósito não está amplamente difundida, principalmente tratando-se da utilização de macrofibras poliméricas.

Diversos estudos foram publicados sobre a investigação do comportamento de fibras de aço em matrizes de concreto (BANTHIA; SAPPAKITTIPAKORN, 2007; BARRAGÁN, 2002; FIGUEIREDO, 1997; KIM; NAAMAN; EL-TAWIL, 2008). As reações ocasionadas por esforços de flexão e a deformação resultante desse processo são caracterizadas. Os parâmetros fundamentais que influenciam as propriedades do concreto reforçado com fibras 
são o tipo de fibra (material constituinte, geometria e propriedades de interface com a matriz) e sua fração volumétrica (FIGUEIREDO, 2011a).

Surgidas na década de 1990 como materiais alternativos às fibras de aço, as macrofibras poliméricas, compostas principalmente de polipropileno, se mostram muito interessantes para aplicações em pisos e pavimentos, concreto projetado e elementos préfabricados (AULIA, 2002; FIGUEIREDO, 2011a). Sua utilização já está amplamente difundida no mercado brasileiro, que apresenta vasta gama de produtos e distribuidores. Dentre as principais vantagens apresentadas por esse tipo de fibra, podem ser citadas a maior facilidade de homogeneização e distribuição durante a mistura e das operações de acabamento superficial, maior flexibilidade, maior resistência química e durabilidade (BENTUR; MINDESS, 2007).

A forma mais tradicional para a avaliação do comportamento mecânico do concreto com fibras é por meio da determinação da tenacidade ou da resistência residual pós-fissuração no ensaio de flexão em prismas. Os ensaios de flexão são os mais utilizados, pois esse é o modo que o elemento de concreto recebe aplicação de carga quanto este está em uso, como em pisos e revestimentos de túneis (BERNARD, 2009). Existem várias normas que focam esse tipo de ensaio, como a ASTM C1609 (2010a), a ASTM C1399 (2010b), a JSCE-SF4 (1984) e a EN 14651 (2007), cujas descrições estão no capítulo 4.

Um ensaio que apresenta uma configuração diferente de um ensaio de flexão é o ensaio Barcelona. Nesse caso, é realizado um ensaio de compressão de corpos-de-prova cilíndricos com um indutor de fissuração em cada face. É obtida uma curva de carga por abertura da circunferência do corpo-de-prova, que é analisada pela obtenção das cargas residuais. É um método bastante interessante para a avaliação de estruturas, já que a extração do testemunho é mais facilmente executada (REQUENA, 2006).

O objetivo de um ensaio de flexão de concreto reforçado com fibras é obter uma curva da carga aplicada pelo deslocamento vertical ou abertura de fissura para caracterização do comportamento mecânico do compósito. Esses ensaios sofrem influência das características do equipamento $\operatorname{logo}$ após a ruptura do corpo-de-prova, sendo necessários equipamentos sofisticados para a obtenção de resultados mais confiáveis (BERNARD, 2009).

A norma americana ASTM C1609 e o método japonês JSCE-SF4 são similares entre si. A principal diferença é que o método japonês é realizado mantendo-se a velocidade de avanço do pistão constante, independentemente de qual seja o comportamento do corpo-deprova. Já a norma americana estabelece que a velocidade de deslocamento do corpo-de-prova 
seja mantida constante durante o ensaio e que essa medida seja utilizada como sinal de retorno ao controlador (BERNARD, 2009).

O parâmetro de controle da velocidade do ensaio apresenta grande influência na obtenção da curva carga-deslocamento vertical (BERNARD, 2009; GETTU et al, 1996). Quando são utilizados sistemas open-loop, onde a velocidade do pistão é utilizada para controlar o ensaio, é frequente a ocorrência de uma região de instabilidade pós-pico, que corresponde a um intervalo de deformação rápida e sem controle, devido à rápida transferência de carga da matriz para as fibras quando ocorre a ruptura do concreto. Este fenômeno é característico de concretos com baixo teor de fibras, pois a capacidade resistente pós-fissuração é menor que a capacidade resistente da matriz. Seu efeito é uma superestimativa da deformação do material, aumentando a área abaixo da curva cargadeslocamento vertical para baixos níveis de deslocamento e, consequentemente, aumentando a tenacidade do compósito (BANTHIA; DUBEY, 1999; BERNARD, 2009).

O método mais preciso para determinação da tenacidade e da resistência residual pósfissuração de matrizes cimentícias reforçadas com fibras é baseado em um sistema fechado de controle de velocidade de deslocamento (closed-loop). Esse sistema permite que o deslocamento vertical ou a abertura de fissura do corpo-de-prova sejam mantidos constantes, além de serem utilizados para controlar a aplicação de carga. Utilizando esse sistema, obtémse uma grande diminuição da instabilidade pós-pico e verifica-se que mesmo após a ruptura da matriz é necessário continuar aplicando carga no corpo-de-prova para que este sofra deformação. Com isso, obtém-se maior confiabilidade na caracterização de diferentes fibras para reforço de concreto (BANTHIA; DUBEY, 1999; BERNARD, 2009; GETTU et al, 1996). Para promover aumento da precisão do ensaio, é necessário utilizar equipamentos de alta rigidez, para que, após o rompimento da matriz, a energia liberada não seja dissipada no corpo-de-prova em teste. Além disso, é necessário que o sistema de aquisição de dados possa computar os sinais de retorno rapidamente (BERNARD, 2009).

Apesar destes fatos já serem discutidos na literatura há algum tempo, não se tem conhecimento de resultados publicados utilizando-se essa metodologia no Brasil, para a avaliação de comportamento mecânico de concretos reforçados com macrofibras poliméricas, que são pouco enfocadas em pesquisas. Dessa forma, no sentido de prover valores referenciais de comportamento para esse tipo de compósito nesta condição de avaliação, foi desenvolvido o estudo experimental descrito a seguir. 


\subsection{Justificativa da pesquisa}

No Brasil, ainda não foram publicados estudos sobre a utilização de equipamento com sistema fechado de controle de velocidade de deslocamento vertical para ensaio de concreto reforçado com macrofibras poliméricas. Para realização de um ensaio com esse sistema, é exigida uma instrumentação complexa e sofisticada, que não está presente na maioria dos laboratórios brasileiros de controle tecnológico e em centros de pesquisa.

Os resultados obtidos com os diversos métodos e a correlação entre eles são de extrema importância, pois podem fornecer dados necessários para o dimensionamento de elementos compostos por concreto reforçado com fibras. Além disso, no Brasil ainda não foi publicada norma específica para avaliar o comportamento mecânico desse compósito. Portanto, este programa experimental pode servir como literatura base para a elaboração de um procedimento normatizado para o mercado brasileiro.

\subsection{Objetivo}

Este projeto de pesquisa tem como objetivo principal a comparação e a correlação entre métodos de ensaio utilizados para caracterização do desempenho mecânico de concreto reforçado com fibras. Para isso, serão utilizados quatro procedimentos de ensaio: ASTM C1609 (2010a), ASTM C1399 (2010b), JSCE-SF4 (1984) e EN 14651 (2007). Além disso, pretende-se comparar o desempenho de macrofibras sintéticas com as fibras de aço, com o intuito de avaliar a capacidade de reforço dessas macrofibras.

\subsection{Estrutura do trabalho}

Esta dissertação está organizada em 9 capítulos, que versam sobre os seguintes temas:

a) Capítulo 1: Introdução ao tema, com o objetivo e a justificativa da pesquisa; 
b) Capítulo 2: Revisão bibliográfica sobre a química de macromoléculas e a utilização de polímeros em engenharia;

c) Capítulo 3: Revisão bibliográfica sobre concreto reforçado com fibras e sobre fibras utilizadas para essa finalidade;

d) Capítulo 4: Métodos de ensaio de concreto reforçado com fibras. Esse capítulo descreve cada ensaio realizado no programa experimental;

e) Capítulo 5: Metodologia experimental. Nesse capítulo, são descritos todos os procedimentos realizados, as variáveis dos ensaios, os materiais e equipamentos utilizados;

f) Capítulo 6: Resultados e discussão. São expostos os resultados encontrados;

g) Capítulo 7: Comparação de métodos. Nesse capítulo, são mostradas as correlações entre os métodos de ensaio avaliados;

h) Capítulo 8: Conclusões;

i) Capítulo 9: Referências bibliográficas. 


\section{Química e propriedades de polímeros}

Os polímeros são um dos grupos de materiais sintéticos mais importantes para a vida moderna. São materiais de alto peso molecular, produzidos pela união de pequenas moléculas (monômeros) por ligações covalentes. Essas macromoléculas são interessantes devido às suas características físicas, que as tornam úteis para diversas aplicações (ASUA, 2007; BRUICE, 2010).

Desde a década de 1930, avanços na pesquisa e no desenvolvimento na química de polímeros orgânicos promoveram um altíssimo crescimento na tecnologia de diversos materiais, como plásticos, polímeros de alto desempenho, revestimentos (tintas e vernizes) e elastômeros. Dentre os principais motivos para essa evolução, podem ser citados (BROWN, 2002; EBEWELE, 1996):

a) As principais matérias-primas para a síntese de polímeros, que são derivadas de petróleo, tem custo relativamente baixo;

b) Existem processos especiais de fabricação de polímeros que os tornam específicos para seu uso final;

c) O custo baixo de matérias-primas aliado ao conhecimento de processos de produção faz com que a fabricação de diversos produtos a partir de polímeros seja mais barata do que se forem utilizados madeira, cerâmica ou metais;

d) Devido à sua baixa densidade, os produtos finais são relativamente leves.

A grande versatilidade dos polímeros é devida à variedade e à diversidade de possibilidades de organização de sua complexa microestrutura, podendo-se obter líquidos e borrachas macias até sólidos rígidos. Diversos fatores podem influenciar as propriedades desses materiais, como a composição química, a distribuição de massa molecular, a configuração da cadeia e o processo de produção, dentre outros (ASUA, 2007; BROWN, 2002; EBEWELE, 1996).

Este capítulo versa sobre a química e a microestrutura de polímeros, além de suas características, propriedades macroscópicas e comportamento mecânico. 


\subsection{Química e microestrutura de polímeros}

\subsubsection{Composição química e sequencia de distribuição de monômero}

A composição química do polímero é um dos principais fatores que determinam suas propriedades e aplicações. Dependendo da estrutura dos monômeros (grupos funcionais, cadeia carbônica, estado físico, etc.), determina-se o qual o processo mais adequado para a obtenção do polímero e quais propriedades físicas podem ser obtidas (WIEBECK; HARADA, 2005).

A tabela 2.1 apresenta alguns polímeros, com suas propriedades e aplicações (BRUICE, 2010; CALLISTER, 2002; MARK, 1999; WIEBECK; HARADA, 2005).

Tabela 2.1 - Propriedades e aplicações de alguns polímeros (BRUICE, 2010; CALLISTER, 2002; MARK, 1999; WIEBECK; HARADA, 2005).

\begin{tabular}{|c|c|c|c|c|}
\hline Polímero & Sigla & $\begin{array}{c}\text { Tipo de } \\
\text { polimerização }\end{array}$ & Propriedades físicas & Aplicações típicas \\
\hline Poliamidas & $\begin{array}{l}\text { Nylon } 6,6 \\
\text { (exemplo) }\end{array}$ & Condensação & $\begin{array}{l}\text { Alta resistência mecânica, } \\
\text { boa tenacidade }\end{array}$ & $\begin{array}{l}\text { Produtos têxteis e revestimentos } \\
\text { para fios e cabos }\end{array}$ \\
\hline $\begin{array}{l}\text { Policloreto de } \\
\text { vinila }\end{array}$ & PVC & Aniônica & $\begin{array}{l}\text { Isolante elétrico, } \\
\text { alta rigidez }\end{array}$ & Canos e conduítes \\
\hline Poliestireno & PS & Aniônica & $\begin{array}{l}\text { Estabilidade térmica, } \\
\text { isolante térmico e elétrico }\end{array}$ & $\begin{array}{c}\text { Embalagens, peças automotivas e } \\
\text { itens para isolamento térmico }\end{array}$ \\
\hline $\begin{array}{l}\text { Polietileno de } \\
\text { alta densidade }\end{array}$ & PEAD & Coordenada & $\begin{array}{l}\text { Alto módulo, } \\
\text { alta tenacidade }\end{array}$ & Embalagens e tubulações \\
\hline $\begin{array}{l}\text { Polietileno de } \\
\text { baixa densidade }\end{array}$ & PEBD & Radicalar & $\begin{array}{l}\text { Alta flexibilidade, } \\
\text { alta tenacidade }\end{array}$ & Filmes, sacolas e fibras têxteis \\
\hline $\begin{array}{l}\text { Polietileno } \\
\text { tereftalato }\end{array}$ & PET & Condensação & $\begin{array}{l}\text { Impermeável ao ar } \\
\text { e hidrofobicidade }\end{array}$ & Fibras têxteis, filmes e embalagens \\
\hline Polipropileno & PP & Coordenada & $\begin{array}{l}\text { Dureza moderada, } \\
\text { alta tenacidade }\end{array}$ & $\begin{array}{l}\text { Fibras, filmes orientados, peças } \\
\text { automotivas e embalagens }\end{array}$ \\
\hline
\end{tabular}

Os polímeros produzidos por apenas um tipo de monômero são chamados de homopolímeros. Utilizando-se mais de um monômero, são obtidos copolímeros, cujas propriedades químicas e físicas são aprimoradas, superando-se limitações dos respectivos homopolímeros (BRUICE, 2010; MORRISON; BOYD, 2002; WIEBECK; HARADA, 2005). 
Dependendo do tipo de processo e das frações de cada monômero, diferentes arranjos de cadeia podem ser obtidos, como (BRUICE, 2010; CALLISTER, 2002):

a) Copolímero randômico: os dois monômeros estão dispersos na cadeia de forma aleatória;

b) Copolímero alternado: a posição das duas unidades monoméricas alterna sequencialmente;

c) Copolímeros em bloco: existem blocos de unidades repetidas ao longo da cadeia;

d) Copolímero graftizado: contém ramificações derivadas de um homopolímero ligadas à cadeia principal proveniente do outro homopolímero.

A figura 2.1 mostra as representações esquemáticas dos tipos de copolímeros que podem ser obtidos (BRUICE, 2010; CALLISTER, 2002).

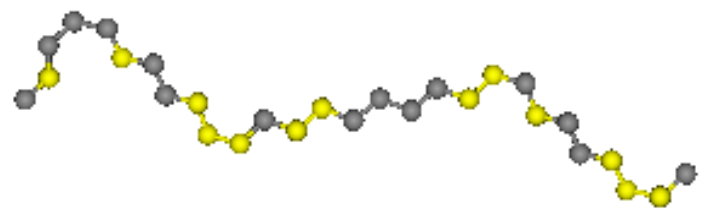

(a)

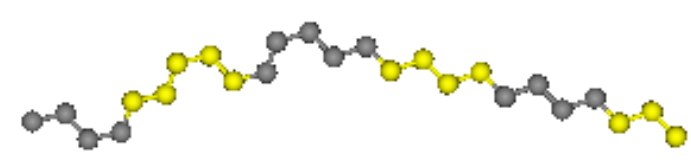

(c)

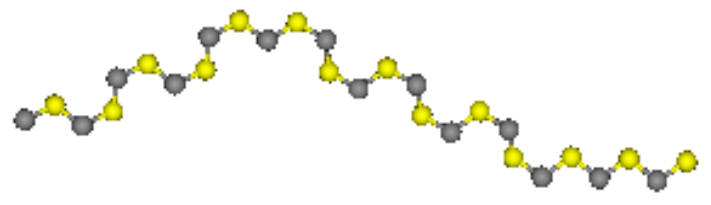

(b)

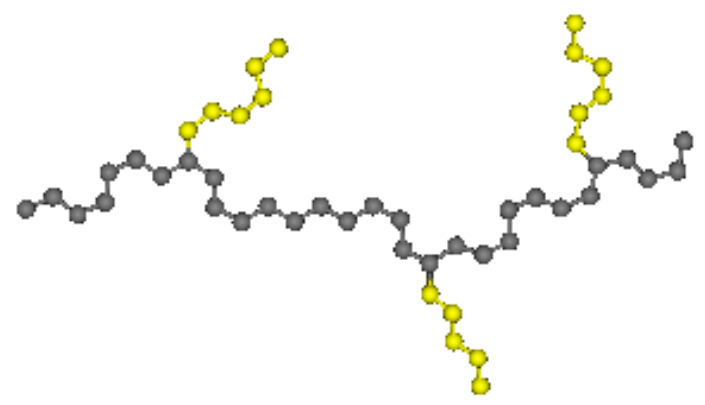

(d)

Figura 2.1 - Representação esquemática de copolímeros randômicos (a); alternados (b); em bloco (c); e graftizado (d). Nessas figuras, as unidades monoméricas estão representadas por esferas cinzas e amarelas (BRUICE, 2010; CALLISTER, 2002). 


\subsubsection{Distribuição de massa molecular}

Durante o processo de polimerização, nem todas as cadeias crescem até o mesmo tamanho. Isso resulta em uma distribuição de massa molecular, que pode ser medida pela viscosidade do polímero ou por sua pressão osmótica. Uma forma alternativa de definir o tamanho das cadeias é pelo grau de polimerização, que representa o número médio de unidades repetidas na cadeia (CALLISTER, 2002).

A massa molecular e o grau de polimerização tendem a obedecer a uma distribuição normal, conforme a figura 2.2. Quanto mais estreita a distribuição, melhores serão suas propriedades físicas (SPERLING, 2006).

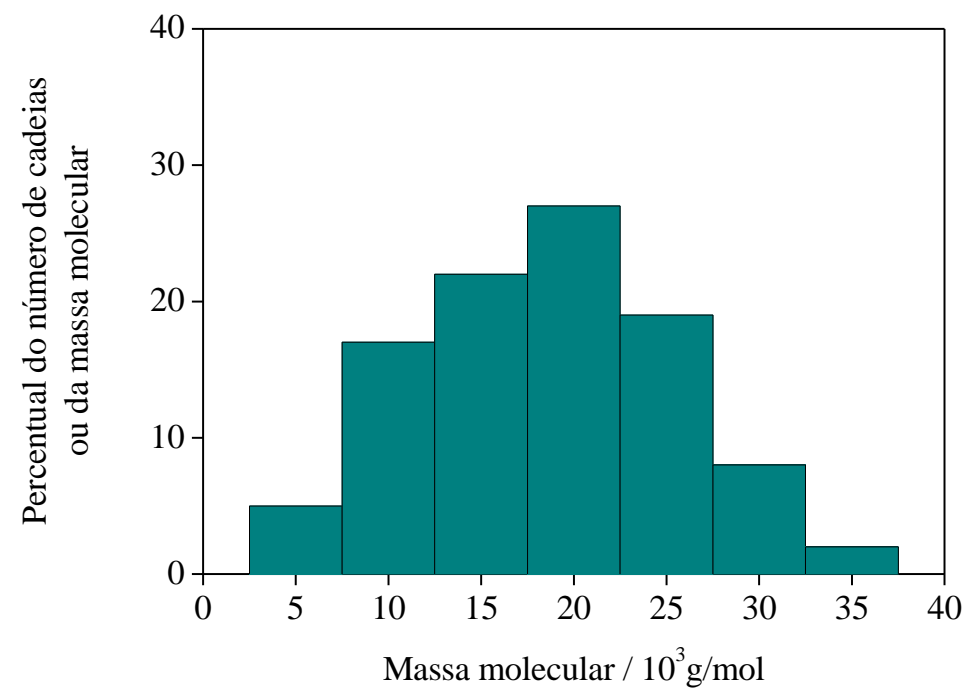

Figura 2.2 - Distribuição do tamanho da molécula por meio da distribuição da massa molecular ou do número de moléculas de determinado tamanho (CALLISTER, 2002).

Muitas propriedades do polímero são dependentes do tamanho de suas cadeias, como as temperaturas de fusão e de amolecimento, que aumentam com a massa molecular, assim como suas propriedades mecânicas. Em temperatura ambiente, compostos com cadeias curtas (massa molecular de aproximadamente $100 \mathrm{~g} / \mathrm{mol}$ ) são líquidos ou gases. Aumentando-se a massa molecular para $1000 \mathrm{~g} / \mathrm{mol}$, encontram-se ceras e resinas macias. Já os polímeros sólidos apresentam massa molecular acima de $10000 \mathrm{~g} / \mathrm{mol}$ e podem atingir a casa de $10^{6} \mathrm{~g} / \mathrm{mol}$. Verifica-se, então, que compostos produzidos a partir das mesmas matérias-primas 
podem ter propriedades muito diferentes, variando-se apenas sua massa molecular (CALLISTER, 2002).

\subsubsection{Estrutura molecular}

Técnicas modernas de síntese de polímeros permitem um controle considerável sobre as características estruturais das cadeias moleculares. Dependendo de sua arquitetura, os polímeros podem ser classificados em (ASUA, 2007; CALLISTER, 2002):

a) Lineares: são polímeros que apresentam os monômeros ligados em uma sequencia linear. A interação intermolecular para esses polímeros é grande. Exemplo: polietileno de alta densidade;

b) Ramificados: são aqueles em que há cadeias laterais ligadas à cadeia principal. Exemplo: policloreto de vinila;

c) Polímeros em rede: são polímeros onde ocorre alto grau de ligações covalentes cruzadas, formando uma estrutura tridimensional. Exemplo: resina epóxi curada com amina trifuncional.

Exemplos dessas estruturas moleculares estão mostrados na figura 2.3.

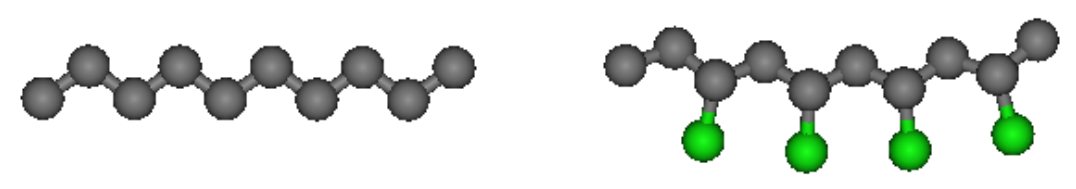

(a)

(b)

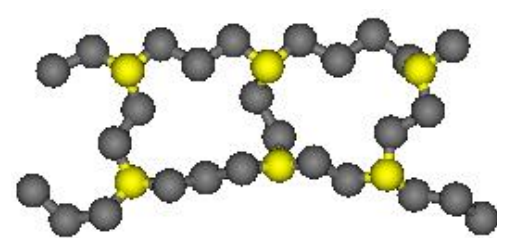

(c)

Figura 2.3 - Estruturas moleculares de polímeros lineares (a); ramificados (b); e em rede (c) (ASUA, 2007; CALLISTER, 2002). 
De acordo com seu comportamento macroscópico, esses materiais podem ser classificados em (ASUA, 2007; BRUICE, 2010; CALLISTER, 2002):

a) Termoplásticos: são polímeros lineares e ramificados, que amolecem, ou até mesmo se fundem, quando aquecidos, em um processo reversível. Polietileno e polipropileno são exemplos desse tipo de polímero, que pode ser reciclado;

b) Termofixos: são polímeros rígidos, com alta densidade de ligações cruzadas. Com o aquecimento, sofrem degradação ao invés de fusão. Poliuretano e epóxi são exemplos desse tipo de polímero, que não é passível de ser reciclado;

c) Elastômeros: são polímeros que podem apresentar alto grau de alongamento quando estirados e que retornam às dimensões originais quando a tensão é liberada.

\subsubsection{Estereoquímica da polimerização}

A polimerização de um etileno monossubstituído, como o propileno e o cloreto de vinila, leva à formação de polímeros cujo átomo de carbono substituído se torna um estereocentro. Nesses tipos de compostos, cada grupo ligado a esse átomo de carbono é diferente e, portanto, sua localização tridimensional é de fundamental importância para determinar a configuração da cadeia (BRUICE, 2010; CALLISTER, 2002; SPERLING, 2006).

As três configurações possíveis para esses polímeros (polipropileno adotado como exemplo na figura 2.4) são (ASUA, 2007; BRUICE, 2010; CALLISTER, 2002; MORRISON; BOYD, 2002):

a) Isotático: possuem todos os substituintes (radicais metila) no mesmo lado da cadeia;

b) Sindiotático: possuem os substituintes alternando de posição regularmente (em determinado carbono, estão de um lado da cadeia e, no próximo estereocentro, estão do lado oposto);

c) Atático: possuem os substituintes dispostos de forma aleatória na cadeia. 


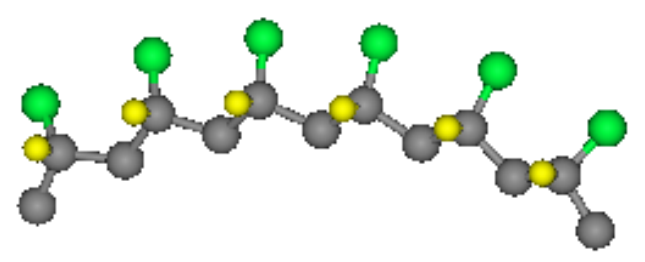

(a)

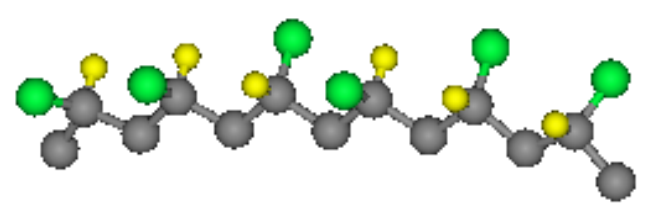

(c)

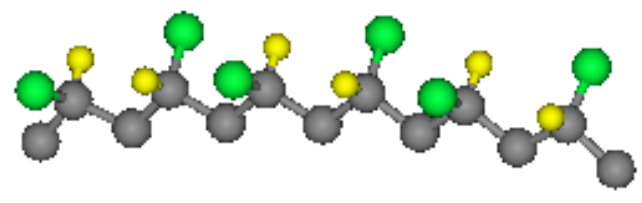

(b)

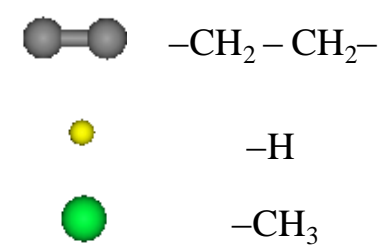

Figura 2.4 - Representação esquemática do polipropileno com configuração isotática (a); sindiotática (b); e atática (c).

A configuração da cadeia depende do mecanismo pelo qual a polimerização ocorre. No geral, a polimerização radicalar leva a polímeros ramificados, com configuração atática. Utilizando catalisadores de Ziegler-Natta, a entrada de um novo monômero é coordenada, levando a polímeros isotáticos ou sindiotáticos (BRUICE, 2010).

\subsubsection{Morfologia}

Assim como pequenas moléculas, polímeros tendem a se cristalizar quando resfriados após sua fusão. Devido à sua longa cadeia e à sua estrutura, o empacotamento das macromoléculas, que é realizado por atração intermolecular de van der Waals, não é sempre eficiente. Por esse motivo, polímeros no estado sólido tendem a ser compostos por domínios cristalinos e amorfos (BROWN, 2002; BRUICE, 2010; EBEWELE, 1996).

Conforme indicado na figura 2.5, nas regiões cristalinas, chamadas de cristalitos, as cadeias do polímero são altamente ordenadas. Entre os cristalitos, há regiões amorfas, onde as cadeias poliméricas apresentam baixo grau de orientação (BRUICE, 2010). 


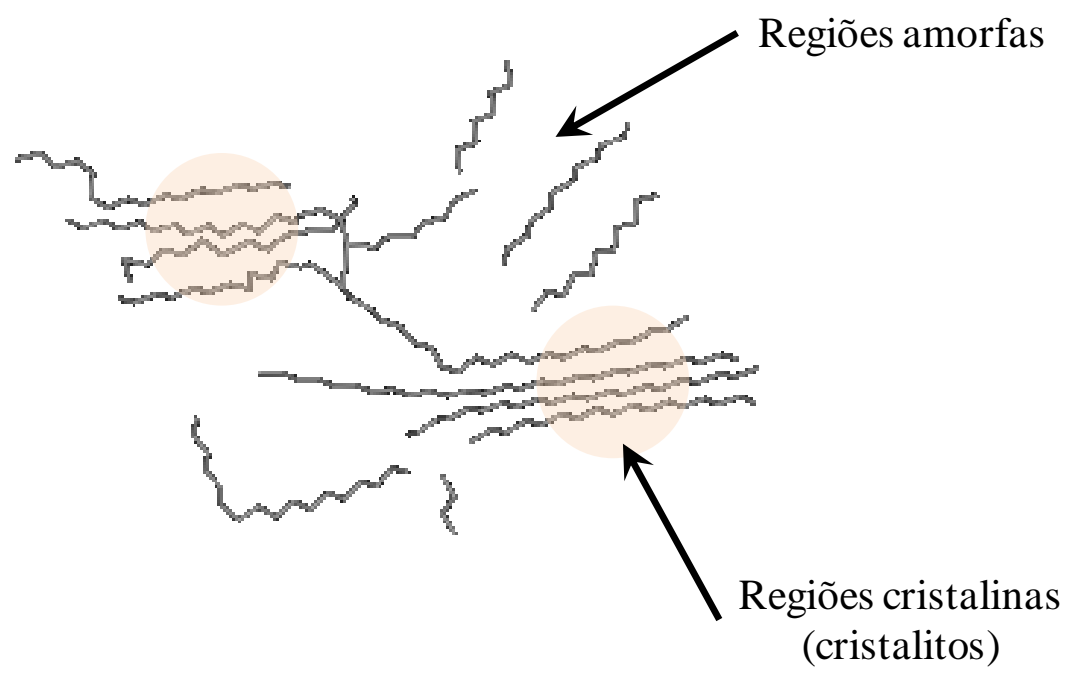

Figura 2.5 - Regiões cristalinas e amorfas de um polímero (BRUICE, 2010).

Altos graus de cristalinidade são mais frequentes em polímeros que apresentam estrutura compacta, cadeias lineares e interações intermoleculares mais fortes, como ligações de hidrogênio. Quanto maior o grau de cristalinidade, serão melhores as propriedades físicas e mecânicas do polímero, como dureza, resistência à tração, resistência ao calor, etc. (BROWN, 2002; BRUICE, 2010).

Polímeros com muitas regiões amorfas podem ser chamados de polímeros vítreos e são, normalmente, transparentes à luz. Apresentam alta flexibilidade e baixa resistência mecânica. A presença de grandes ramificações na cadeia contribui para a formação de regiões amorfas (BROWN, 2002; BRUICE, 2010).

\subsubsection{Temperatura de transição vítrea}

A transição vítrea é um fenômeno que ocorre em polímeros amorfos ou semicristalinos devido à redução da temperatura. Quando esses polímeros, na forma líquida, são resfriados, inicialmente adquirem estrutura similar à de uma borracha e permanecem com essa estrutura durante um pequeno intervalo de temperatura. Depois disso, se tornam sólidos rígidos, que mantém uma estrutura molecular desordenada característica do estado líquido. A temperatura na qual o polímero passa por essa transição é denominada temperatura de transição vítrea, com a sigla $\mathrm{T}_{\mathrm{g}}$ (CALLISTER, 2002). 
Essa sequência de eventos acontece na ordem reversa quando um polímero no estado sólido abaixo da $\mathrm{T}_{\mathrm{g}}$ é aquecido. Quando essa mudança na estrutura molecular ocorre, diversas propriedades físicas são alteradas, como a dureza, a capacidade calorífica e o coeficiente de expansão térmica (CALLISTER, 2002).

\subsection{Comportamento mecânico de polímeros}

As aplicações dos polímeros são definidas de acordo com seu comportamento mecânico, que é uma função de sua microestrutura e morfologia. Comparativamente a metais e cerâmicas, as propriedades dos polímeros apresentam grande dependência da temperatura, do tempo e da forma de aplicação de carga, como consequência de sua natureza viscoelástica (EBEWELE, 1996). O conhecimento dos mecanismos pelos quais os polímeros se deformam é de grande utilidade em engenharia e permite controlar suas propriedades mecânicas (CALLISTER, 2002; SPERLING, 2006).

As propriedades mecânicas de materiais poliméricos são especificadas pelos mesmos parâmetros utilizados para metais, como módulo de elasticidade, limite de escoamento e resistência à tração. Para a maioria dos polímeros, a caracterização do comportamento mecânico é realizada pelo ensaio de tração, obtendo-se uma curva de tensão-deformação (CALLISTER, 2002).

\subsubsection{Deformação e viscoelasticidade em polímeros}

Para aliviar as tensões, todos os materiais sob a influência de uma carga externa se deformam. A habilidade de um material sólido recuperar suas dimensões iniciais quando a carga aplicada é removida é representada pelo comportamento elástico. Após o limite elástico, o material sofre deformação plástica, permanente, mesmo quando a carga aplicada é removida (comportamento plástico). Para a maioria dos polímeros (exceto os elastômeros), a lei de Hooke é obedecida dentro do limite elástico, ou seja, a tensão aplicada é proporcional à deformação ocasionada no material (BRINSON; BRINSON, 2008; EBEWELE, 1996). 
A figura 2.6 apresenta curvas de tensão-deformação obtidas com um ensaio de tração de diferentes polímeros (CALLISTER, 2002; SPERLING, 2006).

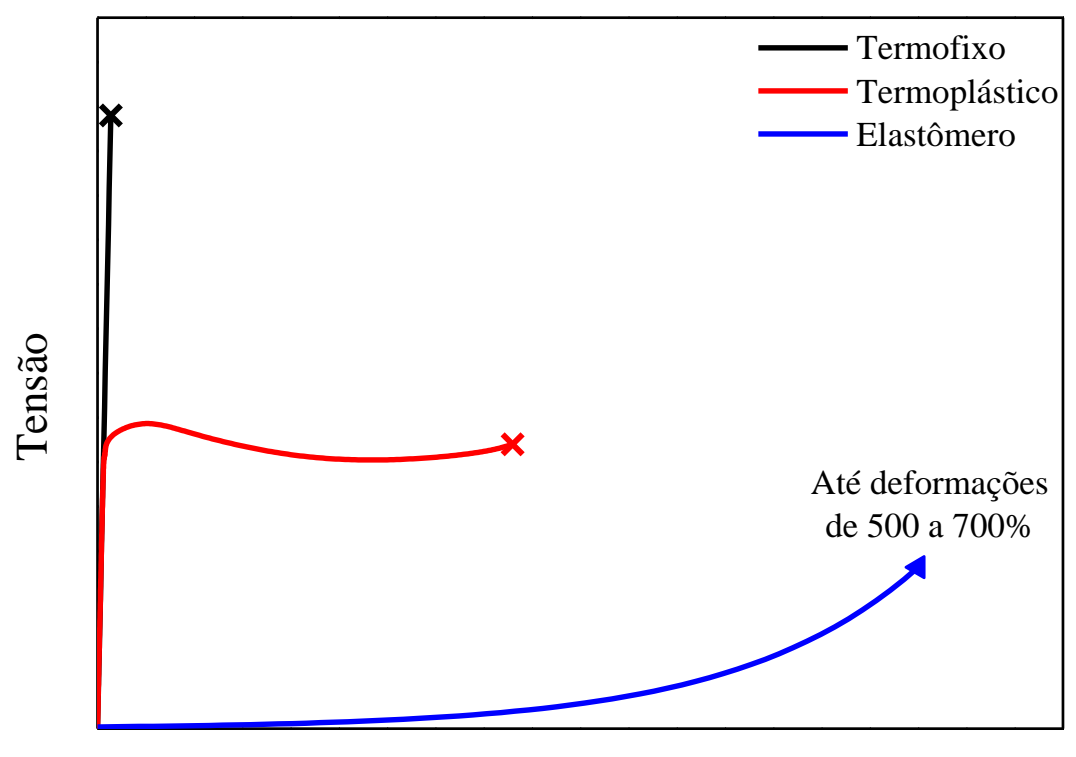

Deformação

Figura 2.6 - Curvas de tensão-deformação de termofixos, termoplásticos e elastômeros (CALLISTER, 2002; SPERLING, 2006).

Polímeros rígidos (termofixos) são relativamente frágeis, se rompem em baixas taxas de deformação, enquanto se deformam elasticamente, e apresentam alto módulo de elasticidade (maior coeficiente angular da reta inicial) (BRUICE, 2010; CALLISTER, 2002; SPERLING, 2006). Os polímeros dúcteis (termoplásticos), cujas cadeias poliméricas podem alinhar-se e deslizar entre si perante esforços de tração, por exemplo, apresentam uma boa relação entre tensão e deformação e necessitam de alta energia para sua ruptura (grande área sob a curva tensão-deformação) (BRUICE, 2010; SPERLING, 2006). Já os elastômeros apresentam altas taxas de deformação mesmo com baixas solicitações mecânicas (ASUA, 2007; BRUICE, 2010; SPERLING, 2006).

A figura 2.7 mostra uma curva de tensão-deformação de um termoplástico semicristalino, inicialmente não deformado, com as representações esquemáticas que o corpode-prova sofre durante os vários estágios da deformação. 


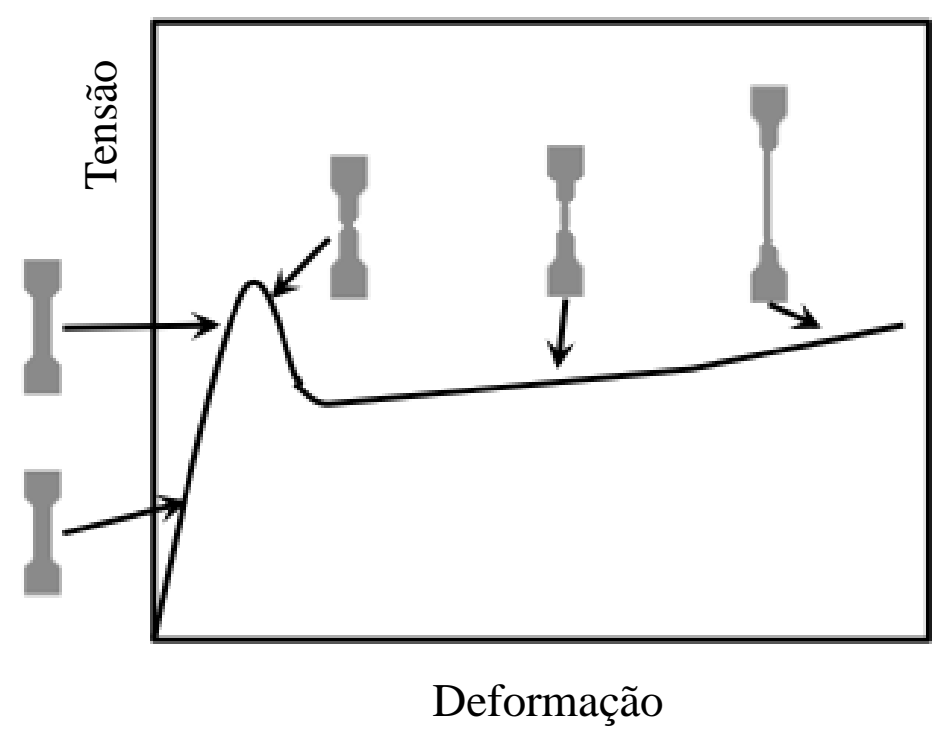

Figura 2.7 - Curva de tensão-deformação de um termoplástico semicristalino (CALLISTER, 2002; OSSWALD; MENGER, 2003).

As regiões com as deformações elástica e plástica são evidentes na figura 2.7. Quando atingido o limite de escoamento, forma-se uma estricção no corpo-de-prova, onde a área da seção é reduzida. Nessa região, as cadeias se tornam altamente orientadas, levando a um comportamento de strain-hardening do polímero (CALLISTER, 2002; SPERLING, 2006). Se o hardening induzido pela orientação das cadeias é suficientemente grande para resistir ou superar o aumento da tensão devido à redução da área da seção, as deformações futuras ocorrerão somente pela extensão da região da estricção. Já se o aumento da tensão for mais rápido que a orientação das cadeias na região da estricção, ocorre ruptura nessa região (CALLISTER, 2002; EBEWELE, 1996; SPERLING, 2006).

A resposta de um polímero a uma determinada tensão é dependente da escala de tempo em que essa tensão é aplicada, podendo ser observados comportamentos de um sólido vítreo ou de um líquido viscoso (BRINSON; BRINSON, 2008; CALLISTER, 2002; OSSWALD; MENGER, 2003). Para pequenas deformações, o comportamento mecânico em baixas temperaturas pode ser elástico. Para temperaturas altas, o comportamento de um líquido viscoso prevalece. Para situações intermediárias, o comportamento do polímero é uma combinação desses dois extremos, ou seja, seu comportamento é viscoelástico. Nesse caso, a aplicação de uma tensão resulta em uma deformação elástica imediata, seguida por uma deformação viscosa, dependente do tempo (CALLISTER, 2002). 


\subsubsection{Fratura em polímeros}

A resistência à tração de polímeros é baixa, quando comparada à resistência de metais. Como regra geral, a ruptura de termofixos é frágil e ocorre devido à formação de fissuras em pontos onde há localização de tensões. Para essa classe de polímeros, as ligações covalentes da cadeia ou as ligações cruzadas da rede são rompidas durante a fratura e a ruptura ocorre em baixos níveis de deformação (CALLISTER, 2002).

Em termoplásticos, como o polipropileno, tanto rupturas frágeis quanto dúcteis podem ocorrer, sendo o primeiro modo mais comum quando a temperatura é baixa ou quando a velocidade de aplicação de carga é alta (EBEWELE, 1996). As rupturas dúcteis ocorrem principalmente pelo rompimento das ligações intermoleculares (forças de van der Waals), ocasionadas pela extensão das cadeias ou pelo deslizamento de uma cadeia em relação às outras. Quanto maior a temperatura, maior é o grau de liberdade das cadeias e, portanto, seu deslizamento é mais fácil, facilitando sua ruptura. Esse tipo de ruptura ocorre para níveis de tensão mais baixos e para maiores deformações (BRUICE, 2010; SPERLING, 2006).

A figura 2.8 representa os mecanismos de ruptura em polímeros (SPERLING, 2006):

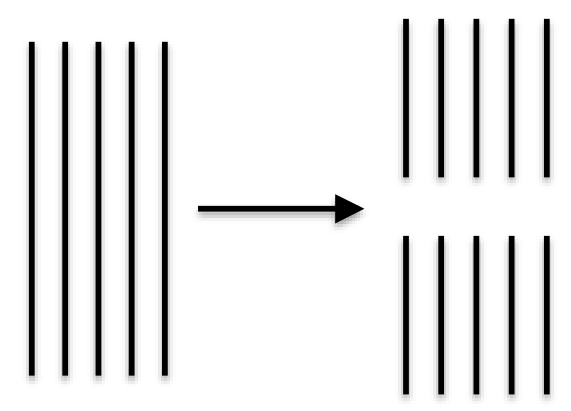

(a)

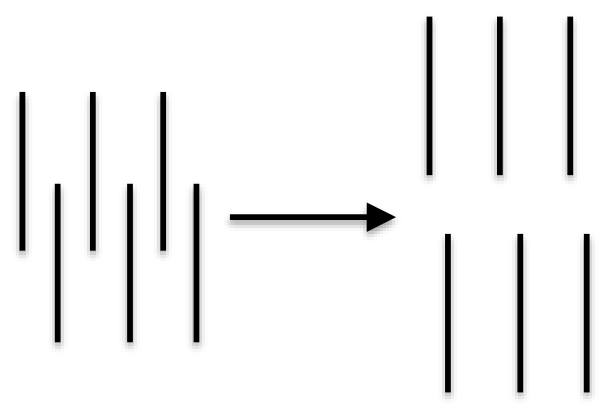

(b)

Figura 2.8 - Mecanismos de fratura em materiais poliméricos: quebra de ligações covalentes (a) e escorregamento entre cadeias (b) (SPERLING, 2006).

Um fenômeno que frequentemente precede a fratura em termoplásticos é a formação de fissuras microscópicas, levando à formação de regiões com deformações plásticas localizadas e a microvazios (CALLISTER, 2002). Esses microvazios são unidos por regiões fibriladas, onde as cadeias poliméricas apresentam alto grau de orientação e, portanto, alta capacidade de absorção de energia. Se o nível de tensão aplicado for suficiente, essas regiões 
se estendem e se rompem, causando o crescimento e a coalescência dos vazios. Com isso, formam-se fissuras e o material se rompe (CALLISTER, 2002; SPERLING, 2006).

A figura 2.9 ilustra como os microvazios e as fissuras são formados em um termoplástico sob esforços de tração, levando à sua ruptura (CALLISTER, 2002).

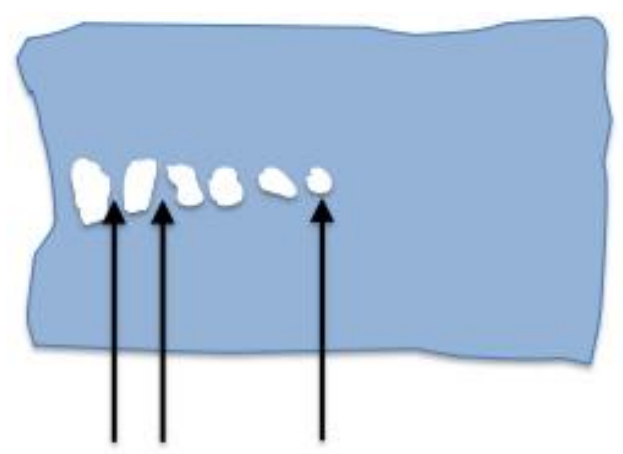

regiões microvazios fibriladas

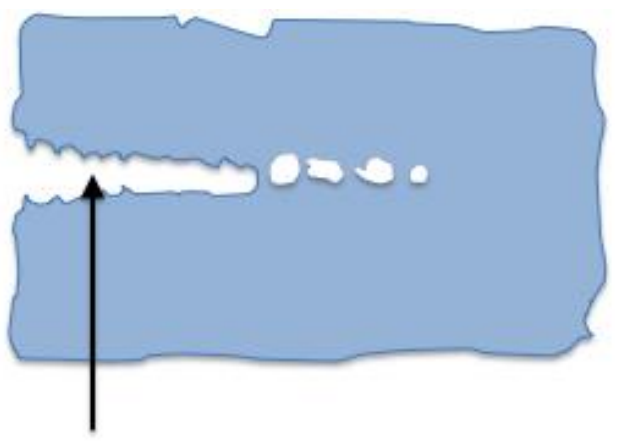

fissura

Figura 2.9 - Formação de microvazios unidos por regiões fibriladas (a) e a formação de fissuras causada pelo rompimento das regiões fibriladas (b) (CALLISTER, 2002).

A figura 2.10 trata dos aspectos moleculares relacionados à fratura de um termoplástico. O efeito inicial de uma tensão externa é estender as cadeias que estão no plano de fratura (região amorfa do polímero), até atingir o alongamento máximo. Após esse alongamento, ocorre quebra ou o arrancamento das cadeias das superfícies formadas (SPERLING, 2006). 


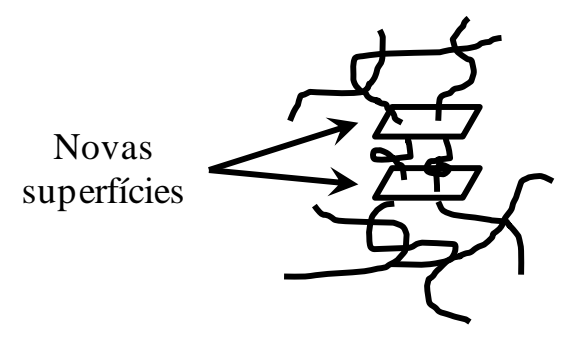

(a)

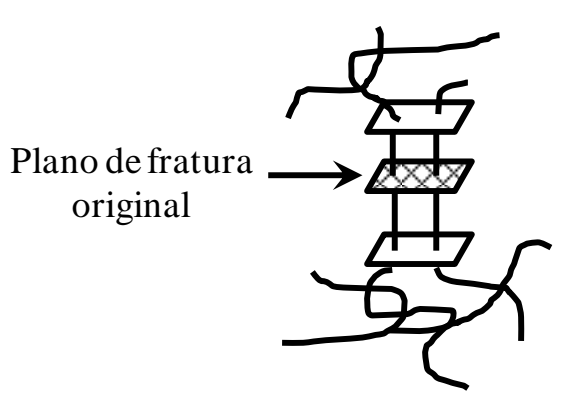

(c)

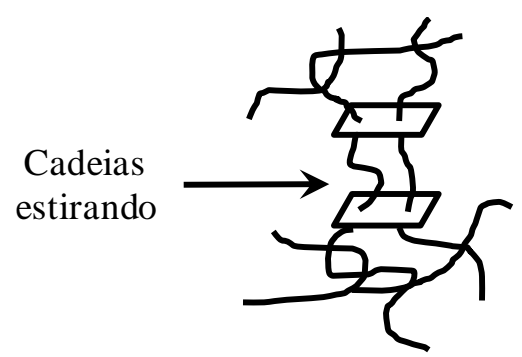

(b)

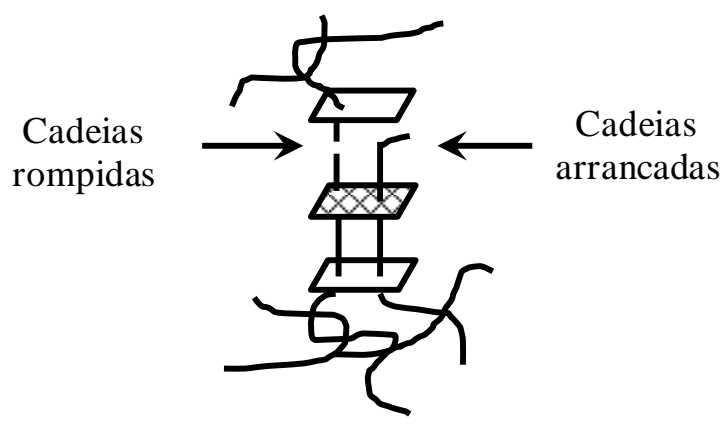

(d)

Figura 2.10 - Micromecanismos da fratura de um termoplástico: formação de planos de fratura (a); alongamento de segmentos de cadeia (b); alongamento máximo das cadeias (c); ruptura ou arrancamento da cadeia (d) (SPERLING, 2006).

\subsubsection{Mecanismo de deformação para aumento da resistência mecânica de polímeros}

Para a produção de fibras e filmes poliméricos, especificamente, são utilizados os processos de extrusão ou injeção. Como esses processos são realizados em temperaturas elevadas (próximo à temperatura de fusão do polímero) e o fio ou filme são resfriados rapidamente, as cadeias poliméricas não apresentam bom grau de cristalinidade e são predominantemente amorfas. Com isso, as propriedades mecânicas do produto final não são boas (BRUICE, 2010; SPERLING, 2006).

No caso de fibras, para melhorar suas propriedades mecânicas, após a extrusão, o fio é estirado a quente, aumentando-se seu comprimento em 4 a 8 vezes (SPERLING, 2006). Com isso, é induzida uma deformação plástica permanente no polímero, fazendo com que as regiões amorfas sejam reorganizadas, tornando-as altamente orientadas na direção do 
estiramento e aumentando o grau de cristalinidade entre as cadeias. Então, são obtidos fios anisotrópicos, muito mais longos e finos, com maiores resistência à tração e módulo de elasticidade (BRINSON; BRINSON, 2008; SPERLING, 2006).

A figura 2.11 mostra como a pré-deformação no polímero aumenta o grau de alinhamento e cristalinidade entre as cadeias (CALLISTER, 2002).

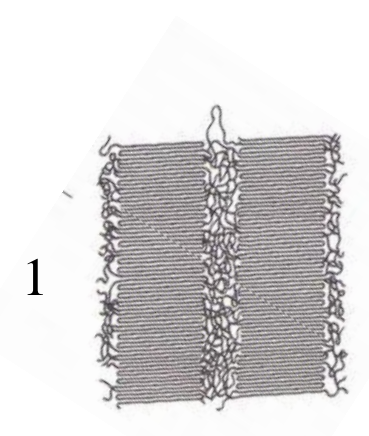

(a)

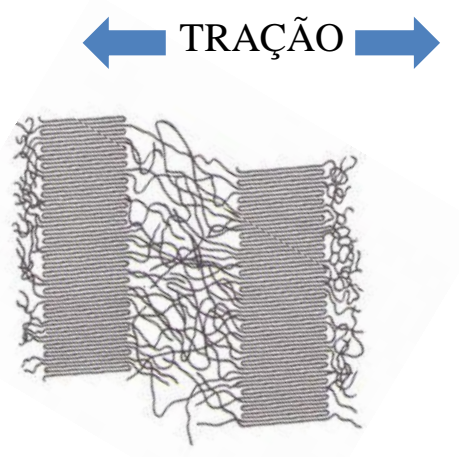

(b)

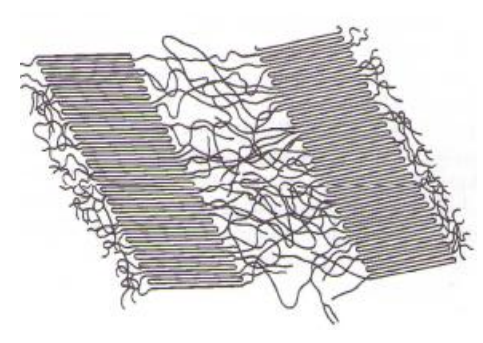

(c)

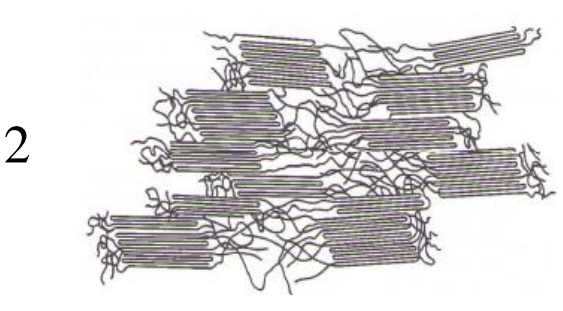

(d)

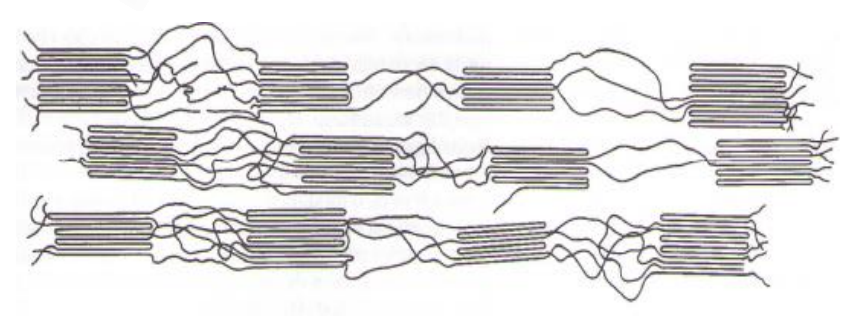

(e)

Figura 2.11 - 1: Estágios na deformação elástica de um polímero semicristalino: Duas cadeias lamelares adjacentes e material amorfo interlamelar antes da deformação (a); Alongamento das cadeias amorfas durante o primeiro estágio de deformação (b); Aumento da dimensão do cristalito lamelar (processo reversível) devido à torção e estiramento das cadeias na região cristalina (c). 2: Estágios na deformação plástica de um polímero semicristalino: Inclinação e separação dos segmentos cristalinos em blocos (d); Orientação dos segmentos em bloco e aumento da interação das cadeias no eixo de tração do polímero (e) (CALLISTER, 2002).

Se o fio produzido após o estiramento continuar sendo tracionado, pode ocorrer o fenômeno de strain-hardening. Como o pré-estiramento causou uma aproximação entre as cadeias e, portanto, uma maior interação entre elas, a resistência a novos deslocamentos fica maior, necessitando de maiores níveis de tensão para deformar o material. Então, o fio pode apresentar um aumento na absorção de energia durante sua deformação (BRINSON; BRINSON, 2008; CALLISTER, 2002). 


\subsubsection{Fatores que influenciam as propriedades mecânicas de polímeros}

As propriedades físicas e o comportamento mecânico dos polímeros são altamente dependentes de sua microestrutura e de suas propriedades moleculares. Alguns dos fatores que influenciam as propriedades macroscópicas de materiais poliméricos estão descritos a seguir.

\section{a) Massa molecular}

A tensão de ruptura de polímeros com baixa massa molecular é próxima de zero, pois a interação entre as cadeias é composta majoritariamente por forças de interação de van der Waals. Aumentando-se o tamanho da cadeia e, consequentemente, a massa molecular, a interação entre as cadeias é aprimorada, ocasionando um aumento na resistência à tração. A figura 2.12 mostra como a resistência à tração depende do peso molecular, sendo que a curva tende a obedecer a um comportamento assintótico para massas moleculares elevadas (SPERLING, 2006).

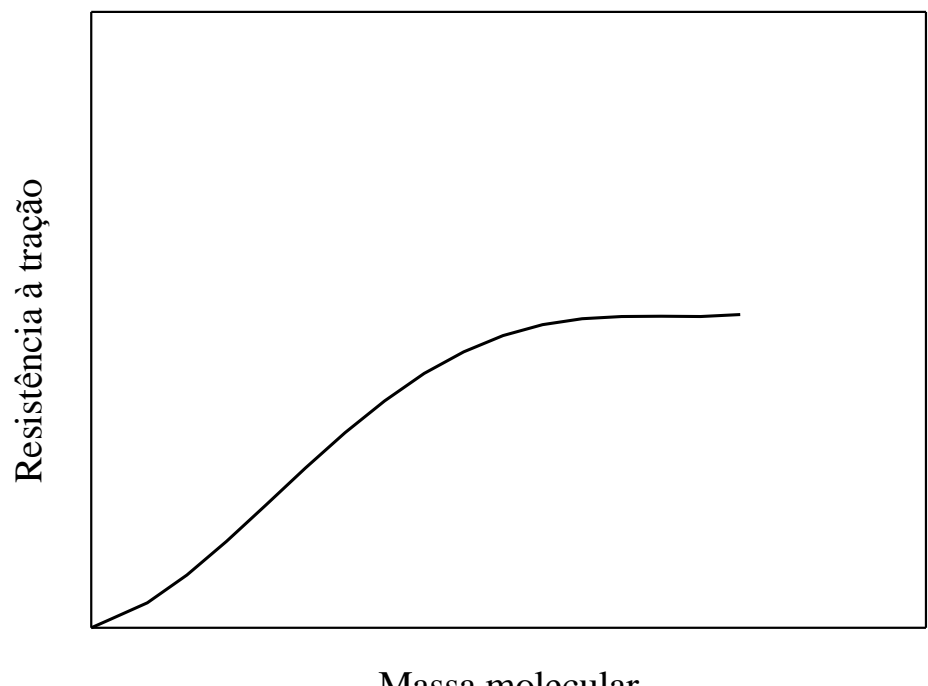

Figura 2.12 - Efeito da massa molecular na resistência à tração do polímero (SPERLING, 2006). 


\section{b) Número de ligações cruzadas}

Introduzindo-se ligações cruzadas no polímero, diminui-se o grau de mobilidade entre as cadeias poliméricas, aumentando-se sua resistência à deformação. Portanto, quanto maior o número de ligações cruzadas, maior o módulo de elasticidade e a resistência à tração do polímero (EBEWELE, 1996).

\section{c) Grau de cristalinidade}

O grau de cristalinidade influencia principalmente as interações intermoleculares (atração de van der Waals). Polímeros cristalinos apresentam as cadeias mais empacotadas, ordenadas e paralelas, levando a maior resistência à tração e módulo de elasticidade. Entretanto, o material apresenta ruptura mais frágil (CALLISTER, 2002).

\section{d) Configuração da cadeia}

A configuração da cadeia do polímero influencia suas propriedades físicas. Aqueles com configuração isotática ou sindiotática apresentam maior grau de cristalinidade, pois a posição dos substituintes em uma ordem regular proporciona um melhor empacotamento das cadeias. Já os polímeros atáticos não apresentam bom empacotamento de cadeias, levando a compostos amorfos, pouco rígidos e quebradiços, não tendo grandes aplicações (BRUICE, 2010).

\section{e) Copolimerização}

A copolimerização é utilizada para obtenção de materiais com propriedades melhoradas em relação aos respectivos homopolímeros. Quando o estireno, por exemplo, é polimerizado sozinho, obtém-se um polímero com alta rigidez, mas com baixa resistência ao impacto. Quando copolimerizado com 20 a 30\% de butadieno, torna-se um polímero tenaz. Utilizando-se acrilonitrila na proporção de 20 a 30\%, aumenta-se sua resistência ao impacto. Com alto teor de butadieno (75\%), obtém-se um elastômero (MORRISON; BOYD, 2002). 


\section{f) Temperatura de transição vítrea}

Quando um polímero sólido é aquecido e a temperatura atinge um valor dentro do intervalo da transição vítrea, ocorre uma grande diminuição do seu módulo de elasticidade e um aumento em sua capacidade de alongamento. Portanto, a temperatura em que o polímero é utilizado apresenta grande influência em suas propriedades mecânicas. Se esta estiver abaixo da $\mathrm{T}_{\mathrm{g}}$, o polímero apresentará o comportamento de um sólido rígido. Entretanto, se a temperatura estiver acima da $\mathrm{T}_{\mathrm{g}}$, o polímero apresentará o comportamento similar ao de uma borracha (SPERLING, 2006).

\section{g) Polaridade}

Pela inserção de grupos polares na cadeia polimérica, aumenta-se a interação intermolecular, pois as forças de atração são mais fortes devido ao dipolo formado. Atuante principalmente nas regiões amorfas, o aumento da polaridade da cadeia promove um aumento no módulo de elasticidade do polímero (EBEWELE, 1996).

\subsection{Superfícies e interfaces de materiais poliméricos}

A superfície de qualquer material é diferente de seu bulk. As modificações químicas incluem oxidação da superfície, plastificação ou a grafitização. Fisicamente, a principal alteração é a maior orientação das cadeias. Não importa o quão polida seja uma superfície macroscópica, pois em escala nanométrica sempre existem rugosidades, deixando-a com alta rugosidade (SPERLING, 2006).

A modificação superficial dos polímeros pode ser feita para modificar algumas de suas propriedades de interface, como a forma de ligação aos substratos, a tensão superficial, a permeabilidade e o coeficiente de atrito. Os métodos mais comuns são o tratamento com plasma ou por reações químicas de oxidação ou halogenação. Tais métodos alteram apenas a superfície dos polímeros, sem apresentar influências no bulk. A modificação da tensão superficial é particularmente importante para alterar a molhabilidade da superfície, tornando-a mais hidrofílica ou hidrofóbica (SPERLING, 2006; EBEWELE, 1996). 
A adesão na interface polímero / substrato pode ocorrer de diversas maneiras, como (SPERLING, 2006):

a) Mecânica, devido ao intertravamento das superfícies;

b) Física, pela atração intermolecular, por meio de ligações de hidrogênio ou interações de van der Waals;

c) Química, pela formação de ligações químicas.

\subsection{Propriedades do polipropleno}

Introduzido comercialmente no mercado em 1957, o polipropileno é a resina que apresenta o segundo maior volume de produção em escala mundial (BARCELLOS, 2012). O propileno, derivado da refinação de petróleo, é a matéria-prima desse polímero. Sua produção é realizada utilizando catalisadores de Ziegler-Natta, tanto em batelada quanto em reatores contínuos, em temperaturas de 50 a $80^{\circ} \mathrm{C}$ e em pressões de 5 a 25atm (EBEWELE, 1996).

A forma principal produzida é o polipropileno isotático ( $90 \%$ da produção total), pois é a que apresenta propriedades de interesse. Este polímero é essencialmente linear, com arranjos moleculares ordenados, apresentando forma cristalina helicoidal. É um termoplástico bastante leve (massa específica entre 0,90 e $0,91 \mathrm{~g} / \mathrm{cm}^{3}$ ) e com alto grau de cristalinidade (EBEWELE, 1996).

Suas propriedades de interesse são: baixo custo, facilidade de processamento, excelente resistência química, resistência mecânica e rigidez moderadas, boa ductilidade e excelente resistência à fadiga. Suas aplicações mais comuns são a produção de fibras, filmes orientados, utensílios domésticos e peças automotivas (EBEWELE, 1996; MARK, 1999).

O polipropileno é um polímero hidrofóbico, sendo necessária a modificação de sua superfície para que seja apto à utilização em fibras poliméricas (assunto discutido no capítulo 3.1.2.1).

A figura 2.13 mostra uma curva de tensão-deformação de um fio de polipropileno, produzido a partir da extrusão do homopolímero PP H604 (fornecido pela Braskem), em extrusora de rosca simples e estirado na taxa de 8 vezes, na temperatura de $95^{\circ} \mathrm{C}$. Pode ser observado que o fio apresenta ductilidade e deformação de, aproximadamente, $26 \%$ até sua ruptura. 


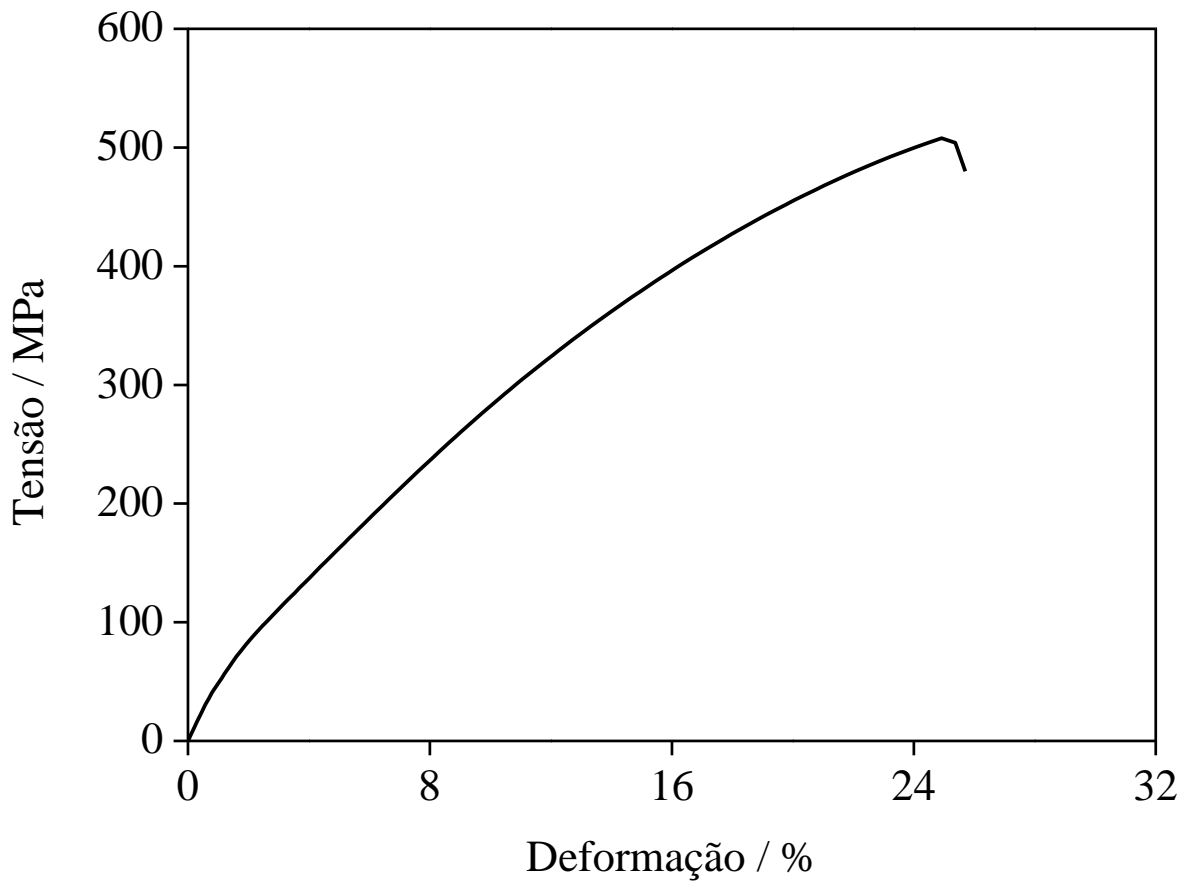

Figura 2.13 - Curva tensão-deformação de um fio de polipropileno. 


\section{Concreto reforçado com fibras}

O concreto simples é caracterizado por possuir baixa resistência à tração e baixa capacidade de deformação (BENTUR; MINDESS, 2007; FIGUEIREDO, 2011a). Para determinadas aplicações, seu reforço é necessário, de forma que essas limitações sejam minimizadas. Reforços contínuos (barras de aço) e descontínuos (fibras) são comumente utilizados, sendo o primeiro tipo mais tradicional (ACI, 2002; BENTUR; MINDESS, 2007).

A figura 3.1 representa os principais tipos de reforço de matrizes cimentícias (NAAMAN, 2000).

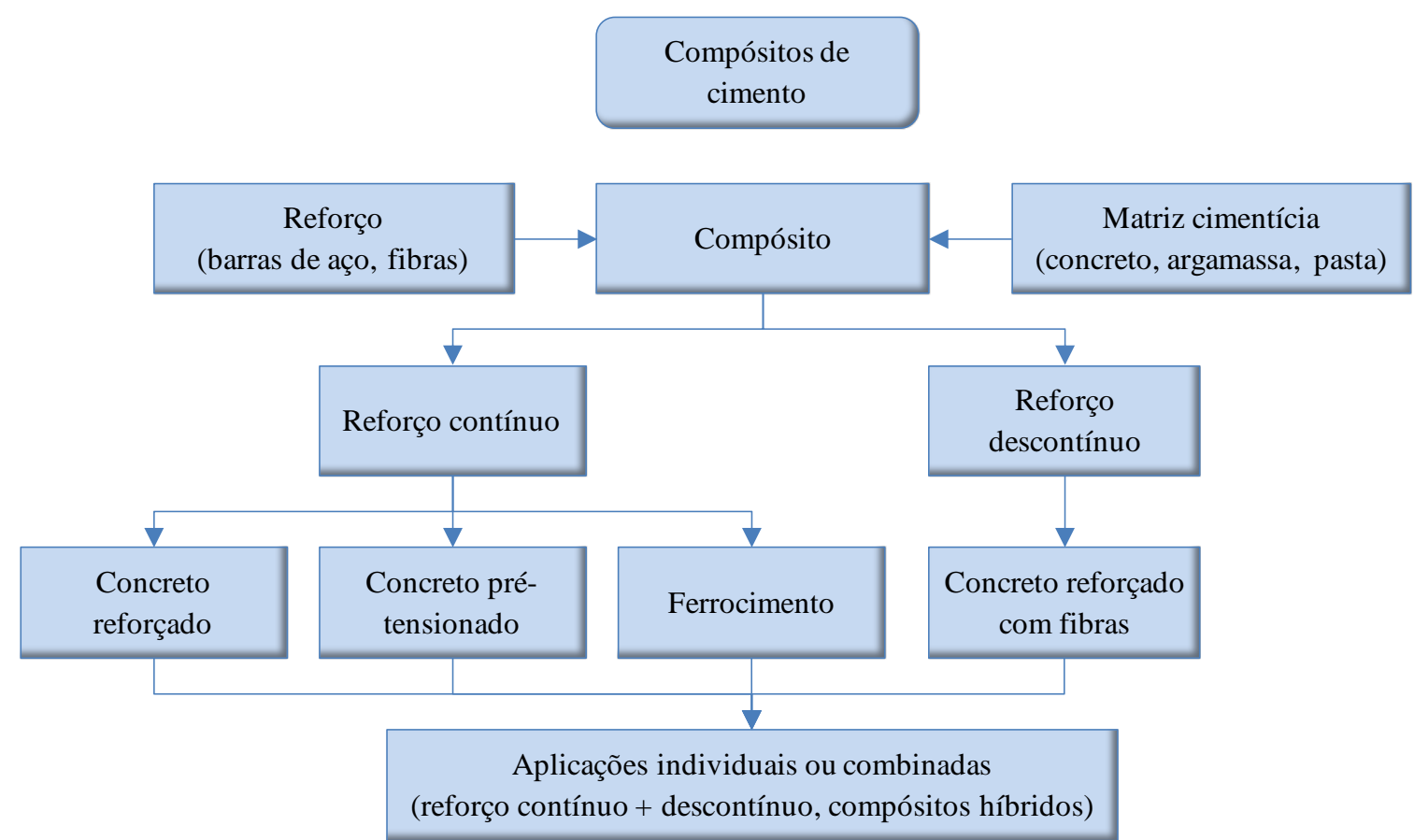

Figura 3.1 - Compósitos de cimento vistos como sistemas bicomponentes e suas combinações híbridas (NAAMAN, 2000).

Devido à maior flexibilidade para a fabricação, o concreto reforçado com fibras apresenta-se com um material estrutural relativamente econômico e útil em diversas aplicações. Em pisos, pavimentos e revestimentos de túneis, fibras de aço e sintéticas têm sido amplamente utilizadas em substituição às telas soldadas (ACI, 2002; FIGUEIREDO, 2011b). O reforço com fibras é particularmente interessante em elementos de baixa espessura ou 
elementos sujeitos a grandes cargas ou deformações localizadas (BENTUR; MINDESS, 2007).

A sinergia entre as fibras e a matriz contribui para que o comportamento do compósito seja aprimorado (FIGUEIREDO, 2011b; NAAMAN, 2003a). As fibras transferem tensões através das fissuras, diminuindo sua propagação e expansão, conferindo resistência residual pós-fissuração ao concreto (di PRISCO; PLIZZARI; VANDEWALLE, 2009; FIGUEIREDO, 2011a). Distribuídas aleatoriamente por toda a matriz, as fibras proporcionam grande capacidade de absorção de energia, tornando o comportamento do compósito pseudo-dúctil (FIGUEIREDO, 2011a; KIM; NAAMAN; EL-TAWIL, 2008; LIM; OH, 1999).

O concreto reforçado com fibras passou por diversos avanços desde a década de 1970. Os principais motivos para essa evolução foram os estudos relacionados à pesquisa e ao desenvolvimento envolvendo a matriz, as fibras, a interface fibra-matriz, o processo de produção do compósito e o melhor conhecimento dos mecanismos fundamentais que controlam seu comportamento (NAAMAN, 2003b). Com isso, a utilização de concreto reforçado com fibras vem aumento progressivamente em escala mundial.

\subsection{Estrutura de matrizes cimentícias reforçadas com fibras}

As propriedades do concreto reforçado com fibras são dependentes da estrutura do compósito. Portanto, para analisá-lo e para prever seu comportamento em diversas condições, sua microestrutura deve ser caracterizada. Os três principais componentes que devem ser considerados, segundo Bentur e Mindess (2007), são:
a) A estrutura da matriz;
b) A estrutura e as propriedades da fibra;
c) A estrutura da interface fibra-matriz.

Os conceitos fundamentais relacionados às propriedades do concreto reforçado com fibras estão descritos a seguir. 


\subsubsection{A matriz cimentícia}

A natureza microestrutural de compósitos de cimento Portland é complexa e altamente heterogênea. As propriedades físicas e mecânicas de concretos são dependentes do tempo e são controladas pelas três principais fases do concreto: a pasta de cimento hidratada, os agregados e a zona de transição na interface. Cada fase apresenta caráter multifásico, contendo microfissuras e vazios, influenciando na resistência, na estabilidade dimensional e na durabilidade de matrizes cimentícias (MEHTA; MONTEIRO, 2008).

Matrizes cimentícias possuem falhas e microfissuras em sua microestrutura, mesmo antes que uma carga externa seja aplicada. Esses defeitos são gerados por exsudação da água, retração plástica, retração por secagem e por concentração de tensões em elementos restringidos. A presença desses defeitos é prejudicial à resistência à fratura, pois uma tensão aplicada ao material tende a se concentrar nas extremidades dessas falhas. Quando a magnitude de uma tensão de tração supera o valor da tensão crítica, uma fissura se forma e propaga, conduzindo à fratura do material (BANTHIA, 1998; FIGUEIREDO, 2011b).

A figura 3.2 (a) mostra a seção transversal de um corpo sob esforços de tração. Esse elemento possui uma falha de diâmetro igual 2 r, localizada ao longo do eixo X-X'. A figura 3.2 (b) mostra a variação de tensão ao longo do eixo $\mathrm{X}-\mathrm{X}$ '. Pode ser observado que a magnitude da tensão diminui com o aumento da distância da falha. Quanto mais próximo da falha, a concentração de tensões é maior e a tensão máxima $\left(\sigma_{\mathrm{m}}\right)$ é atingida em sua extremidade (CALLISTER, 2002). 


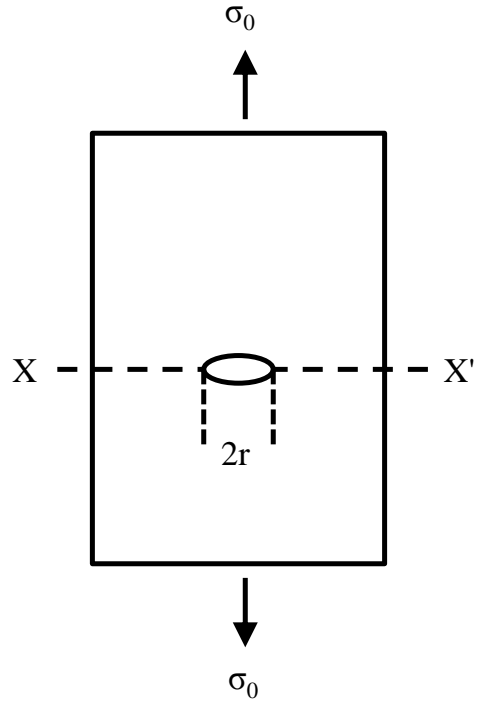

(a)

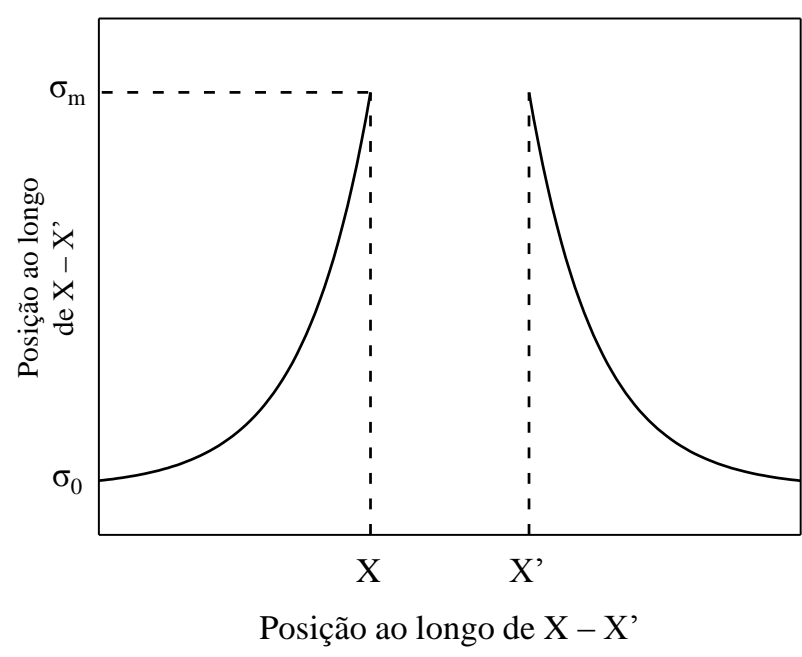

(b)

Figura 3.2 - Geometria das fissuras e das falhas internas da matriz (a); Perfil de tensão ao longo do eixo X-X', demonstrando a amplificação da tensão na extremidade da fissura (b) (CALLISTER, 2002).

A resistência mecânica é um dos principais parâmetros utilizados para a caracterização de produtos a base de cimento. Apesar de alta resistência à compressão, o concreto apresenta comportamento notavelmente frágil quando submetido a esforços de tração. A rápida propagação de fissuras, devido à baixa capacidade da matriz em inibir seu crescimento, é o principal fator que influencia a resistência à tração do material (MEHTA; MONTEIRO, 2008).

A energia associada à ruptura da matriz pode ser aumentada pela utilização de fibras, pois estas inibem a propagação de fissuras (FIGUEIREDO, 2011b). Em pastas de cimento e argamassas, as fibras podem ser adicionadas em teores entre 5 e $15 \%$ em volume, para a produção de compósitos com comportamento de strain-hardening. Já em concretos, os teores são inferiores a $2 \%$ em volume, e os compósitos apresentam o comportamento de strainsoftening. As fibras são utilizadas, principalmente para controle de fissuração, tanto na fase plástica quanto na endurecida, além de conferirem tenacidade (BENTUR; MINDESS, 2007). 


\subsubsection{Fibras para reforço de concreto}

Fibras são elementos descontínuos, longos e finos, caracterizados por alta resistência à tração em sua direção longitudinal (MORRISON; BOYD, 2002). Dentre as fibras mais comuns disponíveis no mercado atualmente, estão as de aço, de polipropileno e de vidro, podendo ser classificadas como micro ou macrofibras (FIGUEIREDO, 2011b).

As microfibras possuem diâmetro da ordem de 10 a $30 \mu \mathrm{m}$ e comprimento entre $3 \mathrm{e}$ $18 \mathrm{~mm}$. O principal motivo de sua utilização é o controle de retração e fissuração de matrizes cimentícias na fase plástica. As fibras de vidro, por possuírem alto módulo de elasticidade (72GPa), também podem ser utilizadas para diminuir os efeitos da retração de concreto na fase endurecida. As dosagens de microfibras giram em torno de 0,10 a 0,30\% em volume (ACI, 2002).

Já as macrofibras possuem diâmetro maior que $0,30 \mathrm{~mm}$ e comprimento que varia entre 30 e 60mm. Disponíveis comercialmente desde a década de 1990, são indicadas para conferir resistência residual pós-fissuração ao concreto (aumento da capacidade de absorção de energia após o rompimento da matriz). As dosagens mais comuns para obtenção de compósitos com comportamento de softening variam entre 0,20 e 0,60\% em volume (BENTUR; MINDESS, 2007; FIGUEIREDO, 2011b).

As principais características das fibras estão identificadas na figura 3.3 (NAAMAN, 2000). 


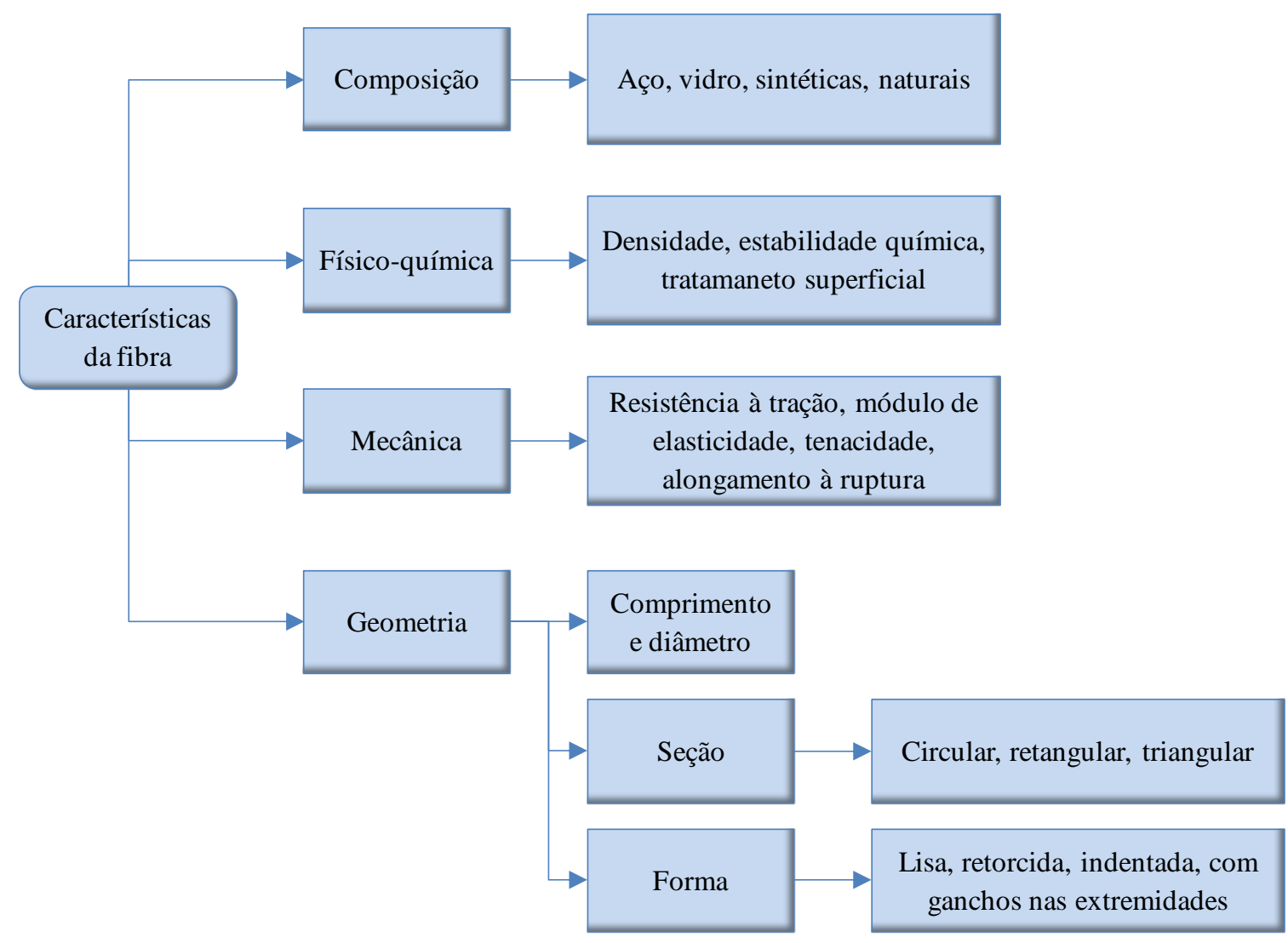

Figura 3.3 - Características principais das fibras de interesse para matrizes cimentícias (NAAMAN, 2000).

A partir da seleção do material constituinte da fibra, inúmeras combinações de propriedades geométricas podem ser utilizadas para aperfeiçoar seu desempenho. Tratamentos químicos e físicos realizados na superfície da fibra aprimoram a interação com a matriz cimentícia. Deformações na estrutura da fibra podem aumentar sua ancoragem mecânica (BENTUR; MINDESS, 2007; BENTUR; MINDESS; VONDRAN, 1989; NAAMAN, 2000). Tais propriedades serão discutidas adiante.

As principais propriedades que influenciam a capacidade de reforço que a fibra pode conferir são sua resistência mecânica (à tração e ao cisalhamento) e seu módulo de elasticidade. As fibras são caracterizadas como de alto ou baixo módulo, se tiverem módulo de elasticidade superior ou inferior ao do concreto endurecido, respectivamente. De forma geral, as fibras poliméricas têm baixo módulo e as inorgânicas (aço e vidro) possuem alto módulo (FIGUEIREDO, 2011a).

Abordando a importância dessas propriedades, a figura 3.4 mostra as curvas tensãodeformação de uma matriz de concreto reforçada com três tipos de fibra: uma de baixo módulo, outra de alto módulo e baixa resistência mecânica e a última com alto módulo e alta 
resistência, considerando o comportamento do compósito como elástico perfeito (FIGUEIREDO, 2011a).

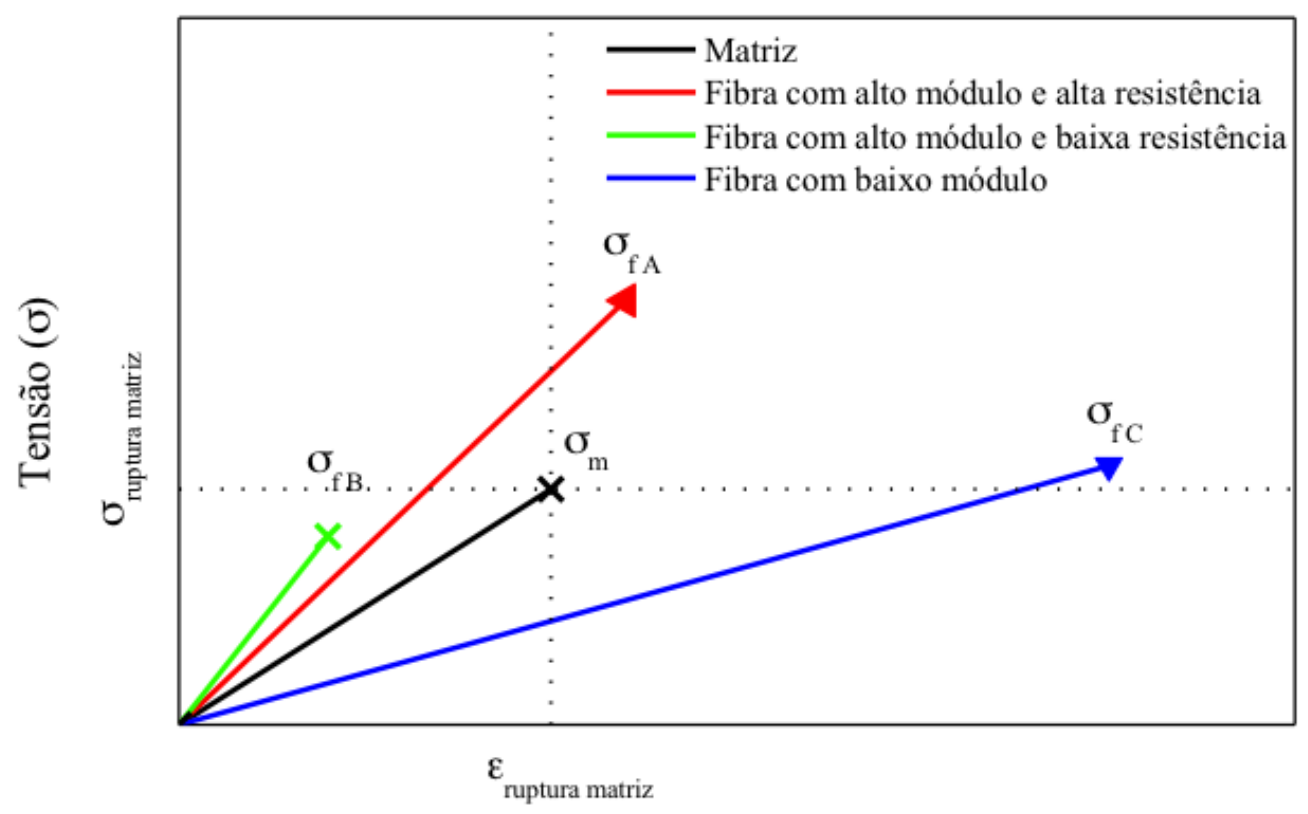

Deformação $(\varepsilon)$

Figura 3.4 - Diagrama de tensão por deformação elástica de matriz e fibras de alto e baixo módulo de elasticidade trabalhando em conjunto (FIGUEIREDO, 2011a).

Onde:

$\sigma_{\mathrm{fA}}$ : tensão de ruptura da fibra de alto módulo e de alta resistência;

$\sigma_{\mathrm{fB}}$ : tensão de ruptura da fibra de alto módulo e de baixa resistência;

$\sigma_{\mathrm{fC}}$ : tensão de ruptura da fibra de baixo módulo;

$\sigma_{\mathrm{m}}$ : tensão de ruptura da matriz.

Supondo que haja uma aderência perfeita entre as fibras e a matriz, o compósito apresentará diferentes deformações perante esforços de tração, dependendo do tipo de fibra utilizada. O nível de tensão que uma fibra de baixo módulo pode suportar é inferior à tensão de ruptura da matriz. Então, para que essa fibra apresente capacidade de reforço adequado e consiga controlar a abertura da fissura, seu teor deve ser alto, para que a tensão por fibra não exceda sua tensão de ruptura (FIGUEIREDO, 2011b).

A utilização de fibras de alto módulo e de baixa resistência mecânica pode não conferir capacidade de reforço pós-fissuração ao compósito, pois estas são frágeis e têm baixa 
capacidade de deformação elástica. No momento em que ocorre a ruptura da matriz, já foi ultrapassado o limite último de deformação da fibra e, mesmo com altos teores, as fibras já terão sido rompidas antes da matriz (FIGUEIREDO, 2011b).

Fibras de alto módulo e alta resistência mecânica apresentam elevado nível de tensão no momento em que a matriz atinge sua deformação crítica. Esse tipo de fibra proporciona um elevado nível de reforço quando a matriz se rompe, mesmo quando utilizada em baixos teores, contanto que sua resistência não seja superada (FIGUEIREDO, 2011b).

Em suma, para apresentar capacidade de reforço, é necessário que a fibra possua as seguintes propriedades (NAAMAN, 2000):

a) Resistência à tração superior à da matriz (duas a três ordens de magnitude);

b) Módulo de elasticidade três vezes maior, no mínimo, que o da matriz;

c) Energia de ligação da mesma ordem (ou maior) que a resistência à tração da matriz.

Além disso, o coeficiente de Poisson e a expansão térmica da fibra devem ser equivalentes aos da matriz. Se o coeficiente de Poisson for significativamente maior que o da matriz, o arrancamento da fibra ocorrerá sob tensões de tração. Entretanto, essa limitação pode ser superada se deformações forem impostas na fibra, com o intuito de aprimorar a ancoragem mecânica (NAAMAN, 2000).

\subsubsection{Macrofibras poliméricas para reforço de concreto}

As macrofibras sintéticas foram lançadas no mercado internacional na década de 1990 (FIGUEIREDO, 2011a). As primeiras aplicações foram em concreto projetado, especialmente na Austrália e no Canadá (MORGAN; RICH, 1996). No Brasil, essas fibras foram inseridas no mercado em 2007 e atualmente há uma diversa gama de produtos e distribuidores. Alguns exemplos de macrofibras poliméricas estão mostrados na figura 3.5. 


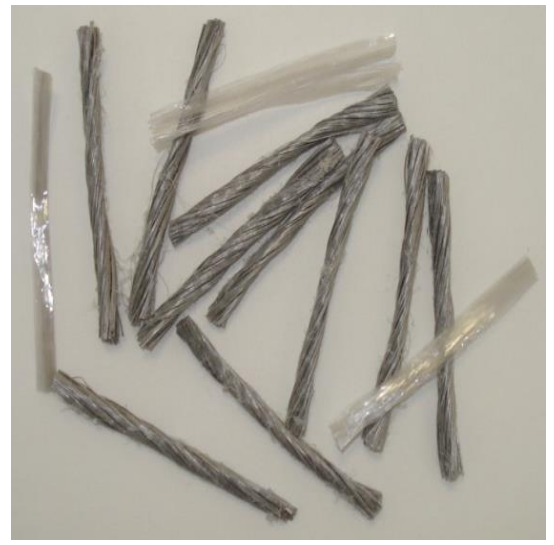

(a)

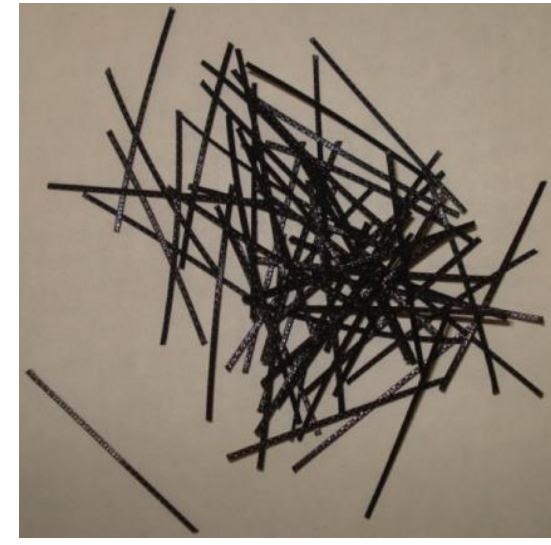

(b)

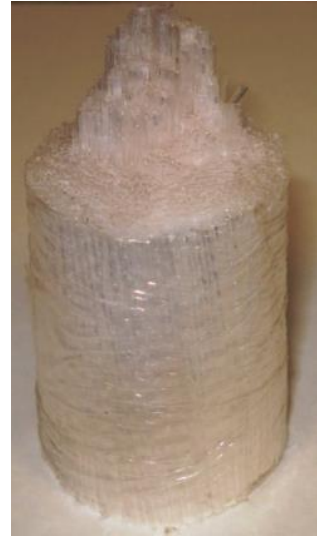

(c)

Figura 3.5 - Exemplos de macrofibras poliméricas disponíveis no mercado brasileiro: macrofibra flexível na forma torcida (a); macrofibra rígida fornecida solta (b); macrofibra rígida na forma de feixe, envolvida por plástico hidrossolúvel (c).

As fibras poliméricas são capazes de ser produzidas em filamentos que possuem fator de forma maior que 100 (CALLISTER, 2002). Suas propriedades mecânicas são dependentes de sua estrutura molecular, sendo a energia de ligação e as interações intermoleculares os principais fatores que influenciam sua resistência. Dependendo do tipo de polímero utilizado, algumas fibras podem apresentar resistência à tração superior à do aço BRUICE, 2010; (MORRISON; BOYD, 2002; WIEBECK; HARADA, 2005).

A massa molecular dos polímeros utilizados para a produção das fibras deve ser alta para que a interação intermolecular seja grande. Além disso, as cadeias poliméricas devem ser lineares e estereorregulares preferencialmente, de forma que sejam obtidos alto grau de cristalinidade e alinhamento entre as mesmas (CALLISTER, 2002; MORRISON; BOYD, 2002). Polímeros orientados são comumente utilizados para essa finalidade (BRUICE, 2010).

O processo de produção também apresenta grande influência sobre as propriedades finais da fibra. O método mais utilizado é a extrusão, no qual o polímero aquecido passa por uma matriz com múltiplos orifícios. O fio formado é estirado, a fim de introduzir deformações plásticas permanentes, aumentando o grau de cristalinidade e orientação das cadeias (CALLISTER, 2002; EBEWELE, 1996; SPERLING, 2006).

A utilização de fibras sintéticas para reforço de matrizes cimentícias tem crescido continuamente. Os principais polímeros utilizados são polietileno, polipropileno, poliamidas, álcool polivinílico (PVA) e poliacrilonitrila (PAN) (BENTUR; MINDESS, 2007; ZHENG; FELDMAN, 1995). A tabela 3.1 apresenta as propriedades típicas de algumas fibras disponíveis comercialmente. 
Tabela 3.1 - Propriedades típicas de fibras sintéticas (BENTUR; MINDESS, 2007).

\begin{tabular}{cccccc}
\hline Tipo de fibra & $\begin{array}{c}\text { Diâmetro / } \\
\boldsymbol{\mu m}\end{array}$ & $\begin{array}{c}\text { Massa específica / } \\
\mathbf{g} / \mathbf{c m}^{\mathbf{3}}\end{array}$ & $\begin{array}{c}\text { Resistência à } \\
\text { tração / Mpa }\end{array}$ & $\begin{array}{c}\text { Módulo de } \\
\text { elasticidade / GPa }\end{array}$ & $\begin{array}{c}\text { Deformação na } \\
\text { ruptura / \% }\end{array}$ \\
\hline Polietileno & $25-1000$ & $0,92-0,96$ & $80-600$ & $2-10$ & $3-100$ \\
\hline Polipropileno & $20-400$ & $0,90-0,95$ & $450-760$ & $3,5-10$ & $15-25$ \\
\hline Nylon & $23-400$ & 1,14 & $750-1000$ & $4,1-5,2$ & $16-20$ \\
\hline PVA & $14-650$ & 1,30 & $800-1500$ & $29-36$ & 5,7 \\
\hline PAN & $20-350$ & $1,16-1,18$ & $200-1000$ & $14-19$ & $10-50$ \\
\hline $\begin{array}{c}\text { Aço (para } \\
\text { comparação) }\end{array}$ & $100-1000$ & 7,84 & $500-2600$ & 210 & $0,5-3,5$ \\
\hline $\begin{array}{c}\text { Concreto (para } \\
\text { comparação) }\end{array}$ & - & $1,5-2,5$ & $3-7$ & $10-45$ & 0,02 \\
\hline
\end{tabular}

Para proporcionar boa resistência residual ao compósito, as fibras devem possuir módulo de elasticidade superior ao do concreto, que varia entre 15 e 40GPa. Entretanto, diversos artigos reportaram que fibras de baixo módulo podem conferir aumento de tenacidade, maior resistência ao impacto, controle de fissuração e maior capacidade de deformação às matrizes cimentícias (KIM; NAAMAN; EL-TAWIL, 2008; ZHENG; FELDMAN, 1995; ZOLLO, 1996). Para a maioria das aplicações, essas propriedades são as de maior interesse.

As fibras de polipropileno apresentam algumas propriedades muito interessantes para aplicação em matrizes cimentícias. Possuem alta resistência química, alta durabilidade no ambiente alcalino do concreto e as matérias-primas para sua fabricação têm custo relativamente baixo. Entretanto, são sensíveis a oxigênio e aos raios ultravioleta, têm baixo módulo de elasticidade e ligação fraca com a matriz (BENTUR; MINDESS, 2007; ZHENG; FELDMAN, 1995).

Para aumentar a capacidade de transferência de tensões entre a fibra e a matriz, fibras auto-fibriláveis são uma alternativa bastante interessante. Durante o processo de mistura para a produção do compósito e quando a fibra sofre esforços de tração devido à abertura de fissuras, o monofilamento é dividido em múltiplos micro filamentos, aumentando a área de contato da fibra com a matriz. Com isso, a ancoragem mecânica da fibra é aprimorada e, portanto, sua capacidade de reforço também (TROTTIER; MAHONEY, 2001). 


\subsubsection{A interface fibra-matriz}

A interface é a região principal que determina uma série de propriedades de sistemas multifásicos (ZHANDAROV; MADER, 2004). Compósitos cimentícios possuem uma zona de transição da interface (entre 10 e $40 \mu \mathrm{m}$ ) ao redor do elemento de reforço, cuja microestrutura é consideravelmente diferente do bulk. As características da interface variam com tipo de fibra e são modificadas ao longo do tempo. Além disso, apresentam grande influência na ligação entre a fibra e a matriz e no processo de quebra dessa ligação, quando a fibra é arrancada (BENTUR; MINDESS, 2007).

A figura 3.6 (a) e (b) mostram fotos tiradas por microscopia eletrônica de varredura, onde podem ser visualizadas as interfaces entre uma fibra de aço e uma microfibra de polipropileno com a matriz cimentícia, respectivamente. Devido aos tratamentos feitos na superfície da microfibra polimérica, a interface fibra-matriz é mais densa e homogênea que a interface entre a matriz e a fibra de aço.

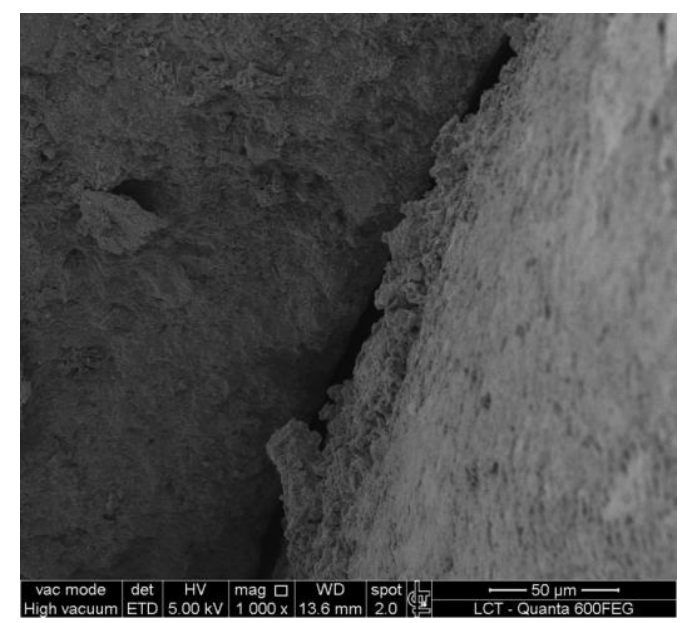

(a)

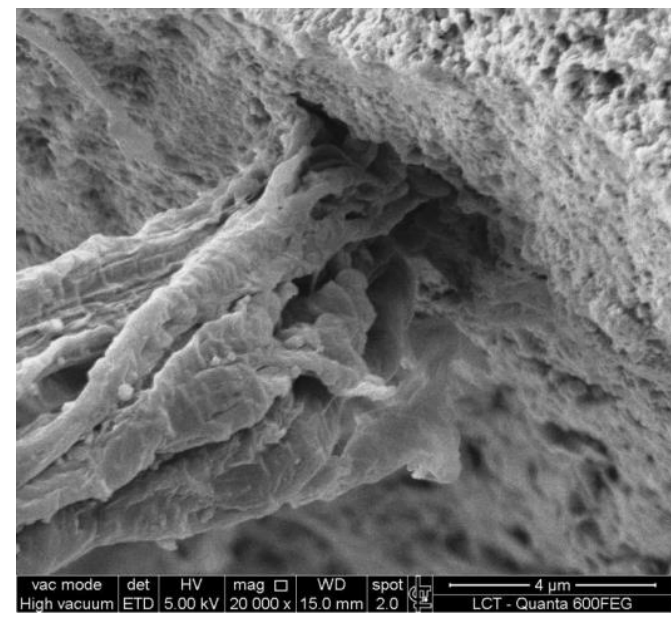

(b)

Figura 3.6 - Interface entre fibra de aço (a) e a microfibra de polipropileno (b) com a matriz.

A natureza particulada da matriz leva à formação de espaços preenchidos com água ao redor das fibras, principalmente nos monofilamentos, assim como em fibras de aço. Isso pode ocorrer devido à exsudação do concreto fresco e ao empacotamento ineficiente dos grãos de cimento na superfície da fibra. Com isso, a interface fibra-matriz é mais porosa e menos densa, além de apresentar maior concentração de cristais de hidróxido de cálcio, que tendem a 
se depositar em grandes cavidades. Como esse composto apresenta menor resistência mecânica que o C-S-H, a zona de transição da interface é a região limitante da resistência do compósito (BENTUR; MINDESS, 2007).

Na figura 3.7 pode ser visualizada a representação esquemática da interface fibra matriz (BENTUR; MINDESS, 2007).

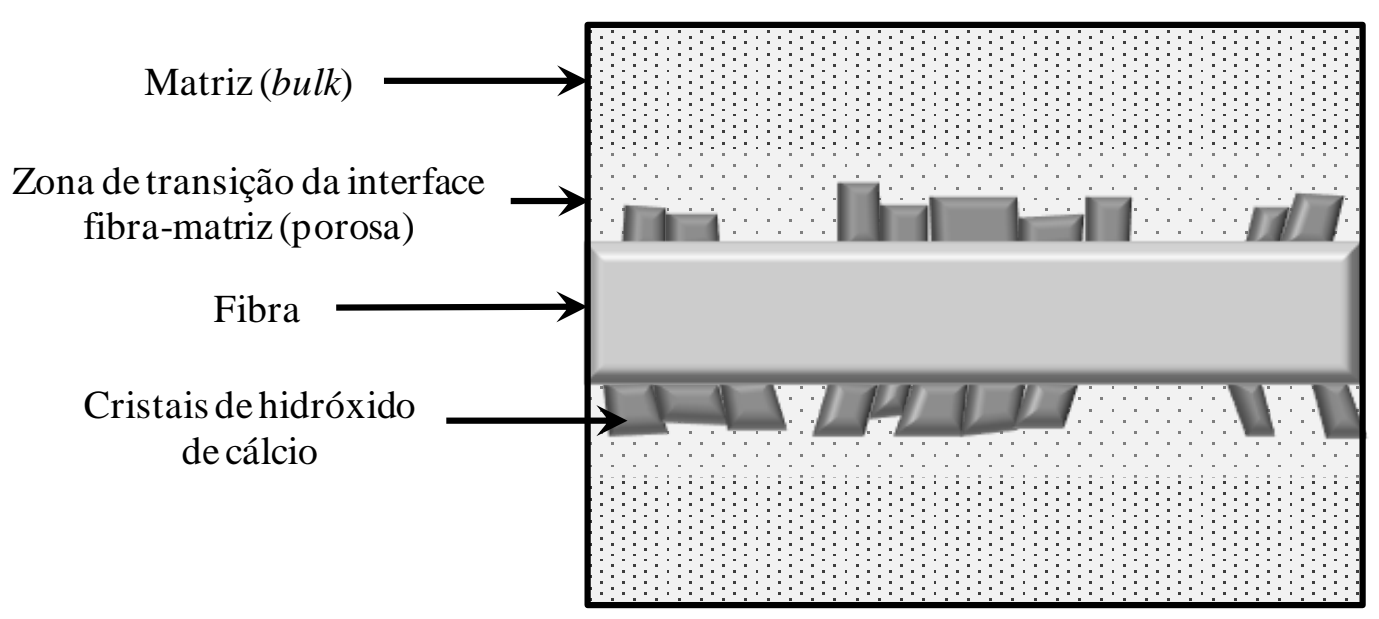

Figura 3.7 - A interface fibra-matriz (adaptada de BENTUR; MINDESS, 2007).

Fibras na forma de multifilamentos podem permanecer na forma de feixes mesmo após a mistura na matriz cimentícia. As fibras que permanecem com essa morfologia possuem espaços entre os filamentos, que tendem a ser preenchidos com produtos da hidratação do cimento se o compósito for mantido em ambiente com alta umidade, sendo a superfície da fibra um sítio para a nucleação desses compostos. Assim, a ligação entre a matriz e a fibra não apresenta grande uniformidade em baixas idades, tendendo a ser mais homogênea com o decorrer da hidratação do cimento (BENTUR; MINDESS, 2007). Esse assunto será mais bem apresentado no item 5.3.3.

\subsection{O compósito e a interação fibra-matriz}

Assim como em todos os compósitos reforçados com fibras, a ligação entre a fibra e a matriz de concreto é extremamente importante. Macrofibras retas com baixa área superficial serão arrancadas em baixos níveis de tensão interfacial e as tensões geradas na fibra são muito 
menores que sua resistência à tração. A deformação das fibras pode melhorar sua ligação com a matriz. Entretanto, se a ligação for muito forte, as tensões que se desenvolvem na fibra podem ultrapassar sua resistência, causando sua ruptura. Nesse caso, a energia absorvida pelas fibras é baixa, proporcionando baixa tenacidade. A eficiência da fibra é aprimorada quando seu arrancamento ocorre em tensões que se aproximam de sua resistência à tração (BANTHIA, 1998).

Os tipos de interação principais que ocorrem entre a fibra e a matriz são a aderência química e física, o atrito e a ancoragem mecânica induzida por deformações na superfície da fibra. A ligação fibra-matriz por aderência ou por atrito é relativamente fraca e somente é significativa em compósitos com fibras de alta área superficial (microfibras, com diâmetro aproximado de $10 \mu \mathrm{m}$ ) ou em matrizes com porosidade muito baixa (fator água/cimento de cerca de 0,30). Em concretos convencionais (fibras com diâmetro superior a $0,10 \mathrm{~mm}$ e fator água/cimento da ordem de 0,40), a ancoragem mecânica é necessária (BENTUR; MINDESS, 2007).

A forma mais comum de quantificar a energia de ligação entre a fibra e a matriz é pela realização de ensaios de arrancamento (single pull-out). A partir desse teste, pode ser previsto o comportamento pós-fissuração do compósito e o mecanismo de ligação entre a fibra e a matriz pode ser analisado (BENTUR; MINDESS, 2007).

Em compósitos com matrizes frágeis, os processos de transferência de tensões são diferentes nas fases pré e pós-fissuração. Antes da formação da fissura, a transferência de tensões é predominantemente elástica e os deslocamentos entre a fibra e a matriz na interface são geometricamente compatíveis. A tensão desenvolvida na interface é de cisalhamento e distribui as cargas externas entre a matriz e a fibra (que possuem módulos de elasticidade diferentes), de forma que suas deformações sejam as mesmas (BENTUR; MINDESS, 2007).

Em estágios de carregamento posteriores, pode ocorrer a quebra da ligação na interface e o processo de transferência de tensões que predomina é o atrito gerado pelo deslizamento entre a fibra e a matriz. Nesse caso, ocorrem deslocamentos diferentes para a fibra e para a matriz. A tensão de atrito é uma tensão de cisalhamento e é considerada como sendo uniforme ao longo da interface fibra-matriz. Esse processo é de maior importância na fase pós-fissuração e controla a resistência e a deformação últimas do compósito (BENTUR; MINDESS, 2007).

A transição entre a transferência elástica e a transferência por atrito ocorre quando a tensão de cisalhamento devido à aplicação de carga supera a força de ligação de aderência 
entre a fibra e a matriz. Quando essa força é superada, a quebra da ligação fibra-matriz é iniciada e a tensão por atrito ocorre na interface onde a ligação já foi rompida (BENTUR; MINDESS, 2007).

Essa transição é um processo gradual onde ambos os mecanismos de transferência de tensões podem ocorrer, dependendo da energia de ligação por aderência entre a fibra e a matriz e a resistência à tração da matriz. Em matrizes de alta resistência à tração, a quebra de ligação fibra-matriz pode ocorrer antes da formação de fissuras, quando a tensão elástica excede a energia de ligação por aderência (BENTUR; MINDESS, 2007).

A principal diferença entre a transferência de tensões na fase pré ou pós-fissuração é que em matrizes não fissuradas a máxima tensão de cisalhamento na interface ocorre nas extremidades da fibra, enquanto que em matrizes fissuradas essa tensão é máxima no ponto em que a fibra entra na matriz. Se a ligação fibra-matriz já foi quebrada previamente, a tensão de cisalhamento será elástica na região afastada da fissura e de atrito nas regiões próximas da fissura (BENTUR; MINDESS, 2007).

A figura 3.8 representa a distribuição de tensões na interface fibra-matriz (BANTHIA, 1998; BENTUR; MINDESS, 2007).

(a)

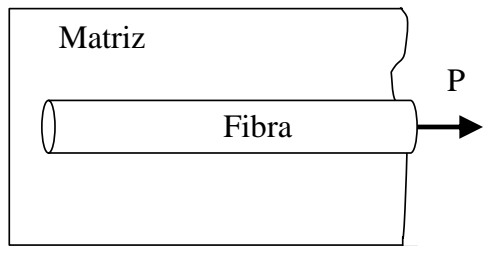

(b)

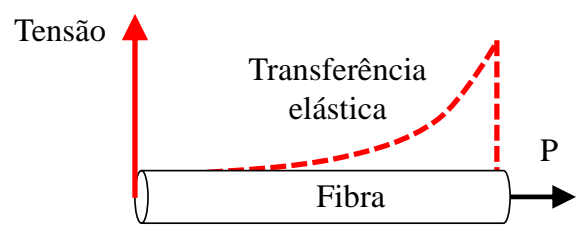

(c)

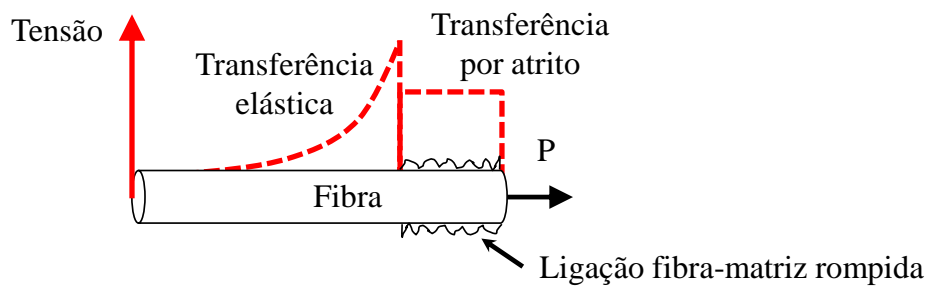

Figura 3.8 - Distribuição de tensões ao longo da fibra interceptando uma fissura: matriz fissurada (a); interface intacta (b); ligação fibra-matriz parcialmente rompida (c) (BANTHIA, 1998; BENTUR; MINDESS, 2007). 


\subsection{Comportamento mecânico de concreto reforçado com fibras}

Como dito anteriormente, o concreto possui comportamento marcadamente frágil perante esforços de tração. Uma fissura funciona como uma barreira à propagação de tensões de tração, que se concentram em sua extremidade. Quando o valor dessa tensão supera a tensão crítica do material, ocorre sua ruptura, normalmente de forma abrupta. Portanto, o concreto simples não apresenta resistência residual (FIGUEIREDO, 2011b).

A ruptura de concreto reforçado com fibras em muitas aplicações práticas ocorre principalmente devido às tensões de tração localizadas. Em uma curva tensão-deformação, há o trecho elástico inicial, onde a deformação é proporcional à tensão aplicada. Esse trecho é seguido de uma zona não linear antes do pico, que ocorre antes da localização da fissura, onde o mecanismo de dissipação de energia pode ser atribuído à absorção de energia volumétrica. Depois que a fissura é localizada, a energia é absorvida na zona de fratura e a dissipação de energia é essencialmente planar (GOPALARATNAM; GETTU, 1995).

A deformação total do corpo-de-prova consiste na soma da deformação na seção crítica com a deformação nas regiões fora da zona de fratura. Na região pós-fissuração, a deformação total é relacionada apenas à deformação na seção crítica, pois a carga aplicada deixa de atuar nas demais regiões após a ruptura da matriz. Para altos valores de abertura de fissura, a dissipação de energia planar pode ser considerada como o trabalho realizado para a fratura do compósito (GOPALARATNAM; GETTU, 1995).

No geral, tanto a dissipação de energia volumétrica quanto a planar contribuem para o comportamento mecânico do compósito. A contribuição de cada mecanismo depende da geometria e do tamanho da estrutura, além da configuração da aplicação de carga. A determinação da contribuição de cada componente e dos parâmetros que quantificam esses mecanismos proporcionam uma maneira de correlacionar a caracterização e a aplicação da tenacidade do concreto reforçado com fibras (GOPALARATNAM; GETTU, 1995).

A principal função das fibras ocorre na fase pós-fissuração, na qual inibem a propagação das fissuras. As fibras podem proporcionar um aumento de resistência ao compósito, por transferências de tensões através das fissuras. Entretanto, sua função mais importante é conferir tenacidade ao compósito, por meio de mecanismos de absorção de energia relacionados à quebra de sua ligação com a matriz e ao seu arrancamento (BENTUR; MINDESS, 2007). 
A figura 3.9 representa o mecanismo de aumento de capacidade portante pósfissuração proporcionado pelas fibras (NUNES; TANESI; FIGUEIREDO, 1997).
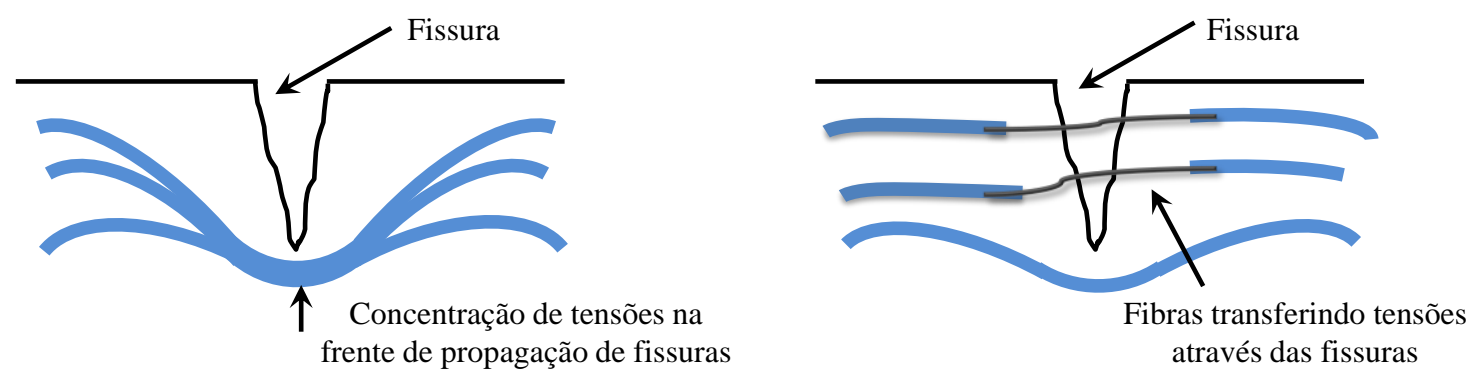

Figura 3.9 - Esquema de concentração de tensões para um concreto sem fibras (a) e com fibras (b) (NUNES; TANESI; FIGUEIREDO, 1997).

A representação esquemática da figura 3.10 demonstra as maneiras pelas quais as fibras absorvem a energia e controlam a abertura das fissuras. Da esquerda para a direita, estão representados a ruptura da fibra, o arrancamento da fibra, a fibra transferindo tensões através da fissura e a quebra da ligação na interface fibra-matriz, respectivamente. $\mathrm{O}$ efeito cumulativo de grande quantidade de fibras localizadas na região onde a fissura ocorreu tende a promover maior capacidade de absorção de energia (ZOLLO, 1996). Nesse esquema, pode ser visto que a propagação de fissuras ocorre na interface fibra-matriz, pois esta é a zona de menor resistência. 


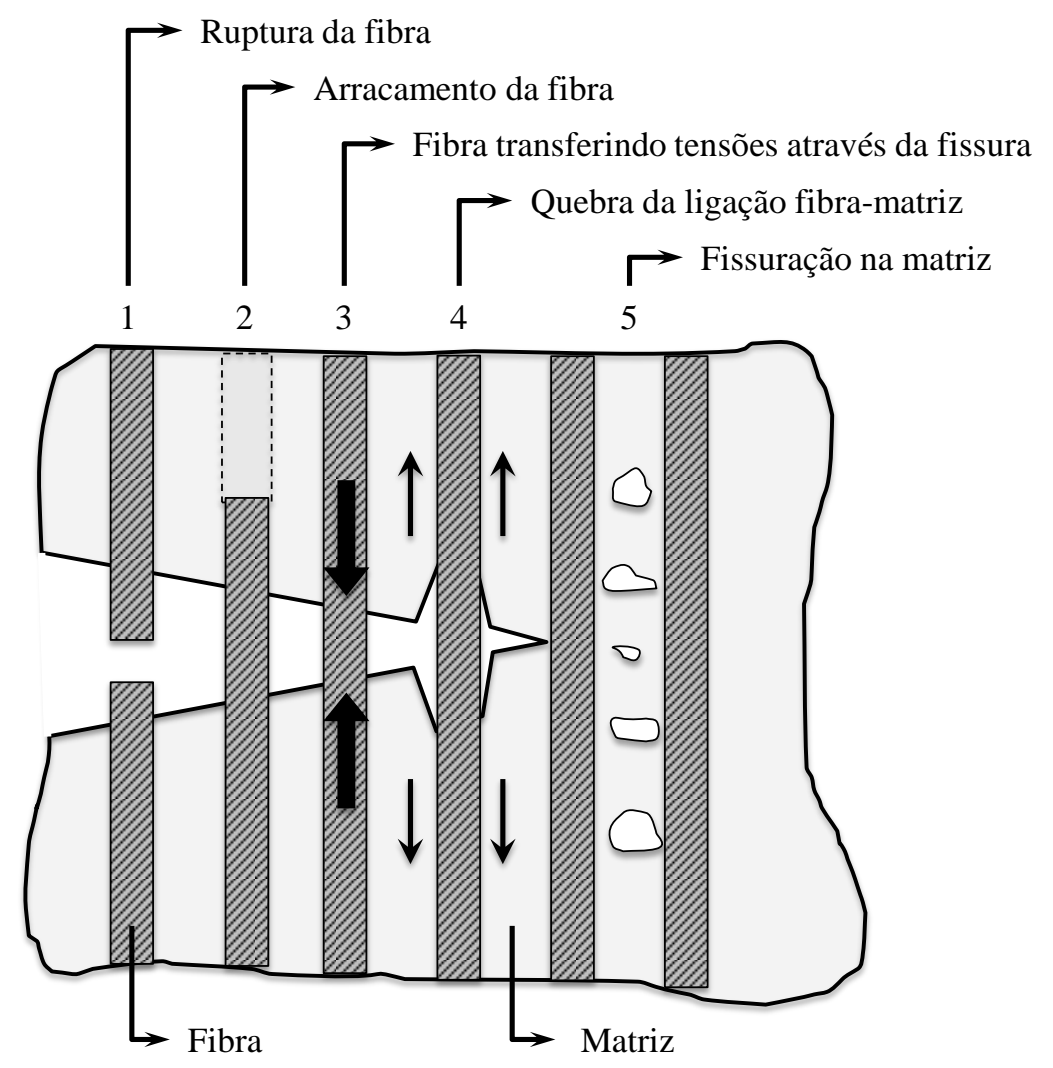

Figura 3.10 - Mecanismos de absorção de energia entre a fibra e a matriz (ZOLLO, 1996).

\subsubsection{Classificação de comportamento}

Tratando-se do comportamento do compósito em um ensaio de tração, podem ser obtidos duas respostas diferentes (NAAMAN, 2003b):

a) Strain-softening: há uma perda progressiva da capacidade resistente da matriz após sua ruptura. Esse fenômeno ocorre devido à abertura de apenas uma fissura (NAAMAN, 2003b);

b) Strain-hardening: o compósito apresenta um ganho de capacidade resistente após a fissuração da matriz. Esse fenômeno está associado à formação de múltiplas fissuras até a obtenção da tensão máxima pós-fissuração. A partir desse ponto, o compósito apresenta o comportamento de strain-softening, com a abertura das fissuras formadas (NAAMAN, 2003b). 
Para ensaios de flexão, o comportamento do compósito também pode ser classificado de duas maneiras (NAAMAN, 2003c):

a) Deflection-softening: após a ruptura da matriz, a carga resistida pelo compósito é menor do que a carga de pico obtida no ensaio. É acompanhado da abertura de apenas uma fissura (NAAMAN, 2003c);

b) Deflection-hardening: após a ruptura da matriz, a carga resistida pelo compósito é maior do que a carga necessária para romper a matriz. É acompanhado da formação de múltiplas fissuras, até atingir a carga máxima pós-fissuração. A partir desse ponto, o compósito apresenta o comportamento de deflection-softening, com a abertura das fissuras formadas (NAAMAN, 2003c).

Para que o comportamento do compósito à flexão seja de deflection-hardening, a tensão pós-fissuração resistida pelas fibras em um ensaio de tração deve ser, no mínimo, 1/3 da tensão de ruptura da matriz. Em ensaios de flexão, a deformação na seção não fissurada favorece a propagação estável das fissuras, induzindo o comportamento de hardening. Então, se um compósito apresenta comportamento de deflection-hardening em um ensaio de flexão, não necessariamente apresentará o comportamento de strain-hardening em um ensaio de tração (BENTUR; MINDESS, 2007; di PRISCO; PLIZZARI, VANDEWALLE, 2009; NAAMAN, 2003b).

A classificação desses comportamentos depende majoritariamente do volume de fibras utilizado. Para volumes acima do volume crítico (para ensaios de tração ou flexão), obtém-se o comportamento de hardening. Para volumes abaixo do volume crítico, o comportamento é de softening (di PRISCO; PLIZZARI, VANDEWALLE, 2009; NAAMAN, 2003c).

A figura 3.11 ilustra os comportamentos do compósito em ensaios de tração e de flexão. 


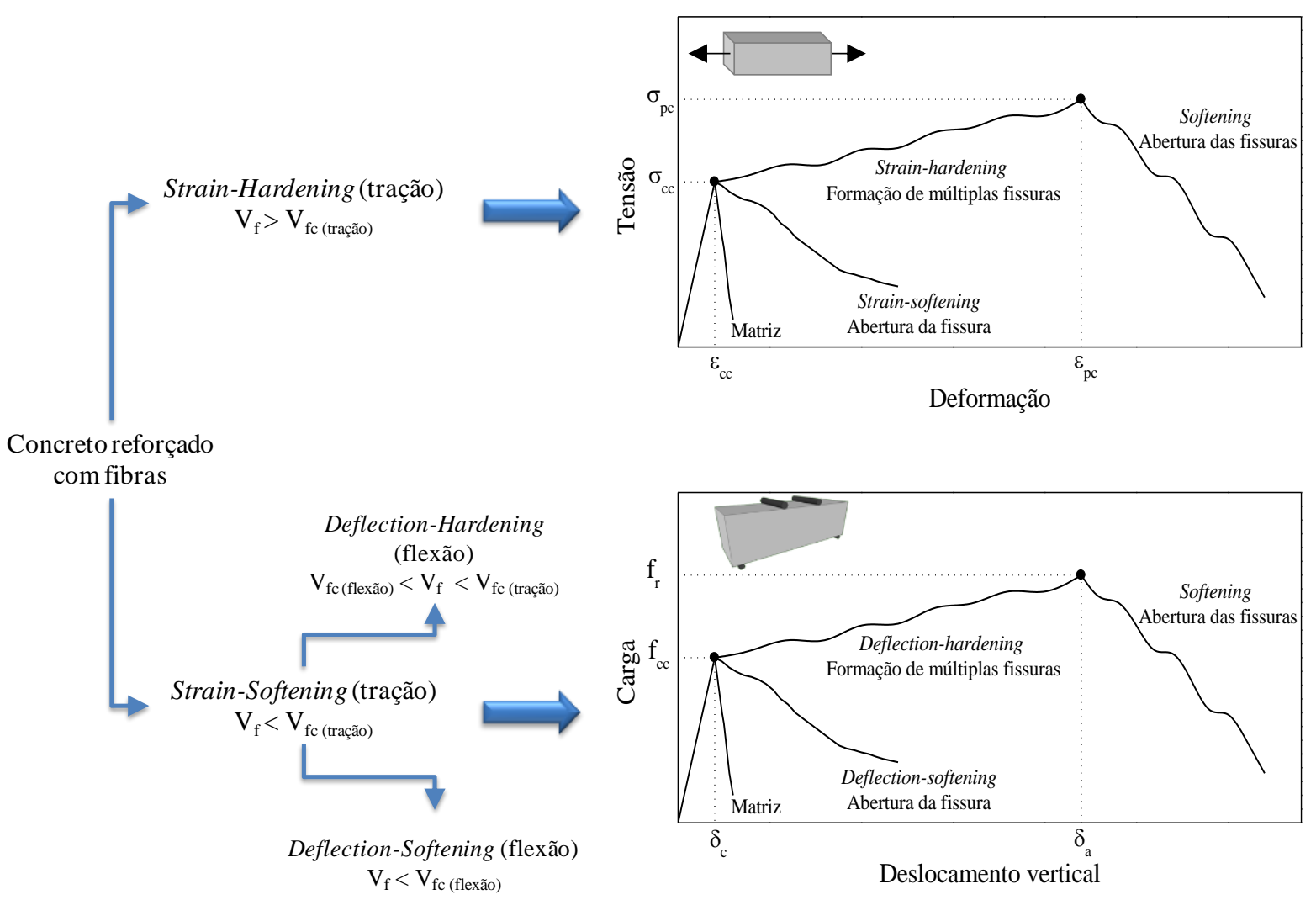

Figura 3.11 - Conceitos de softening e hardening para classificação do comportamento de concreto reforçado com fibras (di PRISCO; PLIZZARI, VANDEWALLE, 2009; NAAMAN, 2003c).

Quando o comportamento do compósito for de deflection-softening, a carga resistida pelas fibras pode aumentar com o aumento da abertura da fissura, devido à maior resistência da fibra ao deslizamento. Esse fenômeno é chamado de slip-hardening e é recorrente principalmente devido à abrasão na superfície da fibra imposta pelo atrito com a matriz. Com isso, fragmentos são liberados da superfície da fibra, aumentando sua superfície de contato com a matriz e, portanto, aumentando sua resistência ao arrancamento (LIN; LI, 1996). Outro motivo para a ocorrência desse fenômeno são as deformações impostas na fibra, principalmente do torcimento dos fios (BENTUR; MINDESS, 2007; NAAMAN, 2000). Com a maior ancoragem na matriz, a carga que a fibra resiste promove deformações plásticas que proporcionam uma reorganização de sua estrutura molecular, tornando-a mais resistente (BENTUR; MINDESS, 2007). No item 5.3.1, sobre a caracterização da fibra polimérica, esse assunto volta a ser discutido.

O comportamento da fibra durante seu arrancamento está demonstrado na figura 3.12. 


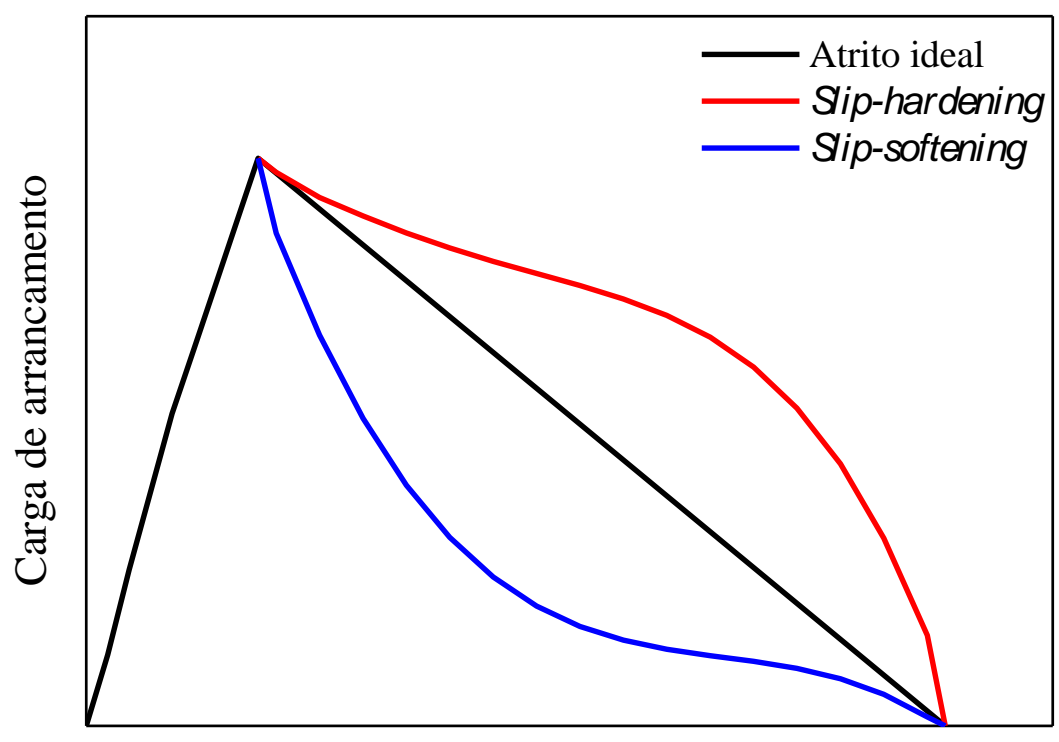

Deslocamento

Figura 3.12 - Comportamentos da fibra durante seu arrancamento, mostrando o atrito ideal, slip-hardening e slip-softening (BENTUR; MINDESS, 2007; LIN; LI, 1996).

A composição química de fibras poliméricas (baixo módulo de elasticidade) é o principal fator que promove o comportamento de slip-hardening. Dependendo dos polímeros e dos aditivos utilizados, podem ser produzidas fibras auto-fibriláveis (TROTTIER; MAHONEY, 2001). Essa propriedade tende a compensar a contração radial da fibra, devido ao seu coeficiente de Poisson ser menor que o da matriz (BENTUR; MINDESS, 2007) (ver item 5.3.1).

A figura 3.13 representa esse fenômeno. 


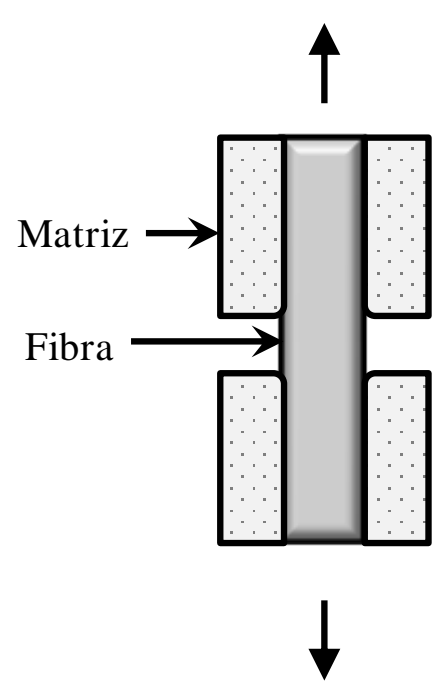

(a)

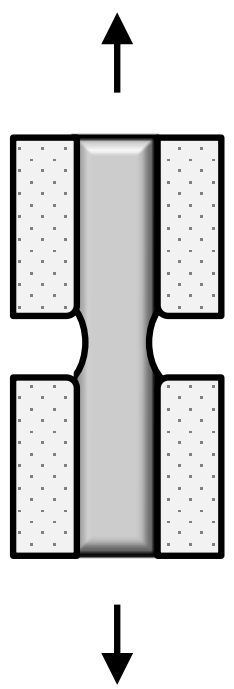

(b)
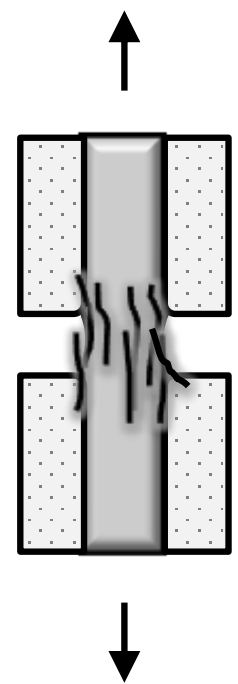

(c)

Figura 3.13 - Representação da fibra e da matriz na região da fissura: seção fissurada (a); contração da fibra, devido ao efeito de Poisson (b); fibrilação da fibra perante esforço de tração (c) (adaptado de BENTUR; MINDESS, 2007).

\subsubsection{Fatores que influenciam o comportamento mecânico de concreto reforçado com fibras}

A partir de uma curva tensão-deformação de uma matriz reforçada com fibras, determinam-se duas propriedades de interesse para avaliação do material. A primeira delas é a tensão de ruptura, $\sigma_{c c}$, que é influenciada pela resistência da matriz. A segunda é a tensão máxima na região pós-fissuração, $\sigma_{\mathrm{pc}}$, que é dependente dos parâmetros de reforço da fibra e de sua ligação com a matriz. A chave para o desempenho do compósito é a resistência pósfissuração (NAAMAN, 2000).

Para representar quais os parâmetros influenciam a resistência pós-fissuração, a equação (3.1) pode ser analisada. Esta equação trata de fibras que são arrancadas da superfície e não rompidas (NAAMAN, 2000).

$$
\sigma_{\mathrm{pc}}=\Lambda \tau \mathrm{V}_{\mathrm{f}} \cdot \frac{\mathrm{L}}{\mathrm{d}}
$$


Onde:

$\sigma_{\mathrm{pc}}$ : tensão máxima na região pós-fissuração;

$\Lambda$ : produto de diversos coeficientes associados ao comprimento da fibra que foi arrancado, orientação e distribuição da fibra, número de fibras sendo arrancadas por unidade de área, etc. $\tau$ : energia de ligação na interface fibra-matriz;

$\mathrm{V}_{\mathrm{f}}$ : volume de fibras;

L: comprimento da fibra;

d: diâmetro da fibra;

A equação (3.1) trata principalmente de fibras que possuem seção circular. Para utilizá-la com outros tipos de fibra, essa equação pode ser reformulada, chegando à equação (3.2).

$$
\sigma_{\mathrm{pc}}=\frac{\Lambda \tau \mathrm{V}_{\mathrm{f}}}{4} \cdot \frac{\Psi}{\mathrm{A}}
$$

Onde:

$\Psi:$ perímetro da fibra;

A: área da seção da fibra.

Uma maneira de caracterizar a influência da razão $\Psi / A$ da fibra é por uma variável desenvolvida por Naaman (2003a), definida como a razão de eficiência intrínseca da fibra (fiber intrinsic efficiency ratio - FIER). O FIER é a razão da área da superfície lateral ligada à matriz pela área da seção e é calculado a partir da equação (3.3).

$$
\text { FIER }=\frac{\Psi \cdot \mathrm{L}}{\mathrm{A}}
$$

Em suma, o comportamento mecânico do concreto reforçado com fibras depende dos fatores resumidos na figura 3.14 . 


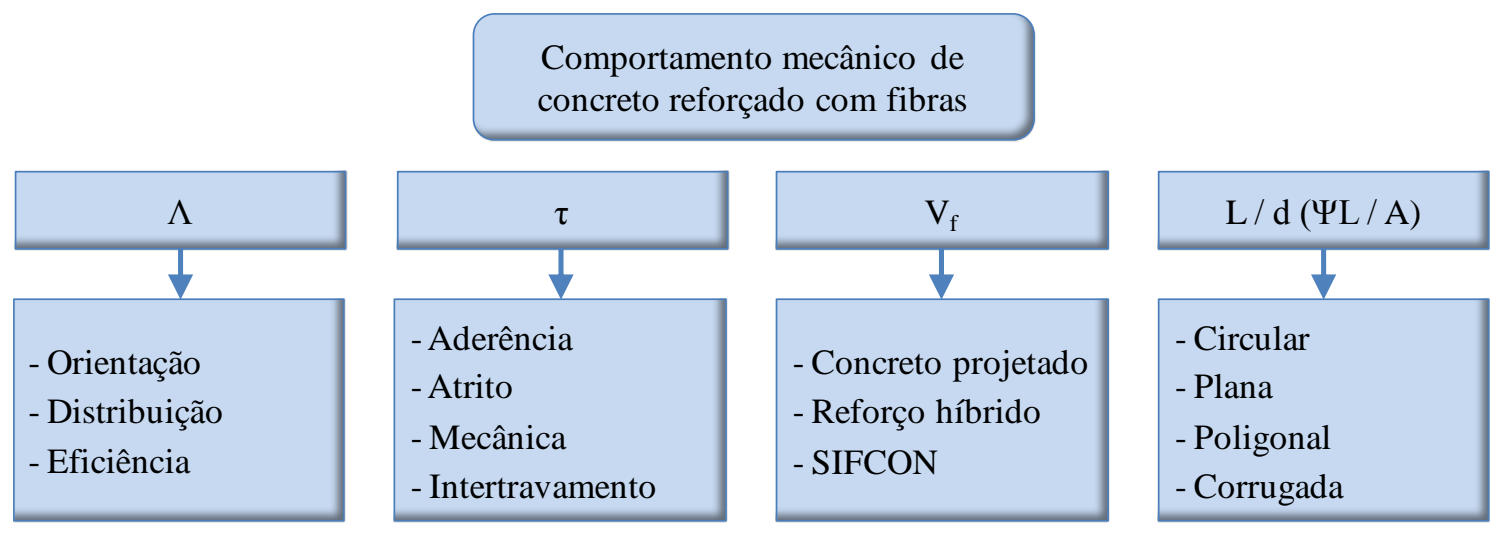

Figura 3.14 - Parâmetros mecânicos que controlam o comportamento do compósito (NAAMAN, 2003b).

Cada um desses fatores será mais bem discutido adiante.

\subsubsection{Orientação das fibras}

Apesar de distribuídas homogeneamente na matriz, nem todas as fibras estão alinhadas na direção do esforço principal. A posição da fibra em relação à fissura pode diminuir sua eficiência, dependendo do ângulo em que a fibra esteja orientada. Em elementos restringidos não fissurados, a carga de arrancamento de uma fibra orientada em um ângulo $\theta$ corresponde a $\cos ^{4} \theta$ da carga de arrancamento de uma fibra alinhada (HANNAN, 1978).

Um parâmetro importante é o fator de eficiência da orientação da fibra, que é calculado pela equação (3.4). Esse valor varia entre 0 e 1 e expressa a razão entre o resultado obtido a partir de uma fibra orientada em um ângulo $\theta$ e uma fibra alinhada na direção do esforço (BENTUR; MINDESS, 2007).

$$
\eta_{\theta}=\Sigma \mathrm{a}_{\theta} \cos ^{4} \theta
$$

Onde:

$\eta_{\theta}$ : fator de eficiência de orientação;

$a_{\theta}$ : proporção de fibras orientadas em um ângulo $\theta$. 
As equações para elementos não restringidos são mais complexas, pois a orientação depende do volume de fibras. A tabela 3.2 mostra os fatores de eficiência obtidos para elementos restringidos e não restringidos.

Tabela 3.2 - Fator de orientação para elementos restringidos e não restringidos (HANNANT, 1978).

\begin{tabular}{ccc}
\hline Orientação da fibra & Restringido & Não restringido \\
\hline Alinhada, 1D & 1 & 1 \\
\hline Aleatória, 2D & $1 / 3$ & $3 / 8$ \\
\hline Aleatória, 3D & $1 / 6$ & $1 / 5$ \\
\hline
\end{tabular}

Para aprimorar a eficiência do reforço proporcionado pelas fibras, é possível diminuir a espessura do elemento reforçado, de forma que as fibras estejam mais bem alinhadas em relação à carga aplicada. Assim, obtém-se um reforço bidimensional, ao invés de tridimensional (di PRISCO; PLIZZARI, VANDEWALLE, 2009). Tal fato já foi observado por Figueiredo et al (2010) em estudo de tubos de concreto reforçado com fibras de aço.

\subsubsection{Energia de ligação com a matriz}

Para aprimorar a aderência de fibras de polipropileno na matriz e desenvolver uma zona de transição mais densa na interface, tratamentos químicos em sua superfície podem ser utilizados. A adição de silanos e a lavagem das fibras com ácido forte em meio oxidante (PELED; GUTTMAN; BENTUR, 1992) promovem uma ponte de aderência química entre a fibra e a matriz. Tratamentos para aumento da rugosidade superficial podem aumentar a área de contato das fibras com a matriz, conduzindo a uma melhor ligação (PELED; GUTTMAN; BENTUR, 1992).

A conformação das fibras também pode proporcionar melhora na ancoragem mecânica, aumentando sua resistência ao arrancamento. As principais conformações impostas em fibras poliméricas são a ondulação, a fibrilação, o recartilhamento (indução de rugosidades por meio de prensagem) e o torcimento dos fios (BENTUR; MINDESS, 2007; BENTUR; PELED; YANKELEVSKY, 1997; NAAMAN, 2000; ZHENG; FELDMAN, 1995). Para as fibras serem torcidas, é necessário que sua seção transversal seja poligonal, pois fibras com seção circular tendem a não permanecer torcidas. Com a maior área lateral 
das fibras poligonais, maior a interação entre os fios e, portanto, o feixe produzido consegue manter-se torcido (NAAMAN, 2000). Esses tipos de deformação não só aumentam o contato com a matriz, aumentando a resistência ao arrancamento, mas diminuem a tendência das fibras a formar aglomerados quando misturadas no concreto fresco (NANNI; MEAMARIAN, 1991).

As fibras de aço mais comuns do mercado possuem ganchos em suas extremidades. Com isso, sua ancoragem mecânica é melhorada, devido ao vínculo mais forte com a matriz. Esse tipo de deformação aprimora a resistência residual conferida pela fibra principalmente para baixos níveis de deformação (FIGUEIREDO, 2011b).

A fibrilação de fibras poliméricas é o processo para criar fendas longitudinais no fio, formando uma rede de filamentos, que tende a se abrir quando misturada no concreto. A utilização de fibras fibriladas apresenta algumas vantagens sobre fibras na forma de monofilamentos, como a maior facilidade de distribuição na matriz e à melhor ancoragem mecânica (NANNI; MEAMARIAN, 1991). Além disso, ocorre um preenchimento dos espaços entre os filamentos por produtos de hidratação do cimento, promovendo um intertravamento das fibras (BENTUR; MINDESS; VONDRAN, 1989).

\subsubsection{Teor de fibras}

A capacidade de reforço que as fibras podem proporcionar é diretamente dependente do teor utilizado. Quanto maior o teor de fibra, maior o número de filamentos que pode transferir tensões através das fissuras e, portanto, a capacidade portante pós-fissuração do concreto reforçado também é maior (FIGUEIREDO, 2011b).

O efeito do teor de fibras está ilustrado na figura 3.15, que representa um diagrama de distribuição de tensões de uma seção fissurada de uma viga fletida. O modelo original foi proposto pelo Comitê Rilem de concreto reforçado com fibras (RILEM TC 162, 2003) e o modelo mostrado na figura 3.15 é uma adaptação desenvolvida por Figueiredo (2011b).

O tratamento feito é baseado na divisão da seção em três partes: zona de compressão até a linha neutra, zona de tração entre a linha neutra e a ponta da fissura e zona fissurada, localizada entre o topo da fissura e a borda do corpo-de-prova. Nas zonas de compressão e 
tração, as tensões são de natureza elástica, enquanto que na zona fissurada, esse fenômeno possui diversas modelagens (BENTUR; MINDESS, 2007).

Verifica-se que a resistência à tração da seção abaixo da linha neutra é a somatória das cargas resistidas por cada fibra presentes nessa seção. Então, pode-se concluir que quanto maior for o número de fibras localizadas naquela posição, maior será a força resultante de tração e, portanto, maior a capacidade resistente do compósito (quanto maior o teor de fibras, maior $\left.\mathrm{F}_{\mathrm{fc}, \mathrm{t}}\right)($ FIGUEIREDO, 2011b).

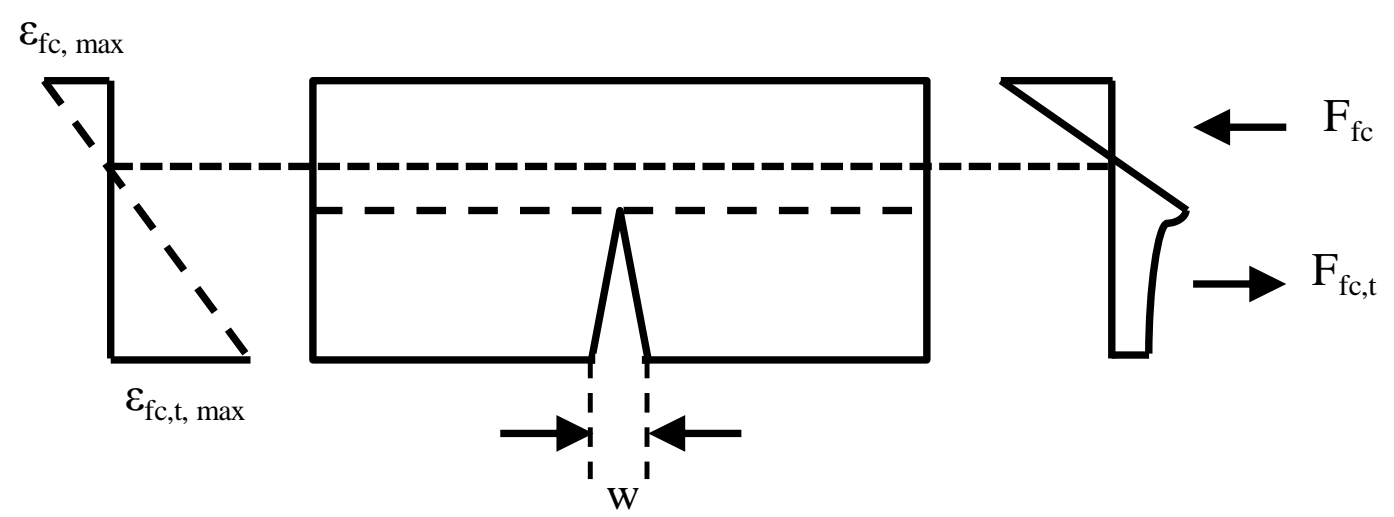

Figura 3.15 - Modelo de distribuição de tensões na seção transversal de um elemento reforçado com fibras durante a flexão (FIGUEIREDO, 2011b).

Onde:

w: Abertura de fissura;

$\varepsilon_{\mathrm{fc}, \max }$ : Deformação máxima do compósito na compressão;

$\varepsilon_{\mathrm{fc}, \mathrm{t}, \max }$ : Deformação máxima do compósito na tração;

$\mathrm{F}_{\mathrm{fc}}$ : Resultante de compressão na seção flexionada;

$\mathrm{F}_{\mathrm{fc}, \mathrm{t}}$ : Resultante de tração na seção flexionada.

O volume crítico de fibras é aquele que proporciona resistência residual ao compósito cuja magnitude é igual à tensão de ruptura da matriz. Para volumes abaixo do crítico, a capacidade portante pós-fissuração diminui após a ruptura da matriz. Para volumes acima do crítico, o compósito pode aceitar níveis de carregamento crescentes após a ruptura da matriz (FIGUEIREDO, 2000). 


\subsubsection{Geometria das fibras}

O comprimento das fibras apresenta grande influência no desempenho pós-fissuração do concreto. Quanto maior o comprimento, maior seu embutimento na matriz e, portanto, maior a resistência ao arrancamento que essa fibra pode apresentar (FIGUEIREDO, 2011b).

Um conceito importante associado à eficiência das fibras é o comprimento crítico $\left(l_{c}\right)$, definido como o comprimento no qual a carga resistida pela fibra causa sua ruptura, ao invés de seu arrancamento da matriz (BENTUR; MINDESS, 2007). Fibras cujos comprimentos estão abaixo do crítico são arrancadas da matriz, pois a tensão resistida por elas não supera sua resistência à tração. Já as fibras que possuem comprimento acima do crítico são preferencialmente rompidas, pois devido ao grande embutimento na matriz, a tensão para o arrancamento da fibra supera sua resistência à tração (FIGUEIREDO, 2011b). Com isso, aumentando-se o comprimento, a resistência mecânica da fibra pode limitar a capacidade resistente do compósito.

A figura 3.16 representa o exposto acima. São mostradas três situações de distribuição de tensões na fibra, dependendo de seu comprimento $\left(1<1_{c}, 1=1_{c}\right.$ e $1>1_{c}$ ) (BENTUR; MINDESS, 2007).
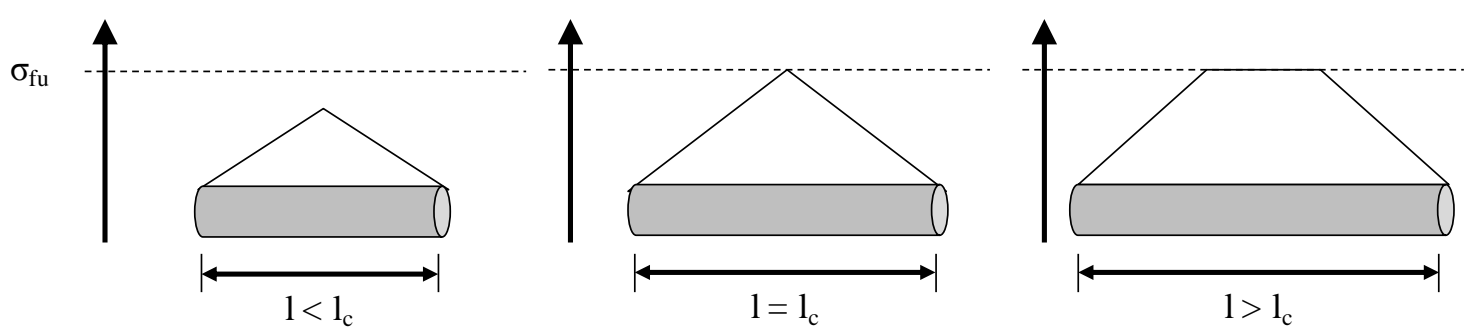

Figura 3.16 - Distribuições de tensão ao longo da fibra em função de seu comprimento crítico (BENTUR; MINDESS, 2007).

É necessário que haja compatibilidade dimensional entre as fibras e os agregados (comprimento da fibra duas vezes maior, no mínimo, que a dimensão máxima do agregado), para que a fibra proporcione reforço ao concreto e não somente à argamassa presente na matriz. Fibras com grande comprimento podem afetar negativamente o desempenho do compósito, devido à maior dificuldade para a mobilidade do concreto no estado fresco, 
prejudicando as operações de lançamento e adensamento do concreto reforçado (FIGUEIREDO, 2011b).

Além do comprimento, a seção transversal da fibra também é um fator determinante do desempenho pós-fissuração do concreto. Para determinado comprimento, quanto maior o diâmetro, maior a área de contato da fibra com a matriz, e, portanto, maior a carga que a fibra pode suportar durante seu arrancamento. Entretanto, fibras com menor diâmetro possuem maior número de filamentos por unidade de massa. Como as fibras são dosadas por massa ou volume por volume de concreto, fibras com menor diâmetro estão presentes na seção de ruptura em maior número, conferindo maior resistência residual para determinado teor. Tal fato foi observado por Figueiredo (1997) em estudo de concreto projetado reforçado com fibras de aço.

A partir da forma geométrica da seção transversal da fibra define-se a área lateral que estará em contato com a matriz. Fibras com seções cilíndricas possuem menor FIER (item 3.3.2) e, portanto, menor energia de ligação com a matriz. Entretanto, fibras com seções quadradas, triangulares ou modificações dessas geometrias podem aumentar o FIER da fibra, aprimorando seu contato com a matriz (NAAMAN, 2003a).

A tabela 3.3 representa como o FIER varia com a geometria da seção transversal da fibra (para seções com mesma área) (NAAMAN, 2003a).

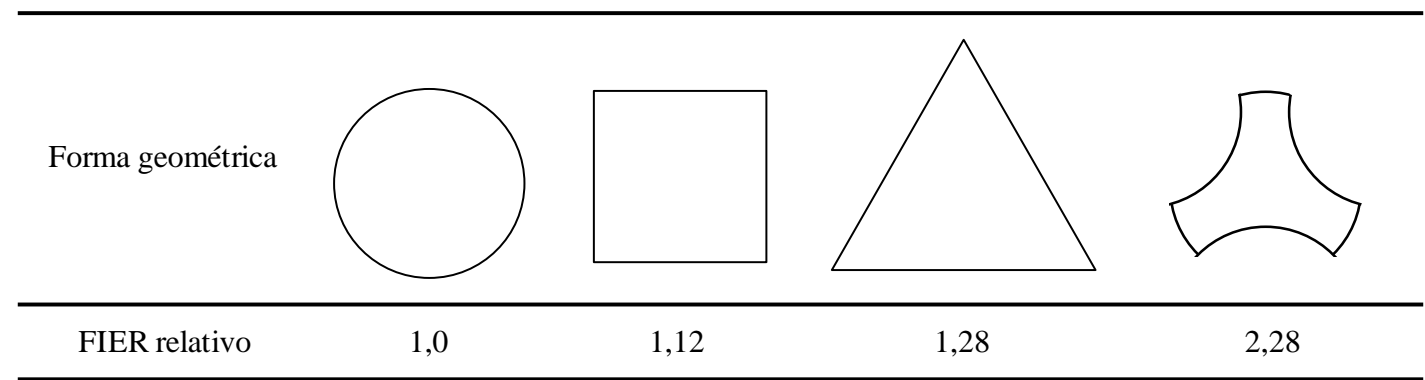

Tabela 3.3 - Seções possíveis para fibras e os valores correspondentes do FIER, comparados com a fibra circular (NAAMAN, 2003a).

\subsubsection{Resistência das fibras}

No momento em que a fissura se forma, há uma transferência de tensões da matriz para as fibras, cuja resistência é acionada. Daí, quanto maior a resistência das fibras, maior a 
capacidade resistente que estas podem proporcionar (FIGUEIREDO, 2011b). Além disso, conforme demostrado na equação (3.5), o volume crítico de fibras é inversamente proporcional à resistência mecânica das fibras (FIGUEIREDO, 2000).

A resistência e o teor das fibras são variáveis interdependentes. Com o aumento do número de fibras na seção de ruptura, menor será a carga que cada fibra deve resistir individualmente, reduzindo a probabilidade de sua ruptura. Assim, teores elevados podem compensar o efeito da baixa resistência da fibra no comportamento do compósito (FIGUEIREDO, 2011b).

Além disso, conforme mencionado no item 3.3.2.4, quanto maior o comprimento da fibra, maior deve ser sua resistência, para que prevaleça o mecanismo de arrancamento das fibras, ao invés de sua ruptura.

\subsubsection{Módulo de elasticidade da matriz}

O módulo de elasticidade do concreto reforçado com fibras é a soma dos módulos da matriz e da fibra, multiplicados pelos respectivos volumes. Como o volume de fibras é baixo em relação ao da matriz, o módulo do compósito é predominantemente dependente do módulo da matriz. Assim, quanto maior o módulo da matriz, maior será o volume de fibras necessário para proporcionar ao compósito o comportamento de elasto-plástico perfeito (maior será o volume crítico) (FIGUEIREDO, 2011b).

\subsubsection{Resistência da matriz}

A resistência mecânica da matriz pode ter dois efeitos distintos no comportamento pós-fissuração do compósito, dependendo da resistência das fibras. Esses dois efeitos estão discutidos adiante: 


\section{a) Fibras de baixa resistência}

Quanto maior a resistência da matriz, a transferência de tensões para a fibra ocorre de forma abrupta, no momento em que a matriz se rompe. Então, se as fibras possuem baixa resistência, maior a probabilidade de ocorrer sua ruptura, ao invés de seu arrancamento, levando a uma menor capacidade resistente pós-fissuração.

Nesse caso, matrizes de menor resistência proporcionam maior tenacidade ao compósito. Além disso, essa diferença de comportamento pós-fissuração entre matrizes de alta e baixa resistência é tão maior quanto menor for o teor de fibras. Quanto maior for o teor de fibras, menor a carga recebida por cada fibra, reduzindo a probabilidade de sua ruptura.

Os resultados expostos acima foram observações realizadas por Figueiredo (1997) e por Figueiredo, Nunes e Tanesi (2000).

\section{b) Fibras de alta resistência}

Quanto maior a resistência das fibras, menor a probabilidade que seu comprimento crítico seja ultrapassado em matrizes de maior resistência. Devido à maior aderência da fibra em matrizes de maior resistência, maior a carga resistida por cada fibra durante seu arrancamento. Assim, o aumento da resistência da matriz promove um aumento da resistência residual do compósito.

Os resultados expostos acima foram observações realizadas por Figueiredo, Mourad e Carvalho (2000).

\subsection{Propriedades de concreto reforçado com fibras de poliproprileno}

Assim como as fibras de aço, as fibras de polipropileno podem ser utilizadas como reforço para produção de compósitos com comportamento de hardening ou de softening. No primeiro caso, a espessura do elemento de concreto é baixa e os teores de fibra são da ordem de 5\% (acima do volume crítico), obtendo-se concretos de alto desempenho. Já no segundo caso, que é o mais usual, são obtidos concretos reforçados convencionais, com teores de fibra que variam entre 0,20 e 0,60\% em volume (BENTUR; MINDESS, 2007). 
As fibras de polipropileno influenciam as propriedades do concreto tanto no estado fresco quanto no endurecido, conforme discutido nos itens subsequentes.

\section{a) Estado fresco}

Durante a mistura, a dispersão das fibras na matriz promove uma redução da trabalhabilidade. Devido à sua alta área superficial, sua utilização diminui a mobilidade dos agregados. A redução da consistência do concreto é maior para maiores teores de fibra e para fibras mais longas, principalmente (BENTUR; MINDESS, 2007).

\section{b) Fase plástica}

Logo após o lançamento, a água de amassamento tende a evaporar e a retração do sistema se inicia, criando tensões na matriz. Devido à sua alta área superficial, as fibras acumulam água em sua superfície e, portanto, reduzem a exsudação e a segregação (TANESI, 1999). Além disso, as fibras apresentam boa eficiência na supressão das fissuras que ocorrem por retração plástica, diminuindo sua extensão em uma ordem de magnitude (BENTUR; MINDESS, 2007).

\section{c) Estado endurecido}

No estado endurecido, as fibras interagem com a matriz no nível das microfissuras, proporcionando meios de transferência de tensões, de forma que a propagação dessas microfissuras seja retardada. Quando a resistência do compósito for atingida e as macrofissuras forem formadas, as fibras podem restringir a abertura e o crescimento dessas macrofissuras (BANTHIA, 1998).

As resistências à compressão e à tração de concretos reforçados com baixos volumes de fibra não são significativamente alteradas em relação a matrizes não reforçadas (ARMELIN, 1992). As propriedades aprimoradas pela utilização de fibras são a tenacidade e a ductilidade, pois proporcionam à matriz frágil capacidade de deformação e de absorção de energia (BENTUR; MINDESS, 2007; FIGUEIREDO, 2011b). 


\subsection{Aplicações de concreto reforçado com fibras}

Desde seu lançamento, a utilização de concreto reforçado com fibras tem crescido continuamente. No Brasil, o compósito é utilizado principalmente em aplicações com baixo consumo de fibras e em estruturas contínuas. Segundo pesquisa realizada por Figueiredo (2011b), o grande mercado para as fibras, tanto de aço quanto de polipropileno, é o de pisos e pavimentos. Os outros dois principais campos de aplicação são concreto projetado e préfabricados.

Essas estruturas são caracterizadas pelo alto grau de redundância e, portanto, apresentam boa redistribuição de esforços. Com isso, a utilização de fibras proporciona uma distribuição de fissuras mais favorável, com larguras limitadas, no estado limite de serviço do elemento (di PRISCO; PLIZZARI, VANDEWALLE, 2009).

As principais aplicações e vantagens do concreto reforçado com fibras estão descritas a seguir.

\subsubsection{Pisos e pavimentos}

Quando utilizadas em pisos e pavimentos, as fibras proporcionam algumas vantagens tecnológicas. A primeira é que a colocação da armadura é eliminada, reduzindo tempo e custo de mão-de-obra para essa etapa. Além disso, o acesso do caminhão betoneira ao local de lançamento do concreto é mais fácil. Como são homogeneamente distribuídas na matriz, proporcionam reforço a todo o piso, inclusive às bordas das juntas, evitando seu esborcinamento (FIGUEIREDO, 2011a).

Entretanto, o compósito também apresenta algumas limitações, como o maior risco ao empenamento por retração diferencial (FIGUEIREDO, 2011a). Em relação ao acabamento superficial, alguns tipos de fibras, principalmente as rígidas, podem aflorar na superfície, dificultando a etapa de finalização do piso. 


\subsubsection{Concreto projetado}

O concreto projetado reforçado com fibras é muito interessante para aplicação em revestimentos de túneis. Eliminando-se o uso da tela metálica, o túnel pode ser revestido imediatamente após a escavação, aumentando a segurança do processo. Além disso, a espessura do revestimento é menor, pois há um melhor cobrimento das paredes, que têm superfície irregular. Com telas metálicas, é necessário maior volume de concreto para preencher o espaço entre a tela e a parede, além de haver necessidade de recobrimento mínimo da armadura (FIGUEIREDO, 2011a). Com a projeção, as fibras são alinhadas em duas dimensões preferenciais, conferindo maior eficiência da capacidade de reforço (BENTUR; MINDESS, 2007).

\subsubsection{Concreto pré-fabricado}

A utilização de fibras na indústria de pré-moldados simplifica o processo de produção dos elementos, pela eliminação do uso da tela. As peças produzidas apresentam maior resistência ao impacto, reduzindo a possibilidade de perdas e ocorrência de defeitos devido ao manuseio da peça. Os principais elementos produzidos são aduelas e tubos para água e esgoto (BENTUR; MINDESS, 2007; FIGUEIREDO, 2011a).

Tradicionalmente, as fibras de aço são as mais utilizadas, devido ao seu alto desempenho. Entretanto, as macrofibras poliméricas podem proporcionar maior durabilidade de elementos expostos a ambientes agressivos, como os tubos para esgoto, devido à sua maior resistência química (BENTUR; MINDESS, 2007; FIGUEIREDO, 2011a). 


\section{Métodos para avaliação do comportamento mecânico de concreto reforçado com fibras}

A avaliação do comportamento mecânico de concreto reforçado com fibras é de extrema importância para que esse compósito seja utilizado de maneira eficiente e econômica. Algumas propriedades podem ser medidas por métodos utilizados para concreto simples, como a resistência à compressão. As propriedades aprimoradas pela utilização de fibras devem ser avaliadas por métodos de ensaios específicos, a partir da determinação da tenacidade ou da resistência residual do compósito (BENTUR; MINDESS, 2007).

A tenacidade de concreto reforçado com fibras é definida como a energia absorvida pelo compósito quando este é carregado, abrangendo a energia antes e após a ruptura da matriz. Pode ser determinada a partir de ensaios de flexão, sendo calculada como a área abaixo da curva carga-deslocamento, que representa o trabalho dissipado no corpo-de-prova. Já a resistência residual é calculada a partir da carga sustentada pelo corpo-de-prova em determinados deslocamentos, cujo valor é inserido normalmente na equação do módulo de ruptura (FIGUEIREDO, 2011b).

Diversos ensaios foram desenvolvidos para caracterizar a capacidade de absorção de energia de concretos reforçados com fibras. Os ensaios de flexão de corpos-de-prova prismáticos são os mais populares porque simulam de forma mais realística as condições em muitas situações práticas e são mais simples de serem conduzidos que ensaios de tração direta. Entretanto, os resultados obtidos por esses testes são afetados pela dimensão e geometria dos corpos-de-prova (GOPALARATNAM; GETTU, 1995).

A maioria dos ensaios de flexão é realizada com corpos-de-prova sem entalhe e o sistema de aplicação de carga possui quatro cutelos. Para essa configuração, é obtida uma curva da carga aplicada pelo deslocamento vertical do corpo-de-prova, medido na metade de seu vão. É requerido o uso de um yoke, onde são alocados os defletômetros, cuja função é fazer com que a medida do deslocamento do corpo-de-prova seja realizada em seu eixo neutro, eliminando valores espúrios gerados pela acomodação do corpo-de-prova no suporte (BARR, et al, 1996). Nesse sistema de ensaio, o corpo-de-prova deve romper no seu terço central, pois nessa região o momento é máximo e a força cortante é igual a zero.

Também é possível utilizar corpos-de-prova que receberam um entalhe no meio de sua face inferior. Nesse caso, o corpo-de-prova é apoiado sobre dois cutelos e a carga é aplicada 
por apenas um cutelo superior. A curva gerada é da carga aplicada pela abertura da fissura. Essa configuração foi uma alternativa desenvolvida com o objetivo de reduzir a variabilidade da resposta do material, visto que a formação da fissura sempre ocorre na região do plano de entalhe e o restante dos corpos-de-prova não sofre deformações inelásticas significativas, minimizando a dissipação de energia no próprio corpo-de-prova. Portanto, a absorção de energia é diretamente atribuída à fratura ao longo desse plano (di PRISCO; PLIZZARI; VANDEWALLE, 2010; GOPALARATNAM; GETTU, 1995). Com essa configuração de ensaio, a tenacidade do compósito pode ser prontamente associada a limites de abertura de fissura e, consequentemente, a limites de serviço específicos para determinada aplicação (GOPALARATNAM; GETTU, 1995).

As configurações para cada tipo de ensaio encontram-se detalhadas na figura 4.1.

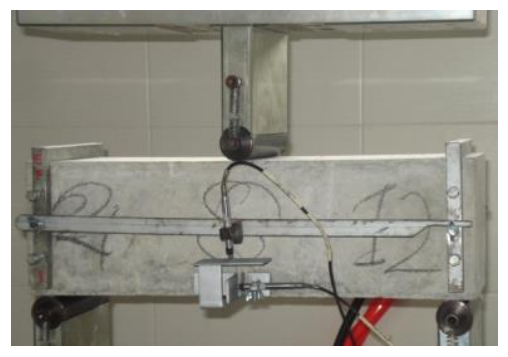

(a)

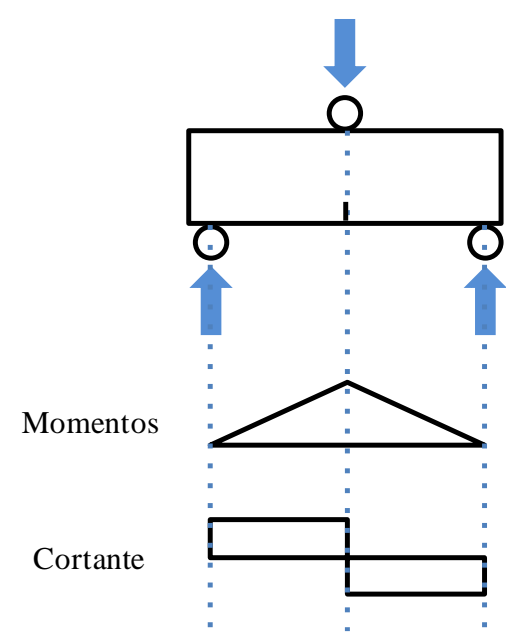

(c)

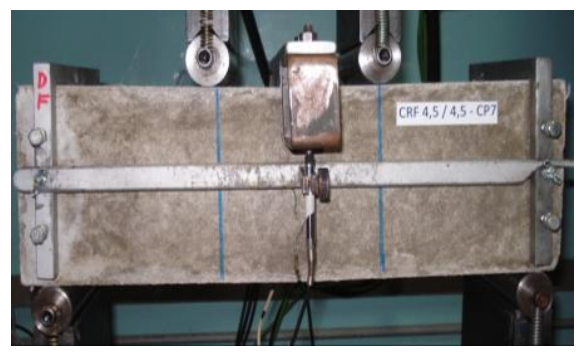

(b)

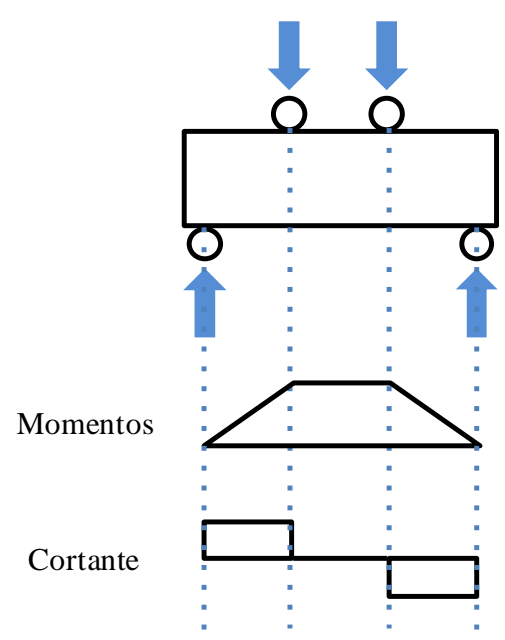

(d)

Figura 4.1 - Configuração de ensaio para flexão em três (a) e quatro pontos (b); distribuição dos momentos para os ensaios em três (c) e quatro pontos (d).

Para que a curva carga-deslocamento represente apropriadamente a energia absorvida pelo corpo-de-prova, métodos precisos para controle do ensaio devem ser prescritos. Uma grande evolução nessa área é a utilização de sistema fechado de controle de velocidade de 
deslocamento para realização desses ensaios, cujo parâmetro de controle é o deslocamento vertical do corpo-de-prova ou a abertura da fissura. Os ensaios de corpos-de-prova com entalhe devem ser realizados com esse sistema, necessariamente (GIACCIO; TOBES; ZERBINO, 2007). Esse assunto será discutido em maiores detalhes no item a seguir.

\subsection{A instabilidade pós-pico e o efeito dos sistemas operacionais na determinação da tenacidade}

Em ensaios de flexão de concreto reforçado com fibras pode ocorrer a instabilidade pós-pico, no momento em que a carga é transferida para fibras após a ruptura da matriz. Quando são utilizados baixos teores de fibra (abaixo de 0,20\% em volume) ou fibras de baixa resistência, a capacidade resistente conferida por sua utilização é menor que a tensão de ruptura da matriz. Por esse motivo, a transferência de carga não é estável e o corpo-de-prova em teste pode sofrer uma queda abruta (FIGUEIREDO, 2011b).

Devido a esse fenômeno, a região do gráfico situada imediatamente após a ruptura da matriz não é bem caracterizada e seu efeito é uma superestimativa da deformação do material. A área abaixo da curva carga-deslocamento é aumentada nos níveis iniciais de deslocamento e, consequentemente, a tenacidade do compósito é majorada (BANTHIA; DUBEY, 1999; FIGUEIREDO, 2011b).

Em estudos realizados por Tiguman (2004), foi reportado que a região de instabilidade para um concreto reforçado com fibras de polipropileno no teor de $0,50 \%$ em volume ocorreu entre 0,05 e 1,2-2,0mm de deslocamento vertical, quando corpos-de-prova prismáticos de $100 \times 100 \times 400 \mathrm{~mm}^{3}$ foram utilizados. $\mathrm{O}$ fator de tenacidade para esse teor de fibra foi cerca de $10 \%$ maior do que o teor de $1,5 \%$ da mesma fibra, devido aos efeitos prejudiciais da instabilidade pós-pico.

O sistema operacional do equipamento utilizado nos ensaios de flexão também apresenta grande influência nos resultados de determinação da tenacidade. Os equipamentos disponíveis na grande maioria dos laboratórios de controle de tecnológico e em algumas universidades e centros de pesquisa são dotados de sistema open-loop, cuja variável de controle de ensaio é o deslocamento vertical do pistão da prensa, que é mantido constante durante todo o ensaio. Se esses equipamentos não apresentarem elevada rigidez, a energia 
elástica decorrente da ruptura do corpo-de-prova é dissipada no próprio corpo-de-prova em teste, aumentando a instabilidade pós-pico (GETTU et al, 1996; GUIMARÃES; FIGUEIREDO, 2002).

Para evitar tal consequência, a utilização de equipamentos dotados de sistema fechado de controle de velocidade de deslocamento (closed-loop) é um os principais fatores para reduzir a instabilidade pós-pico em ensaios de flexão. Com esse sistema, o deslocamento vertical do corpo-de-prova ou a abertura da fissura é mantido constante durante todo o ensaio. Além disso, essa variável funciona como sinal de retorno para o programa do equipamento e controla o ensaio, contribuindo para que a aplicação de carga varie proporcionalmente com a deformação do corpo-de-prova. Dessa forma, os resultados obtidos apresentam maior confiabilidade e reprodutibilidade (GETTU et al, 1996).

$\mathrm{O}$ esquema apresentado na figura 4.2 ilustra a diferença entre equipamentos com sistemas open-loop e closed-loop (BERNARD, 2009) e a figura 4.3 mostra as curvas cargadeslocamento vertical obtidas a partir de cada procedimento de ensaio (BANTHIA; DUBEY, 1999). 


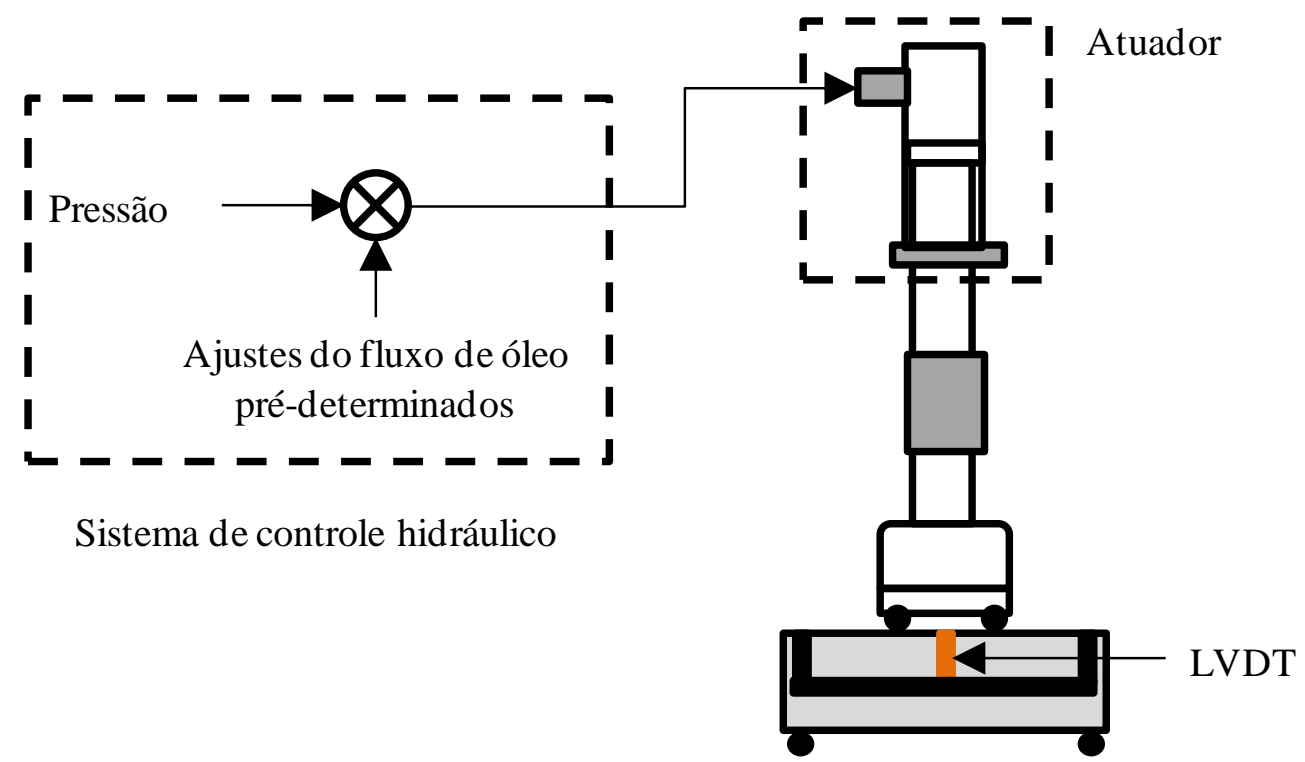

(a)

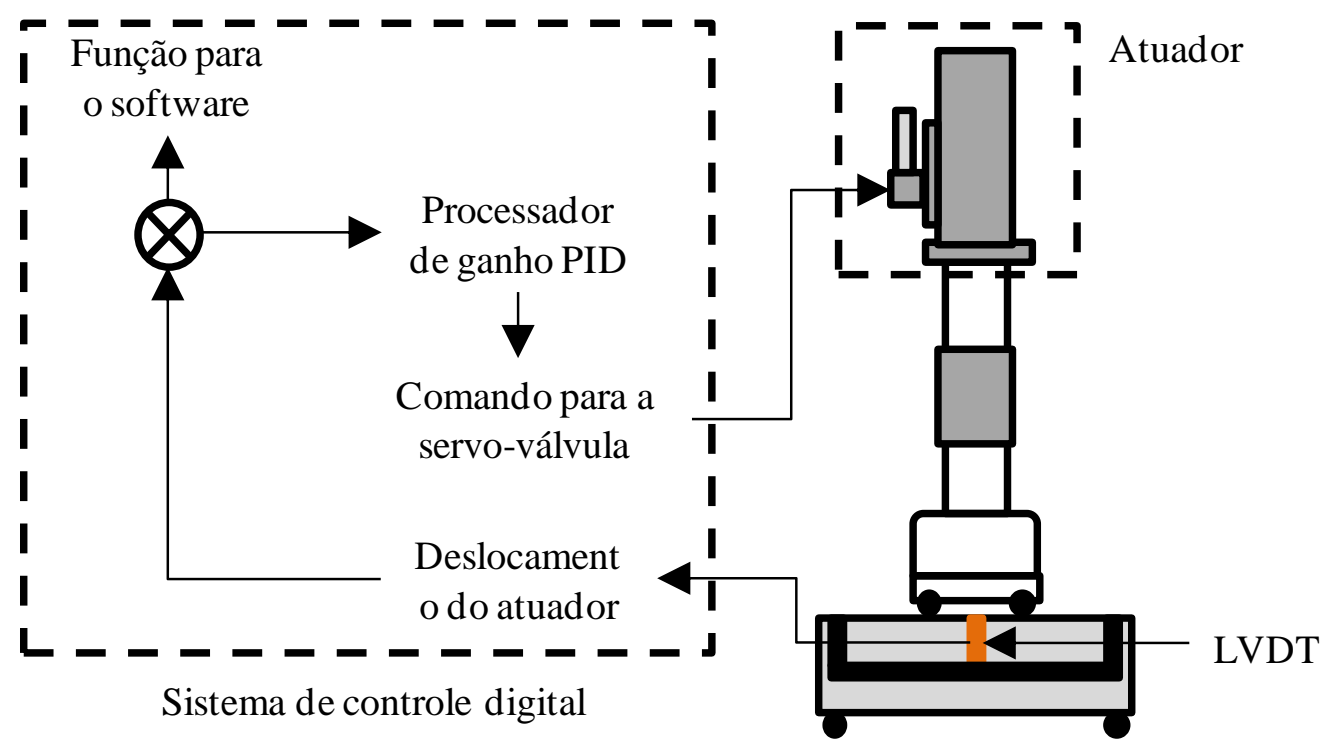

(b)

Figura 4.2 - Diferença entre sistemas open-loop (a) e closed-loop (b) (BERNARD, 2009). 


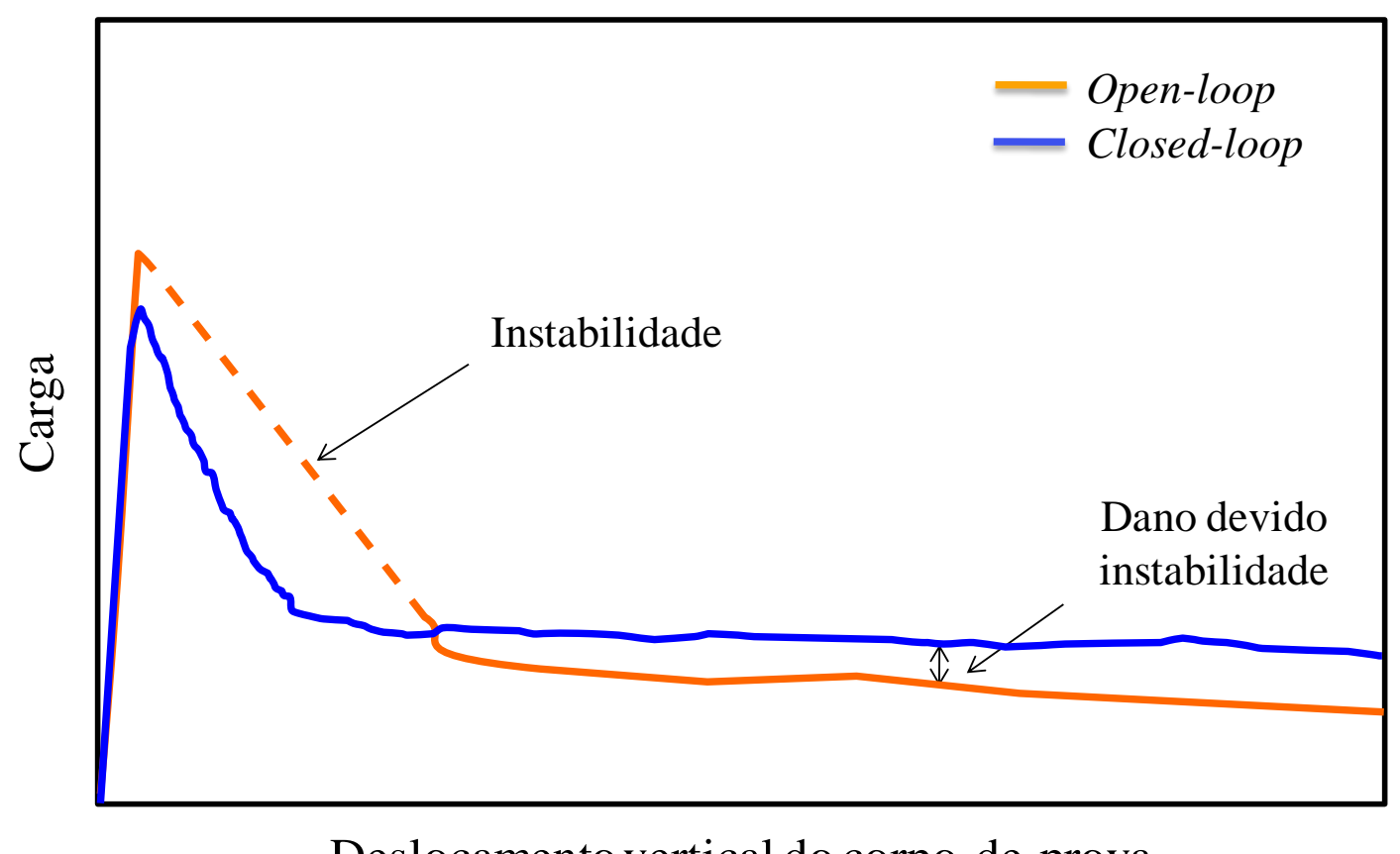

Figura 4.3 - Curvas carga - deslocamento vertical obtidas com sistemas open e closed-loop (BANTHIA; DUBEY, 1999).

Com sistemas closed-loop, a instabilidade que ocorre após a ruptura da matriz cimentícia é praticamente reduzida a zero. Os pontos de leitura que definem esse intervalo são equidistantes, ou seja, a curva carga-deslocamento vertical é bem caracterizada. Com isso, há menores desvios nos resultados obtidos (BANTHIA; DUBEY, 1999; GETTU et al, 1996).

Em sistemas open-loop, o intervalo entre o ponto de carga máxima e o ponto em que as fibras passam a atuar não é bem caracterizado, mesmo com elevada frequência de aquisição de dados. Essa região é representada por uma reta com poucos pontos, pois esse fenômeno ocorre em uma fração de segundo. Verifica-se que a área abaixo da curva nesse intervalo fica superestimada, e, além disso, a porção final da curva não representa a resposta real do material, levando a grandes desvios na análise de resultados (BANTHIA; DUBEY, 1999; GETTU et al, 1996). 


\subsection{Procedimentos de ensaio normalizados}

Segundo Mindess, Young e Darwin (2003), os parâmetros de tenacidade ou de resistência residual para concreto reforçado com fibras devem, idealmente, satisfazer os seguintes critérios:

a) Devem ter um significado físico para ser usado para especificação ou controle de qualidade de concreto reforçado com fibras;

b) $\mathrm{O}$ deslocamento utilizado para a determinação da tenacidade deve refletir as condições de serviço mais severas para determinada aplicação;

c) A variabilidade nas medidas das propriedades do concreto deve ser baixa o suficiente para proporcionar níveis aceitáveis de precisão entre lotes e entre laboratórios;

d) Devem refletir as características da curva carga-deslocamento;

e) Devem ser independentes do tamanho e da geometria do corpo-de-prova.

Entretanto, os métodos de ensaio normatizados descritos adiante não satisfazem todos esses critérios. Além disso, a correlação entre eles pode ser complicada, pois podem fornecer resultados conflitantes e dependentes do tipo de fibra, do equipamento e do operador.

\subsubsection{JSCE-SF4 (1984) - Método de ensaio de resistência e tenacidade à flexão de concreto reforçado com fibras de aço}

Este método de ensaio foi um dos primeiros a prescrever ensaios de flexão de corposde-prova prismáticos para avaliação da tenacidade de concreto reforçado com fibras. Os demais, como o descrito na norma ASTM C1609, são variantes desse procedimento. É requerido equipamento cujo pórtico tenha com elevada rigidez, para minimização da instabilidade pós-pico (FIGUEIREDO, 2011b). A variável de controle do ensaio é o deslocamento vertical do pistão da prensa. 
A recomendação japonesa baseia-se na flexão de corpos-de-prova prismáticos sem entalhe, que podem ser moldados ou extraídos. Suas dimensões são de 100mm x 100mm x $350 \mathrm{~mm}$ ou de $150 \mathrm{~mm}$ x $150 \mathrm{~mm}$ x $500 \mathrm{~mm}$, com vão de 300 ou de $450 \mathrm{~mm}$, respectivamente. O tamanho do corpo-de-prova é dependente do comprimento da fibra utilizada. É necessário que a menor dimensão do prisma seja, no mínimo, três vezes maior que o comprimento da fibra (FIGUEIREDO, 2011b).

O suporte para o apoio dos corpos-de-prova e o suporte para aplicação de carga contêm dois cutelos cilíndricos, que possuem rotação livre sobre seus eixos. São necessários dois LVDTs para leitura do deslocamento vertical do corpo-de-prova, centralizados em cada face lateral do prisma, utilizando-se um yoke. O carregamento é feito até que o deslocamento vertical mínimo de (L/150)mm seja atingido. O rompimento do corpo-de-prova deve ocorrer em seu terço central. Se ocorrer fora dessa região, seu resultado deve ser descartado.

O esquema do ensaio pode ser verificado na figura 4.4.

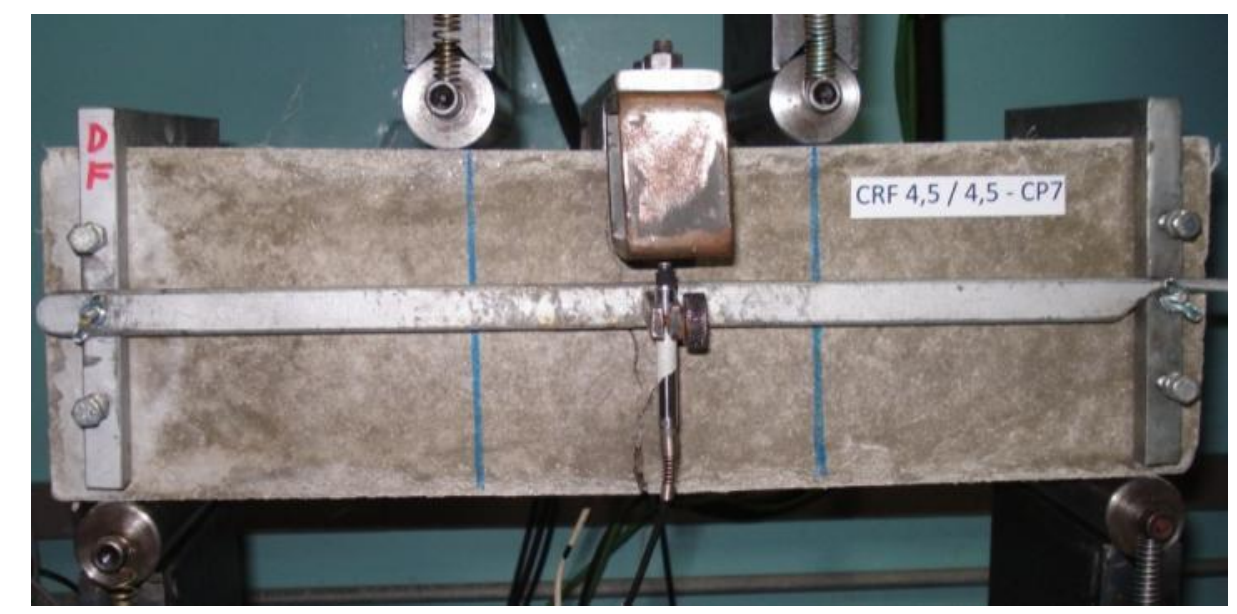

Figura 4.4 - Esquema representativo do ensaio segundo JSCE-SF4 (1984).

É fixada uma velocidade para o deslocamento vertical do corpo-de-prova, no intervalo de 0,15 a $0,30 \mathrm{~mm} / \mathrm{min}$. A análise da curva carga-deslocamento é feita através da determinação do módulo de ruptura, pela equação (4.1), da tenacidade, que representa a energia absorvida pelo corpo-de-prova, integrando-se a curva entre os pontos 0 e $\delta_{\mathrm{tb}}$, e do fator de tenacidade à flexão, utilizando a equação (4.2). Em suma, o valor de $\mathrm{T}_{\mathrm{b}}$ dividido por $\delta_{\mathrm{tb}}$ irá fornecer a carga média equivalente à que o corpo-de-prova suportou durante o ensaio até dado nível de deslocamento. 


$$
\begin{aligned}
& \text { MOR }=\mathrm{P}_{\text {pico }} \cdot \frac{\mathrm{L}}{\mathrm{b} \cdot \mathrm{d}^{2}} \\
& \bar{\sigma}_{\mathrm{b}}=\frac{\mathrm{T}_{\mathrm{b}}}{\delta_{\mathrm{tb}}} \cdot \frac{\mathrm{L}}{\mathrm{b} \cdot \mathrm{d}^{2}}
\end{aligned}
$$

Onde:

MOR: módulo de ruptura do (MPa);

$\mathrm{P}_{\text {pico: }}$ carga de pico (máxima) obtida no ensaio de flexão (N);

$\sigma_{\mathrm{b}}$ : Fator de tenacidade à flexão quando o deslocamento vertical do corpo-de-prova for $\delta_{\mathrm{tb}}$ (MPa);

$\mathrm{T}_{\mathrm{b}}$ : Tenacidade à flexão (área abaixo da curva carga por deslocamento vertical), no intervalo de 0 a $\delta_{\mathrm{tb}}(\mathrm{J})$;

$\delta_{\mathrm{tb}}$ : Deslocamento vertical no ponto $\mathrm{L} / 150 \mathrm{~mm}$ (para vãos de ensaio de $300 \mathrm{e}$ de $450 \mathrm{~mm}$, $\delta_{\mathrm{tb}}$ é igual a 2,0 e $3,0 \mathrm{~mm}$, respectivamente);

L: Vão de ensaio (mm);

b: Largura do corpo-de-prova (mm);

d: Altura do corpo-de-prova (mm).

A curva carga-deslocamento obtida está representada na figura 4.5. 


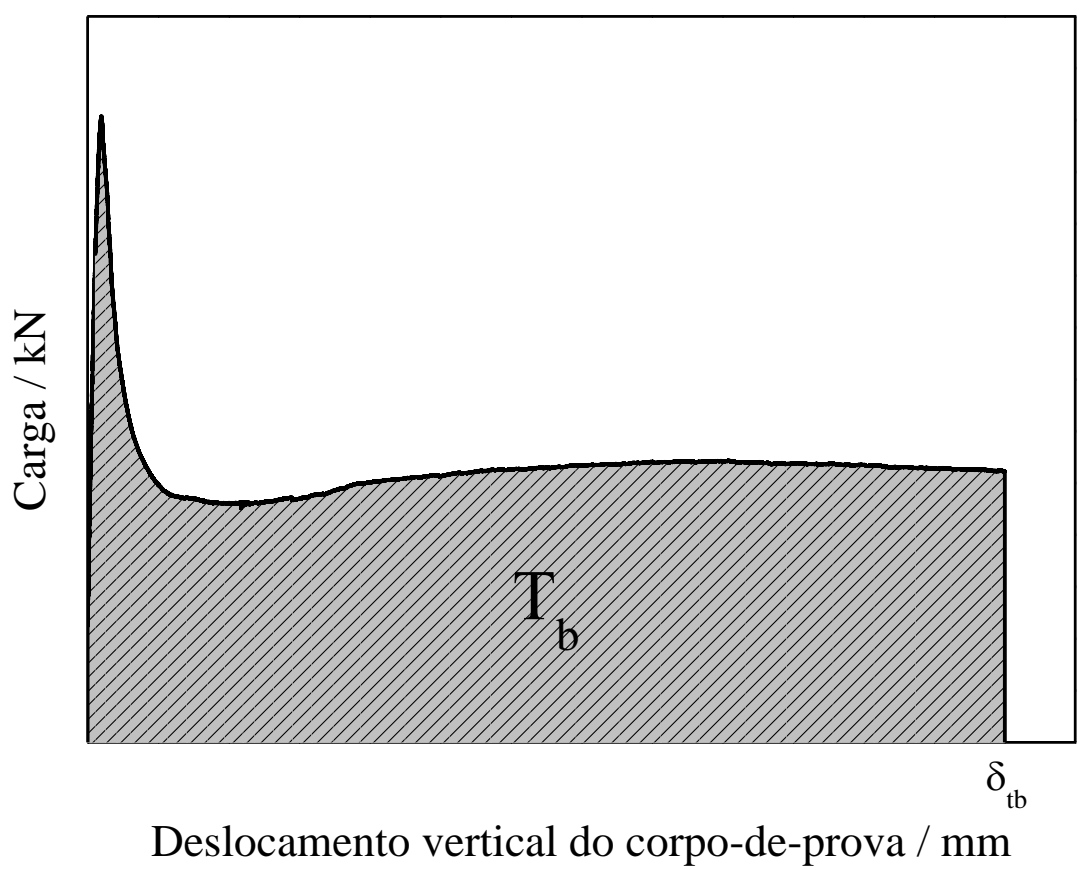

Figura 4.5 - Curva carga por deslocamento vertical obtida segundo JSCE-SF4 (1984) (FIGUEIREDO; HELENE, 1997).

Esse é o método mais comumente utilizado para dimensionamento de elementos de concreto reforçado com fibras e o que apresenta a concepção mais simples (FIGUEIREDO, 2011b). Foi o pioneiro na recomendação do uso do yoke para o ensaio de flexão de corpos-deprova prismáticos (BANTHIA, 1998).

Uma grande vantagem desse método de ensaio é que os parâmetros de tenacidade são pouco influenciados por diferentes sistemas de aplicação de carga ou por deflexões externas. Entretanto, algumas de suas limitações são:

a) A tenacidade é dependente das dimensões do corpo-de-prova (BENTUR; MINDESS, 2007);

b) Os parâmetros de tenacidade não distinguem entre comportamento pré e pós-pico. Diferentes curvas carga-deslocamento podem conferir o mesmo resultado (BENTUR; MINDESS, 2007);

c) O comportamento imediatamente após a formação da primeira fissura não é indicado no fator de tenacidade (BANTHIA; MINDESS, 2004);

d) Como o ensaio tem um ponto fixo para finalização, não pode ser adaptado para outras deflexões ou para diferentes condições de serviço (BENTUR; MINDESS, 2007);

e) A tenacidade é dependente da idade do corpo-de-prova, até que este complete 60 dias (BENTUR; MINDESS, 2007). 


\subsubsection{ASTM C1609 (2010) - Método de avaliação do desempenho à flexão de concreto reforçado com fibras}

Este ensaio é uma variante do proposto pelo método japonês. São utilizadas a mesma configuração de ensaio e as mesmas dimensões dos corpos-de-prova e é obtida a mesma curva carga-deslocamento vertical. Entretanto, para sua realização, é requerido um equipamento com sistema fechado de controle de velocidade de deslocamento, necessariamente. Além disso, a variável de controle de ensaio é o deslocamento vertical do corpo-de-prova. Dessa forma, os resultados obtidos a partir desse método tendem a ser mais confiáveis que os obtidos pelo método japonês (BERNARD, 2009).

A velocidade de carregamento é dividida em dois segmentos: no primeiro (0 - L/600), é utilizada velocidade de deslocamento vertical do corpo-de-prova de 0,06 a $0,12 \mathrm{~mm} / \mathrm{min}$; no segundo (L/600 - L/150), a velocidade pode estar entre 0,06 e 0,24mm/min. É adotada menor velocidade no trecho inicial, pois esta é a etapa crítica da realização dos ensaios, onde a carga é transferida da matriz para as fibras, podendo ocorrer a instabilidade. Esse intervalo de

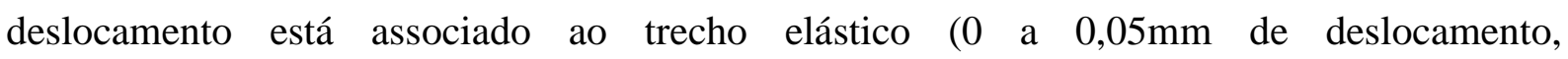
aproximadamente) e ao início do comportamento elasto-plástico. No segundo trecho, correspondente ao comportamento pós-fissuração, é adotada maior velocidade de ensaio, pois não é esperado nenhum tipo de instabilidade nesta etapa. Essas faixas de velocidades de ensaio são mais adequadas do que a proposta pelo método JSCE-SF4, pois minimizam a possibilidade de ocorrer a instabilidade pós-pico (FIGUEIREDO et al, 2012).

A análise da curva é feita por meio da obtenção das cargas residuais $\mathrm{P}_{\mathrm{d}, \mathrm{L} / 600}$ e $\mathrm{P}_{\mathrm{d}, \mathrm{L} / 150}$, utilizadas para calcular as resistências residuais $\mathrm{f}_{\mathrm{d}, \mathrm{L} / 600}$ e $\mathrm{f}_{\mathrm{d}, \mathrm{L} / 150}$, quando o deslocamento vertical do corpo-de-prova for L/600 e L/150, respectivamente. A resistência residual referente ao deslocamento vertical de L/600 está correlacionada ao estado limite de serviço e a resistência no deslocamento de L/150 ao estado limite último.

Os cálculos das resistências residuais são feitos utilizando-se as equações (4.3) e (4.4):

$$
f_{d, L / 600}=P_{d, L / 600} \cdot \frac{L}{\text { b.d } d^{2}}
$$




$$
f_{d, L / 150}=P_{d, L / 150} \cdot \frac{L}{b . d^{2}}
$$

Onde:

$\mathrm{f}_{\mathrm{d}, \mathrm{L} / 600}$ e $\mathrm{f}_{\mathrm{d}, \mathrm{L} / 150}$ : Resistências residuais para corpos-de-prova de altura $\mathrm{d}$, quando $\mathrm{o}$ deslocamento vertical do corpo-de-prova for L/600 e L/150, respectivamente (MPa);

$\mathrm{P}_{\mathrm{d}, \mathrm{L} / 150}$ e $\mathrm{P}_{\mathrm{d}, \mathrm{L} / 150}$ : Cargas residuais para corpos-de-prova de altura $\mathrm{d}$, quando o deslocamento vertical do corpo-de-prova for $\mathrm{L} / 600$ e L/150, respectivamente (N);

L: vão de ensaio (mm);

b: largura do corpo-de-prova (mm);

d: altura do corpo-de-prova (mm).

Além disso, a tenacidade, $\mathrm{T}_{\mathrm{b}, \mathrm{L} / 150}$, conferida pela utilização de fibras, pode ser mensurada integrando-se a curva obtida, na região entre 0 e L/150mm de deslocamento vertical.

\subsubsection{ASTM C1399 (2010) - Método para obtenção de resistência residual de concreto reforçado com fibras}

Esta norma não prescreve utilização de equipamento com sistema fechado de controle de velocidade de deslocamento. Uma prensa menos sofisticada, com controle da velocidade de deslocamento do pistão, é adequada.

Corpos-de-prova prismáticos de 100mm x 100mm x 400mm, moldados ou extraídos, são ensaiados com vão de 300mm. O suporte para os corpos-de-prova e o suporte para aplicação de carga obedecem ao mesmo esquema que o proposto pela norma JSCE-SF4.

Esse ensaio é realizado em duas etapas: A primeira consiste no rompimento da matriz de concreto, onde é utilizada uma chapa de aço inoxidável padrão, de medidas $12 \mathrm{~mm}$ (espessura) x 100mm x 400mm, que tem a função de suportar o corpo-de-prova durante o carregamento inicial. Assim, elimina-se o problema da instabilidade após a ruptura da matriz (BANTHIA; MINDESS, 2004). O carregamento é feito até o deslocamento vertical do sistema corpo-de-prova / chapa metálica atingir $0,50 \mathrm{~mm}$. 
Segundo a versão publicada no ano de 2007, era recomendado utilizar um LVDT para medidas de deslocamento vertical do corpo-de-prova na primeira etapa desse ensaio, centralizado sob a chapa metálica. Entretanto, a versão mais recente dessa norma prescreve que os LVDTs devem ser instalados no yoke, de forma que o real deslocamento do corpo-deprova (e não o do sistema chapa/corpo-de-prova) seja obtido na primeira etapa.

A segunda etapa é realizada sem a chapa metálica e consiste no carregamento do corpo-de-prova já fissurado. São necessários dois LVDTs para leitura do deslocamento vertical do corpo-de-prova, centralizados, utilizando-se um yoke. $\mathrm{O}$ carregamento é feito até que o deslocamento vertical mínimo de $1,25 \mathrm{~mm}$ seja atingido. Em ambas as etapas, a velocidade de aplicação de carga é ajustada na faixa entre 0,50 e $0,80 \mathrm{~mm} / \mathrm{min}$.

As curvas obtidas através do procedimento acima estão mostradas na figura 4.6:

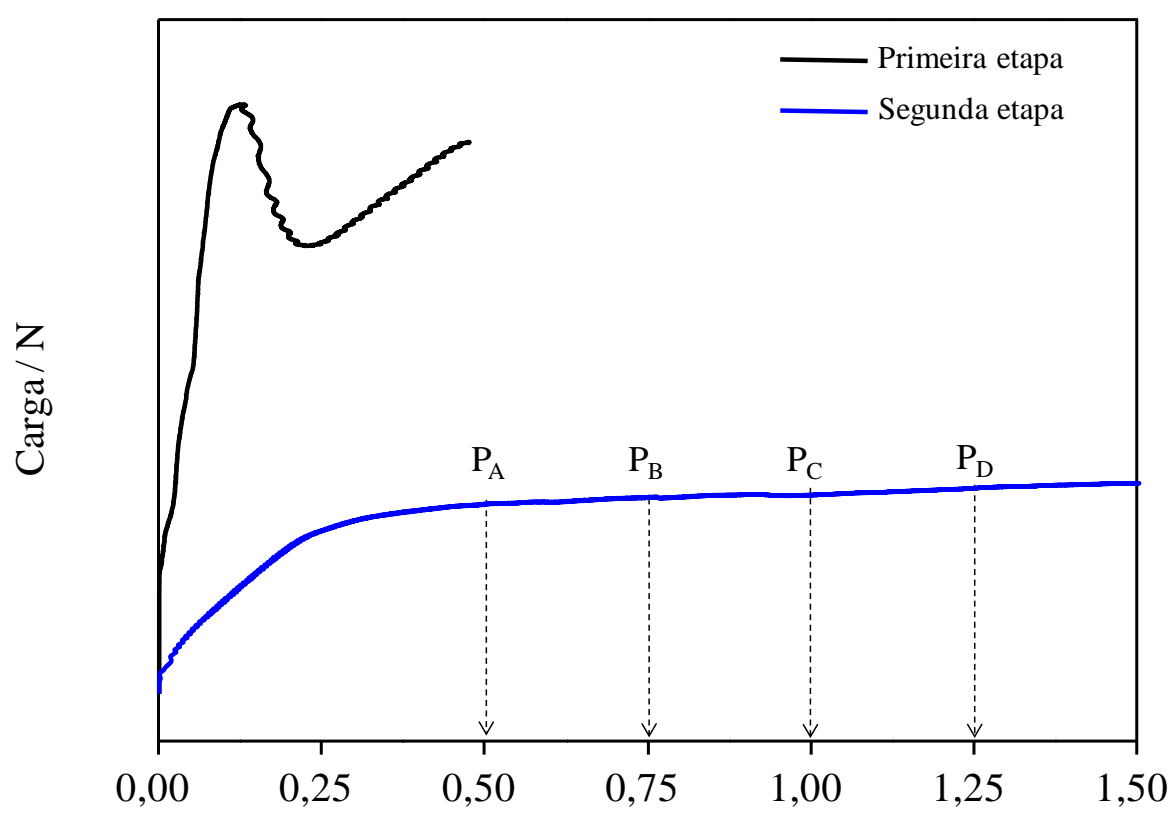

Deslocamento vertical do corpo-de-prova / $\mathrm{mm}$

Figura 4.6 - Curvas carga por deslocamento vertical obtidas com sistemas open-loop, segundo ASTM C1399 (2010).

A carga máxima obtida na primeira etapa não pode ser utilizada para o cálculo do módulo de ruptura, pois representa a carga suportada pelo corpo-de-prova e pela chapa metálica. A curva da segunda etapa é analisada por meio da obtenção das cargas residuais $\mathrm{P}_{\mathrm{A}}$, $\mathrm{P}_{\mathrm{B}}, \mathrm{P}_{\mathrm{C}}$ e $\mathrm{P}_{\mathrm{D}}$, quando os deslocamentos verticais forem de $0,50,0,75,1,0$ e $1,25 \mathrm{~mm}$ 
respectivamente. Com esses quatro pontos, são calculadas a carga residual média, $\mathrm{P}_{\text {média }}$, e a resistência residual média, ARS, através das equações (4.5) e (4.6), respectivamente.

$$
\begin{aligned}
& \mathrm{P}_{\text {média }}=\frac{\left(\mathrm{P}_{\mathrm{A}}+\mathrm{P}_{\mathrm{B}}+\mathrm{P}_{\mathrm{C}}+\mathrm{P}_{\mathrm{D}}\right)}{4} \\
& \mathrm{ARS}=\mathrm{P}_{\text {média }} \cdot \frac{\mathrm{L}}{\mathrm{b} \cdot \mathrm{d}^{2}}
\end{aligned}
$$

Onde:

ARS: Resistência residual média (MPa);

$\mathrm{P}_{\text {média: }}$ Carga residual média $(\mathrm{N})$;

$\mathrm{P}_{\mathrm{A}}+\mathrm{P}_{\mathrm{B}}+\mathrm{P}_{\mathrm{C}}+\mathrm{P}_{\mathrm{D}}$ : Soma das cargas residuais nos deslocamentos verticais de $0,50,0,75,1,0$ e $1,25 \mathrm{~mm}$, respectivamente $(\mathrm{N})$;

L: Vão de ensaio (mm);

b: Largura do corpo-de-prova (mm);

d: Altura do corpo-de-prova ( $\mathrm{mm})$.

A grande vantagem desse método é a realização de um ensaio em equipamento com sistema open-loop sem que haja instabilidade pós-pico (TIGUMAN; FIGUEIREDO, 2005). Banthia e Dubey (1999) relataram que as curvas obtidas por esse ensaio apresentaram boa concordância com as obtidas por ensaios contínuos em equipamentos com sistema closedloop, quando utilizados corpos-de-prova de mesmas dimensões. Dessa forma, pode-se ter uma boa ferramenta para controle de obras onde é utilizado concreto reforçado com fibras, já que a maioria dos laboratórios de controle de qualidade não possui equipamento com sistema fechado de controle de velocidade de deslocamento.

Algumas limitações desse método de ensaio são:

a) A utilização da chapa de aço dificulta a identificação da ocorrência da ruptura da matriz, devido à absorção da energia que a chapa proporciona (CALDAS; FIGUEIREDO; BITTENCOURT, 2003);

b) A deformação final do primeiro carregamento não é levada em conta no cálculo das resistências residuais, podendo alterar o desempenho das fibras, 
principalmente as de menor comprimento (CALDAS; FIGUEIREDO; BITTENCOURT, 2003);

c) O efeito das fibras no comportamento do corpo-de-prova logo após sua ruptura é ignorado (BANTHIA; DUBEY, 1999);

d) O cálculo da resistência residual média é baseado no momento de inércia da seção não fissurada, embora o corpo-de-prova já tenha sido rompido. Como a tensão residual é inversamente proporcional ao momento de inércia, se o valor dessa resistência fosse utilizado para dimensionar elementos, seriam recomendados teores de fibra superiores aos ideais, pois o valor do momento de inércia para a seção não fissurada é superior ao da seção fissurada;

e) A resistência residual calculada pode ser utilizada apenas para comparação de diferentes fibras e ensaios, pois não está atrelada a nenhum critério de dimensionamento.

Para aprimorar os resultados obtidos por essa norma, sugere-se que a primeira etapa do ensaio seja realizada até uma menor deflexão $(0,20 \mathrm{~mm}$, por exemplo), para que a utilização da chapa metálica seja limitada apenas à deflexão necessária para romper o concreto. Além disso, essa deflexão deve ser considerada na segunda etapa do ensaio, para que seja utilizada a deflexão total do corpo-de-prova no cálculo da resistência residual.

Outro ponto interessante seria se a segunda etapa fosse realizada até maiores deflexões $(1,80 \mathrm{~mm}$, por exemplo, que somada com a deflexão na primeira etapa resultaria na deflexão total de 2,0mm), para que a resistência residual nesse ponto seja mais facilmente correlacionada com a resistência residual obtida pelos métodos ASTM C1609 e JSCE-SF4, que recomendam leitura no deslocamento de 2,0 $\mathrm{mm}$, quando são utilizados corpos-de-prova prismáticos de dimensões 100 x 100 x $400 \mathrm{~mm}^{3}$.

\subsubsection{EN 14651 (2007) - Método de ensaio para concreto reforçado com fibras metálicas - Determinação da resistência à tração por flexão (limite de proporcionalidade e resistência residual)}

Esta norma prescreve ensaios de flexão de corpos-de-prova prismáticos, cujas dimensões são $150 \mathrm{~mm}$ x 150mm x 550 (até 700)mm, com vão de ensaio de 500mm. É 
utilizado um equipamento dotado de sistema fechado de controle de deformação. As diferenças principais entre os ensaios de flexão expostos anteriormente são:

a) Os corpos-de-prova possuem um entalhe, de $5 \mathrm{~mm}$ de largura por $25 \mathrm{~mm}$ de altura, centralizado em sua face apoiada nos cutelos inferiores, cuja função é induzir o posicionamento da fissura;

b) As dimensões do corpo-de-prova são maiores, para que agregados de até $32 \mathrm{~mm}$ de diâmetro e fibras de até $60 \mathrm{~mm}$ de comprimento possam ser utilizados;

c) A carga é aplicada por apenas um cutelo superior, centralizado em relação ao vão de ensaio;

d) A abertura da fissura é utilizada como parâmetro de controle de ensaio. Pode ser medida diretamente ou calculada a partir do deslocamento vertical do corpo-de-prova;

e) É obtido o limite de proporcionalidade, definido como a resistência calculada a partir da carga máxima dentro do intervalo de abertura de fissura de 0 a $0,050 \mathrm{~mm}$.

Assim como na norma ASTM C1609, são prescritas duas velocidades de ensaio: no primeiro trecho, correspondente ao intervalo de abertura de fissura entre 0 e $0,10 \mathrm{~mm}$, a velocidade de abertura de fissura é de $0,050 \mathrm{~mm} / \mathrm{min}$. Já no segundo trecho, entre 0,10 e 4,0 mm de abertura de fissura, a velocidade adotada é de $0,20 \mathrm{~mm} / \mathrm{min}$. A adoção de uma menor velocidade no trecho inicial tem a função de minimizar a ocorrência da instabilidade pós-pico.

As figuras 4.7 e 4.8 ilustram como o ensaio é realizado e qual é o perfil da curva carga por abertura de fissura obtido. É utilizado um clip-gage para monitorar a abertura de fissura e um LVDT instalado no yoke para medir o deslocamento vertical do corpo-de-prova. Entretanto, um LVDT instalado na posição horizontal pode medir a abertura da fissura com confiança. 


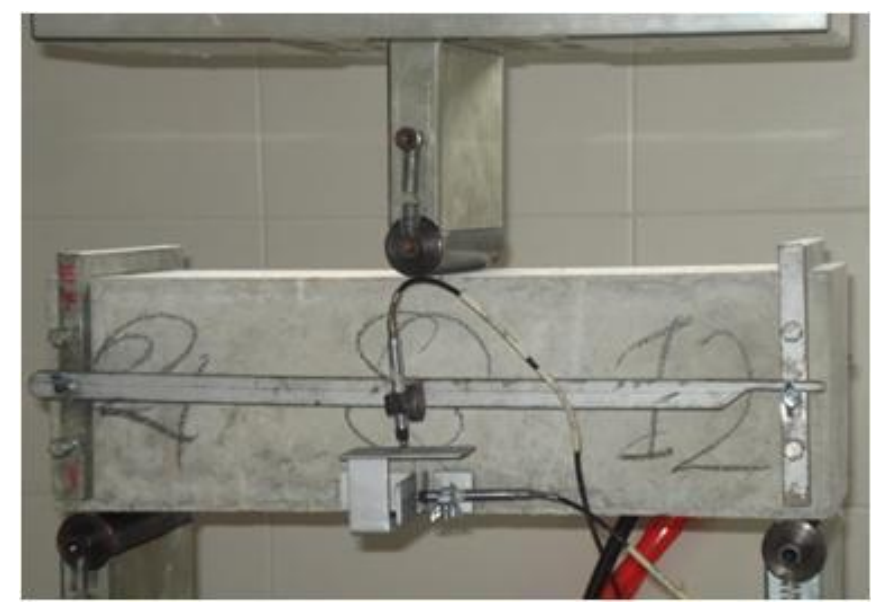

Figura 4.7 - Esquema da realização do ensaio prescrito na norma EN 14651 (2007).

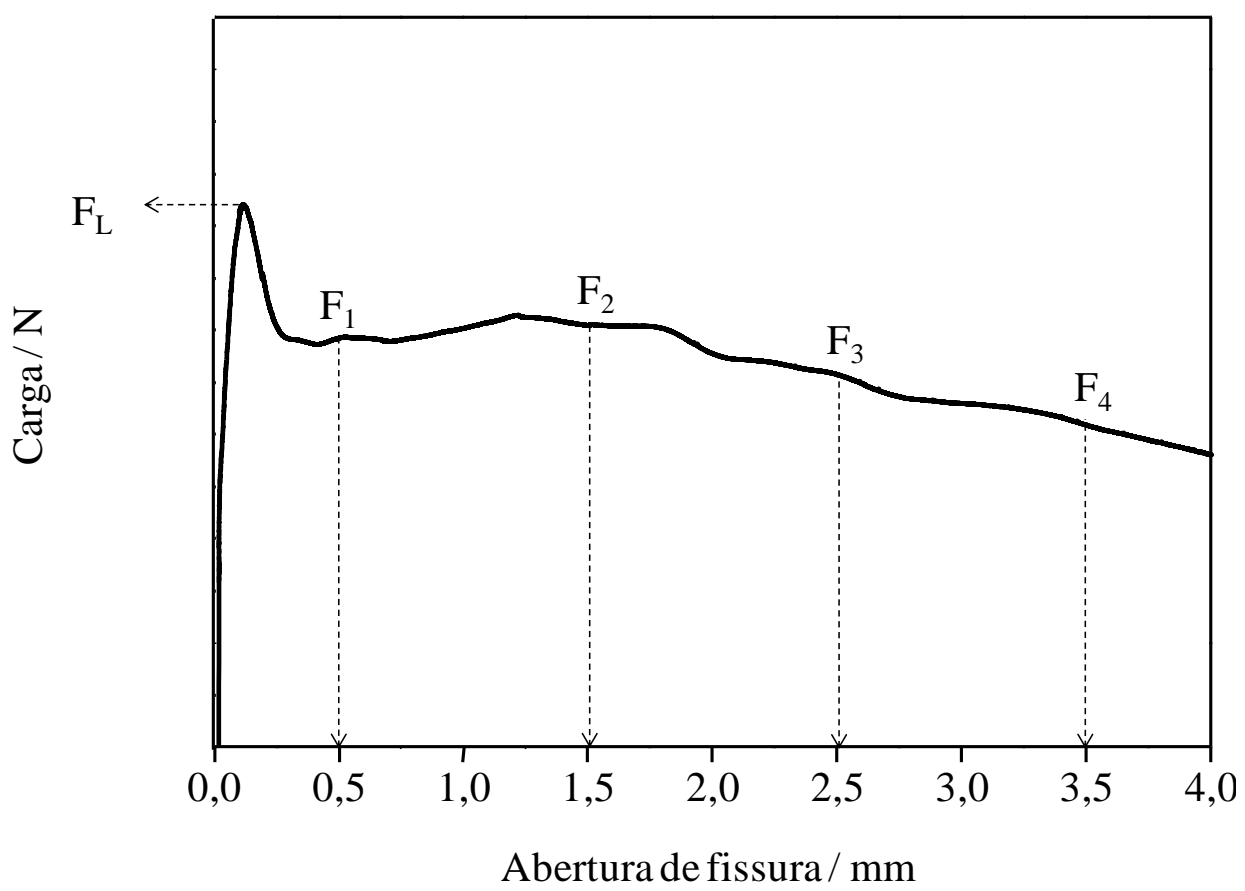

Figura 4.8 - Curva carga por abertura de fissura obtida segundo EN 14651 (2007) (di PRISCO; PLIZZARI; VANDEWALLE, 2010).

A análise da curva carga-abertura de fissura é feita segundo as equações (4.7) e (4.8):

$$
\begin{aligned}
\mathrm{f}_{\mathrm{ct}, \mathrm{L}}^{\mathrm{f}} & =\frac{3 \cdot \mathrm{F}_{\mathrm{L}} \cdot 1}{2 \cdot \mathrm{b} \cdot \mathrm{h}_{\mathrm{sp}}{ }^{2}} \\
\mathrm{f}_{\mathrm{R}, \mathrm{j}} & =\frac{3 \cdot \mathrm{F}_{\mathrm{j}} \cdot 1}{2 \cdot \mathrm{b} \cdot \mathrm{h}_{\mathrm{sp}}{ }^{2}}
\end{aligned}
$$


Onde:

$\mathrm{f}_{\mathrm{ct}, \mathrm{L}}^{\mathrm{f}}$ : limite de proporcionalidade (MPa). Também identificado como LOP;

$f_{R, j}$ : resistência residual à flexão correspondente à abertura de fissura $j$, onde $j=0,50,1,5,2,5$ ou 3,5mm - $f_{R, 1}, f_{R, 2}, f_{R, 3}$ e $f_{R, 4}$, respectivamente $(M P a)$;

$\mathrm{F}_{\mathrm{L}}$ : carga máxima de ensaio no intervalo de abertura de fissura de 0 a $0,050 \mathrm{~mm}(\mathrm{~N})$;

$F_{j}$ : carga correspondente à abertura de fissura $j$, onde $j=0,50,1,5,2,5$ ou $3,5 \mathrm{~mm}-F_{1}, F_{2}, F_{3}$ e $\mathrm{F}_{4}$, respectivamente $(\mathrm{N})$;

1: vão de ensaio (mm);

b: largura do corpo-de-prova (mm);

$\mathrm{h}_{\mathrm{sp}}$ : distância entre o topo do entalhe e a face superior do corpo-de-prova ( $\left.\mathrm{mm}\right)$.

Para dimensionamento de estruturas, a utilização desses quatro valores de resistência residual pode ser um obstáculo para a aceitação do concreto reforçado com fibras. Por esse motivo, foi assumido que as resistências residuais em 0,50 e 2,50mm correspondem ao estado limite de serviço e ao estado limite último, respectivamente, e são as únicas utilizadas para dimensionamento (di PRISCO; PLIZZARI; VANDEWALLE, 2009).

O desempenho do compósito no estado limite último $\left(f_{R, 3}\right)$ pode ser comparado ao do estado limite de serviço $\left(f_{R, 1}\right)$ através da razão $f_{R, 3} / f_{R, 1}$ (utilizando os valores característicos). Para garantir o bom desempenho do compósito em elementos estruturais, as fibras para reforço podem substituir as barras ou as telas metálicas, total ou parcialmente, se as relações (4.9) e (4.10) forem satisfeitas (di PRISCO; PLIZZARI; VANDEWALLE, 2010; fib, 2010).

$$
\begin{gathered}
\mathrm{f}_{\mathrm{R}, 1 \mathrm{k}} / \mathrm{f}_{\mathrm{Lk}} \geq 0,4 \\
\mathrm{f}_{\mathrm{R}, 3 \mathrm{k}} / \mathrm{f}_{\mathrm{R}, 1 \mathrm{k}} \geq 0,5
\end{gathered}
$$

Onde:

$\mathrm{f}_{\mathrm{Lk}}$ : resistência nominal característica do concreto $(\mathrm{MPa})$;

$f_{R, 1 k}$ e $f_{R, 3 k}$ : resistências residuais características para abertura de fissura de 0,50 e 2,50mm, respectivamente $(\mathrm{MPa})$.

Para facilitar a classificação do material, o valor de $\mathrm{f}_{\mathrm{R}, 1 \mathrm{k}}$ pode ser definido pelas seguintes classes: 1,$0 ; 1,5 ; 2,0 ; 2,5 ; 3,0 ; 4,0 ; 5,0 ; 6,0 ; 7,0$ e 8,0 MPa. A razão $f_{R, 3 k} / f_{R, 1 k}$ pode 
ser representada pelas letras a, b, c e d, correspondentes aos valores descritos na tabela 4.1 (di PRISCO; PLIZZARI; VANDEWALLE, 2010; fib, 2010):

Tabela 4.1 - Classes para as resistências residuais $\mathrm{f}_{\mathrm{R}, 3 \mathrm{k}} / \mathrm{f}_{\mathrm{R}, \mathrm{k}}$, obtidas pelo ensaio EN 14651 (di PRISCO; PLIZZARI; VANDEWALLE, 2010; fib, 2010).

\begin{tabular}{cc}
\hline Letra & Condição \\
\hline $\mathrm{a}$ & $0,50 \leq \mathrm{f}_{\mathrm{R}, 3 \mathrm{k}} / \mathrm{f}_{\mathrm{R}, 1 \mathrm{k}} \leq 0,80$ \\
\hline $\mathrm{b}$ & $0,80 \leq \mathrm{f}_{\mathrm{R}, 3 \mathrm{k}} / \mathrm{f}_{\mathrm{R}, 1 \mathrm{k}} \leq 1,1$ \\
\hline $\mathrm{c}$ & $1,1 \leq \mathrm{f}_{\mathrm{R}, 3 \mathrm{k}} / \mathrm{f}_{\mathrm{R}, \mathrm{k}} \leq 1,4$ \\
\hline $\mathrm{d}$ & $1,4 \leq \mathrm{f}_{\mathrm{R}, 3 \mathrm{k}} / \mathrm{f}_{\mathrm{R}, 1 \mathrm{k}}$ \\
\hline
\end{tabular}

Pelos critérios propostos acima, um material que possui $\mathrm{f}_{\mathrm{R}, 1 \mathrm{k}}=2,2 \mathrm{MPa}$ e $\mathrm{f}_{\mathrm{R}, 3 \mathrm{k}} / \mathrm{f}_{\mathrm{R}, 1 \mathrm{k}}=$ $1,8 \mathrm{MPa}$ é classificado como " $2 \mathrm{~b}$ ".

Pode-se estabelecer uma correlação entre o deslocamento vertical e a abertura de fissura, segundo a equação (4.11).

$$
\delta=0,85 . \mathrm{CMOD}+0,04
$$

Onde:

$\delta$ : deslocamento vertical $(\mathrm{mm})$;

CMOD: abertura de fissura (mm)

A grande vantagem desse ensaio é que, diferentemente de corpos-de-prova sem entalhe, a fissura é localizada muito próxima do plano do entalhe e deformações não lineares não ocorrem nas outras regiões do corpo-de-prova. Portanto, toda a energia dissipada pode ser atribuída à abertura da fissura (GIACCIO; TOBES; ZERBINO, 2007) e os dados obtidos tendem a apresentar menor dispersão. Além disso, os resultados obtidos estão atrelados ao dimensionamento de concreto reforçado com fibras (fib, 2010).

A caracterização da tenacidade pela curva carga - abertura de fissura é um método mais confiável. A abertura da fissura é menos susceptível a erros do que o deslocamento vertical e pode ser mais prontamente correlacionada a propriedades de fratura fundamentais (SHAH; KUDER; MU, 2004).

Entretanto, as fibras poliméricas, dependendo de seu módulo de elasticidade, tendem a apresentar valores baixos para a resistência residual $\mathrm{f}_{\mathrm{R}, 1}$. Quanto menor o módulo de elasticidade da fibra, menor sua capacidade de inibir a propagação da fissura em aberturas 
inferiores a 0,50mm. Então, para atender ao critério exposto na equação (4.9), devem ser utilizados altos teores de fibra, o que acarretaria um maior custo relativo a esta fibra.

\subsubsection{Resumo dos procedimentos}

A tabela 4.2 resume os parâmetros necessários para realização dos ensaios segundo os cinco procedimentos: 
Tabela 4.2 - Resumo dos principais itens dos cinco procedimentos normalizados (ASTM 2010; JSCE, 1984; ASTM, 2010; CEN, 2007).

\begin{tabular}{|c|c|c|c|c|}
\hline Item & ASTM C1609 & JSCE-SF4 & ASTM C1399 & EN 14651 \\
\hline \multicolumn{5}{|l|}{ Representação esquemática } \\
\hline Tipo de ensaio & closed-loop & closed-loop & open-loop & closed-loop \\
\hline Variável controlada & $\begin{array}{l}\text { deslocamento vertical do } \\
\text { corpo-de-prova }\end{array}$ & $\begin{array}{l}\text { deslocamento vertical do } \\
\text { corpo-de-prova }\end{array}$ & $\begin{array}{l}\text { deslocamento vertical do } \\
\text { corpo-de-prova }\end{array}$ & $\begin{array}{l}\text { deslocamento vertical do corpo-de- } \\
\text { prova, abertura de fissura }\end{array}$ \\
\hline $\begin{array}{l}\text { Geometria e dimensões do } \\
\text { corpo-de-prova } / \mathrm{mm}^{3}\end{array}$ & $\begin{array}{c}\text { prismático, } \\
100 \times 100 \times 350 \text { ou } \\
150 \times 150 \times 500 \\
\end{array}$ & $\begin{array}{c}\text { prismático, } \\
100 \times 100 \times 350 \text { ou } \\
150 \times 150 \times 500 \\
\end{array}$ & $\begin{array}{c}\text { prismático, } \\
100 \times 100 \text { x } 400\end{array}$ & $\begin{array}{c}\text { prismático, } \\
150 \times 150 \text { x } 550\end{array}$ \\
\hline Vão de ensaio / mm & 300 ou 450 & 300 ou 450 & 300 & 500 \\
\hline $\begin{array}{l}\text { Velocidade de deflexão- } \\
\text { abertura de fissura / } \mathrm{mm} / \mathrm{min}\end{array}$ & $\begin{array}{c}0 \text { a L/600: } 0,06 \text { a } 0,12 \\
\text { L/600 a L/150: } 0,06 \text { a } 0,24\end{array}$ & 0,15 a 0,50 & 0,50 a 0,80 & $\begin{array}{l}0 \text { a } 0,10 \mathrm{~mm}: 0,05 \\
0,10 \text { a } 4,0 \mathrm{~mm}: 0,2\end{array}$ \\
\hline Número de LVDTs & 2 & 2 & $\begin{array}{l}1^{\mathrm{a}} \text { etapa: } 1 \\
2^{\mathrm{a}} \text { etapa: } 2\end{array}$ & 2 \\
\hline Pontos para análise do gráfico & $\begin{array}{c}\text { Cargas residuais }\left(\mathrm{P}_{\mathrm{d}, \mathrm{L} / 600} \mathrm{e}\right. \\
\left.\mathrm{P}_{\mathrm{d}, \mathrm{L} / 150}\right)\end{array}$ & $\begin{array}{l}\text { Área sob a curva carga- } \\
\text { deslocamento vertical }\end{array}$ & $\begin{array}{c}\text { Cargas residuais }\left(\mathrm{P}_{\mathrm{A}}, \mathrm{P}_{\mathrm{B}},\right. \\
\left.\mathrm{P}_{\mathrm{C}} \text { e } \mathrm{P}_{\mathrm{D}}\right)\end{array}$ & $\begin{array}{l}\text { Carga máxima até } 0,050 \mathrm{~mm}\left(\mathrm{~F}_{\mathrm{L}}\right) \text { e } \\
\text { cargas residuais }\left(\mathrm{F}_{\mathrm{j}}\right)\end{array}$ \\
\hline Resultado obtido & $\begin{array}{l}\text { Resistências residuais }\left(\mathrm{f}_{\mathrm{d}, \mathrm{L} / 600} \mathrm{e}\right. \\
\left.\mathrm{f}_{\mathrm{d}, \mathrm{L} / 150}\right) \text {, Tenacidade }\left(\mathrm{T}_{\mathrm{d}, \mathrm{L} / 150}\right)\end{array}$ & $\begin{array}{l}\text { Tenacidade }\left(\mathrm{T}_{\mathrm{b}}\right) \text { e fator de } \\
\text { tenacidade à flexão }\left(\overline{\sigma_{\mathrm{b}}}\right)\end{array}$ & $\begin{array}{l}\text { Resistência residual } \\
\text { média (ARS) }\end{array}$ & $\begin{array}{c}\text { Limite de proporcionalidade }\left(\mathrm{f}_{\mathrm{ct}, \mathrm{L}}^{\mathrm{f}}\right) \\
\text { e resistências residuais }\left(\mathrm{f}_{\mathrm{R}, \mathrm{j}}\right)\end{array}$ \\
\hline
\end{tabular}




\subsection{Determinação da resistência à compressão}

Conforme descrito na literatura (di PRISCO; PLIZZARI; VANDEWALLE, 2010; FIGUEIREDO; NUNES; TANESI, 2000) a utilização de fibras em teores abaixo do volume crítico não apresenta influência na resistência à compressão do concreto. Portanto, o ensaio prescrito para concreto simples, segundo a norma ABNT NBR 5739 (2007a), pode ser adotado para concreto reforçado com fibras. Esse ensaio é utilizado como parâmetro de controle de qualidade do processo.

Para sua realização, são ensaiados corpos-de-prova cilíndricos de 100mm x 200mm ou de $150 \mathrm{~mm}$ x 300mm (diâmetro x altura), que recebem carga na direção de seu eixo axial. Os corpos-de-prova de maior dimensão são preferidos, pois nos menores pode ocorrer má compactação do concreto com fibras, alterando os resultados.

A resistência à compressão é calculada a partir da equação (4.12) (ABNT, 2007a):

$$
\mathrm{f}_{\mathrm{c}}=\frac{4 \cdot \mathrm{F}}{\pi \cdot \mathrm{D}^{2}}
$$

Onde:

$\mathrm{f}_{\mathrm{c}}$ : resistência à compressão do corpo-de-prova (MPa);

F: força máxima obtida durante o ensaio $(\mathrm{N})$;

D: diâmetro do corpo-de-prova (mm). 


\section{Metodologia experimental}

Este capítulo trata dos procedimentos experimentais adotados para avaliação do comportamento mecânico de concreto reforçado com uma macrofibra de polipropileno e uma de aço. A macrofibra polimérica foi estudada com uma maior quantidade de teores e traços, com o intuito de avaliar seu desempenho, e os ensaios com a fibra de aço, cujos resultados já estão amplamente difundidos na literatura, foram feitos para servirem de referência para os resultados obtidos com a macrofibra polimérica.

O projeto consistiu na comparação entre os ensaios propostos pelas normas ASTM C1609 e ASTM C1399. Para isso, foram utilizadas 3 matrizes de concreto (resistências médias à compressão de 30, 35 e 40MPa), com a macrofibra polimérica em 6 dosagens $(2,0$, 3,0, 4,5, 6,0, 7,5 e 9,0kg/m³ ), totalizando 18 composições diferentes. Como uma análise paralela, as curvas carga-deslocamento vertical obtidas pelo ensaio da norma ASTM C1609 também foram analisadas segundo os critérios propostos pelo método JSCE-SF4. O ensaio da norma ASTM C1609 foi realizado com a fibra de aço com uma matriz de concreto (resistência média à compressão de $35 \mathrm{MPa}$ ) e três teores de fibra $\left(15,25\right.$ e $\left.35 \mathrm{~kg} / \mathrm{m}^{3}\right)$.

Também foi avaliada a metodologia proposta pela norma europeia EN 14651, utilizando-se uma matriz de concreto (resistência média à compressão de $35 \mathrm{MPa}$ ), com dosagens de $3,0,4,5$ e $6,0 \mathrm{~kg} / \mathrm{m}^{3}$ para a macrofibra polimérica e de 15,25 e $35 \mathrm{~kg} / \mathrm{m}^{3}$ para a fibra de aço. Essa análise foi feita em uma etapa posterior, após a finalização dos ensaios com as normas americanas e japonesa. Portanto, foi moldada nova série de corpos-de-prova, incluindo os cilíndricos para determinação de resistência à compressão.

Para o controle de qualidade do processo de moldagem dos corpos-de-prova, foi realizado o ensaio de determinação da resistência à compressão, segundo a ABNT NBR 5739.

Para facilitar a visualização, foi utilizada a notação mostrada na tabela 5.1. 
Tabela 5.1 - Notação utilizada na dissertação.

\begin{tabular}{|c|c|c|}
\hline Sigla & Descrição & Exemplo \\
\hline PP & Macrofibra polimérica & - \\
\hline $\mathrm{AÇO}$ & Fibra de aço & - \\
\hline \multirow{2}{*}{ CS XX } & CS: concreto simples (concreto referência) & \multirow{2}{*}{$\begin{array}{l}\text { CS 35: concreto simples de resistência } \\
\text { média à compressão de } 35 \mathrm{MPa}\end{array}$} \\
\hline & $\mathrm{XX}$ : resistência média à compressão $(\mathrm{MPa})$ & \\
\hline \multirow{4}{*}{ CRF XX / YY / WW } & CRF: concreto reforçado com fibras & \multirow{4}{*}{$\begin{array}{l}\text { CRF } 30 \text { / PP / 4,5: concreto de } \\
\text { resistência média à compressão de } \\
\text { 30MPa, reforçado com a macrofibra } \\
\text { polimérica na dosagem de } 4,5 \mathrm{~kg} / \mathrm{m}^{3}\end{array}$} \\
\hline & $\mathrm{XX}$ : resistência média à compressão $(\mathrm{MPa})$ & \\
\hline & YY: tipo de fibra utilizado & \\
\hline & WW: dosagem de fibra $\left(\mathrm{kg} / \mathrm{m}^{3}\right)$ & \\
\hline
\end{tabular}

As tabelas 5.2 e 5.3 mostram quais ensaios, fibras e teores foram utilizados na análise da fibra polimérica e da fibra de aço, respectivamente.

Tabela 5.2 - Ensaios, traços e teores utilizados com a macrofibra polimérica.

\begin{tabular}{|c|c|c|c|c|c|c|c|c|c|c|c|}
\hline \multirow[b]{2}{*}{ Ensaio } & \multicolumn{3}{|c|}{ Traço } & \multicolumn{6}{|c|}{ Teores / kg/m³ (\% em volume) } & \multicolumn{2}{|c|}{ Corpos-de-prova } \\
\hline & $\begin{array}{c}\text { CRF } \\
30\end{array}$ & $\begin{array}{c}\text { CRF } \\
35\end{array}$ & $\begin{array}{c}\text { CRF } \\
40\end{array}$ & $\begin{array}{c}2,0 \\
(0,22)\end{array}$ & $\begin{array}{c}3,0 \\
(0,33)\end{array}$ & $\begin{array}{c}4,5 \\
(0,50)\end{array}$ & $\begin{array}{c}6,0 \\
(0,66)\end{array}$ & $\begin{array}{c}7,5 \\
(0,82)\end{array}$ & $\begin{array}{c}9,0 \\
(1,0)\end{array}$ & Quantidade & $\begin{array}{c}\text { Dimensões / } \\
\text { mm }\end{array}$ \\
\hline ASTM C1609 & $\sqrt{ }$ & $\sqrt{ }$ & $\sqrt{ }$ & $\sqrt{ }$ & $\sqrt{ }$ & $\sqrt{ }$ & $\sqrt{ }$ & $\sqrt{ }$ & $\sqrt{ }$ & 10 & $150 \times 150 \times 500$ \\
\hline ASTM C1399 & $\sqrt{ }$ & $\sqrt{ }$ & $\sqrt{ }$ & $\sqrt{ }$ & $\sqrt{ }$ & $\sqrt{ }$ & $\sqrt{ }$ & $\sqrt{ }$ & $\sqrt{ }$ & 10 & $100 \times 100 \times 400$ \\
\hline EN 14651 & & $\sqrt{ }$ & & & $\sqrt{ }$ & $\sqrt{ }$ & $\sqrt{ }$ & & & 4 & $150 \times 150 \times 500$ \\
\hline ABNT NBR 5739 & $\sqrt{ }$ & $\sqrt{ }$ & $\sqrt{ }$ & $\sqrt{ }$ & $\sqrt{ }$ & $\sqrt{ }$ & $\sqrt{ }$ & $\sqrt{ }$ & $\sqrt{ }$ & 6 & $150 \times 300$ \\
\hline
\end{tabular}

Tabela 5.3 - Ensaios, traços e teores utilizados com a fibra de aço.

\begin{tabular}{|c|c|c|c|c|c|c|}
\cline { 2 - 7 } \multicolumn{1}{c|}{} & Traço & \multicolumn{2}{c|}{ Teores / kg/mº (\% volume) } & \multicolumn{2}{c|}{ Corpos-de-prova } \\
\hline Ensaio & CRF 35 & $\begin{array}{c}15 \\
(0,19)\end{array}$ & $\begin{array}{c}25 \\
(0,32)\end{array}$ & $\begin{array}{c}35 \\
(0,45)\end{array}$ & Quantidade & Dimensões / mm \\
\hline ASTM C1609 & $\sqrt{ }$ & $\sqrt{ }$ & $\sqrt{ }$ & $\sqrt{ }$ & 10 & $150 \times 150 \times 500$ \\
\hline EN 14651 & $\sqrt{ }$ & $\sqrt{ }$ & $\sqrt{ }$ & $\sqrt{ }$ & 4 & $150 \times 150 \times 500$ \\
\hline ABNT NBR 5739 & $\sqrt{ }$ & $\sqrt{ }$ & $\sqrt{ }$ & $\sqrt{ }$ & 6 & $150 \times 300$ \\
\hline
\end{tabular}

Para a realização dos ensaios de flexão de corpos-de-prova de concreto, foi utilizada um servo-atuador com sistema fechado de controle de velocidade de deslocamento (closedloop), com capacidade de 120kN, da marca Brasválvulas, modelo BME 150 200/ATFPS/MB, no laboratório de aplicação da empresa Construquímica. Além disso, foram utilizados dois LVDTs, com precisão de $1,0 \times 10^{-4} \mathrm{~mm}$, um yoke e um sistema de aquisição de dados, conforme prescrito pelo método JSCE-SF4. Já para os ensaios de determinação de resistência à compressão e tração na flexão, foi utilizada uma prensa com sistema open-loop, com capacidade de $1100 \mathrm{kN}$, da marca Forney, modelo F-25EX-F-CPILOT. 


\subsection{Materiais}

\subsubsection{Cimento}

Foi utilizado cimento CPV ARI, para que a operação da desforma dos corpos-de-prova pudesse ser feita depois de 24 horas da moldagem dos mesmos. As propriedades físicas mecânicas estão mostradas na tabela 5.4 e a composição química na tabela 5.5, conforme informações fornecidas pelo fabricante. Os resultados médios de resistência à compressão foram calculados a partir de 8 corpos-de-prova cilíndricos de $50 \mathrm{~mm}$ de diâmetro e $100 \mathrm{~mm}$ de altura.

Tabela 5.4 - Propriedades físicas e mecânicas do cimento.

\begin{tabular}{cc}
\hline Propriedade & Resultado médio \\
\hline Retenção peneira \#400 / \% & $2,6 \pm 0,3$ \\
\hline Finura Blaine / $\mathrm{m}^{2} / \mathrm{kg}$ & $4514 \pm 88$ \\
\hline Início de pega / min & $143 \pm 10$ \\
\hline Fim de pega / min & $203 \pm 10$ \\
\hline Resistência à compressão $1 \mathrm{dia} / \mathrm{MPa}$ & $28,4 \pm 0,7$ \\
\hline Resistência à compressão 3 dias / $\mathrm{MPa}$ & $41,6 \pm 1,0$ \\
\hline Resistência à compressão 7 dias / $\mathrm{MPa}$ & $46,7 \pm 0,8$ \\
\hline Resistência à compressão 28 dias / $\mathrm{MPa}$ & $54,8 \pm 1,1$ \\
\hline
\end{tabular}

Tabela 5.5 - Análise química do cimento.

\begin{tabular}{cc}
\hline Componente & \% em massa \\
\hline Perda ao fogo & 3,58 \\
\hline Perda ao fogo a $500^{\circ} \mathrm{C}$ & 0,91 \\
\hline Resíduo insolúvel & 0,87 \\
\hline $\mathrm{SiO}_{2}$ & 19,41 \\
\hline $\mathrm{Al}_{2} \mathrm{O}_{3}$ & 5,47 \\
\hline $\mathrm{Fe}_{2} \mathrm{O}_{3}$ & 2,97 \\
\hline $\mathrm{CaO} \mathrm{O}$ & 63,44 \\
\hline $\mathrm{MgO} \mathrm{O}$ & 0,77 \\
\hline $\mathrm{SO}_{3}$ & 2,74 \\
\hline $\mathrm{CO}_{2}$ & 2,60 \\
\hline $\mathrm{K}_{2} \mathrm{O}$ & 0,76 \\
\hline $\mathrm{C}_{3} \mathrm{~A} \mathrm{teórico}$ & 7,77 \\
\hline
\end{tabular}




\subsubsection{Agregado miúdo}

Foi utilizada areia lavada de rio, com módulo de finura 2,06, diâmetro máximo de $2,36 \mathrm{~mm}$ e massa específica de $2,62 \mathrm{~g} / \mathrm{cm}^{3}$, cuja composição granulométrica está no gráfico 5.1 .

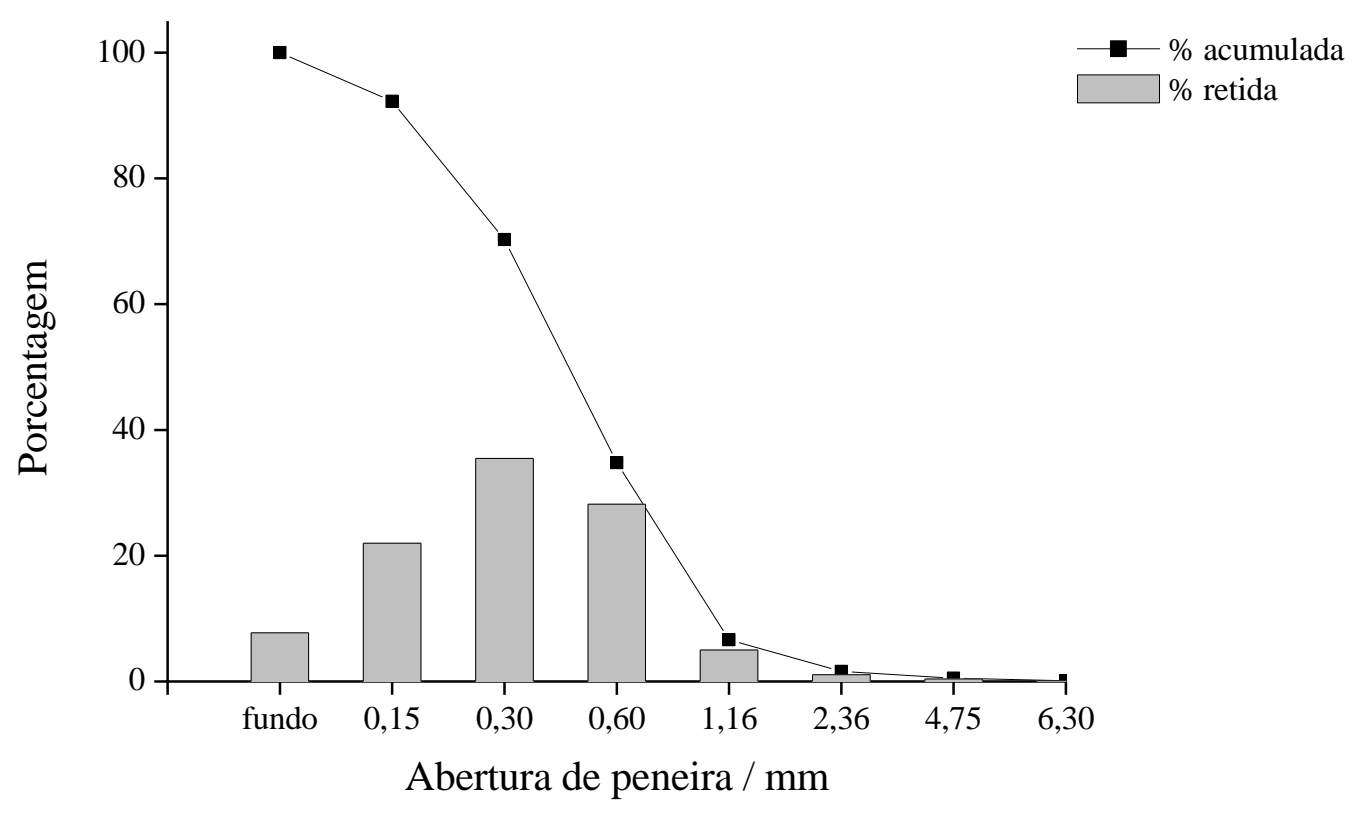

Gráfico 5.1 - Curva granulométrica do agregado miúdo (ABNT, 2005a).

\subsubsection{Agregado graúdo}

Foi utilizada brita 1, proveniente de rocha granítica, com módulo de finura de 6,88 , diâmetro máximo de $19 \mathrm{~mm}$ e massa específica de $2,60 \mathrm{~g} / \mathrm{cm}^{3}$, cuja composição granulométrica está no gráfico 5.2. 


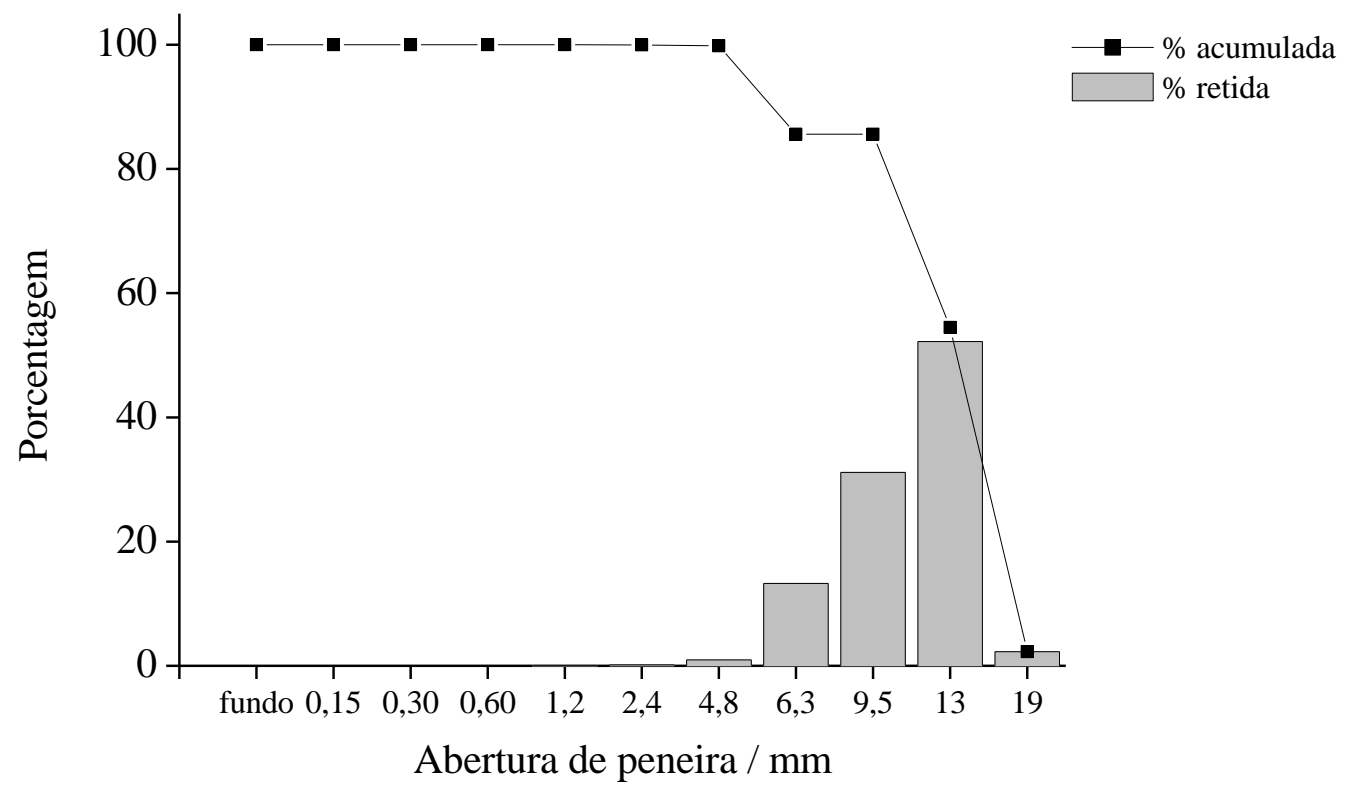

Gráfico 5.2 - Curva granulométrica do agregado graúdo (ABNT, 2005a).

\subsection{Traços}

Para realização desse plano de ensaios, foram utilizados três traços distintos, cujas composiçõos e características estão nas tabelas 5.6 e 5.7.

Tabela 5.6 - Dosagem dos traços utilizados $\left(\mathrm{kg} / \mathrm{m}^{3}\right)$.

\begin{tabular}{cccc}
\hline Material & CS 30 & CS 35 & CS 40 \\
\hline Cimento CPV ARI & 315,00 & 330,00 & 355,00 \\
\hline Agregado miúdo & 836,00 & 825,00 & 805,80 \\
\hline Agregado graúdo & 1020,00 & 1023,00 & 1029,50 \\
\hline Água & 207,90 & 198,00 & 198,80 \\
\hline Aditivo polifuncional & 1,26 & 1,32 & 1,42 \\
\hline
\end{tabular}


Tabela 5.7 - Características de cada traço.

\begin{tabular}{cccc}
\hline Característica & CS 30 & CS 35 & CS 40 \\
\hline Traço unitário & $1,00: 2,65: 3,24: 0,66$ & $1,00: 2,50: 3,10: 0,60$ & $1,00: 2,27: 2,90: 0,56$ \\
\hline Massa específica / kg/m & 2251 & 2287 & 2305 \\
\hline Ar incorporado / \% & 3,4 & 3,2 & 2,6 \\
\hline Abatimento / $\mathrm{mm}$ & 120 & 120 & 120 \\
\hline Teor de argamassa seca / & 53,0 & 53,0 & 53,0 \\
\hline $\mathrm{f}_{\mathrm{cm}} / \mathrm{MPa}$ & $30,1 \pm 0,6$ & $35,2 \pm 0,4$ & $39,8 \pm 0,7$ \\
\hline $\mathrm{f}_{\mathrm{c}, \mathrm{m}} / \mathrm{MPa}$ & $4,26 \pm 0,02$ & $4,53 \pm 0,07$ & $4,96 \pm 0,10$ \\
\hline
\end{tabular}

As resistências à compressão e à tração na flexão foram obtidas segundo os ensaios propostos nas normas ABNT NBR 5729 (2007) e ABNT NBR 12142 (2010). Para o primeiro procedimento, foram utilizados 6 corpos-de-prova cilíndricos, de dimensões $150 \mathrm{~mm}$ x 300mm (diâmetro x altura), com velocidade de carregamento de 0,45MPa / s, com borrachas de neoprene, em conjunto com cápsulas metálicas, para uniformizar a aplicação carga da face de acabamento do corpo-de-prova. Para o segundo procedimento, foram utilizados 4 corposde-prova prismáticos, de dimensões $150 \mathrm{~mm}$ x $150 \mathrm{~mm}$ x $500 \mathrm{~mm}$, com velocidade de carregamento de 1,0MPa / min. Nesse último caso, o corpo-de-prova não foi utilizado nenhum método de regularização das superfícies, pois suas faces eram suficientemente regulares.

\subsection{Fibras}

As propriedades das fibras utilizadas nos ensaios, informadas pelos respectivos fabricantes, estão listadas na tabela 5.8. Cada fibra foi analisada separadamente e os resultados estão nos itens subsequentes. 
Tabela 5.8 - Propriedades das fibras utilizadas.

\begin{tabular}{ccc}
\hline Propriedade & Macrofibra polimérica & Aço \\
\hline Material & copolímero de polipropileno virgem & aço \\
\hline Forma & monofilamento / fibrilado & Tipo A1 \\
\hline Número de filamentos por quilograma & 221000 & 4600 \\
\hline Número de filamentos por litro & 201100 & 36100 \\
\hline Comprimento / mm & 54 & 60 \\
\hline Diâmetro equivalente / mm & 0,32 & 0,75 \\
\hline Densidade / g/cm & 0,91 & 7,85 \\
\hline Módulo de elasticidade / GPa & Não informado & 210 \\
\hline Resistência à tração / $\mathrm{MPa}$ & $570-660$ & 1100 \\
\hline
\end{tabular}

\subsubsection{Macrofibra polimérica}

Para caracterizar a macrofibra polimérica, foi utilizada a norma ASTM D7508 (2010d) como referência, que prescreve os parâmetros de conformidade mostrados na tabela 5.9.

Tabela 5.9 - Parâmetros de conformidade para macrofibras poliméricas, segundo ASTM D7508.

\begin{tabular}{cc}
\hline Parâmetro & Especificação \\
\hline Denier (diâmetro equivalente) & $>581(>0,30 \mathrm{~mm})$ \\
\hline Comprimento & $12-65 \mathrm{~mm}$ \\
\hline Teor de aditivos na superfície & $\leq 1 \%$ \\
\hline Resistência à tração & $>344,4 \mathrm{MPa}$ \\
\hline
\end{tabular}

Além desses dados, esta norma requer que sejam declarados a deformação última da fibra e seu módulo de elasticidade, apesar de não impor especificações mínimas para esses parâmetros. A caracterização da macrofibra está apresentada nos itens subsequentes. Também foi medida a densidade da fibra, para garantir que os dados informados pelo fabricante fossem válidos.

\section{a) Caracterização dimensional}

Primeiramente, como a fibra é composta por uma mescla de uma macrofibra com uma microfibra fibrilada, a proporção de cada uma delas foi determinada. A partir de uma amostra de $2,00 \mathrm{~kg}$, a macrofibra foi separada manualmente da microfibra, e as proporções obtidas 
foram de $95,0 \%$ e 5,0\%, respectivamente. Como a microfibra apenas confere redução de fissuração na fase plástica e não proporciona tenacidade, os ensaios de caracterização posteriores foram apenas realizados com a macrofibra.

As dimensões da fibra foram determinadas a partir de 30 filamentos, coletados em três parcelas (10 filamentos em cada) de uma amostra disponível para comercialização. Foi utilizado um paquímetro digital da marca Starret, modelo 798A-12/300, com precisão de 0,01 mm para a análise. Como a fibra é fornecida na forma de fios torcidos, os filamentos foram esticados para que seu comprimento fosse medido.

Os resultados encontram-se na tabela 5.10.

Tabela 5.10 - Caracterização dimensional da macrofibra polimérica.

\begin{tabular}{cc}
\hline Medida & Resultado médio \\
\hline Comprimento / $\mathrm{mm}$ & $53,30 \pm 0,69$ \\
\hline Largura / $\mathrm{mm}$ & $0,29 \pm 0,03$ \\
\hline Espessura / $\mathrm{mm}$ & $0,70 \pm 0,12$ \\
\hline Diâmetro equivalente / $\mathrm{mm}$ & $0,51 \pm 0,06$ \\
\hline Fator de forma & $106,9 \pm 13,6$ \\
\hline
\end{tabular}

Através da análise dos dados presentes na tabela 5.10, verifica-se que a fibra atende os requisitos comprimento e diâmetro equivalente prescritos na norma ASTM D7508 (2010d). Entretanto, observou-se que a fibra pode apresentar filamentos únicos, duplos ou triplos, pela união de dois ou três filamentos. Os triplos são os mais frequentes e são as suas dimensões que estão apresentadas na tabela 5.10.

Por essa diferença em sua morfologia, a determinação das dimensões da fibra foi de difícil execução, pois a fibra é flexível e macia. A fibra não pode ser totalmente esticada para determinação de seu comprimento, pois os fios unidos não apresentam o mesmo grau de torção, sendo uns mais torcidos que outros. Daí, o comprimento apresentado foi o do fio mais curto que forma o fio triplo.

Entretanto, as características dimensionais apresentadas acima são decorrentes do processo de produção da fibra e são feitas propositalmente para que esta apresente suas propriedades de reforço. Esse assunto será mais bem demonstrado no item que trata da determinação da resistência à tração do fio (item 5.3.1, parte (d)). 


\section{b) Determinação da densidade}

Para essa determinação, foi utilizada uma coluna de densidade. Em uma proveta de $250 \mathrm{~mL}$, foram colocados $20 \mathrm{~mL}$ de oito soluções de água deionizada e etanol anidro (ambos marca Synth) com densidades entre 0,890 e 0,998g/ $\mathrm{cm}^{3}$ (PERRY; GREEN, 1999). Foram preparados $120 \mathrm{~mL}$ de cada solução, por porcentagem em massa. Depois da preparação, as densidades foram conferidas em um picnômetro metálico.

Para elaborar a coluna, a solução mais densa foi colocada primeiro, seguindo a ordem decrescente da densidade. Para melhor visualização, as soluções intermediárias receberam corante azul. Após a finalização, uma amostra de fibra foi inserida na coluna. A fibra se estabiliza na solução cuja densidade é mais próxima da sua.

A tabela 5.11 indica as soluções e densidades utilizadas e a figura 5.1 mostra a coluna obtida, com a amostra de fibra.

Tabela 5.11 - Soluções utilizadas na elaboração da coluna de densidade.

\begin{tabular}{ccc}
\hline $\begin{array}{c}\text { Quantidade de água / } \\
\text { \% em massa }\end{array}$ & $\begin{array}{c}\text { Quantidade de etanol anidro / } \\
\text { \% em massa }\end{array}$ & $\begin{array}{c}\text { Densidade da solução (20 } \mathbf{~ C ) ~ / ~} \\
\mathbf{g}^{\mathbf{0}} \mathbf{c m}^{\mathbf{3}}\end{array}$ \\
\hline 100,0 & 0,0 & 0,998 \\
\hline 90,0 & 10,0 & 0,982 \\
\hline 80,0 & 20,0 & 0,966 \\
\hline 70,0 & 30,0 & 0,952 \\
\hline 60,0 & 40,0 & 0,935 \\
\hline 50,0 & 50,0 & 0,912 \\
\hline 49,0 & 51,0 & 0,898 \\
\hline 45,0 & 55,0 & 0,889 \\
\hline
\end{tabular}




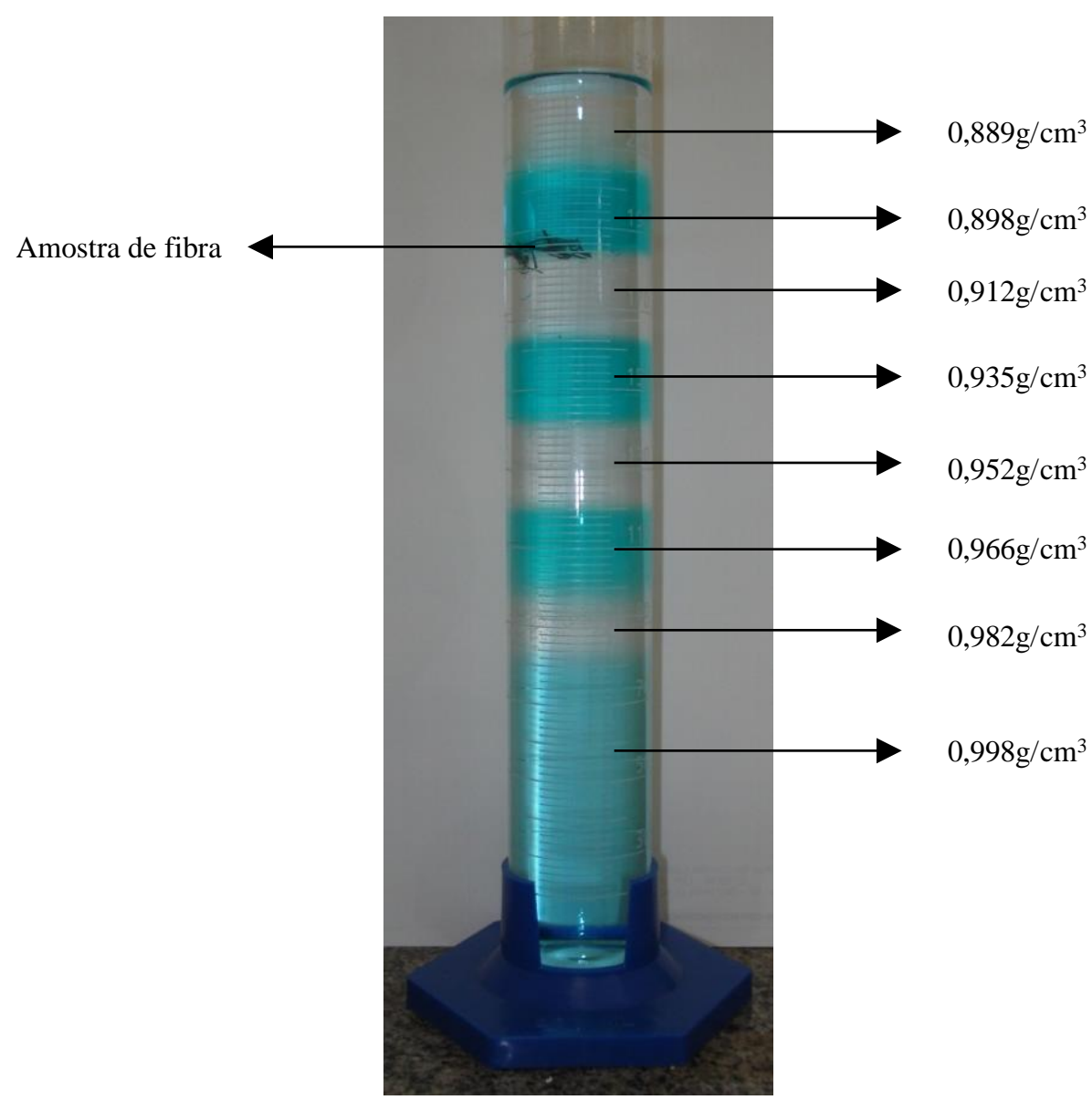

Figura 5.1 - Coluna de densidade elaborada com soluções de água deionizada e etanol anidro.

Pode ser observado que a fibra estabilizou-se entre as soluções de densidades 0,898 e $0,912 \mathrm{~g} / \mathrm{cm}^{3}$, indicando que sua densidade está dentro desse intervalo, validando o dado do fabricante $\left(0,91 \mathrm{~g} / \mathrm{cm}^{3}\right)$.

\section{c) Teor de aditivos na superfície}

Para verificar se a fibra possui algum tipo de aditivo em sua superfície que possa aprimorar a interação com a matriz, foi utilizada a norma ASTM D2257 (2012) como referência. Foram utilizadas uma balança semi-analítica da marca Marte-Shimadzu, modelo UX6200H, com precisão de 0,01g, uma estufa com circulação de ar, um funil de separação de volume de $500 \mathrm{~mL}$ e etanol anidro, marca Synth.

Primeiramente, duas amostras de $10,00 \mathrm{~g}$ da macrofibra foram colocadas em estufa a $105^{\circ} \mathrm{C}$ durante 30 minutos, para saber se existe algum composto volátil na composição da fibra. Depois desse período, as massas das amostras foram determinadas novamente e não foi 
verificada variação em seu valor inicial, indicando que não existem compostos voláteis na superfície da fibra.

Além disso, outras duas amostras de 10,00g de fibra foram lavadas com 3 alíquotas de $50,0 \mathrm{~mL}$ de etanol anidro com o auxílio do funil de separação, sendo cada etapa feita por 2 minutos sob agitação constante. Após a lavagem, as amostras foram colocadas em estufa a $105^{\circ} \mathrm{C}$ durante 30 minutos até a evaporação completa do solvente. Depois dessa etapa, as massas das amostras foram determinadas novamente e, também, não foi verificada variação em seu valor inicial.

A partir dos dados apresentados acima, pode-se concluir que a fibra não possui aditivos em sua superfície.

\section{d) Resistência à tração}

A resistência à tração das fibras foi determinada segundo os critérios propostos pela norma ASTM D2256 (2010c). Foram utilizados 10 filamentos de 500mm de comprimento, ensaiados com comprimento útil de $250 \mathrm{~mm}$. A velocidade de aplicação de carga foi de $200 \mathrm{~N} / \mathrm{min}$, para que o filamento rompesse entre 17 e 23 segundos de duração do ensaio. O ensaio foi realizado no Laboratório de Microestrutura do departamento de Engenharia Civil da Escola Politécnica da Universidade de São Paulo. O equipamento utilizado era da marca Instron, modelo 5569, acoplado ao software Bluehill 2, versão 2.22. Foi utilizada uma célula de carga de capacidade de $1000 \mathrm{~N}$. Este equipamento possuía garras pneumáticas para colocação dos corpos-de-prova. O esquema de realização do ensaio e o filamento rompido estão mostrados na figura 5.2 e 5.3, respectivamente. Os resultados finais calculados estão na tabela 5.12. 


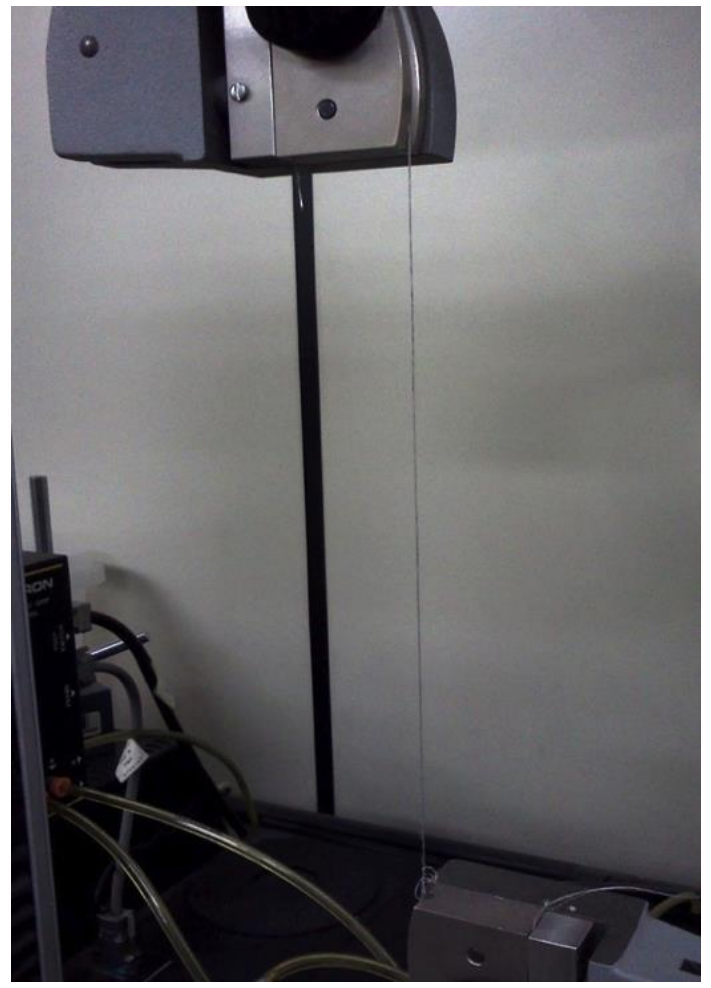

(a)

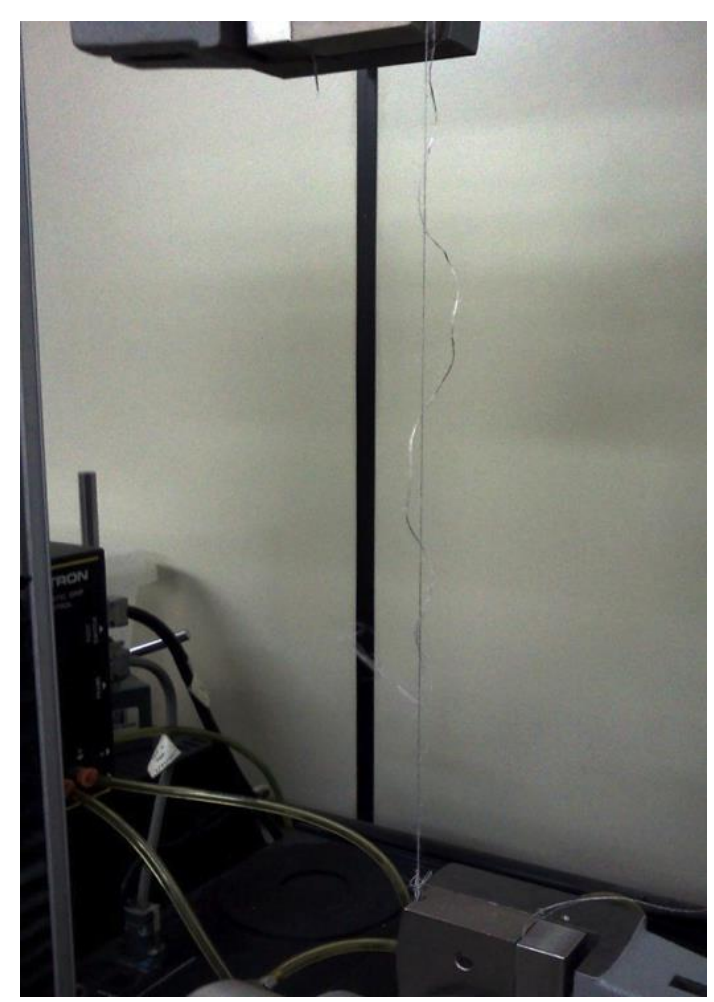

(b)

Figura 5.2 - Ensaio de tração antes (a) e depois (b) do rompimento do fio.

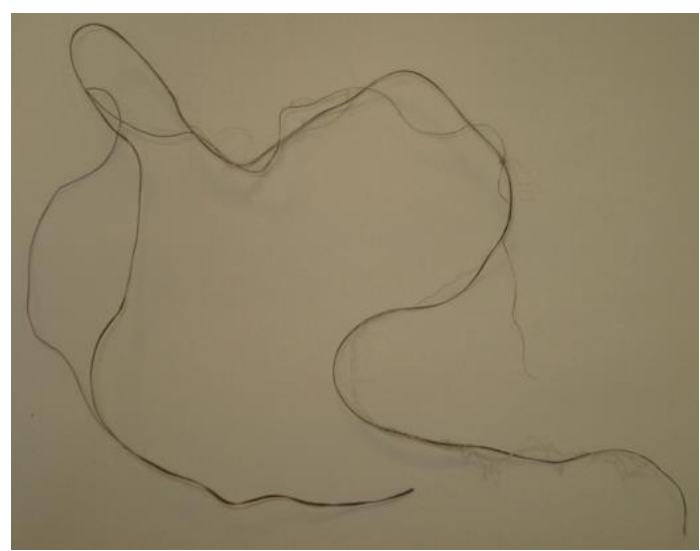

(a)

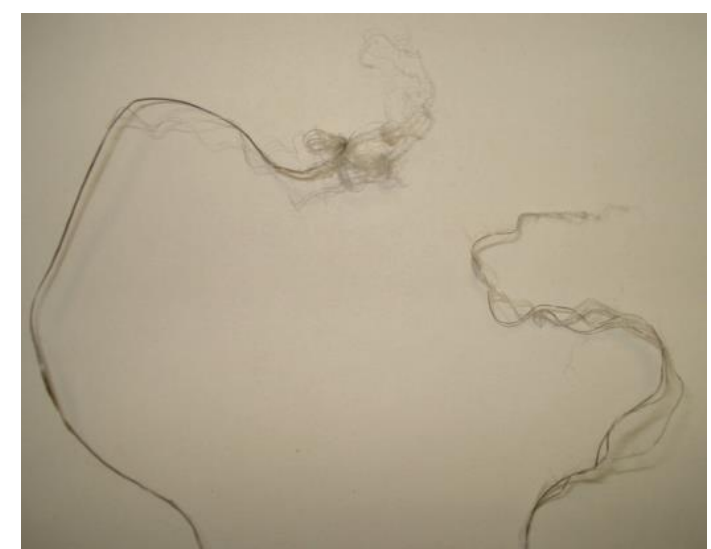

(b)

Figura 5.3 - Amostras do fio após o ensaio: fio desfibrilado (a) e fio rompido(b).

Como pode ser observado, o mecanismo de ruptura da fibra não se dá pela estricção formada quando esta é tracionada. Ao invés de romper, a fibra é desfibrilada, ou seja, o macrofio se transforma em inúmeros microfios, pela quebra das ligações entre os microfios. Isso ocorre principalmente devido à composição química da fibra, que deve conter dois 
polímeros insolúveis entre si. Devido a esse fato, essa fibra pode ser caracterizada como autofibrilável (TROTTIER; MAHONEY, 2001). Maiores detalhes são observados no item 5.3.3.

Além disso, conforme dito anteriormente, a fibra pode apresentar-se em filamentos únicos, duplos e triplos, sendo os últimos os majoritários. Dessa forma, as curvas cargaalongamento podem apresentar comportamentos bastante distintos entre si, pois a carga resistida por um filamento único é inferior à que um fio triplo resiste. Portanto, foram adotados apenas os resultados obtidos com os fios triplos para os cálculos de resistência à tração e módulo de elasticidade.

As curvas carga-alongamento para todas as amostras testadas e somente para os fios triplos estão mostradas no gráfico 5.3 (a) e (b), respectivamente.

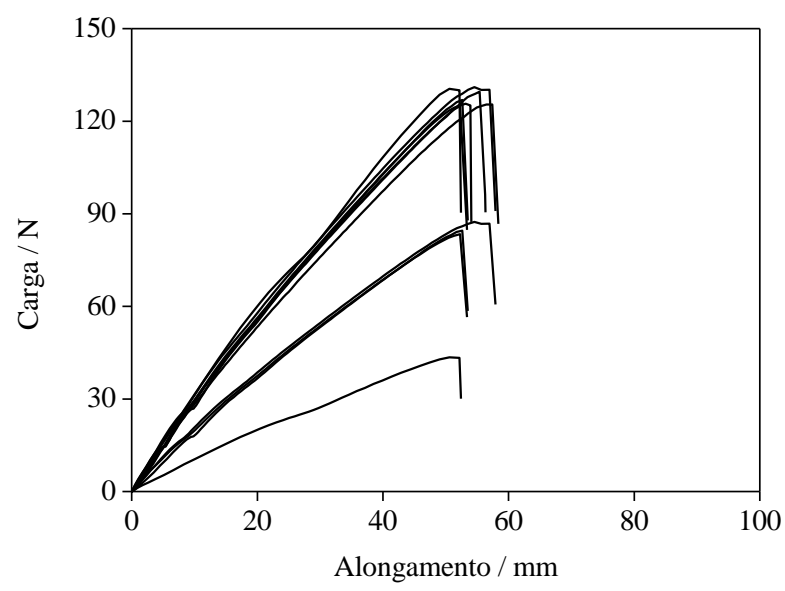

(a)

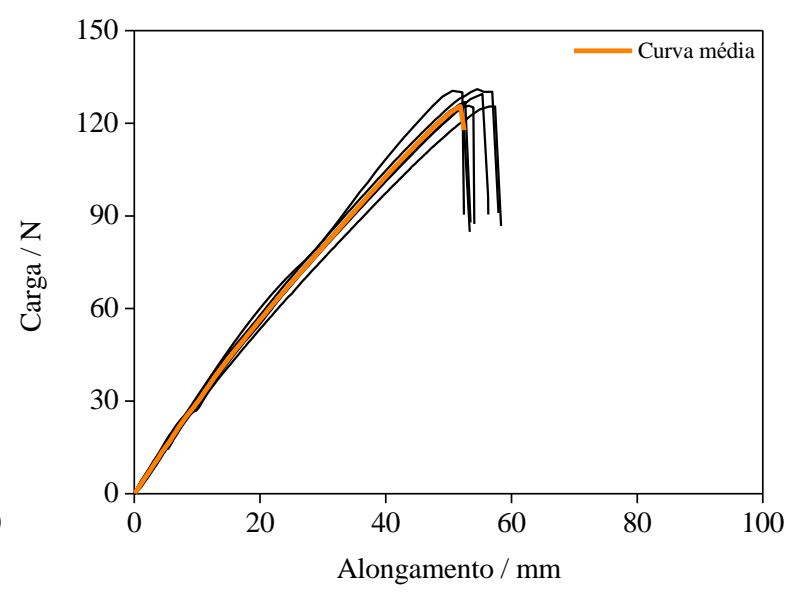

(b)

Gráfico 5.3 - Curvas carga-alongamento obtidas para todos os fios ensaiados (a) e somente para os fios triplos (b).

Os dados de carga e alongamento foram transformados em tensão e deformação pela utilização das equações (5.1) e (5.2), respectivamente.

$$
\sigma_{\mathrm{T}}=\frac{\mathrm{F}}{\mathrm{A}}
$$

Onde:

$\sigma_{\mathrm{T}}$ : Resistência à tração $(\mathrm{MPa})$;

F: Carga de ruptura do fio $(\mathrm{N})$;

A: Área da seção do fio antes do ensaio $\left(\mathrm{mm}^{2}\right)$. 


$$
\varepsilon_{\mathrm{f}}=\frac{\mathrm{L}_{\mathrm{f}}-\mathrm{L}_{\mathrm{i}}}{\mathrm{L}_{\mathrm{i}}}
$$

Onde:

$\varepsilon_{\mathrm{f}}$ : Alongamento do fio (\%);

$\mathrm{L}_{\mathrm{i}}$ : Comprimento inicial do fio $(\mathrm{mm})$;

$\mathrm{L}_{\mathrm{f}}$ : Comprimento final do fio (mm).

Dessa forma, foi possível obter as curvas tensão-deformação, cujo coeficiente angular da reta obtida por regressão linear corresponde ao módulo de elasticidade da fibra (equação (5.3)). As curvas tensão-deformação e as regressões lineares estão mostradas no gráfico 5.4 (a) e (b), respectivamente.

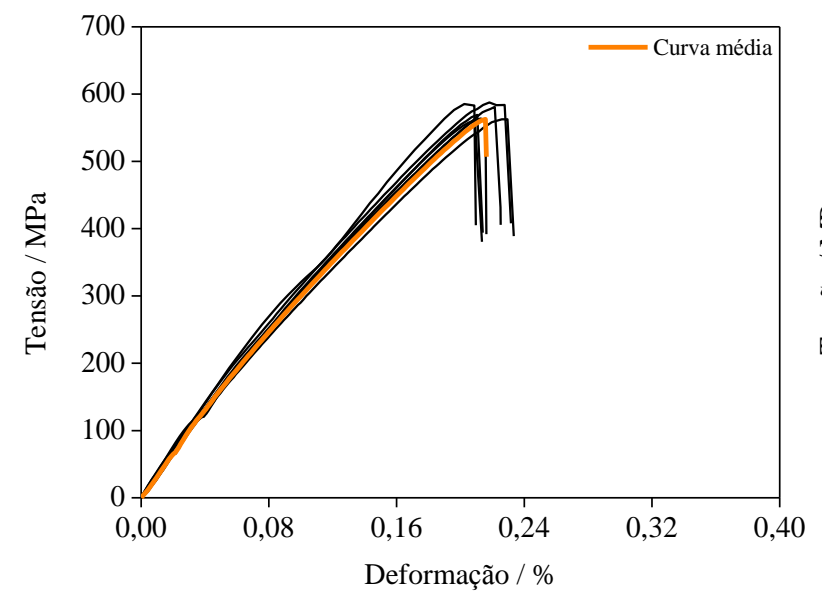

(a)

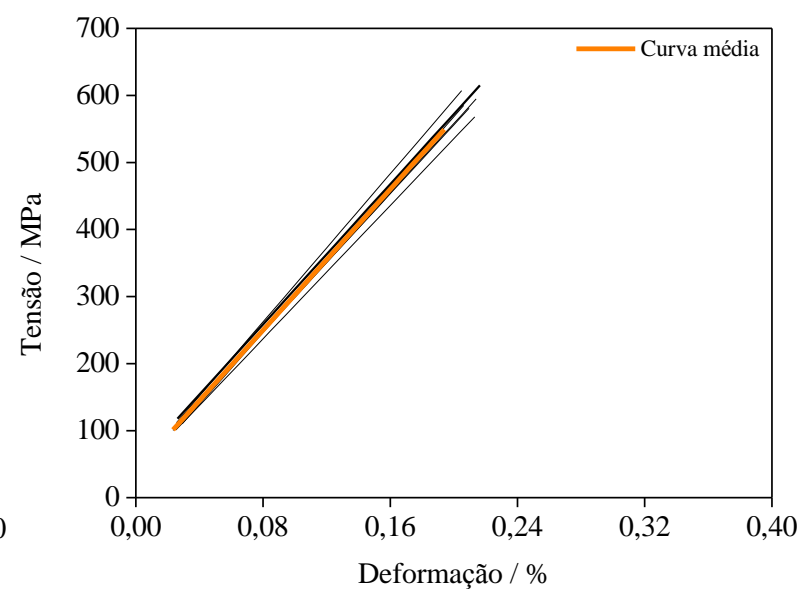

(b)

Gráfico 5.4 - Curvas tensão-deformação obtidas para os fios triplos (a) e regressões lineares para essas curvas (b).

Os resultados obtidos a partir da análise das curvas dos gráficos 5.3 e 5.4 estão mostrados na tabela 5.12. Verifica-se que a fibra atende os requisitos propostos pela norma ASTM D7508, com resistência à tração superior a 344,4MPa. 
Tabela 5.12 - Resultados obtidos a partir da análise das curvas carga-alongamento e tensão-deformação.

\begin{tabular}{cc}
\hline Medida & Resultado \\
\hline Carga máxima / N & $122,8 \pm 2,6$ \\
\hline Alongamento último / mm & $55,1 \pm 2,4$ \\
\hline Resistência à tração / $\mathrm{MPa}$ & $572,1 \pm 11,4$ \\
\hline Módulo de elasticidade / GPa & $2,63 \pm 0,09$ \\
\hline Deformação última / \% & $22,1 \pm 1,0$ \\
\hline
\end{tabular}

\subsubsection{Fibra de aço}

A fibra de aço também foi caracterizada, segundo critérios propostos pela norma ABNT NBR 15530 (2007b). De acordo com essa norma, a fibra de aço utilizada é classificada como do tipo A, classe I, com seção circular, ancoragem nas extremidades e fator de forma igual a 60. Para análise dessa fibra, foram utilizados os ensaios e amostragens mostrados na tabela 5.13 .

Tabela 5.13 - Ensaios e critérios de aceitação para a fibra de aço (ABNT, 2007b).

\begin{tabular}{ccc}
\hline Ensaio & Amostragem mínima & \% mínima de fibras conformes \\
\hline Verificação dimensional & 60 fibras & 90 \\
\hline Dobramento & 10 fibras & 90 \\
\hline Verificação de defeitos & $200 \mathrm{~g}$ & 95 \\
\hline
\end{tabular}

Em relação à verificação dimensional, é aceito que o comprimento e o diâmetro equivalente apresentem variação de $\pm 5 \%$ em relação ao valor nominal. Cada ensaio descrito acima está relatado nos itens subsequentes.

\section{a) Caracterização dimensional}

Para essa análise, foi realizado o mesmo procedimento que o utilizado para a macrofibra polimérica. Os resultados encontram-se na tabela 5.14. Verifica-se que a fibra utilizada atende os requisitos de dimensão prescritos na norma. 
Tabela 5.14 - Caracterização dimensional da fibra de aço.

\begin{tabular}{cc}
\hline Medida & Resultado médio \\
\hline Comprimento / $\mathrm{mm}$ & $60,28 \pm 0,27$ \\
\hline Diâmetro / mm & $0,72 \pm 0,01$ \\
\hline Fator de forma & $84,0 \pm 1,0$ \\
\hline
\end{tabular}

\section{b) Ensaio de dobramento}

Para essa análise, foi realizado o dobramento da fibra manualmente, utilizando-se um pino de $3,2 \mathrm{~mm}$ de diâmetro, com a temperatura ambiente a $24^{\circ} \mathrm{C}$. Como resultado, foi verificado que as 10 fibras passaram no teste, não rompendo quando dobradas.

O esquema da realização desse teste e as fibras dobradas encontram-se na figura 5.4.

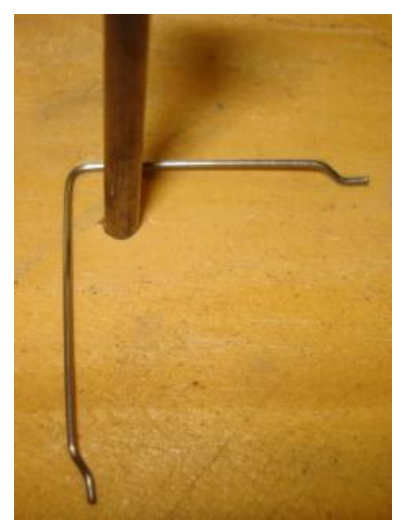

(a)

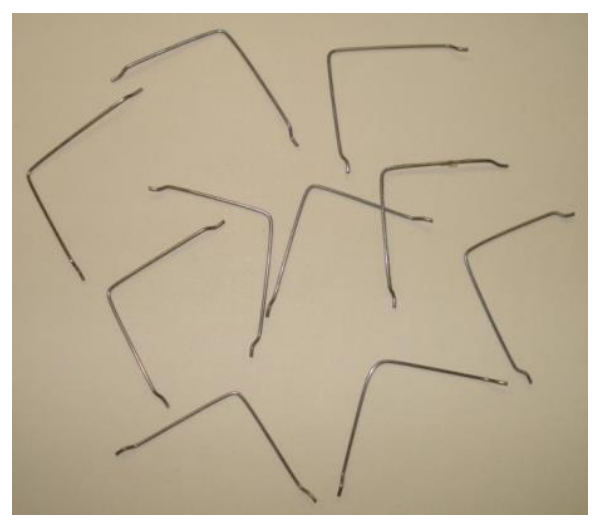

(b)

Figura 5.4 - Esquema da realização do ensaio de dobramento (a) e fibras ensaiadas (b).

\section{c) Análise de defeitos}

Essa análise foi feita apenas visualmente. $\mathrm{Na}$ amostra de $200 \mathrm{~g}$, não foram encontrados defeitos em nenhuma fibra. Parte das fibras analisadas está mostrada na figura 5.5. 


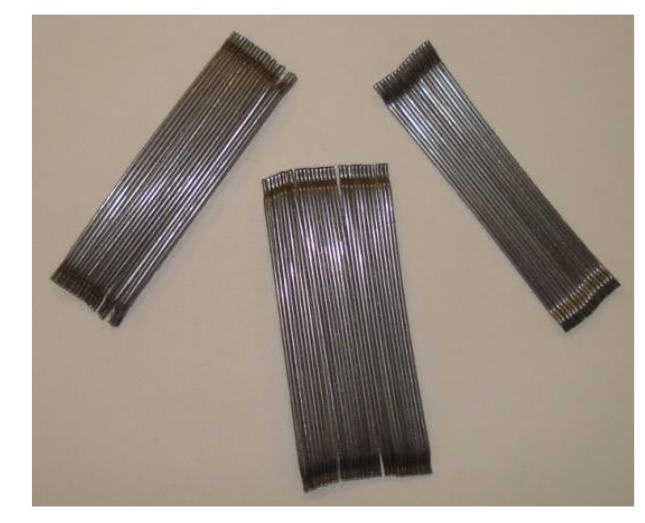

Figura 5.5 - Fibras utilizadas para verificação de defeitos.

\subsubsection{Caracterização microestrutural por Microscopia Eletrônica de Varredura}

Como a macrofibra estudada apresenta algumas particularidades, sua microestrutura foi caracterizada por microscopia eletrônica de varredura para obtenção de maiores informações sobre suas propriedades. Foi utilizado o microscópio do modelo Stereoscan S440, com microanálise química, cuja câmara opera em vácuo. As amostras foram previamente cobertas com platina. As análises foram realizadas no Laboratório de Caracterização Tecnológica da Escola Politécnica da Universidade de São Paulo, com a enorme ajuda da Geóloga MSc Liz Zanchetta D’Agostino.

Para essa análise, foram coletadas quatro amostras distintas: fibra conforme recebida, fibra retirada (lavada) de um concreto fresco após permanência na mistura por 20 minutos e fibras presentes na seção de ruptura do corpo-de-prova prismático que apresentaram falha por arrancamento e por ruptura da fibra. As duas últimas amostras tinham idade de 6 meses na data dessa análise.

As fotos estão mostradas nas figuras 5.6, 5.7 e 5.8. 


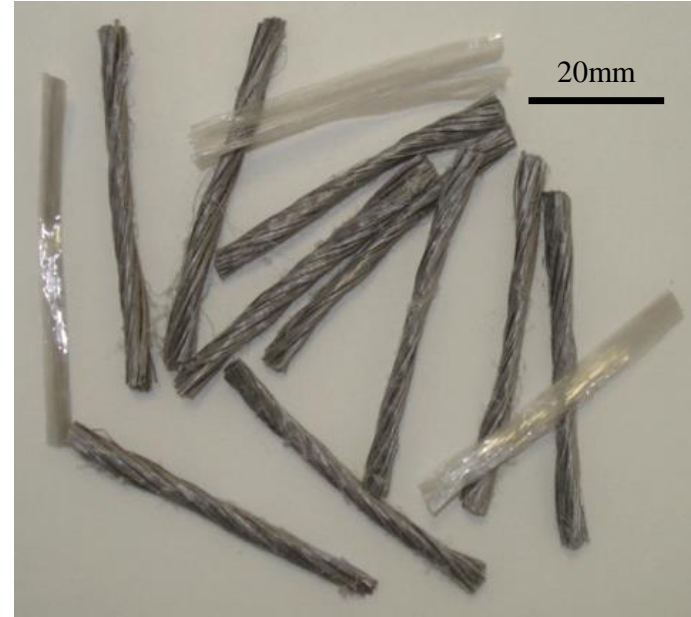

(a)

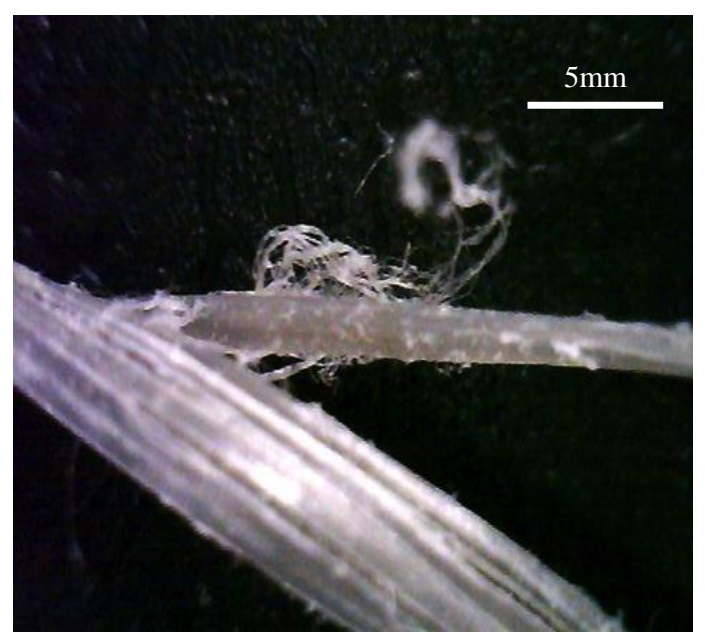

(c)

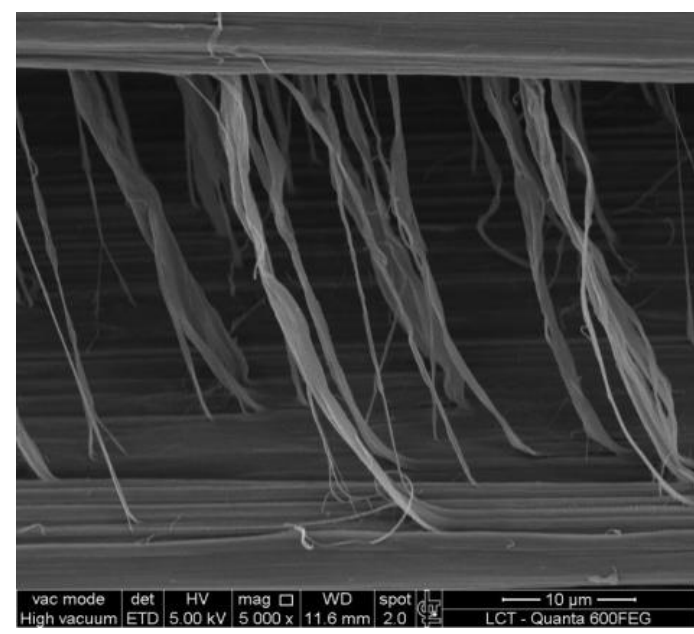

(e)

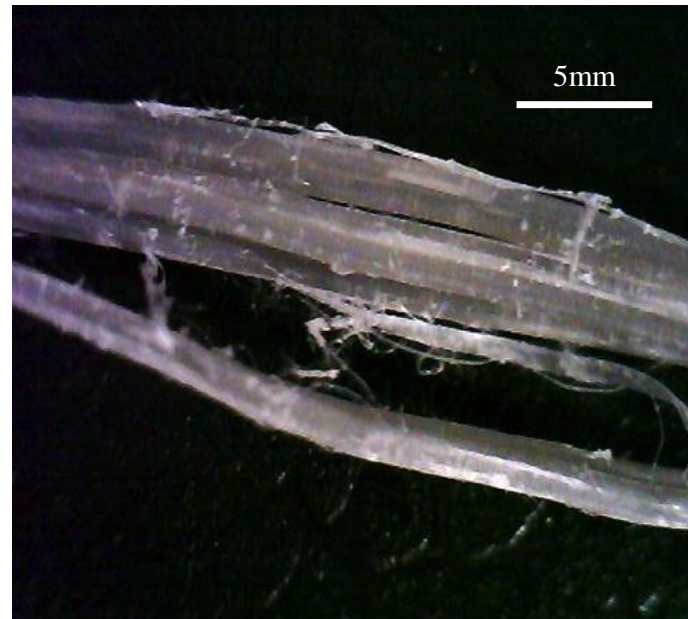

(b)

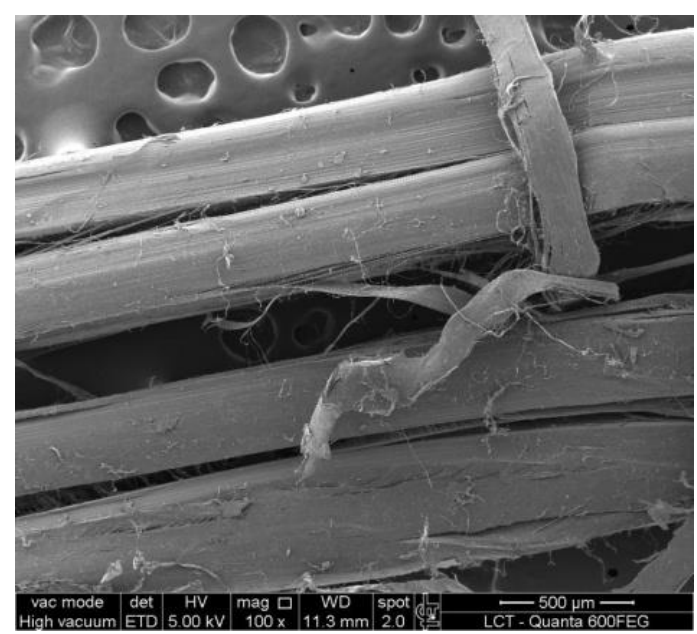

(d)

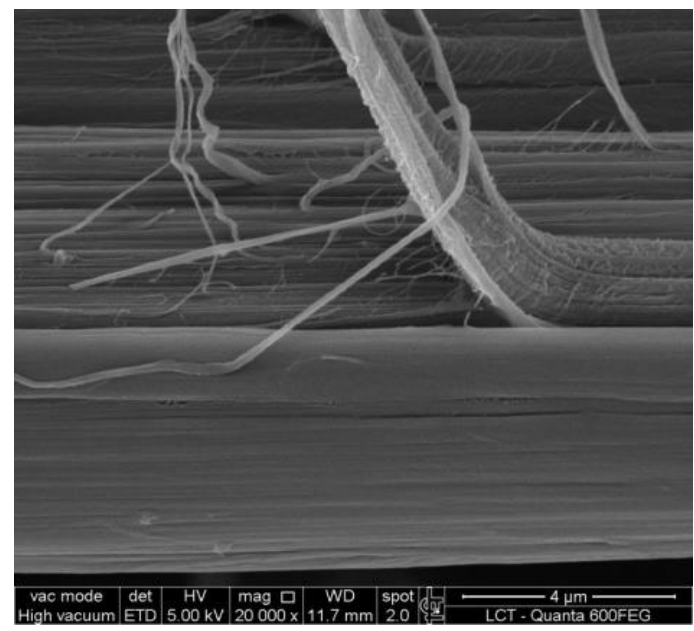

(f)

Figura 5.6 - Amostra de fibra conforme recebida (a); fotos de um macrofio (b, c); fotos de um macrofio por $\operatorname{MEV}(d, e, f)$. 


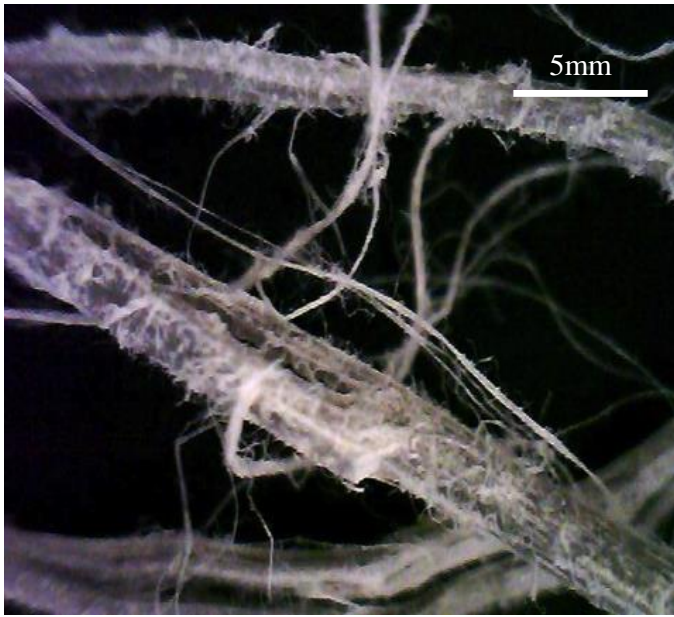

(a)

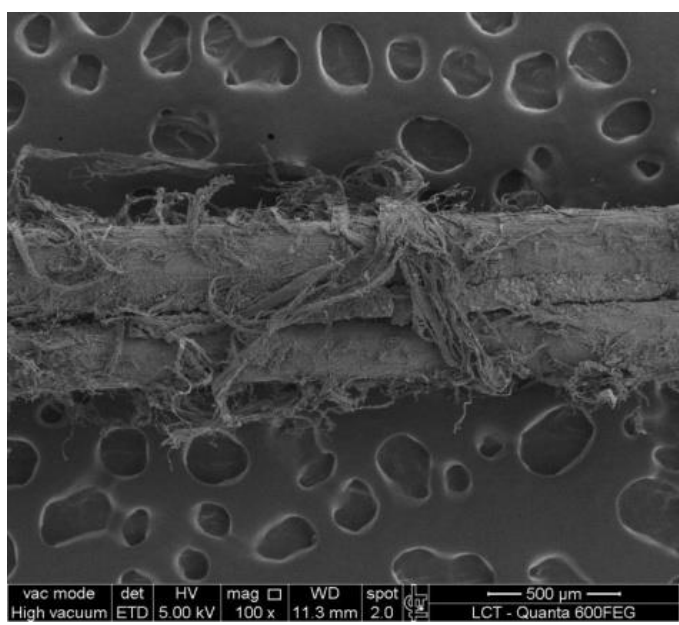

(c)

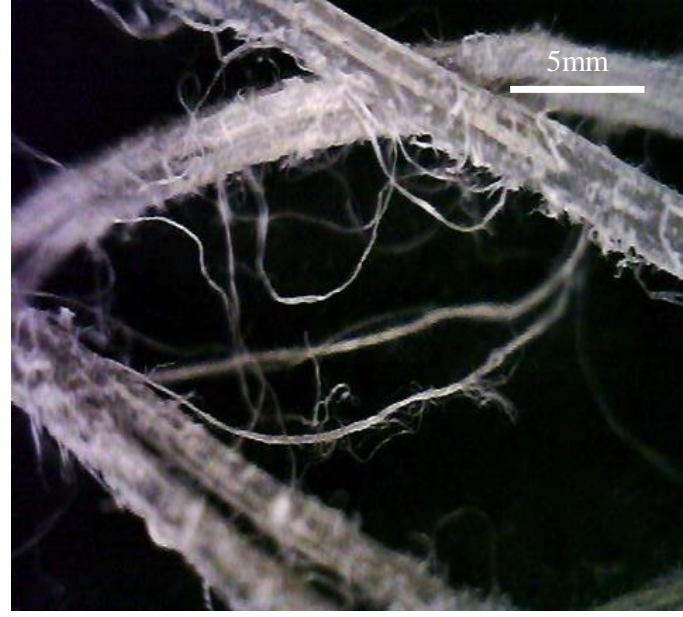

(b)

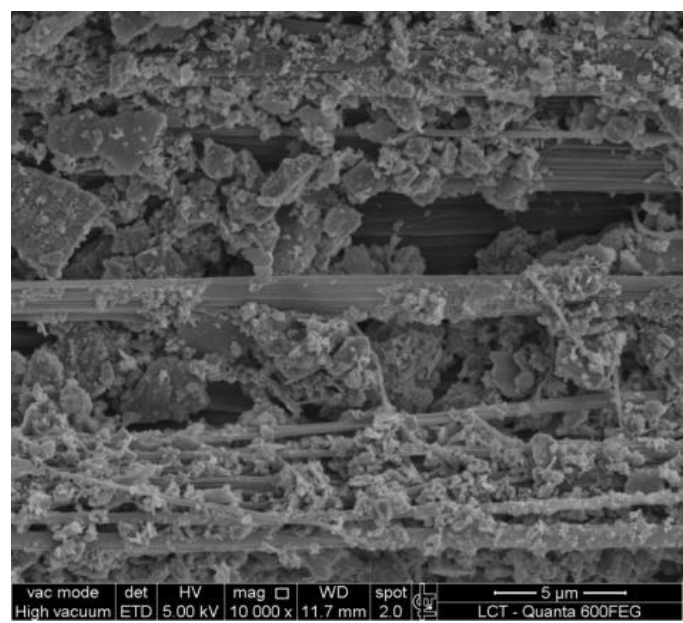

(d)

Figura 5.7 - Amostra de macrofibras retiradas do concreto fresco (a, b, c, d). 


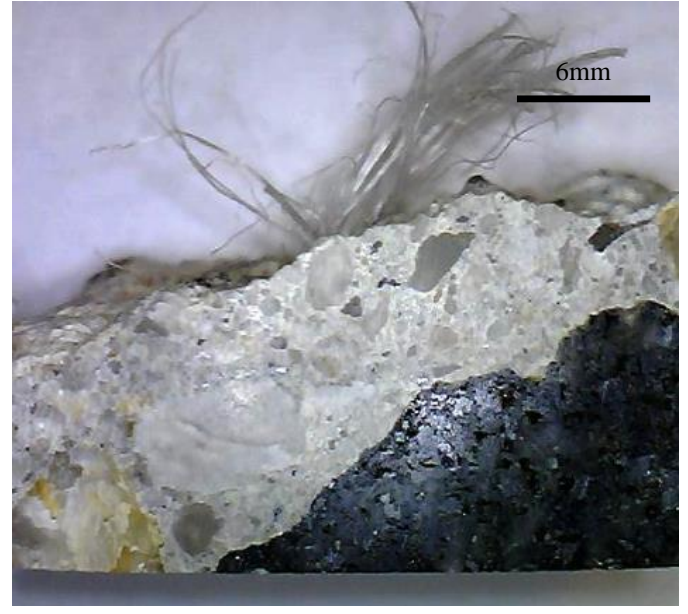

(a)

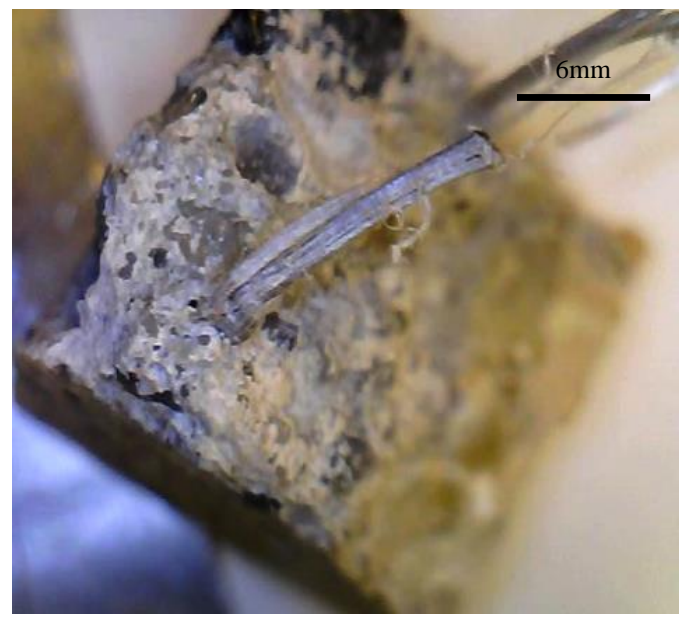

(c)

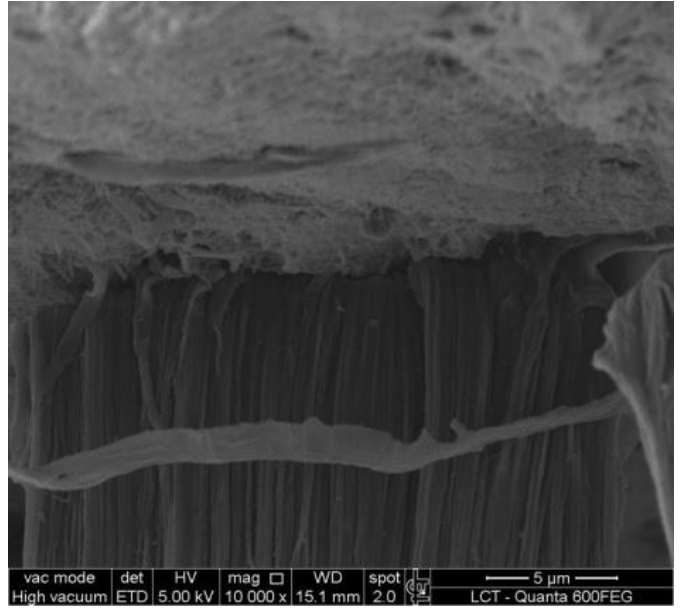

(b)

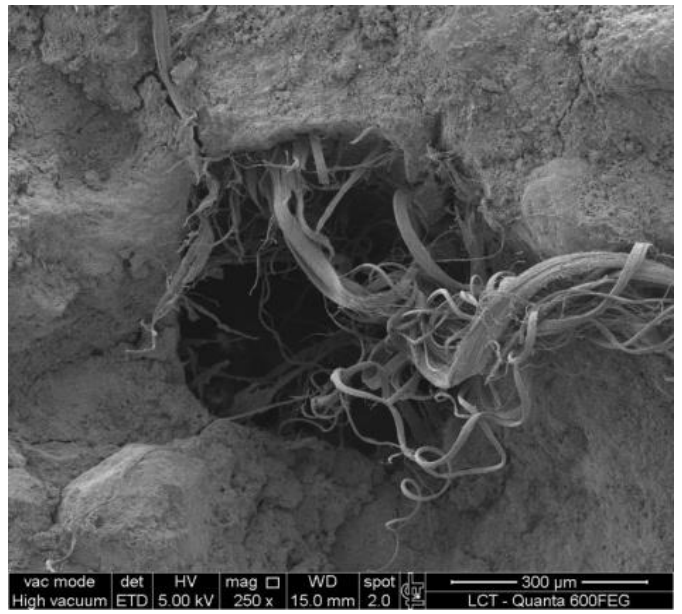

(d)

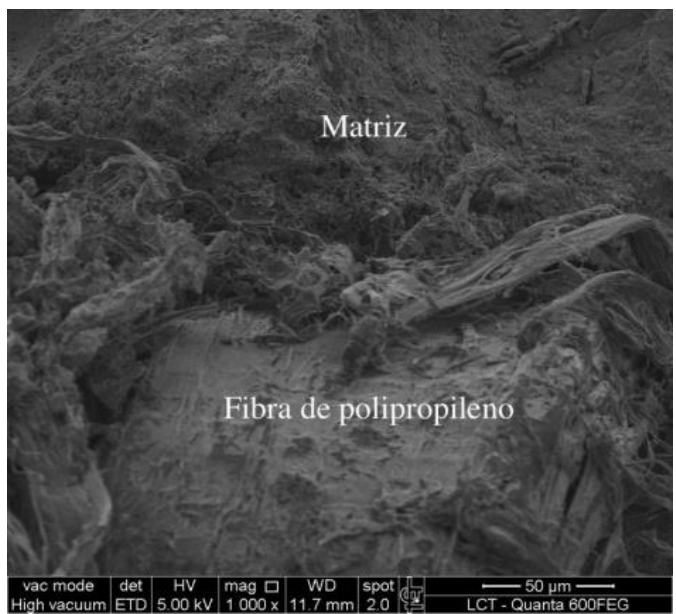

(e)

Figura 5.8 - Amostra retirada da seção de ruptura de um corpo-de-prova, com a macrofibra rompida (a); interface da fibra rompida com a matriz (b); amostra retirada da seção de ruptura de um corpo-de-prova, com a macrofibra arrancada (c); vazio deixado na matriz pela fibra arrancada (d); e interface fibra-matriz (e). 
Na figura 5.6, pode ser observado que a fibra apresenta superfície áspera e irregular, com microfibras saindo do maior fio. Tal fato é devido à determinada abrasão que a fibra sofre durante seu processo produtivo. Além disso, verifica-se que cada macrofio é composto por múltiplos microfios, unidos entre si. Os fios que parecem ser separados estão, na verdade, conectados por uma rede de fios microscópicos. Essas fibras foram desenvolvidas para que apresentem essa propriedade, típica de fibras auto-fibriláveis (TROTTIER; MAHONEY, 2001).

A amostra de fibra retirada do concreto fresco, mostrada na figura 5.7, apresentou superfície ainda mais áspera, devido à abrasão causada pelo processo de mistura com os agregados. Essa característica aumenta a superfície de contato com a matriz. Além disso, pode ser observado que os compostos de hidratação do cimento podem penetrar nos espaços entre os fios, devido à maior afinidade da fibra com a matriz (BENTUR; MINDESS; VONDRAN, 1989).

Pode ser observado na figura 5.8 que a matriz ao redor da fibra é bastante densa, uniforme e não apresenta vazios. Verifica-se que o vazio deixado quando a fibra é arrancada ainda é rico em microfibras, ou seja, à medida que a fibra é arrancada, dois mecanismos estão presentes: a quebra da aderência na interface e a quebra da ligação entre as fibras. Essas características tendem a compensar o baixo módulo da fibra e seu alto coeficiente de Poisson.

A fibra de aço também foi analisada por microscopia eletrônica de varredura. Entretanto, como não apresenta particularidades como a macrofibra polimérica, somente foram tiradas fotos de fibras presentes na seção de ruptura do corpo-de-prova prismático.

As imagens obtidas estão mostradas na figura 5.9. 


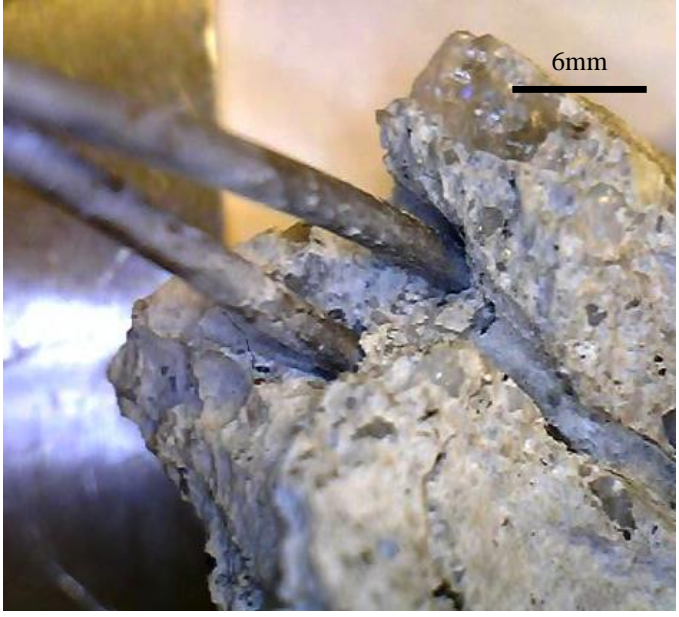

(a)

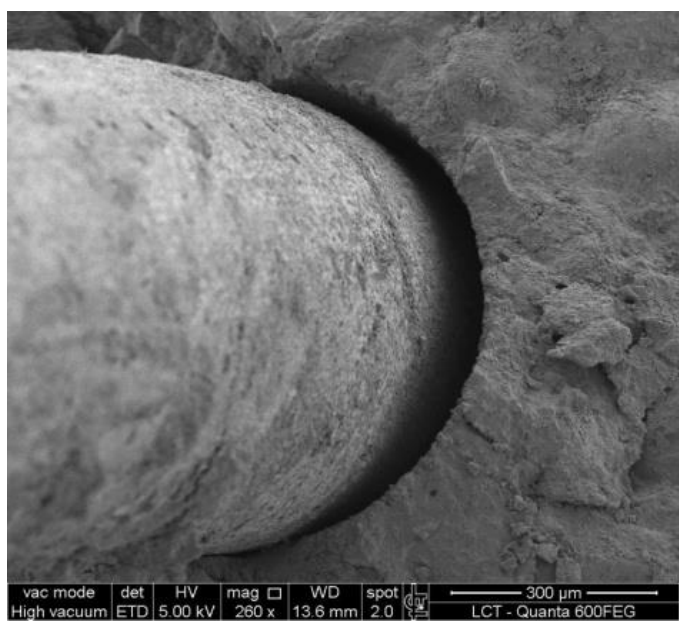

(c)

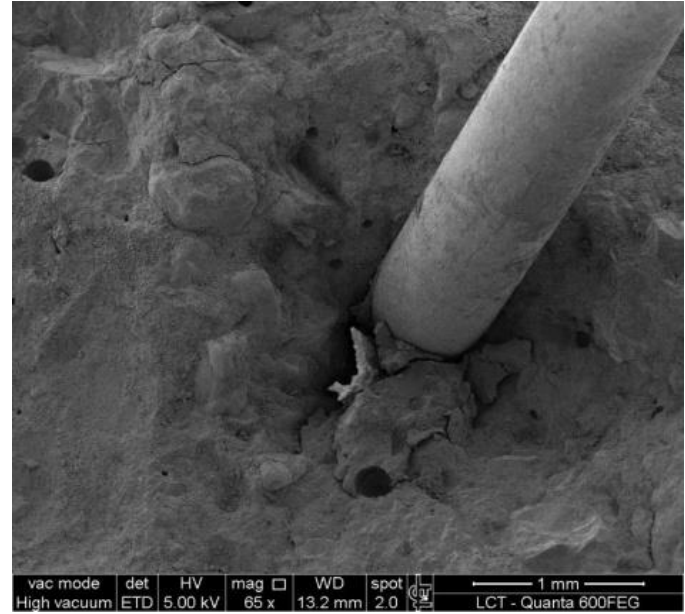

(b)

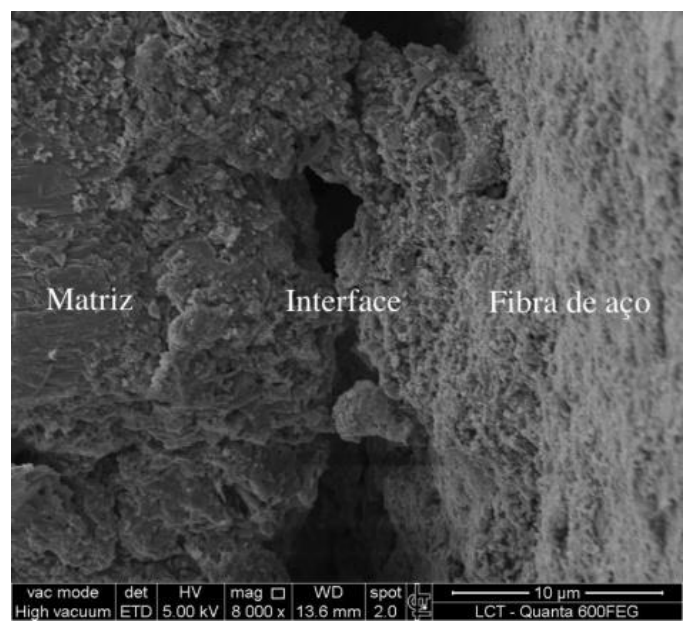

(d)

Figura 5.9 - Amostra retirada da seção de ruptura de um corpo-de-prova, com a fibra de aço (a); interface da fibra com a matriz (b, c, d).

Devido à sua alta resistência, o mecanismo principal pelo qual as fibras de aço conferem tenacidade ao concreto é devido o seu arrancamento da matriz. Tal fato pode ser observado na foto 5.9 (b), onde se verifica que a interface fibra-matriz está danificada. Além disso, na foto 5.9 (c), é possível observar que a ligação entre a fibra de aço e a matriz é fraca, dado que a fibra foi descolada da matriz.

Um fato interessante pode ser observado na foto 5.9 (d), que mostra a zona de transição interface fibra-matriz, que mede cerca de $15 \mu \mathrm{m}$. Essa região apresenta morfologia bastante distinta do bulk da matriz, sendo mais porosa e irregular, enquanto que a matriz é mais densa e uniforme. Isso corrobora com o apresentado na figura 3.7, que explica que as fibras são envolvidas por água quando o concreto está no estado fresco e tende a ocorrer um 
depósito de cristais de hidróxido de cálcio em sua superfície, sendo a zona de transição da interface a região limitante da tenacidade do compósito (BENTUR; MINDESS, 2007).

$\mathrm{Na}$ tentativa de caracterizar a composição química e as fases presentes na interface da macrofibra e da fibra de aço com a matriz, foi feita uma análise por EDS (espectroscopia de energia dispersiva de raios-X). Entretanto, para essa análise é necessário que a seção seja polida, para que o feixe de elétrons consiga atingir apenas o ponto de interesse. O polimento pode alterar muito a microestrutura e a superfície de materiais heterogêneos, falseando os resultados. Devido a esse motivo, não foram obtidas diferenças significativas entre os espectros das duas interfaces.

\subsection{Produção, moldagem e cura dos corpos-de-prova}

A produção de concreto foi baseada no método japonês JSCE-SF1 (1984), obedecendo-se as seguintes etapas:

a) Imprimação da betoneira;

b) Adição dos agregados miúdos e graúdos. Mistura por 1 minuto;

c) Adição do cimento e de metade da quantidade de água. Mistura por um minuto;

d) Diluição do aditivo na água restante. A solução obtida foi, então, adicionada à betoneira e a mistura foi feita por mais 5 minutos;

e) Determinação do abatimento do concreto sem fibras;

f) Adição da fibra com a betoneira em movimento, tomando cuidado para evitar embolamentos. Mistura feita por mais 5 minutos;

g) Determinação do abatimento, da densidade e do teor de ar incorporado do concreto com fibras.

Depois de finalizadas as etapas acima, a moldagem dos corpos-de-prova foi realizada segundo o método japonês JSCE-SF2 (1984). Foram utilizadas formas metálicas que receberam uma fina camada de óleo mineral para auxiliar a desforma. Os seguintes passos foram seguidos:

a) Preenchimento das formas (metálicas), em apenas uma camada, iniciando-se no terço central; 
b) Adensamento com mesa vibratória. Os corpos-de-prova prismáticos foram adensados em pares e os cilíndricos foram adensados todos juntos. Em ambos os casos, foi adotado o período de vibração de 20s;

c) Acabamento da superfície;

d) Estocagem e identificação;

e) Os corpos-de-prova foram cobertos com lona plástica e mantidos à temperatura ambiente por 24 horas.

Após esse período, procedeu-se com a desforma dos corpos-de-prova. Então, realizouse a cura em câmara úmida a $(23 \pm 2)^{\circ} \mathrm{C}$ e umidade relativa superior a $95 \%$. Os ensaios foram realizados aos 28 dias de idade, com os corpos-de-prova secos ao ar previamente por 24 horas.

As figuras 5.10, 5.11 e 5.12 ilustram os processos de caracterização no estado fresco, moldagem e cura dos corpos-de-prova.

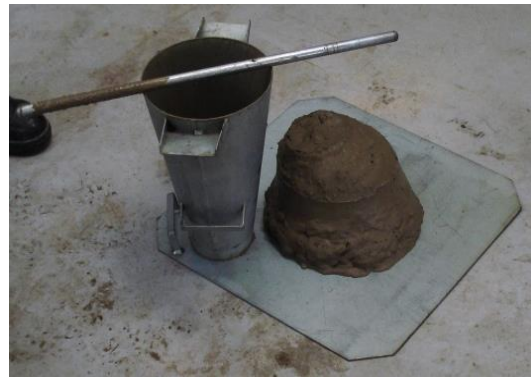

(a)

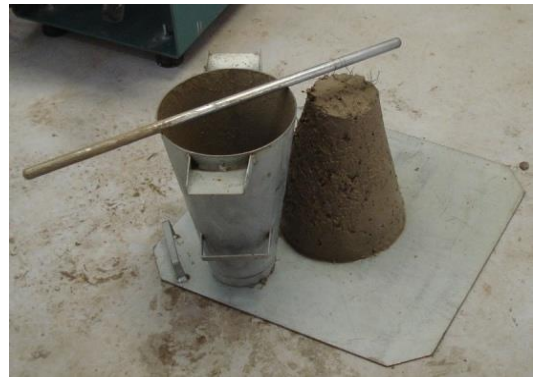

(b)

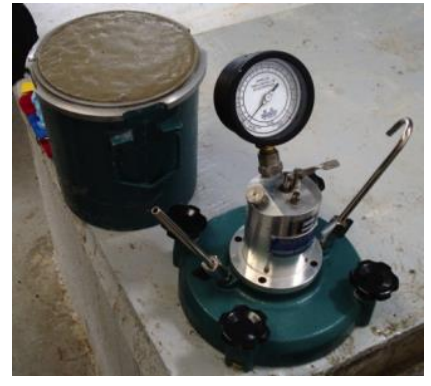

(c)

Figura 5.10 - Determinação do abatimento do tronco de cone com concreto sem fibras (a) e com 7,5kg de fibras por metro cúbico (b); determinação da densidade e do teor de ar incorporado (c). 


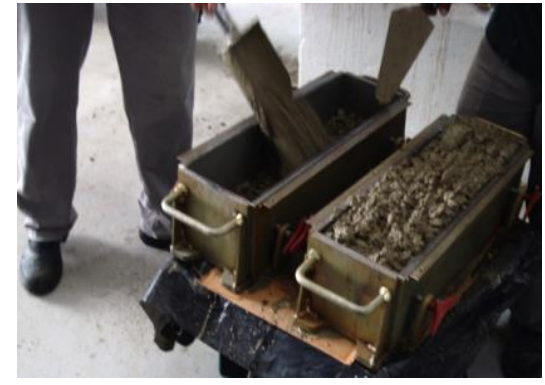

(a)

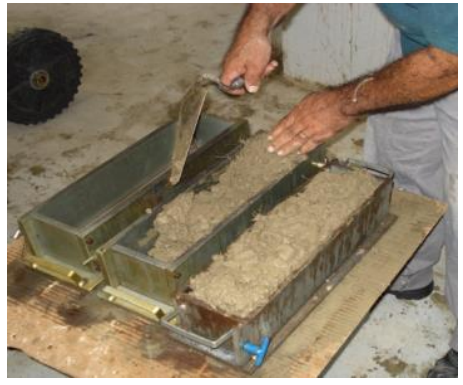

(b)

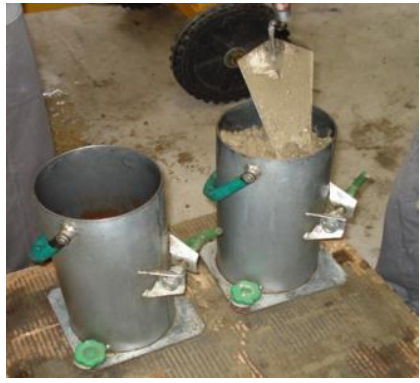

(c)

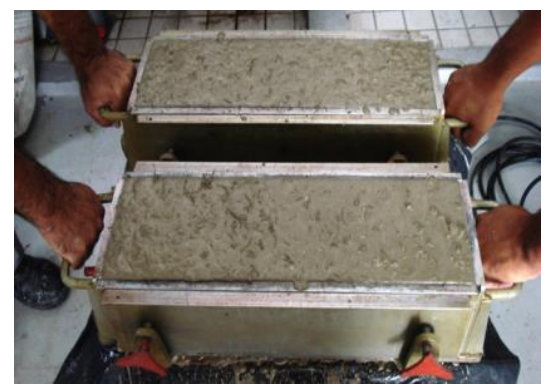

(d)

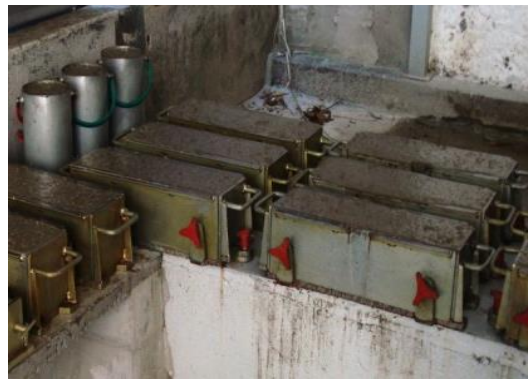

(e)

Figura 5.11 - Moldagem dos corpos-de-prova prismáticos (a, b) e cilíndricos (c); adensamento por mesa vibratória (d); corpos-de-prova após moldagem (e).

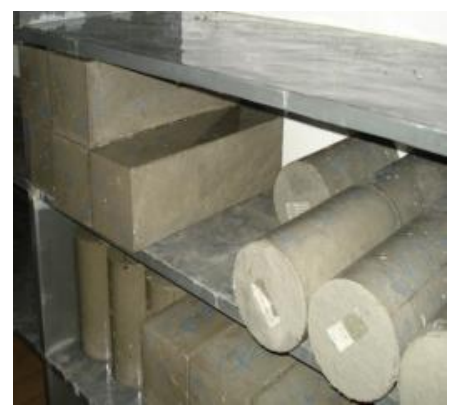

Figura 5.12 - Cura dos corpos-de-prova em câmara úmida.

\subsection{Parâmetros de ensaio}

Os parâmetros de ensaio utilizados para cada procedimento estão descritos na tabela 5.15 . 
Tabela 5.15 - Parâmetros de ensaio para cada procedimento (ASTM 2010; ASTM, 2010; CEN, 2007).

\begin{tabular}{cccc}
\hline Item & ASTM C1609 e JSCE-SF4 & ASTM C1399 & EN 14651 \\
\hline $\begin{array}{c}\text { Geometria e dimensões do } \\
\text { corpo-de-prova / } \mathrm{mm}^{3}\end{array}$ & $\begin{array}{c}\text { prismático, } \\
150 \text { x } 150 \text { x } 500\end{array}$ & $\begin{array}{c}\text { prismático, } \\
100 \times 100 \times \text { x } 400\end{array}$ & $\begin{array}{c}\text { prismático, } \\
150 \text { x } 150 \times 500\end{array}$ \\
\hline Vão de ensaio / mm & 450 & 300 & 450 \\
\hline $\begin{array}{c}\text { Velocidade de deflexão - } \\
\text { abertura de fissura / mm/min }\end{array}$ & 0,75 a 3,0mm: 0,24 & $\begin{array}{c}0,50 \text { para as } \\
\text { duas etapas }\end{array}$ & $\begin{array}{c}0 \text { a } 0,10 \mathrm{~mm}: 0,05 \\
0,10 \text { a } 4,0 \mathrm{~mm}: 0,20\end{array}$ \\
\hline
\end{tabular}

Apesar da recomendação da norma EN 14651 ser de corpos-de-prova prismáticos de 150 x 150 x 550 $\mathrm{mm}^{3}$ ensaiados com vão de 500mm, os corpos-de-prova moldados para esse ensaio tinham as dimensões de $150 \mathrm{~mm}$ x 150mm x 500mm, devido à padronização brasileira para ensaios de tração na flexão e pela disponibilidade de formas e configurações de cutelos. Daí, o vão de ensaio foi de $450 \mathrm{~mm}$.

Em todos os casos, foi utilizada frequência de aquisição de dados de $50 \mathrm{~Hz}$. Para o ensaio segundo a norma ASTM C1609 que tem duração de 937,5 segundos, por exemplo, a curva carga-deslocamento vertical é composta por, aproximadamente, 47000 pontos.

Os ensaios de compressão foram realizados com a velocidade de aplicação de pressão de $0,45 \mathrm{MPa} / \mathrm{s}$. Foram utilizadas borrachas de neoprene, em conjunto com cápsulas metálicas, nas duas faces axiais do corpo-de-prova, para uniformizar a aplicação de carga. Já nos ensaios de flexão, não foi utilizado nenhum método de regularização da superfície do corpo-de-prova, pois suas faces estavam suficientemente regulares.

Antes de cada ensaio, a altura e a largura dos corpos-de-prova prismáticos e o diâmetro dos corpos-de-prova cilíndricos foram medidos com um paquímetro digital e os valores obtidos foram utilizados para o cálculo das resistências pertinentes a cada corpo-deprova. 


\section{Resultados experimentais}

Neste capítulo, são apresentados e analisados, inicialmente, os resultados da caracterização do concreto fresco, reforçado com a macrofibra de polipropileno (item 6.1). Depois disso, vem a análise dos resultados obtidos com o concreto no estado endurecido, abordando a resistência à compressão (item 6.2), o índice de vazios e a massa específica (item 6.3), que fornecem dados sobre a qualidade do processo de moldagem. Por último, estão apresentados e analisados os resultados dos ensaios de tenacidade e resistência residual, que estão agrupados pelo ensaio realizado (itens 6.4 ao 6.6). Dentro de cada item, estão os resultados obtidos com os concretos reforçados com a macrofibra polimérica e com a fibra de aço. A correlação entre os métodos de ensaio está apresentada no capítulo 7.

Para a análise dos resultados experimentais e a decisão da rejeição dos valores medidos que extrapolam a tendência dominante, utilizou-se o critério de Chauvenet, descrito no apêndice 1.

\subsection{Caracterização do concreto no estado fresco}

Para caracterizar o concreto no estado fresco, foram determinados o abatimento (ABNT, 1998), a massa específica (ABNT, 2008) e o teor de ar incorporado (ABNT, 2005c). As propriedades do estado fresco têm grande influência nos processos de moldagem e nas propriedades do estado endurecido. Por esse motivo, é importante que elas sejam uniformes em todos os traços utilizados. As propriedades medidas estão na tabela 6.1. Como pode ser visto, houve uma redução do abatimento com o aumento do teor de fibra. Isto ocorre pelo fato da fibra prejudicar a mobilidade dos agregados e adsorver água em sua superfície. A consequência disso é a redução da fluidez do compósito para baixos níveis de taxa de cisalhamento. 
Tabela 6.1 - Características físicas dos concretos frescos.

\begin{tabular}{|c|c|c|c|c|}
\hline Traço & $\begin{array}{c}\text { Dosagem de fibra } / \mathrm{kg} / \mathrm{m}^{3} \\
(\% \text { em volume })\end{array}$ & $\begin{array}{c}\text { Abatimento / } \\
\text { mm }\end{array}$ & $\begin{array}{c}\text { Massa específica / } \\
\mathrm{kg} / \mathrm{m}^{3}\end{array}$ & $\begin{array}{c}\text { Ar incorporado } / \\
\%\end{array}$ \\
\hline CS 30 & - & 120 & 2251 & 3,4 \\
\hline \multirow{6}{*}{ CRF 30 / PP } & $2,0(0,22)$ & 80 & 2251 & 3,9 \\
\hline & $3,0(0,33)$ & 65 & 2244 & 3,9 \\
\hline & $4,5(0,50)$ & 50 & 2249 & 3,9 \\
\hline & $6,0(0,66)$ & 40 & 2256 & 4,2 \\
\hline & $7,5(0,82)$ & 30 & 2217 & 4,4 \\
\hline & $9,0(1,0)$ & 25 & 2221 & 4,2 \\
\hline CS 35 & - & 120 & 2287 & 3,2 \\
\hline \multirow{6}{*}{ CRF 35 / PP } & $2,0(0,22)$ & 75 & 2288 & 3,2 \\
\hline & $3,0(0,33)$ & 65 & 2311 & 3,0 \\
\hline & $4,5(0,50)$ & 50 & 2278 & 3,2 \\
\hline & $6,0(0,66)$ & 30 & 2300 & 2,8 \\
\hline & $7,5(0,82)$ & 25 & 2311 & 1,0 \\
\hline & $9,0(1,0)$ & 35 & 2315 & 2,2 \\
\hline $\mathrm{CS} 40$ & - & 120 & 2305 & 2,6 \\
\hline \multirow{6}{*}{ CRF 40 / PP } & $2,0(0,22)$ & 75 & 2261 & 4,4 \\
\hline & $3,0(0,33)$ & 70 & 2269 & 4,2 \\
\hline & $4,5(0,50)$ & 55 & 2305 & 1,8 \\
\hline & $6,0(0,66)$ & 35 & 2332 & 1,4 \\
\hline & $7,5(0,82)$ & 25 & 2340 & 1,4 \\
\hline & $9,0(1,0)$ & 20 & 2320 & 2,2 \\
\hline \multirow{3}{*}{ CRF 35 / AÇO } & $15,0(0,19)$ & 55 & 2317 & 2,7 \\
\hline & $25,0(0,32)$ & 80 & 2227 & 3,4 \\
\hline & $35,0(0,45)$ & 50 & 2330 & 2,4 \\
\hline
\end{tabular}

Para melhor visualização do efeito do teor de fibras no abatimento do concreto fresco, essas duas variáveis foram plotadas no gráfico 6.1. A regressão foi feita a partir do valor médio do abatimento dos três traços de concreto. Pode-se considerar que o aumento do teor de fibra promove a mesma redução de abatimento, independentemente do traço utilizado. 


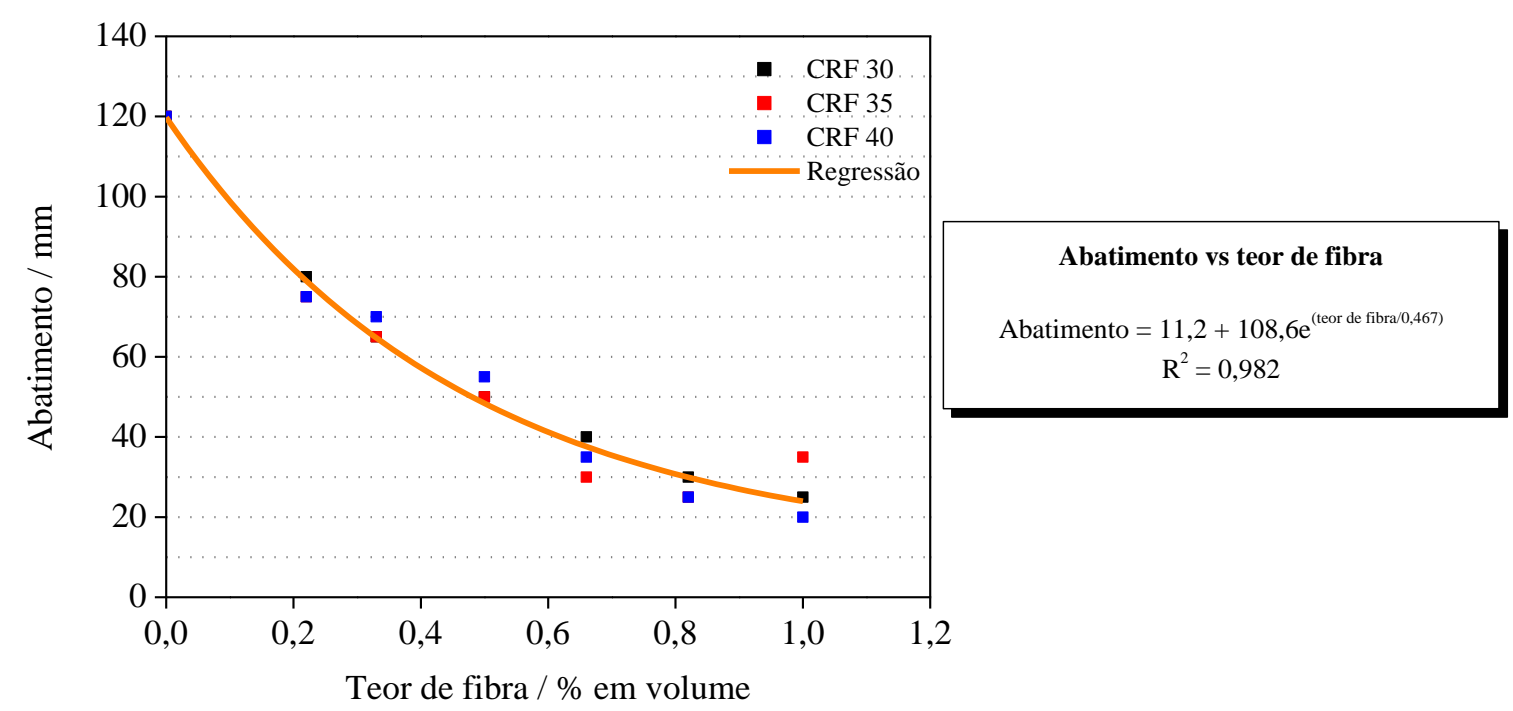

Gráfico 6.1 - Variação do abatimento dos concretos frescos com o aumento do teor de fibra.

No entanto, como demonstrado por Ceccato e Figueiredo (1999), uma vez utilizada a vibração, se recupera boa parte da mobilidade e da capacidade de compactação do material quando baixos teores de fibras (abaixo de $1 \%$ em volume) são utilizados. Isto é corroborado pela uniformidade dos resultados de ar incorporado e pela baixa variação entre os lotes produzidos em termos de resistência à compressão, o que é mais bem analisado no item 6.2. Isto garantiu as condições de comparação dos diferentes compósitos.

\subsection{Determinação da resistência à compressão}

Os resultados médios de resistência à compressão da primeira série de ensaios (ASTM C1609 e ASTM C1399) e da segunda (EN 14651) estão mostrados na tabela 6.2 e 6.3 , respectivamente.

De acordo com os dados obtidos, verifica-se que houve baixa variação entre os resultados. Com os concretos utilizados, a resistência à compressão é praticamente independente do teor de fibra. Tal fato já era esperado e corrobora com dados presentes na literatura (ARMELIN, 1992; BANTHIA; DUBEY, 2000; di PRISCO; PLIZZARI; VANDEWALLE, 2010). As resistências médias à compressão dos traços CRF 30, CRF 35 e CRF 40 com a macrofibra de polipropileno foram $(30,6 \pm 1,3),(36,8 \pm 1,5)$ e $(39,3 \pm 2,2)$, respectivamente. Assim, foram atingidos os valores médios previstos para este programa 
experimental. Com a fibra de aço, houve maior desvio padrão dentro do ensaio devido à maior dificuldade de moldagem dos corpos-de-prova com a fibra rígida.

Tabela 6.2 - Resultados de resistência à compressão obtidos com a primeira série de ensaios (ASTM C1609 e ASTM C1399), com os traços CRF 30 / PP, CRF 35 / PP, CRF 40 / PP e CRF 35 / AÇO.

\begin{tabular}{|c|c|c|}
\hline Traço & $\begin{array}{c}\text { Dosagem de fibra } / \mathrm{kg} / \mathrm{m}^{3} \\
(\% \text { em volume })\end{array}$ & $\mathbf{f}_{\mathrm{cm}} / \mathbf{M P a}$ \\
\hline \multirow{6}{*}{ CRF 30 / PP } & $2,0(0,22)$ & $31,9 \pm 0,5$ \\
\hline & $3,0(0,33)$ & $28,5 \pm 0,2$ \\
\hline & $4,5(0,50)$ & $30,9 \pm 0,4$ \\
\hline & $6,0(0,66)$ & $31,3 \pm 1,0$ \\
\hline & $7,5(0,82)$ & $30,5 \pm 0,3$ \\
\hline & $9,0(1,0)$ & $28,7 \pm 1,0$ \\
\hline \multirow{6}{*}{ CRF 35 / PP } & $2,0(0,22)$ & $38,3 \pm 1,0$ \\
\hline & $3,0(0,33)$ & $37,7 \pm 0,5$ \\
\hline & $4,5(0,50)$ & $34,3 \pm 0,2$ \\
\hline & $6,0(0,66)$ & $34,8 \pm 0,2$ \\
\hline & $7,5(0,82)$ & $36,8 \pm 0,4$ \\
\hline & $9,0(1,0)$ & $36,6 \pm 0,4$ \\
\hline \multirow{6}{*}{ CRF 40 / PP } & $2,0(0,22)$ & $36,8 \pm 0,6$ \\
\hline & $3,0(0,33)$ & $36,3 \pm 0,6$ \\
\hline & $4,5(0,50)$ & $39,3 \pm 0,3$ \\
\hline & $6,0(0,66)$ & $40,9 \pm 0,6$ \\
\hline & $7,5(0,82)$ & $42,7 \pm 0,7$ \\
\hline & $9,0(1,0)$ & $40,9 \pm 0,8$ \\
\hline \multirow{3}{*}{ CRF 35 / AÇO } & $15,0(0,19)$ & $38,8 \pm 0,6$ \\
\hline & $25,0(0,32)$ & $36,1 \pm 1,0$ \\
\hline & $35,0(0,45)$ & $36,5 \pm 1,3$ \\
\hline
\end{tabular}

Tabela 6.3 - Resultados de resistência à compressão obtidos com a segunda série de ensaios (EN 14651), com os traços CRF 35 / PP e CRF 35 / AÇO.

\begin{tabular}{ccc}
\hline Traço & $\begin{array}{c}\text { Dosagem de fibra / } \mathbf{~ k g} / \mathbf{m}^{3} \\
\text { (\% em volume) }\end{array}$ & $\mathbf{f}_{\mathbf{c m}} / \mathbf{M p a}$ \\
\hline \multirow{3}{*}{ CRF 35 / PP } & $3,0(0,33)$ & $33,4 \pm 0,3$ \\
\cline { 2 - 3 } & $4,5(0,50)$ & $34,1 \pm 0,7$ \\
\cline { 2 - 3 } & $6,0(0,66)$ & $33,3 \pm 0,1$ \\
\hline \multirow{3}{*}{ CRF 35 / AÇO } & $15,0(0,19)$ & $35,5 \pm 0,2$ \\
\cline { 2 - 3 } & $25,0(0,32)$ & $32,1 \pm 0,5$ \\
\cline { 2 - 3 } & $35,0(0,45)$ & $32,9 \pm 0,3$ \\
\hline
\end{tabular}




\subsection{Determinação da absorção de água, índice de vazios e massa específica}

Com o intuito de avaliar se a presença de fibras altera a capacidade de compactação da matriz, foi realizado o ensaio de imersão e fervura, para a determinação da absorção de água, do índice de vazios e da massa específica dos concretos reforçados com a macrofibra polimérica, segundo a norma ABNT NBR 9778 (2005b).

Para esse ensaio, foram utilizadas duas amostras de cada traço, correspondentes às frações geradas nos rompimentos dos corpos-de-prova prismáticos de $100 \mathrm{~mm}$ x $100 \mathrm{~mm}$ x $400 \mathrm{~mm}$. Foram selecionadas amostras de tamanho semelhante (de dimensões aproximadas da metade desse corpo-de-prova, ou seja, de 100mm x 100mm x 200mm). Antes da realização desse ensaio, as superfícies dos corpos-de-prova foram lavadas para remover resquícios do desmoldante e fragmentos que poderiam se desprender durante o ensaio.

Os resultados médios de cada traço encontram-se na tabela 6.4. Analisando-se os dados obtidos, conclui-se que, independentemente do teor de fibras utilizado, a capacidade de compactação das três matrizes não foi prejudicada, indicando que o método de adensamento utilizado foi adequado. Além disso, variações no abatimento não significam, necessariamente, que haverá prejuízo à compactação. Os concretos de maior resistência (maior consumo de cimento) apresentam menores índices de vazios, visto que há um maior preenchimento dos poros da matriz pelos produtos da reação de hidratação do cimento. Esse ensaio foi realizado com corpos-de-prova moldados em laboratório e, portanto, essa avaliação merece ser realizada de maneira mais ampla em condições de campo. 
Tabela 6.4 - Resultados obtidos segundo ABNT NBR 9778 (2005b).

\begin{tabular}{|c|c|c|c|c|c|c|}
\hline Traço & $\begin{array}{l}\text { Dosagem de } \\
\text { fibra } / \mathrm{kg} / \mathrm{m}^{3}\end{array}$ & $\begin{array}{c}\text { Absorção / } \\
\%\end{array}$ & $\begin{array}{l}\text { Índice de } \\
\text { vazios / \% }\end{array}$ & $\begin{array}{c}\mathbf{M}_{\text {espec seca }} / \\
\mathbf{g} / \mathbf{c m}^{3}\end{array}$ & $\underset{\mathbf{g}_{\text {espec sat }}}{\mathbf{c}^{3}} /$ & $\begin{array}{c}\mathbf{M}_{\text {espec real }} / \\
\mathbf{g} / \mathbf{c m}^{3}\end{array}$ \\
\hline \multirow{6}{*}{ CRF 30 / PP } & 2,0 & 6,58 & 0,14 & 2,16 & 2,30 & 2,52 \\
\hline & 3,0 & 6,82 & 0,15 & 2,16 & 2,30 & 2,53 \\
\hline & 4,5 & 6,91 & 0,15 & 2,16 & 2,31 & 2,54 \\
\hline & 6,0 & 6,76 & 0,15 & 2,19 & 2,34 & 2,57 \\
\hline & 7,5 & 6,75 & 0,15 & 2,18 & 2,32 & 2,55 \\
\hline & 9,0 & 6,89 & 0,15 & 2,17 & 2,32 & 2,56 \\
\hline \multirow{6}{*}{ CRF 35 / PP } & 2,0 & 6,49 & 0,14 & 2,18 & 2,32 & 2,54 \\
\hline & 3,0 & 6,44 & 0,14 & 2,19 & 2,34 & 2,56 \\
\hline & 4,5 & 6,58 & 0,14 & 2,17 & 2,31 & 2,53 \\
\hline & 6,0 & 6,42 & 0,14 & 2,19 & 2,33 & 2,55 \\
\hline & 7,5 & 6,79 & 0,15 & 2,17 & 2,32 & 2,54 \\
\hline & 9,0 & 6,33 & 0,14 & 2,21 & 2,35 & 2,57 \\
\hline \multirow{6}{*}{ CRF 40 / PP } & 2,0 & 6,13 & 0,13 & 2,17 & 2,30 & 2,50 \\
\hline & 3,0 & 6,20 & 0,13 & 2,17 & 2,30 & 2,50 \\
\hline & 4,5 & 6,14 & 0,14 & 2,20 & 2,34 & 2,55 \\
\hline & 6,0 & 6,17 & 0,14 & 2,21 & 2,34 & 2,56 \\
\hline & 7,5 & 6,10 & 0,14 & 2,22 & 2,35 & 2,56 \\
\hline & 9,0 & 6,15 & 0,14 & 2,22 & 2,35 & 2,57 \\
\hline
\end{tabular}

\subsection{Resultados obtidos com o ensaio da norma ASTM C1609 e do método JSCE-SF4}

Para cada traço, foram moldados 10 corpos-de-prova prismáticos de $150 \mathrm{~mm}$ x $150 \mathrm{~mm}$ x 500mm para o ensaio de flexão. Para cada corpo-de-prova foi obtida uma curva de carga por deslocamento vertical e para cada conjunto de corpos-de-prova do mesmo traço foi calculado seu valor médio. Os gráficos 6.2, 6.3 e 6.4 apresentam as curvas para os concretos CRF 30, CRF 35 e CRF 40, respectivamente, reforçados com a macrofibra polimérica nas dosagens de $2,0,3,0,4,5,6,0,7,5$ e $9,0 \mathrm{~kg} / \mathrm{m}^{3}$. O gráfico 6.5 apresenta as curvas para o concreto CRF 35 reforçado com a fibra de aço nas dosagens de $15,0,25,0$ e $35,0 \mathrm{~kg} / \mathrm{m}^{3}$. O gráfico 6.6 apresenta as curvas médias para os três traços de concreto reforçado com a macrofibra polimérica e do traço CRF 35 reforçado com a fibra de aço.

Pode ser observado que houve uma baixa variabilidade nos resultados e o comportamento apresentado nas curvas é bem uniforme, sem os sinais de instabilidade pós- 
pico. Além disso, verifica-se que as fibras acabam por alterar somente a resistência residual pós-fissuração, com pouca influência na carga de pico, como era esperado, dado que se está trabalhando abaixo do volume crítico de fibras (FIGUEIREDO, 2011).

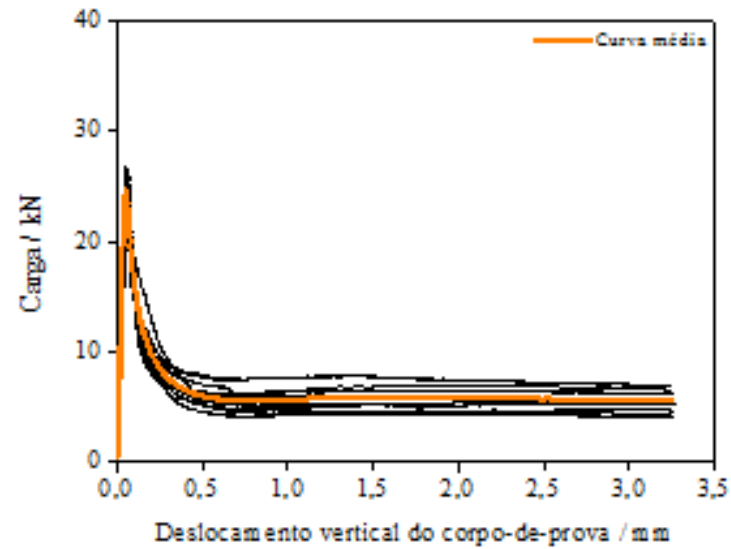

(a)

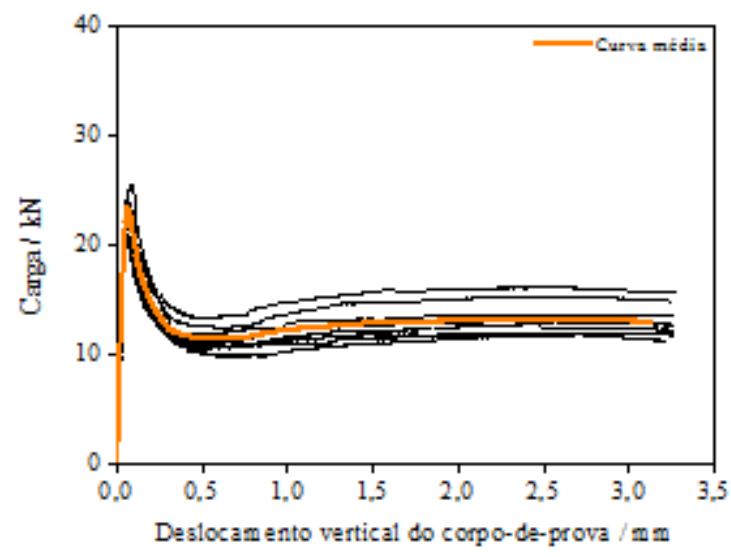

(c)

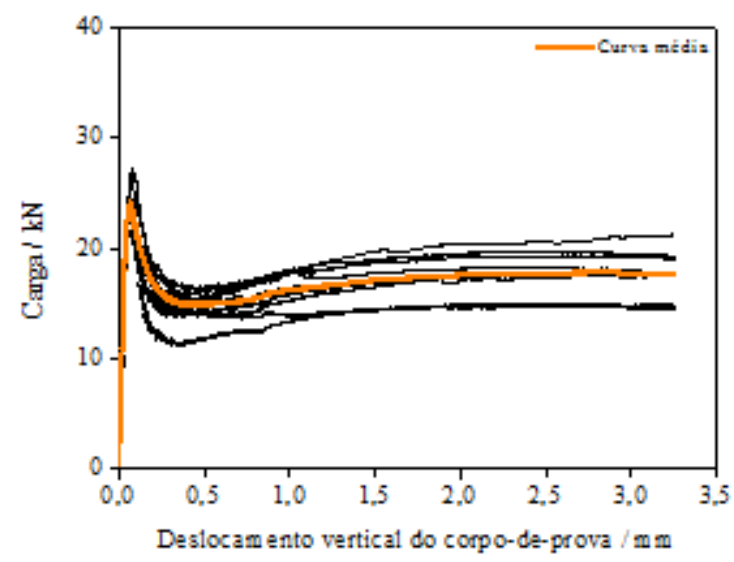

(e)

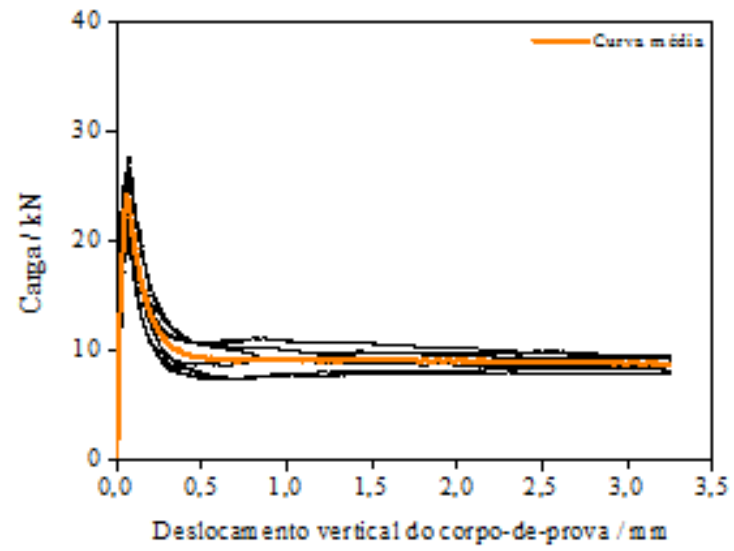

(b)

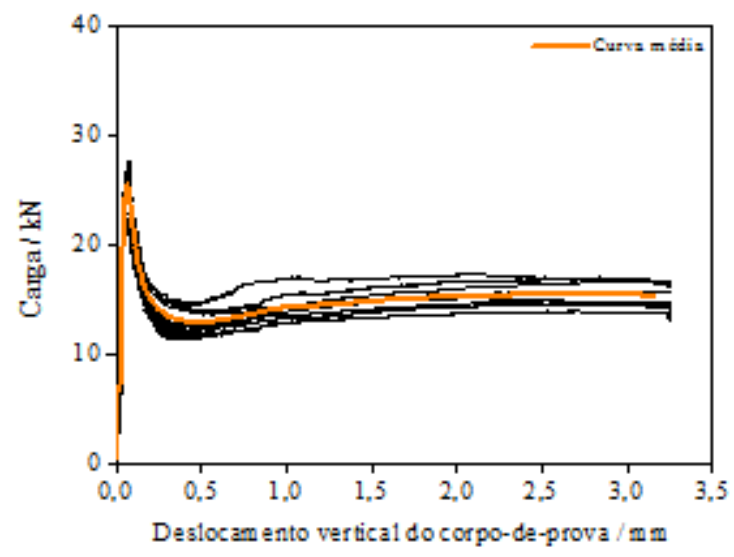

(d)

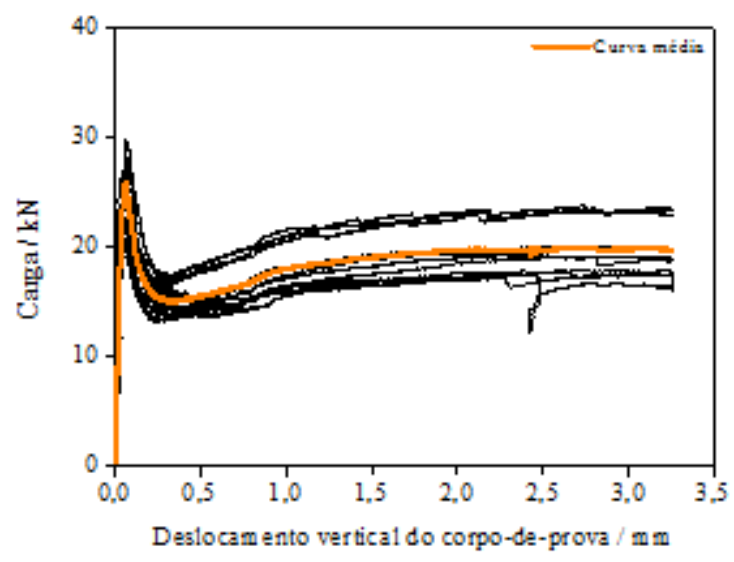

(f)

Gráfico 6.2 - Curvas de carga por deslocamento vertical obtidas com o traço CRF 30, utilizando-se a macrofibra polimérica, segundo ASTM C1609: (a) $2,0 \mathrm{~kg} / \mathrm{m}^{3}$; (b) $3,0 \mathrm{~kg} / \mathrm{m}^{3}$; (c) $4,5 \mathrm{~kg} / \mathrm{m}^{3}$; (d) $6,0 \mathrm{~kg} / \mathrm{m}^{3}$; (e) $7,5 \mathrm{~kg} / \mathrm{m}^{3}$; (f) $9,0 \mathrm{~kg} / \mathrm{m}^{3}$. 


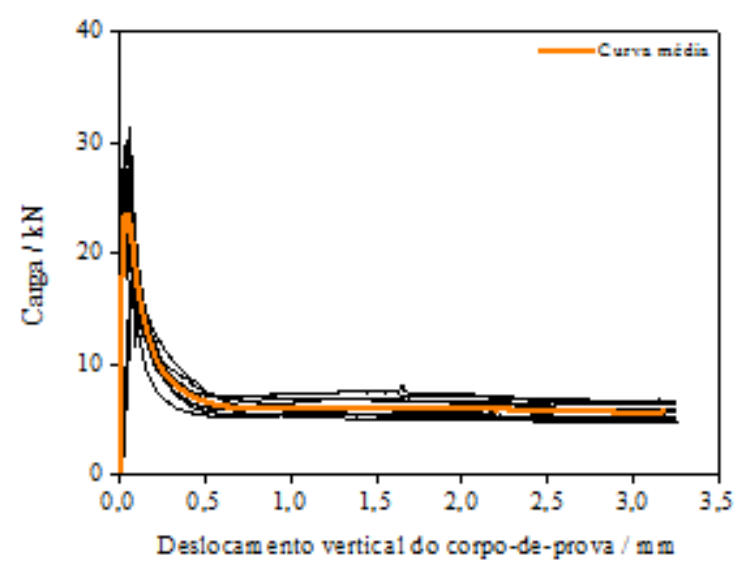

(a)

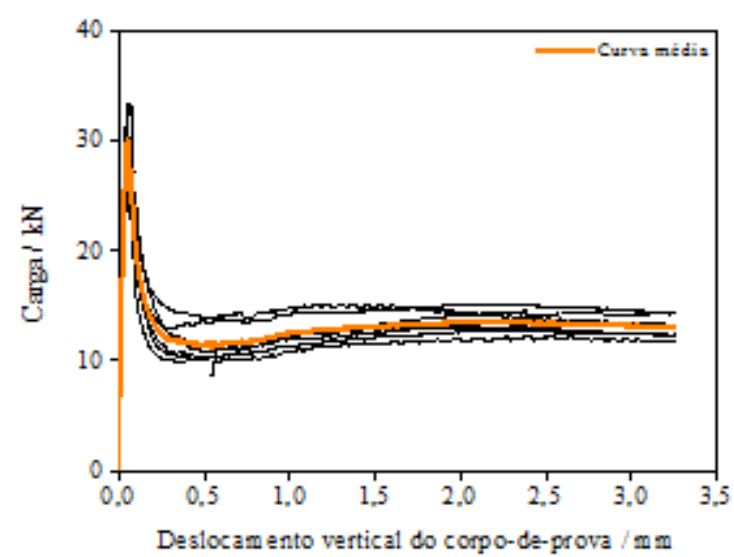

(c)

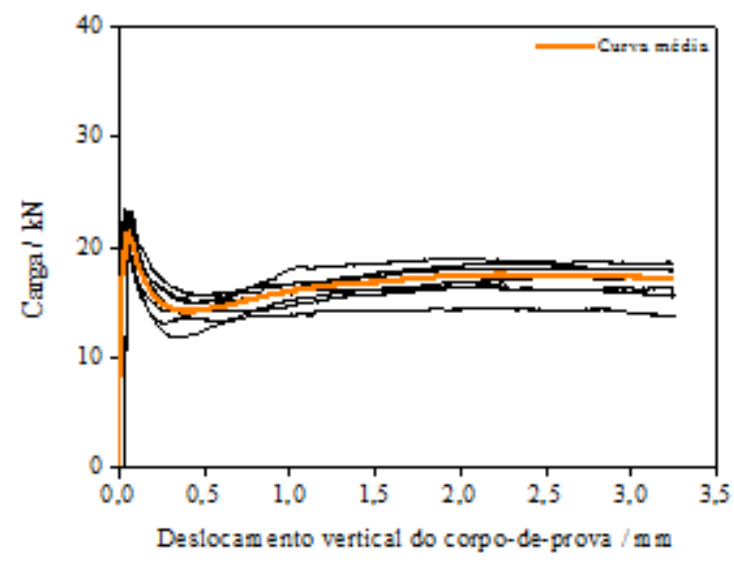

(e)

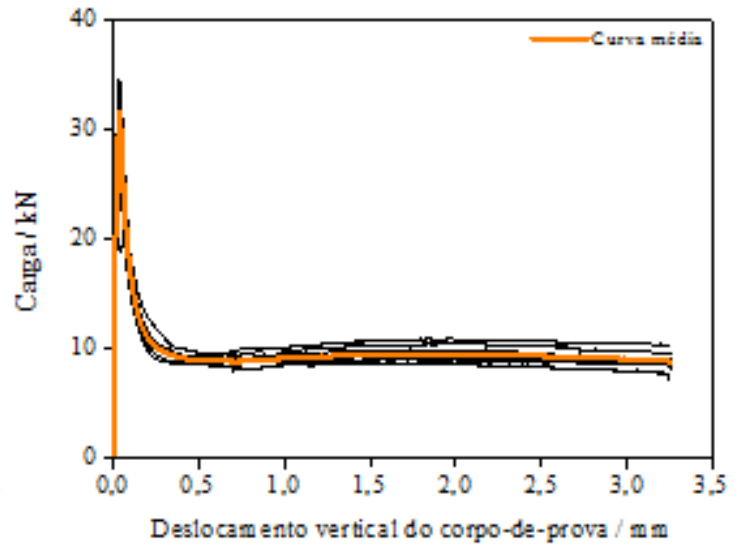

(b)

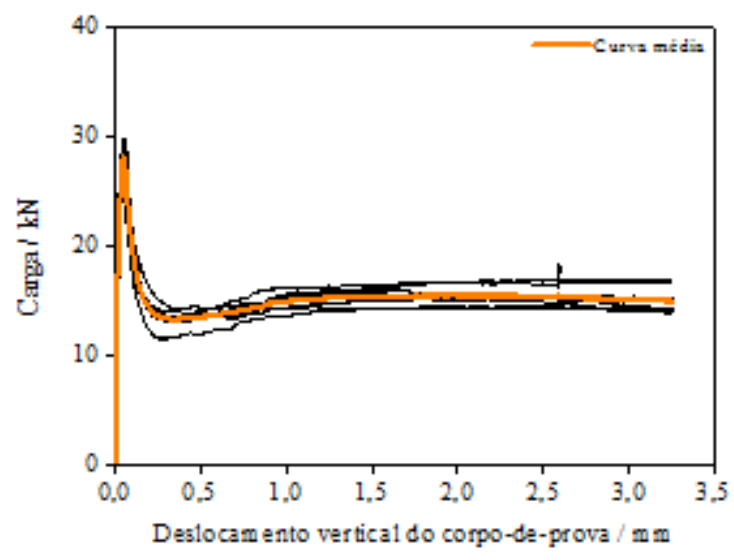

(d)

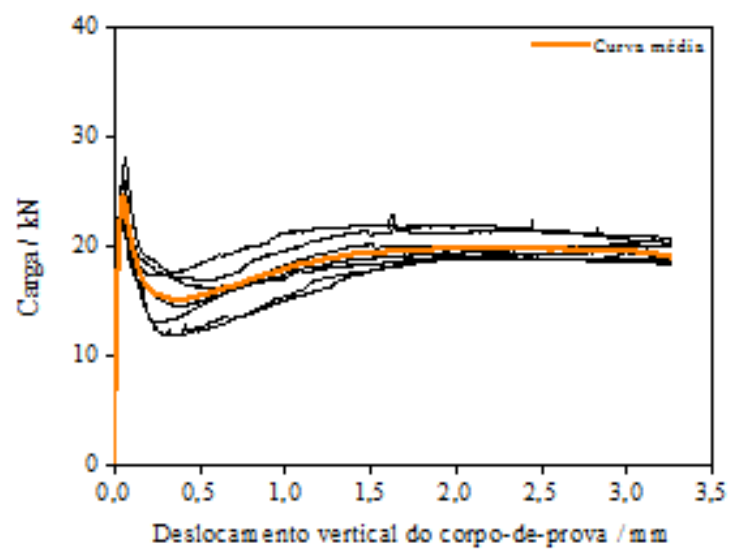

(f)

Gráfico 6.3 - Curvas de carga por deslocamento vertical obtidas com o traço CRF 35, utilizando-se a macrofibra polimérica, segundo ASTM C1609: (a) $2,0 \mathrm{~kg} / \mathrm{m}^{3} ;$ (b) $3,0 \mathrm{~kg} / \mathrm{m}^{3}$; (c) $4,5 \mathrm{~kg} / \mathrm{m}^{3}$; (d) $6,0 \mathrm{~kg} / \mathrm{m}^{3}$; (e) $7,5 \mathrm{~kg} / \mathrm{m}^{3}$; (f) $9,0 \mathrm{~kg} / \mathrm{m}^{3}$. 


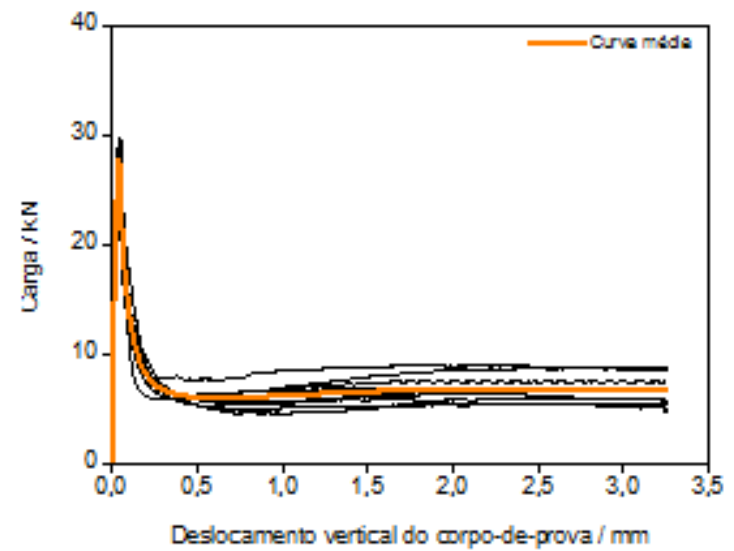

(a)

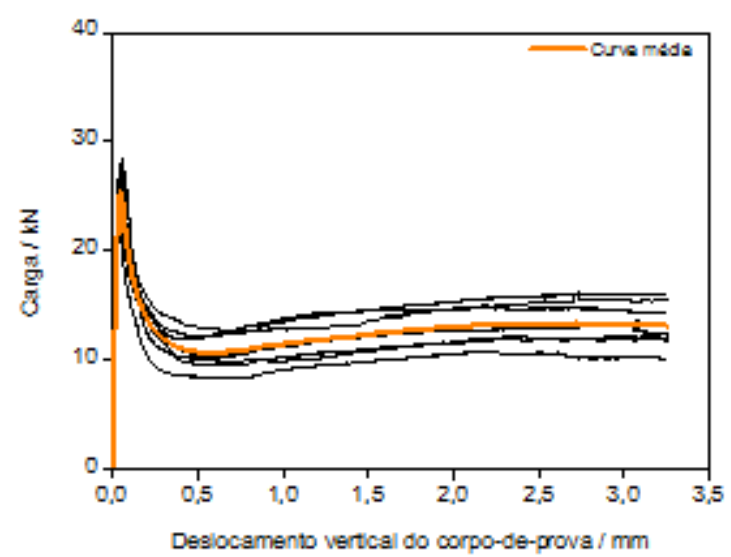

(c)

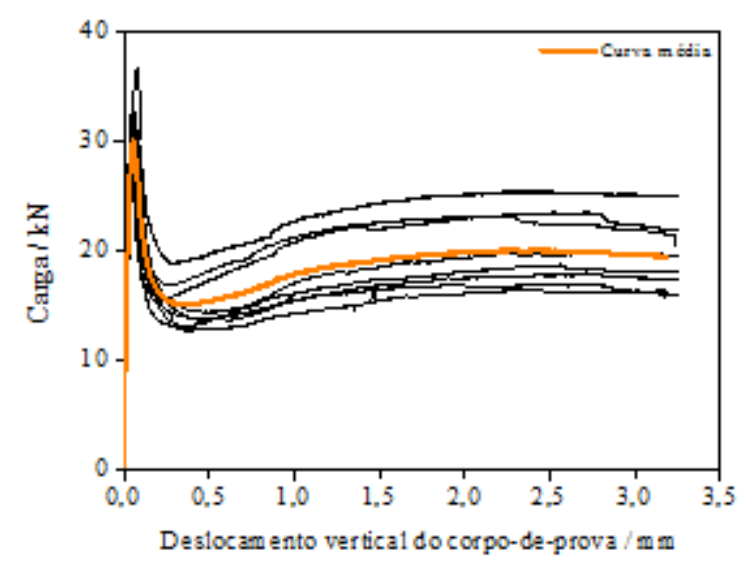

(e)

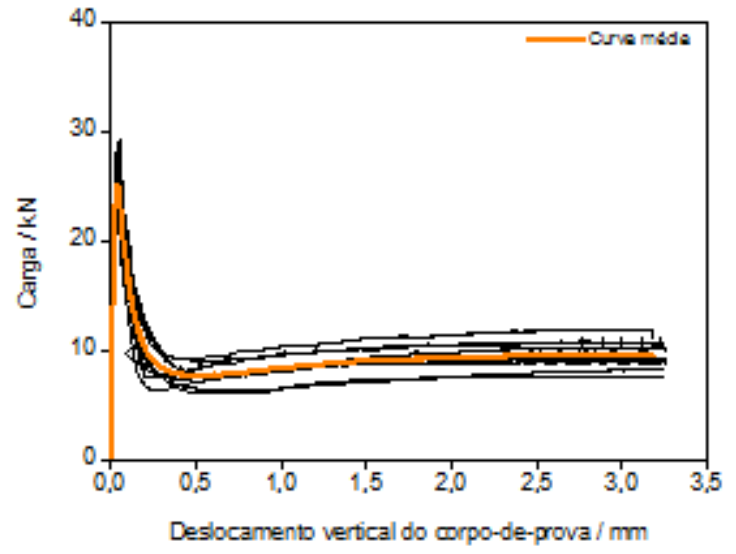

(b)

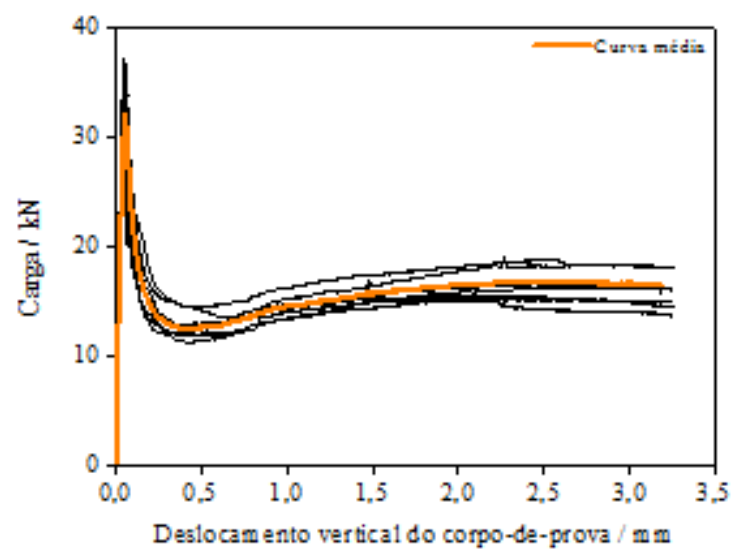

(d)

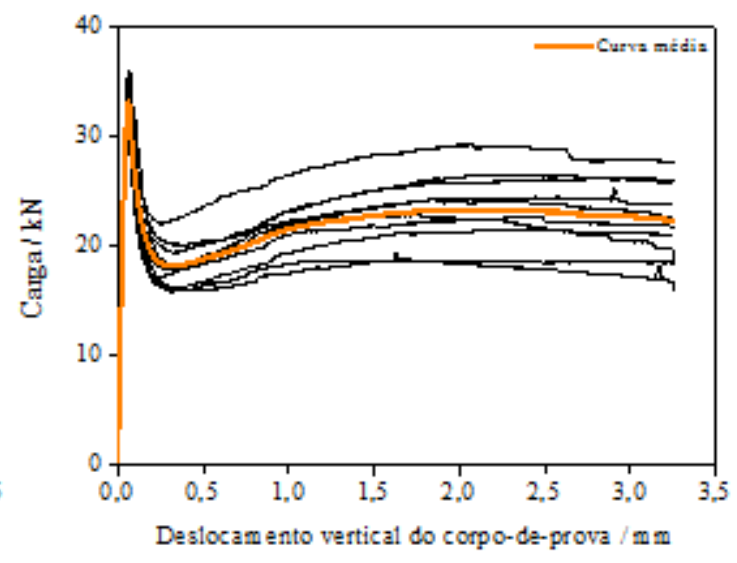

(f)

Gráfico 6.4 - Curvas de carga por deslocamento vertical obtidas com o traço CRF 40, utilizando-se a macrofibra polimérica, segundo ASTM C1609: (a) $2,0 \mathrm{~kg} / \mathrm{m}^{3}$; (b) $3,0 \mathrm{~kg} / \mathrm{m}^{3}$; (c) $4,5 \mathrm{~kg} / \mathrm{m}^{3}$; (d) $6,0 \mathrm{~kg} / \mathrm{m}^{3}$; (e) $7,5 \mathrm{~kg} / \mathrm{m}^{3}$; (f) $9,0 \mathrm{~kg} / \mathrm{m}^{3}$. 


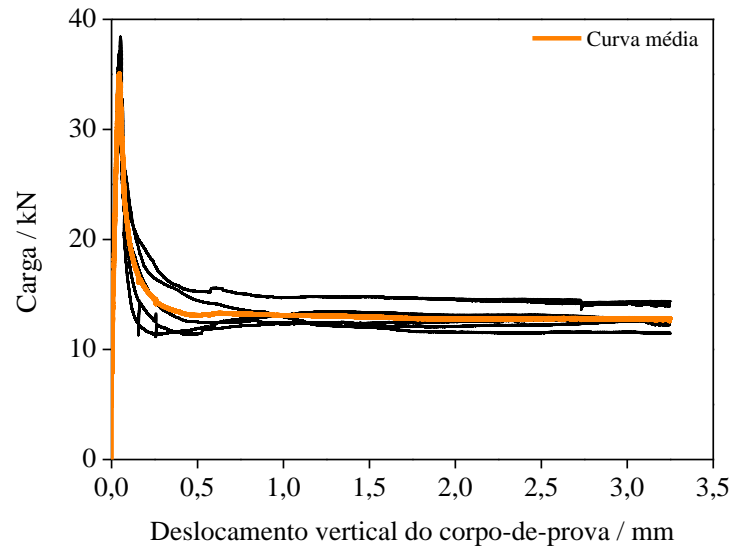

(a)

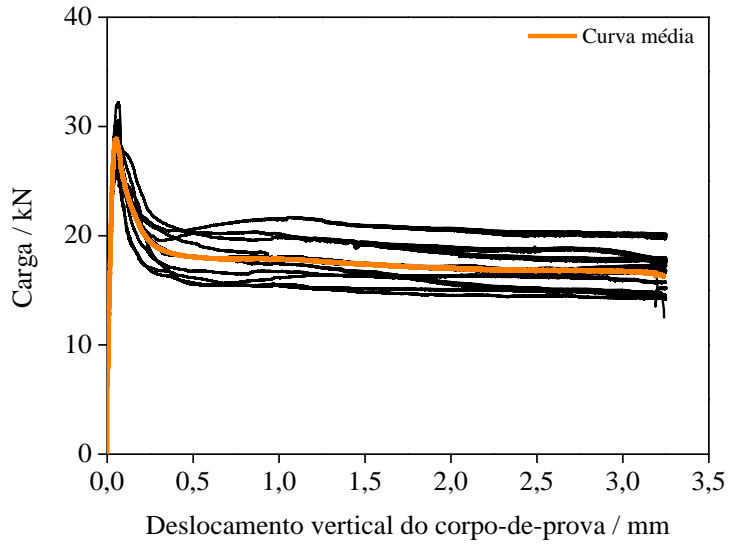

(b)

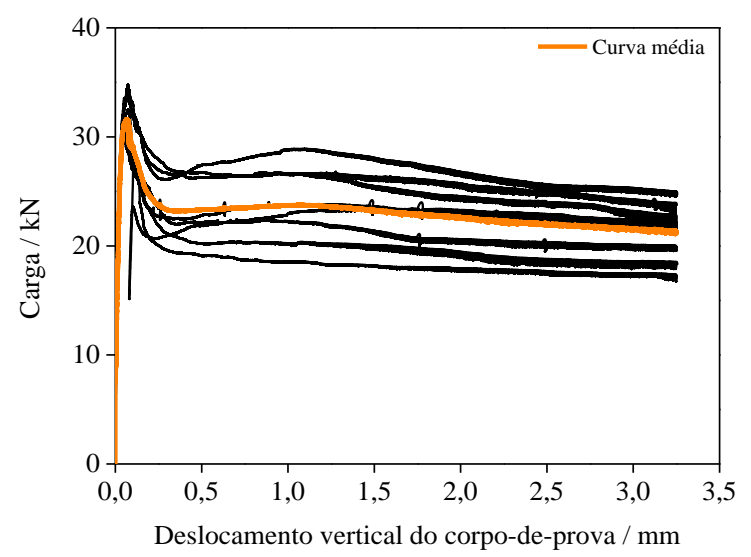

(c)

Gráfico 6.5 - Curvas de carga por deslocamento vertical obtidas com o traço CRF 35, utilizando-se a fibra de aço, segundo ASTM C1609: (a) $15,0 \mathrm{~kg} / \mathrm{m}^{3}$; (b) $25,0 \mathrm{~kg} / \mathrm{m}^{3}$; (c) $35,0 \mathrm{~kg} / \mathrm{m}^{3}$. 


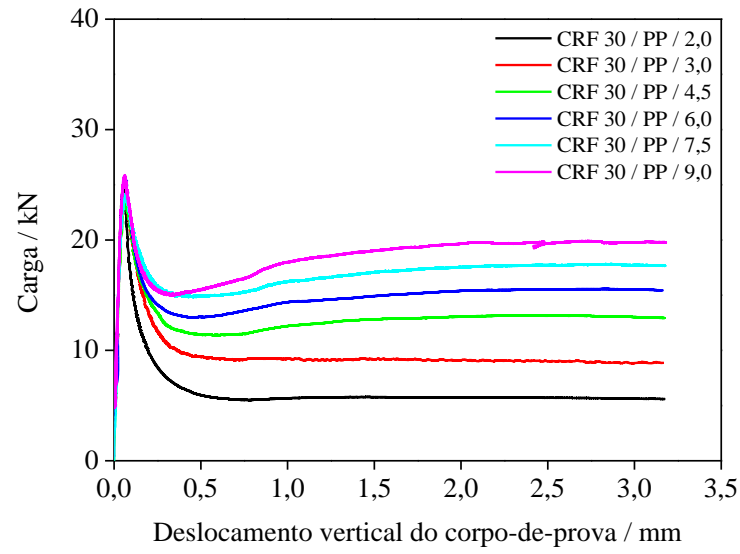

(a)

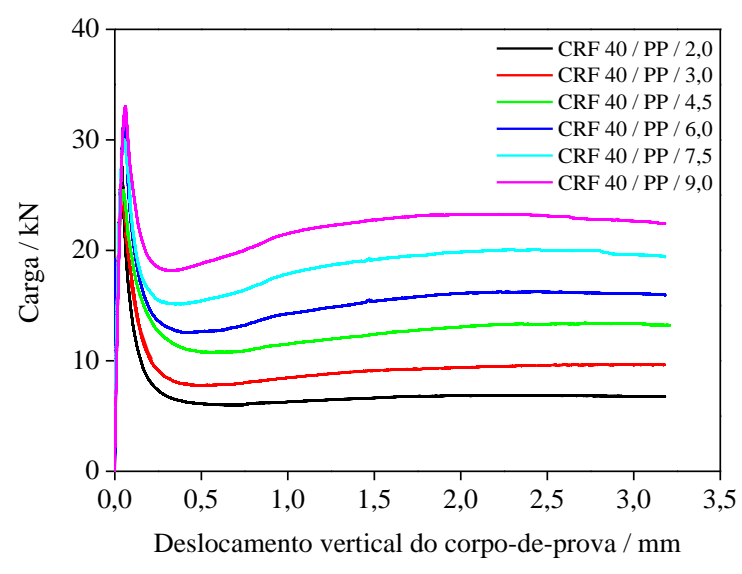

(c)

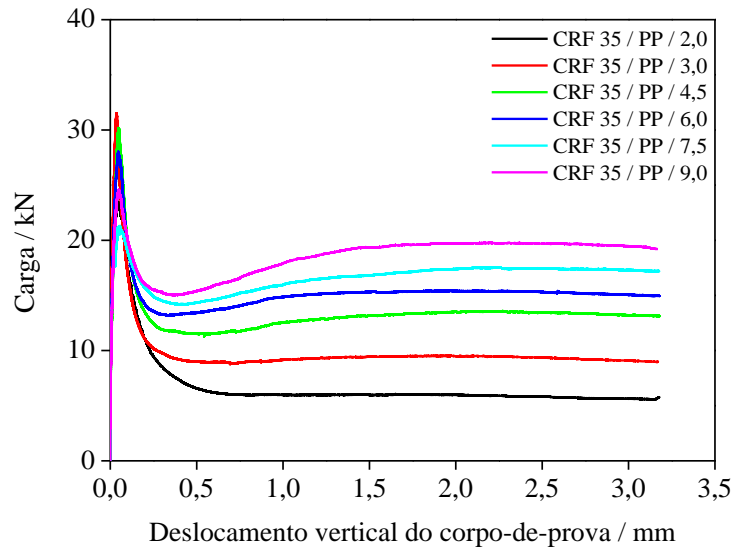

(b)

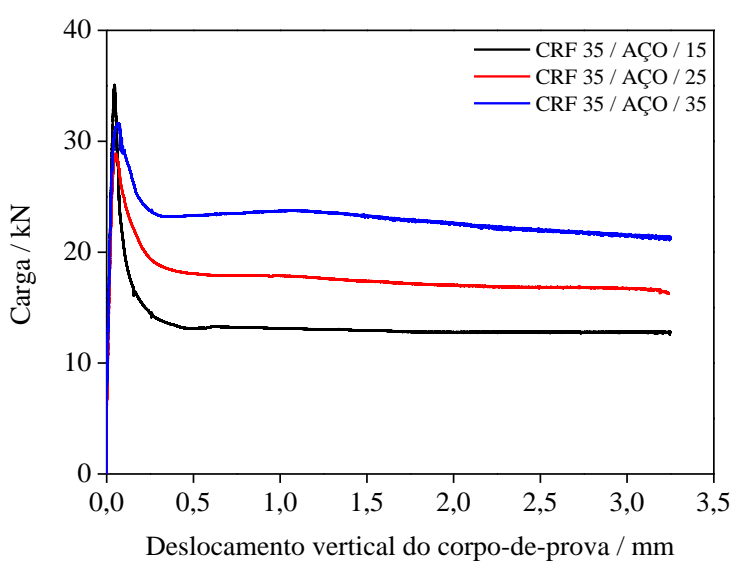

(d)

Gráfico 6.6 - Curvas médias de carga por deslocamento vertical obtidas segundo ASTM C1609: (a) CRF 30, (b) CRF 35 e (c) CRF 40, com a macrofibra polimérica; (d) CRF 35, com a fibra de aço.

Em cada gráfico acima, verifica-se que a resposta elástica inicial, compreendida no intervalo entre 0 e $0,04 \mathrm{~mm}$ de deslocamento vertical, é praticamente inalterada pela adição das fibras, independentemente da dosagem utilizada (FIGUEIREDO, 2011a). Em todos os casos, a ruptura ocorreu devido à apenas uma fissura discreta (não foi verificada a formação de múltiplas fissuras), que apresentou propagação estável.

Tratando-se especificamente do momento que sucede o rompimento da matriz, verifica-se que não ocorreu instabilidade, mesmo para as menores dosagens de fibra. Devido à utilização do sistema fechado de controle de velocidade de deslocamento e à alta rigidez do equipamento, o deslocamento abrupto do corpo-de-prova e, consequentemente, o do LVDT, no momento de ruptura da matriz, foi evitado. Portanto, a curva obtida pode ser considerada como uma resposta precisa e estável, pois o comportamento pós-fissuração apresentado pelo 
compósito imediatamente após a carga de pico não está deturpado pela instabilidade do equipamento durante a realização do ensaio (GOPALARATNAM; GETTU, 1995).

Pode ser observado que a carga residual aumenta com o consumo de fibras, como esperado. Devido ao baixo volume de fibras utilizado (abaixo do volume crítico), os concretos reforçados com a macrofibra polimérica e com a fibra de aço apresentaram o comportamento de deflection-softening (NAAMAN, 2003c). Como o módulo de elasticidade da fibra e sua aderência na matriz influenciam a resposta pós-fissuração, o comportamento mecânico de concretos reforçados com macrofibras poliméricas ou com fibras de aço tende a ser bastante distinto (KIM; NAAMAN; EL-TAWIL, 2008).

No caso das fibras de aço, a ancoragem mecânica na matriz é controlada principalmente pela aderência entre a fibra e a matriz e pelas deformações que existem em suas extremidades. As fibras, quando utilizadas em teores abaixo do volume crítico, sofrem um deslizamento quando a carga é transferida para elas. Nesse momento, apresentam capacidade resistente inferior à carga resistida pela matriz no momento de sua fissuração. A recuperação da capacidade de absorção de energia é alcançada quando a ancoragem é mobilizada e é mais intensa para os menores níveis de deformação (ARAKAKI; FIGUEIREDO, 2000; di PRISCO; PLIZZARI; VANDEWALLE, 2010).

Para a macrofibra polimérica, a queda inicial na absorção de energia é mais pronunciada e ocorre em um intervalo de deslocamento maior, devido ao seu baixo módulo de elasticidade. Por esse motivo, as fibras poliméricas têm menor capacidade de absorção de energia para pequenas deformações (região que sucede a carga de pico), quando comparadas às fibras de aço (FIGUIREDO, 2011a). Entretanto, para grandes aberturas de fissuras, a energia absorvida pelas fibras poliméricas tende a ser maior que a energia absorvida para baixas aberturas de fissuras, devido ao seu comportamento de slip-hardening, que acontece principalmente com teores acima de $4,5 \mathrm{~kg} / \mathrm{m}^{3}$ (LIN; LI, 1997).

Esse comportamento, conforme descrito no item 3.3.1, ocorre devido ao atrito na superfície da fibra, que promove um aumento de sua superfície de contato com a matriz. Devido à baixa dureza das fibras poliméricas, a abrasão ocorre quando estas começam a deslizar, devido ao atrito gerado na interface com a matriz. Com isso, a energia necessária para o arrancamento da macrofibra polimérica, para grandes aberturas de fissura, é maior, devido à maior tensão que existe na interface (LIN; LI, 1997).

A partir da análise das curvas experimentais, foram calculados o módulo de ruptura (MOR), o fator de tenacidade à flexão $\left(\overline{\sigma_{b}}\right)$, e as resistências residuais nos deslocamentos 
verticais de $0,75 \mathrm{~mm}\left(\mathrm{f}_{150,0.75}\right)$ e $3,0 \mathrm{~mm}\left(\mathrm{f}_{150,3.0}\right)$, segundo as equações (4.1), (4.2), (4.3) e (4.4), respectivamente. Os resultados estão apresentados na tabela 6.5. Chama a atenção o nível muito baixo de variação dos resultados, que ficaram bem abaixo dos $30 \%$ de coeficiente de variação apresentados pela literatura como esperados para este tipo de ensaio (MINDESS; CHEN; MORGAN, 1994).

Tabela 6.5 - Resultados obtidos com as curvas carga por deslocamento vertical dos traços CRF 30 / PP, CRF 35 / PP, CRF 40 / PP e CRF 35 / AÇO, segundo ASTM C1609.

\begin{tabular}{|c|c|c|c|c|c|}
\hline Traço & $\begin{array}{c}\text { Dosagem de fibra / } \\
\mathrm{kg} / \mathrm{m}^{3}(\% \text { em volume })\end{array}$ & MOR / MPa & $\overline{\sigma_{b}} / \mathbf{M P a}$ & $\mathbf{f}_{150,0.75} / \mathbf{M P a}$ & $\mathbf{f}_{150,3.0} / \mathrm{MPa}$ \\
\hline \multirow{6}{*}{ CRF 30 / PP } & $2,0(0,22)$ & $3,46 \pm 0,14$ & $0,903 \pm 0,116$ & $0,747 \pm 0,14$ & $0,764 \pm 0,117$ \\
\hline & $3,0(0,33)$ & $3,37 \pm 0,33$ & $1,35 \pm 0,14$ & $1,24 \pm 0,20$ & $1,19 \pm 0,09$ \\
\hline & $4,5(0,50)$ & $3,18 \pm 0,20$ & $1,77 \pm 0,19$ & $1,53 \pm 0,17$ & $1,78 \pm 0,24$ \\
\hline & $6,0(0,66)$ & $3,58 \pm 0,12$ & $2,06 \pm 0,13$ & $1,84 \pm 0,16$ & $2,10 \pm 0,14$ \\
\hline & $7,5(0,82)$ & $3,36 \pm 0,16$ & $2,29 \pm 0,24$ & $2,05 \pm 0,24$ & $2,37 \pm 0,26$ \\
\hline & $9,0(1,0)$ & $3,59 \pm 0,21$ & $2,49 \pm 0,28$ & $2,21 \pm 0,27$ & $2,63 \pm 0,34$ \\
\hline \multirow{6}{*}{ CRF 35 / PP } & $2,0(0,22)$ & $3,50 \pm 0,31$ & $0,918 \pm 0,075$ & $0,800 \pm 0,078$ & $0,750 \pm 0,093$ \\
\hline & $3,0(0,33)$ & $4,22 \pm 0,24$ & $1,32 \pm 0,08$ & $1,20 \pm 0,081$ & $1,22 \pm 0,10$ \\
\hline & $4,5(0,50)$ & $4,00 \pm 0,33$ & $1,81 \pm 0,14$ & $1,58 \pm 0,19$ & $1,77 \pm 0,13$ \\
\hline & $6,0(0,66)$ & $3,78 \pm 0,20$ & $2,01 \pm 0,10$ & $1,88 \pm 0,097$ & $2,00 \pm 0,156$ \\
\hline & $7,5(0,82)$ & $3,02 \pm 0,25$ & $2,17 \pm 0,17$ & $2,02 \pm 0,15$ & $2,25 \pm 0,21$ \\
\hline & $9,0(1,0)$ & $3,29 \pm 0,34$ & $2,45 \pm 0,18$ & $2,17 \pm 0,26$ & $2,60 \pm 0,12$ \\
\hline \multirow{6}{*}{ CRF 40 / PP } & $2,0(0,22)$ & $3,67 \pm 0,23$ & $0,951 \pm 0,132$ & $0,811 \pm 0,126$ & $0,923 \pm 0,164$ \\
\hline & $3,0(0,33)$ & $3,39 \pm 0,26$ & $1,26 \pm 0,17$ & $1,07 \pm 0,16$ & $1,29 \pm 0,18$ \\
\hline & $4,5(0,50)$ & $3,47 \pm 0,43$ & $1,70 \pm 0,28$ & $1,46 \pm 0,22$ & $1,79 \pm 0,26$ \\
\hline & $6,0(0,66)$ & $4,36 \pm 0,35$ & $2,08 \pm 0,14$ & $1,79 \pm 0,16$ & $2,22 \pm 0,18$ \\
\hline & $7,5(0,82)$ & $4,17 \pm 0,42$ & $2,50 \pm 0,40$ & $2,20 \pm 0,39$ & $2,63 \pm 0,43$ \\
\hline & $9,0(1,0)$ & $4,49 \pm 0,21$ & $2,92 \pm 0,37$ & $2,68 \pm 0,32$ & $3,02 \pm 0,46$ \\
\hline \multirow{3}{*}{ CRF 35 / AÇO } & $15,0(0,19)$ & $4,68 \pm 0,30$ & $1,81 \pm 0,14$ & $1,76 \pm 0,16$ & $1,70 \pm 0,13$ \\
\hline & $25,0(0,32)$ & $3,87 \pm 0,22$ & $2,37 \pm 0,24$ & $2,38 \pm 0,28$ & $2,23 \pm 0,24$ \\
\hline & $35,0(0,45)$ & $4,25 \pm 0,21$ & $3,08 \pm 0,40$ & $3,12 \pm 0,43$ & $2,86 \pm 0,35$ \\
\hline
\end{tabular}

Devido à grande quantidade de dados, decidiu-se apresentá-los na forma de boxplots, para que a dispersão, a simetria e o intervalo entre os pontos máximos e mínimos fossem visualizados mais facilmente. A configuração de apresentação das informações contidas em cada boxplot está mostrada na figura 6.1. 


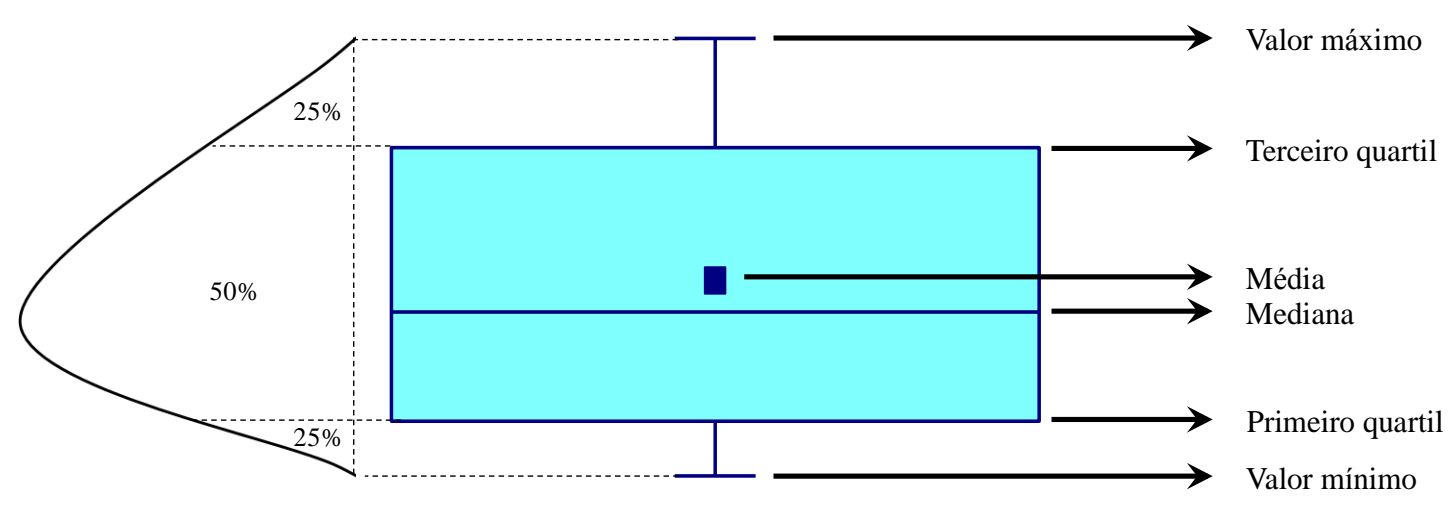

Figura 6.1 - Informações contidas nos gráficos do tipo boxplot (McGILL; TUKEY; LARSEN, 1978).

O intervalo entre o valor mínimo e o primeiro quartil contém $25 \%$ dos dados amostrais que apresentaram os valores mais baixos. Já o intervalo entre o terceiro quartil e o valor máximo contém $25 \%$ dos dados amostrais que apresentaram os valores mais altos. Os dados contidos dentro da caixa correspondem a $50 \%$ dos dados amostrais, que ficaram compreendidos entre o primeiro e o terceiro quartil. O comprimento desses intervalos é proporcional à dispersão entre os dados, ou seja, quanto maior o comprimento, maior será a dispersão (McGILL; TUKEY; LARSEN, 1978).

Os dados apresentados na tabela 6.5 estão nos gráficos 6.7 ao 6.12 . 


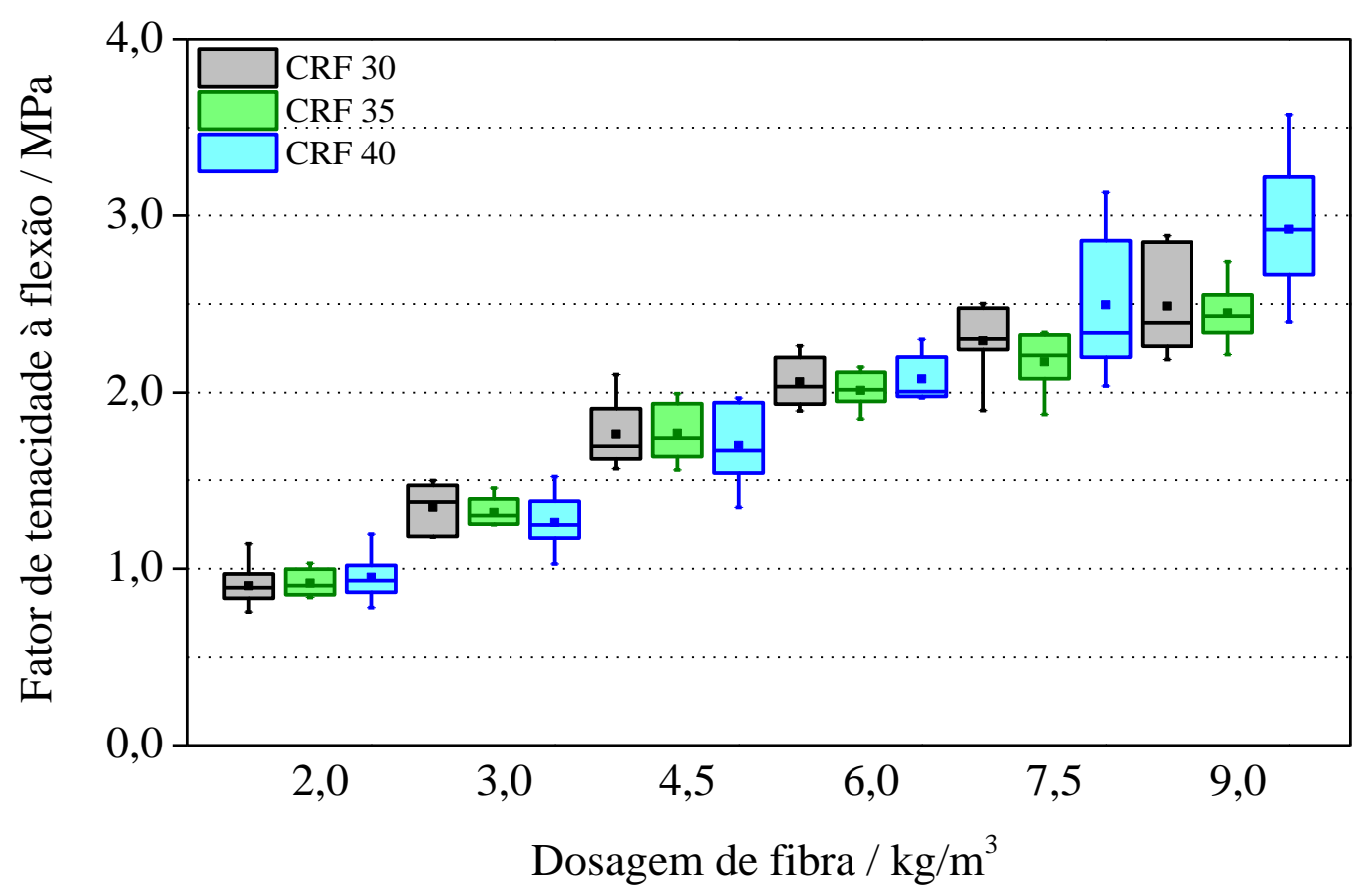

Gráfico 6.7 - Fator de tenacidade à flexão para os concretos CRF 30, CRF 35 e CRF 40 reforçados com a macrofibra polimérica, segundo JSCE-SF4.

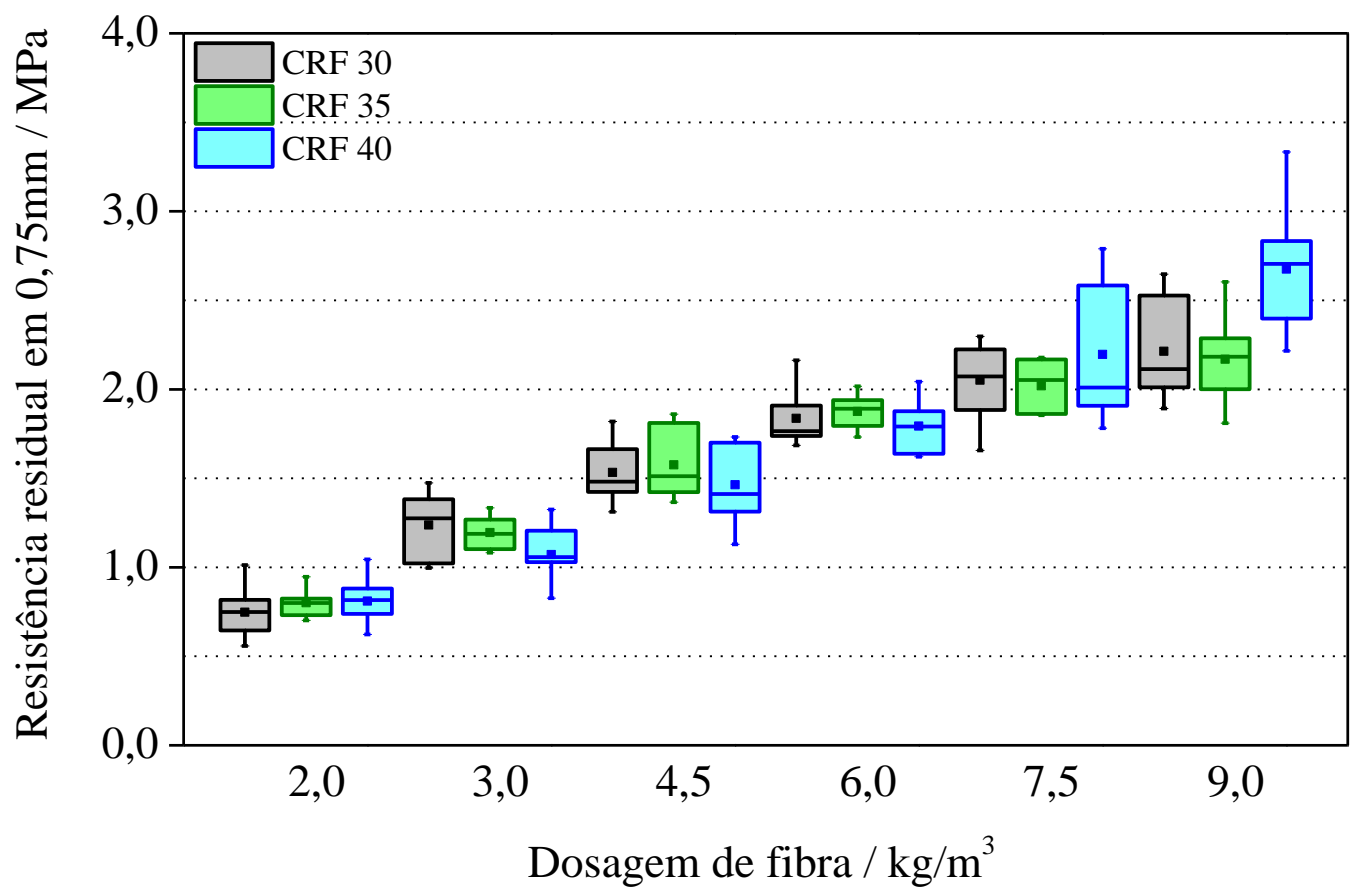

Gráfico 6.8 - Resistência residual em 0,75mm para os concretos CRF 30, CRF 35 e CRF 40 reforçados com a macrofibra polimérica, segundo ASTM C1609. 


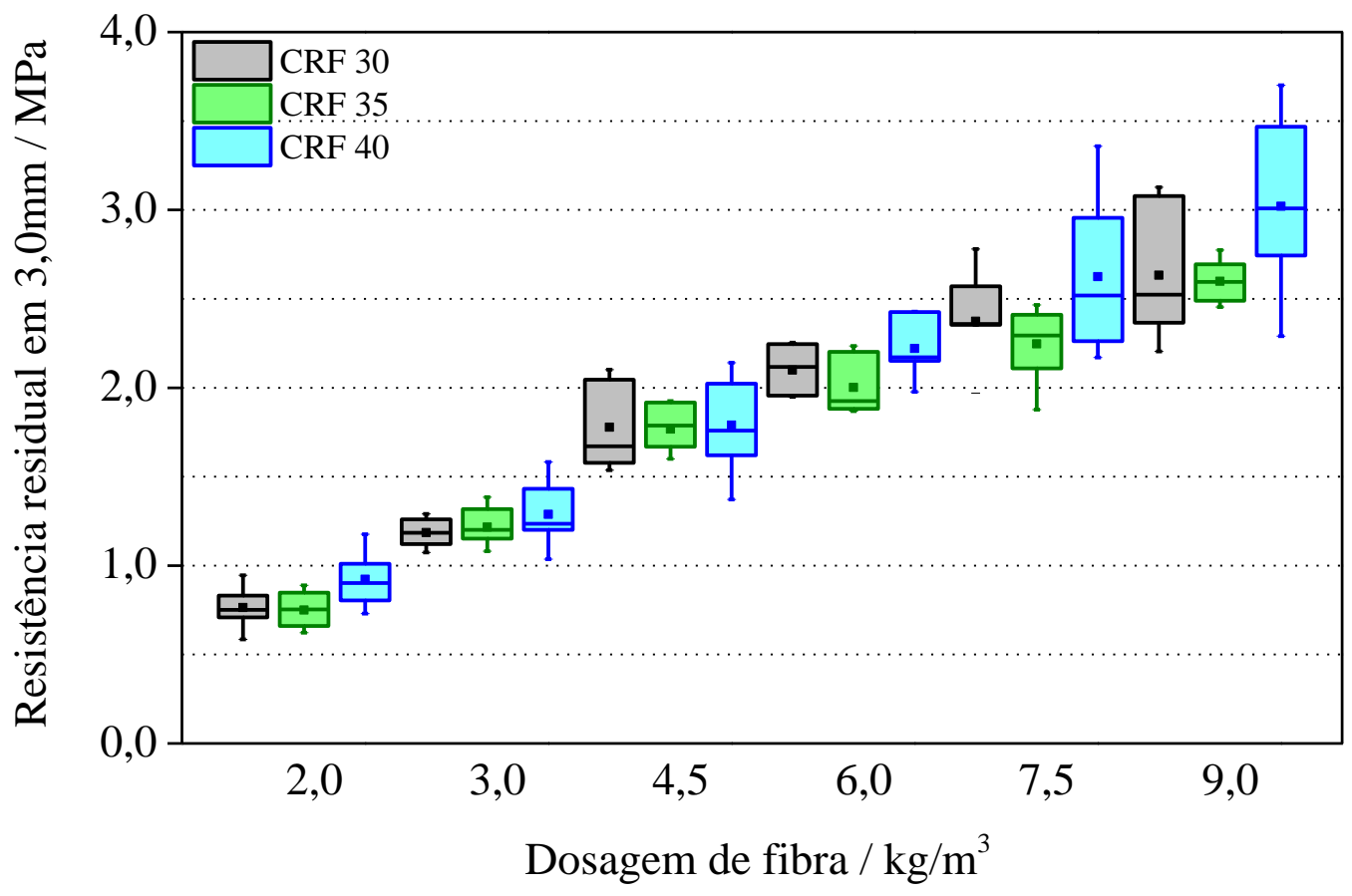

Gráfico 6.9 - Resistência residual em 3,0mm para os concretos CRF 30, CRF 35 e CRF 40 reforçados com a macrofibra polimérica, segundo ASTM C1609.

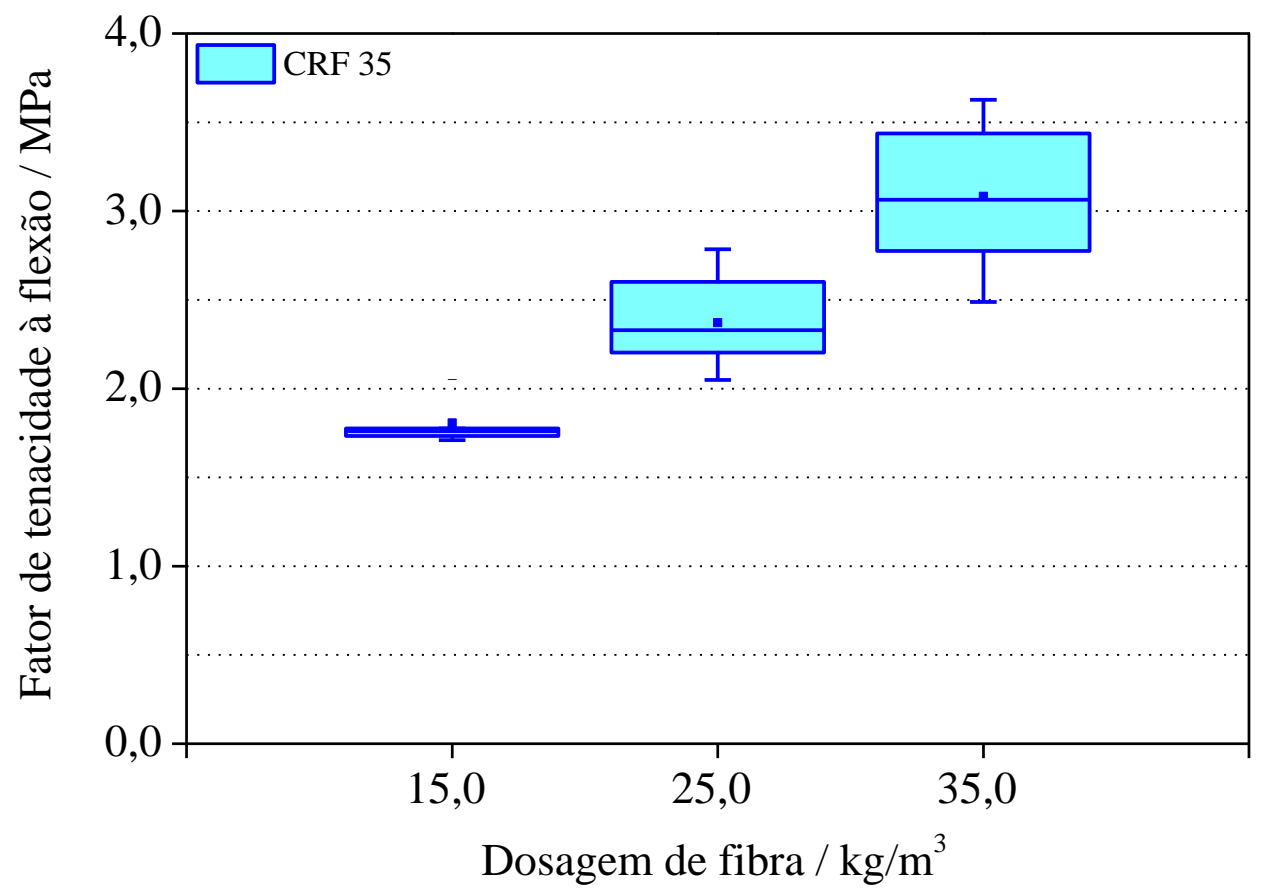

Gráfico 6.10 - Fator de tenacidade à flexão para o concreto CRF 35 reforçado com a fibra de aço, segundo JSCE-SF4. 


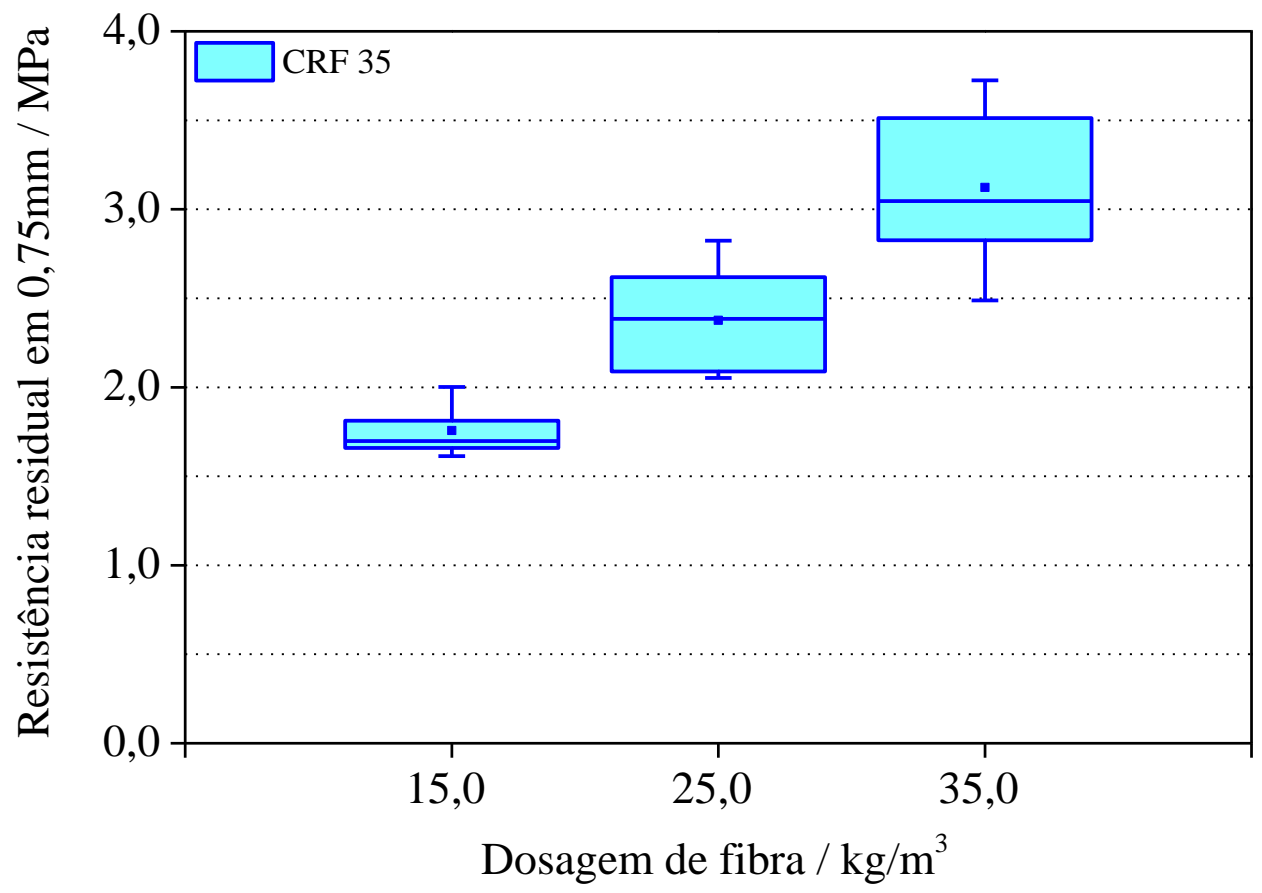

Gráfico 6.11 - Resistência residual em 0,75mm para o concreto CRF 35 reforçado com a fibra de aço, segundo ASTM C1609.

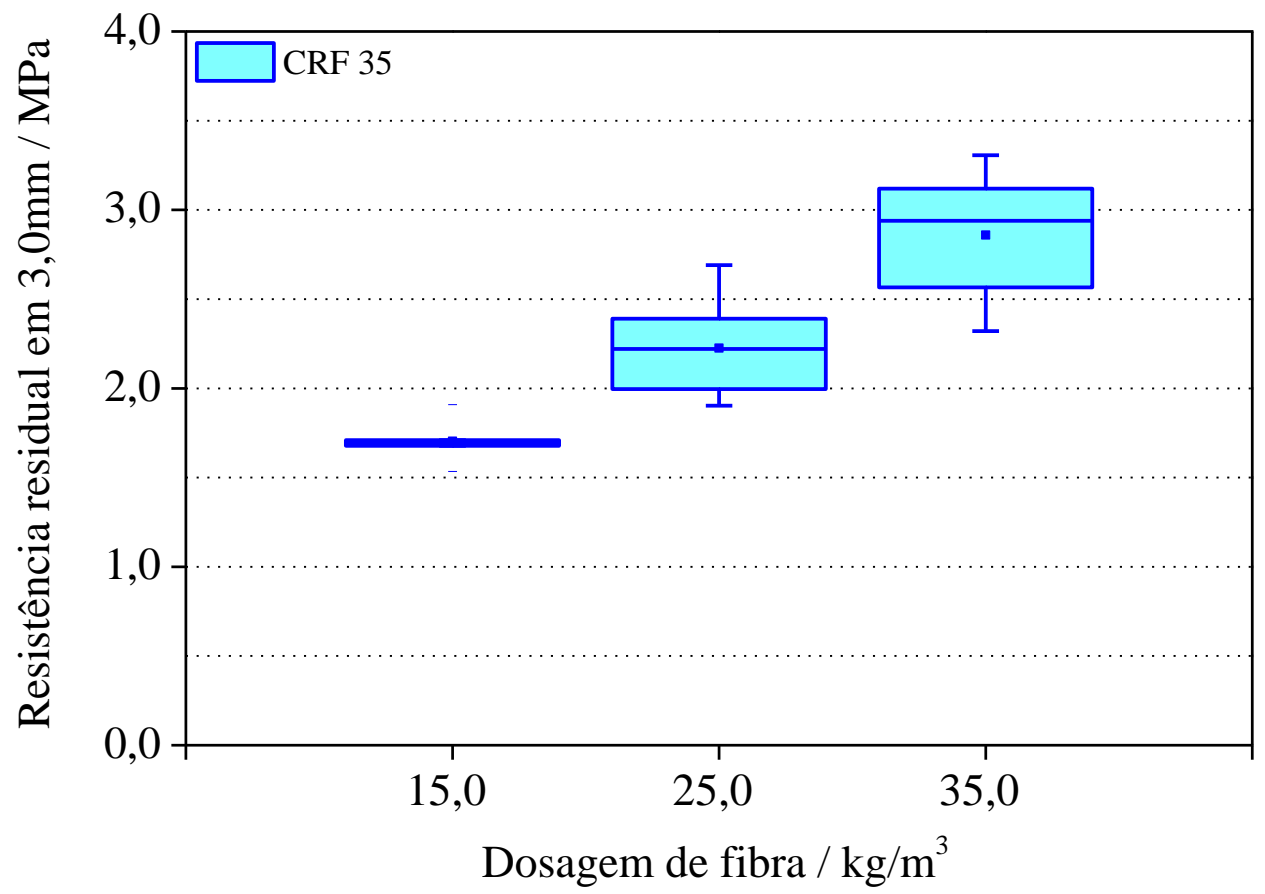

Gráfico 6.12 - Resistência residual em 3,0mm para o concreto CRF 35 reforçado com a fibra de aço, segundo ASTM C1609. 
Verifica-se que as relações entre a resistência residual ou o fator de tenacidade com o teor de fibras obedecem a um comportamento assintótico, assim como em estudos realizados por Figueiredo, Nunes e Tanesi (2000). Com o aumento do consumo de fibras, há um maior gasto energético pela deformação plástica da parcela comprimida da seção flexionada no ensaio de determinação da tenacidade. Essa energia representa uma perda em termos de energia absorvida no corpo-de-prova e, consequentemente, da tenacidade (ARMELIN; BANTHIA, 1997).

Também pode ser observado que com o aumento do teor de fibras, há uma maior dispersão dos resultados (maior desvio padrão), indicando que há heterocedasticidade nos dados amostrais, em uma dependência positiva com o valor médio. Tal fato dá suporte para a utilização de uma distribuição gama nas análises inferenciais (VENABLES; RIPLEY, 2002), descrita no capítulo 7 .

Uma explicação para esse comportamento é que como os corpos-de-prova recebem carga por dois cutelos superiores, a fissura vai ocorrer no ponto que apresentar menor resistência à sua propagação, na região do terço central do corpo-de-prova (di PRISCO; PLIZZARI; VANDEWALLE, 2009). Com maiores teores de fibras, maiores são as possibilidades de caminhos que a fissura pode percorrer e maior sua tortuosidade. Isso foi observado para teores de fibras elevados, mas não para os teores de fibra mais baixos, conforme ilustrado na figura 6.2 .

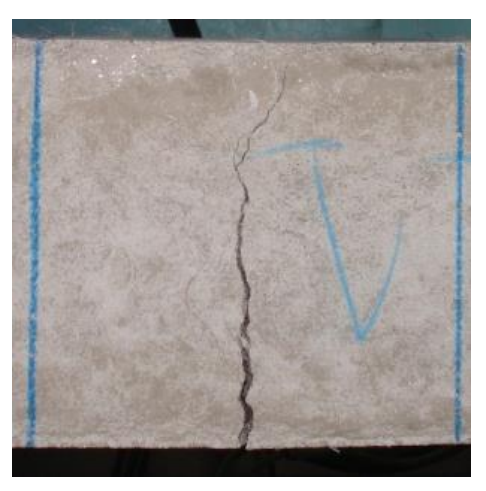

(a)

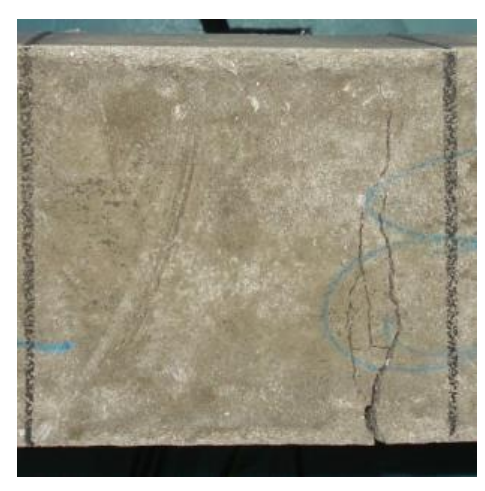

(b)

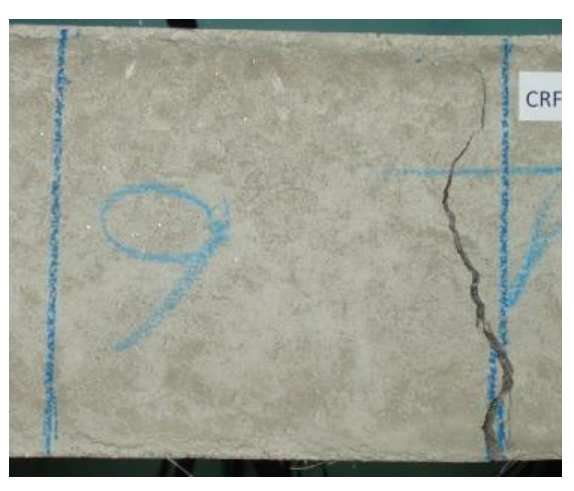

(c)

Figura 6.2 - Fotografias do terço médio de um corpo-de-prova prismático de $150 \mathrm{~mm}$ x $150 \mathrm{~mm}$ x $500 \mathrm{~mm}$, do concreto CRF 30, com os teores de fibra de 2,0 (a), 7,5 (b) e $9,0 \mathrm{~kg} / \mathrm{m}^{3}$ (c).

Esta explicação tem uma correspondência com os resultados obtidos no trabalho de Pietra (2005), que verificou que a utilização de agregados reciclados de baixa resistência 
promovia ruptura sempre localizada no eixo central do corpo-de-prova, enquanto que em concretos com agregados reciclados de maior resistência, não ocorria esse padrão de fissuração, sendo as fissuras mais irregulares.

No gráfico 6.9, pode ser observado que a média e a mediana da resistência residual em 3,0mm para o traço CRF 40 estão sempre acima dos valores para os outros traços, indicando que em concretos de maior resistência, o desempenho da fibra pode ser ampliado. Com o aumento da resistência do concreto, maior sua densificação. Com isso, as fibras estão mais fortemente aderidas à matriz, conduzindo a uma maior resistência para o seu arrancamento e mobilizando mais a resistência à tração da fibra durante o processo de abertura de fissura. $\mathrm{Ou}$ seja, em matrizes de menor resistência, o mecanismo de controle de abertura de fissura tende a ser o arrancamento da fibra. Já em matrizes de resistências maiores, a ruptura da fibra predomina.

De acordo com os dados apresentados na tabela 6.5, verifica-se que para a fibra de aço, a resistência residual em $0,75 \mathrm{~mm}$ é maior do que a resistência residual em 3,0mm, ou seja, a fibra apresentou o comportamento de slip-softening no trecho pós-fissuração. Para menores deslocamentos, a fibra de aço confere maior resistência residual, devido ao seu alto módulo de elasticidade, e pelo grau de dano na matriz ser pequeno, deixando a fibra ainda fortemente ancorada. Para maiores deslocamentos, a fibra de aço apresenta considerável grau de deslizamento e sua resistência ao arrancamento é fundamentalmente dependente da integridade da matriz, que pode apresentar falhas nos pontos onde a ancoragem da fibra é solicitada (ganchos nas extremidades).

Como a fibra de aço possui resistência superior à da matriz, o deslizamento da fibra causa danos na matriz, levando a falhas na interface. A interação de uma fissura que está se propagando na matriz com uma fibra no caminho de propagação normalmente resulta na microfissuração da matriz nas regiões ao redor da fibra. A transferência de tensão da matriz para a fibra se dá por atrito, causando a quebra da ligação fibra-matriz. Por esse motivo, as fibras de aço normalmente apresentam o comportamento de slip-softening (BENTUR; MINDESS, 2007).

Para a macrofibra polimérica, o comportamento tende a ser o oposto. Nas dosagens de 2,0 e $3,0 \mathrm{~kg} / \mathrm{m}^{3}$, a resistência residual nos dois níveis de deflexão é praticamente a mesma. Para as demais dosagens, a resistência residual em $3,0 \mathrm{~mm}$ supera a medida em $0,75 \mathrm{~mm}$, devido ao comportamento de slip-hardening da macrofibra. A diferença entre os dois valores pode chegar a $20 \%$ quando o teor de fibra é de $9,0 \mathrm{~kg} / \mathrm{m}^{3}$. 
Os valores da resistência residual em 3,0mm (ASTM C1609) e do fator de tenacidade (JSCE-SF4) são ligeiramente diferentes. Tratando-se da macrofibra polimérica nas menores dosagens, pode ser observado que o fator de tenacidade é maior que a resistência residual, devido ao fato da tenacidade ser calculada pela área total abaixo da curva, incluindo a área sob o pico. A influência dessa região no cálculo da tenacidade é maior para baixos teores, pois a área no trecho pós-fissuração é menor.

Entretanto, à medida que o teor de fibra é aumentado, o valor da resistência residual torna-se mais alto do que o fator de tenacidade, pois, como o comportamento de sliphardening é mais pronunciado, o valor da carga no ponto de deslocamento de 3,0mm é maior do que a carga média da curva.

Já para a fibra de aço, a resistência residual é sempre menor que o fator de tenacidade, pois, como a fibra apresenta o comportamento de slip-softening, a resistência residual no deslocamento de 3,0mm é sempre menor que a resistência equivalente.

O coeficiente de variação obtido para a medida do fator de tenacidade foi inferior ao obtido para a resistência residual em 3,0mm, para todos os resultados encontrados. Tal fato é devido à primeira leitura ser medida a partir da área sob a curva carga-deslocamento, em um grande intervalo de deslocamento. Como a resistência residual é medida a partir da carga em um único ponto, a variação nesse resultado é maior.

Ocorreu maior dispersão dos resultados de resistência residual pós-fissuração com o concreto reforçado com a fibra de aço. Como a densidade do aço $\left(7,85 \mathrm{~g} / \mathrm{m}^{3}\right)$ é cerca de 9 vezes maior que a do polipropileno $\left(0,91 \mathrm{~g} / \mathrm{cm}^{3}\right)$ e as fibras de aço possuem maiores dimensões, a quantidade de fibras de aço por unidade de massa é menor. Além disso, sua homogeneização no concreto e o processo de moldagem são mais difíceis, devido à sua alta rigidez. Com isso, a variação do número de fibras aço presentes na seção de ruptura do corpode-prova é superior à variação do número de fibras poliméricas nessa seção, conduzindo à maior dispersão nos dados experimentais para a fibra rígida.

Um fato que chama a atenção é a diferença entre os valores dos módulos de ruptura obtidos pelo ensaio de tenacidade (tabela 6.5) e os de caracterização do concreto (tabela 5.7). No ensaio proposto pela norma ASTM C1609, chega-se ao limite de deformação do concreto (aproximadamente $0,04 \mathrm{~mm}$ de deslocamento vertical) em apenas $20 \mathrm{~s}$, ou seja, o corpo-deprova rompe nesse tempo. Já para o ensaio de determinação da resistência à tração na flexão, pela norma ABNT NBR 12142, o corpo-de-prova rompe em, aproximadamente, 4 a 5 minutos. Com a maior velocidade de aplicação de carga, há menor tempo para a acomodação 
do corpo-de-prova sobre os cutelos, levando a diferenças nos resultados. Dessa forma, o módulo de ruptura obtido no ensaio proposto pela norma ASTM C1609 é menor que o valor da resistência à tração na flexão utilizada para a caracterização do concreto.

Os valores do módulo de ruptura mostrados na tabela 5.7 (ABNT NBR 12142) são 18,5, 19,2 e 20,9\% maiores que os módulos de ruptura médios mostrados na tabela 6.5 (ASTM C1609), para o CRF 30, CRF 35 e CRF 40, respectivamente. Por análise de variância (ANOVA) realizada no programa Origin versão 6, as médias dos módulos de ruptura são

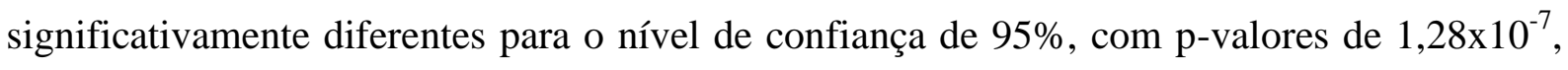
$7,06 \times 10^{-4}$ e 3,66×10 $10^{-4}$, para os dados do CRF 30, CRF 35 e CRF 40, respectivamente.

Para melhor visualização do desempenho de cada uma das fibras, os valores das resistências residuais em 0,75 e 3,0mm e do fator de tenacidade obtidos com o concreto CRF35 reforçado com a fibra de aço e com a macrofibra polimérica foram plotados nos gráficos 6.13 (a), (b) e (c). Nesses gráficos, estão apresentados os valores médios da resistência residual com o respectivo desvio padrão. As regressões foram feitas a partir dos valores médios. 


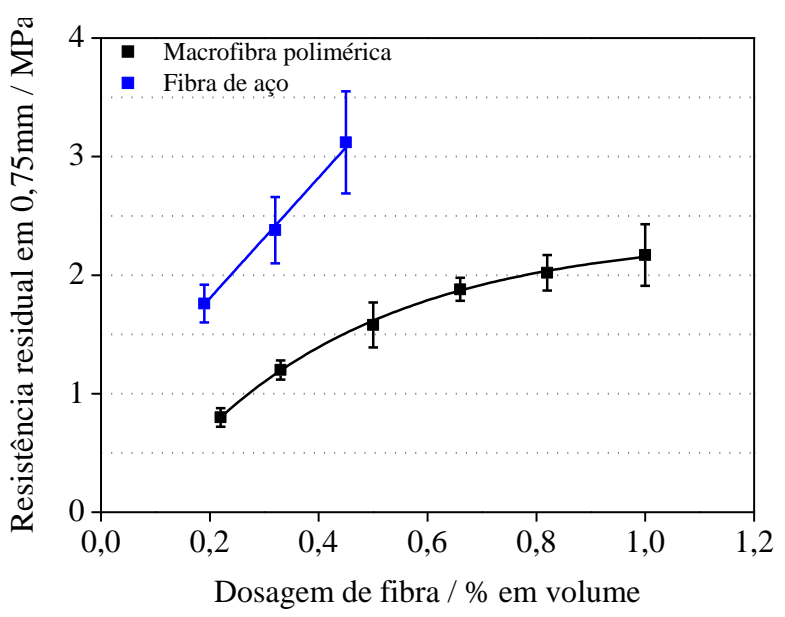

(a)

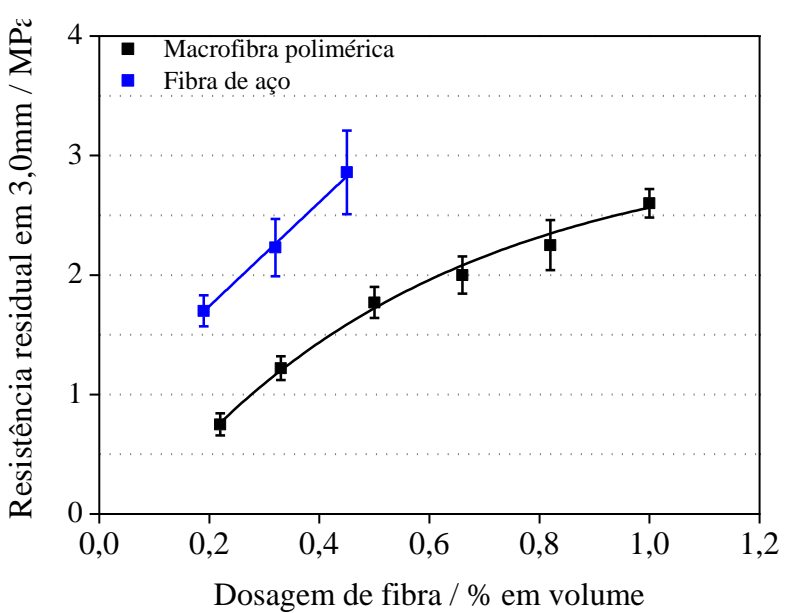

(b)

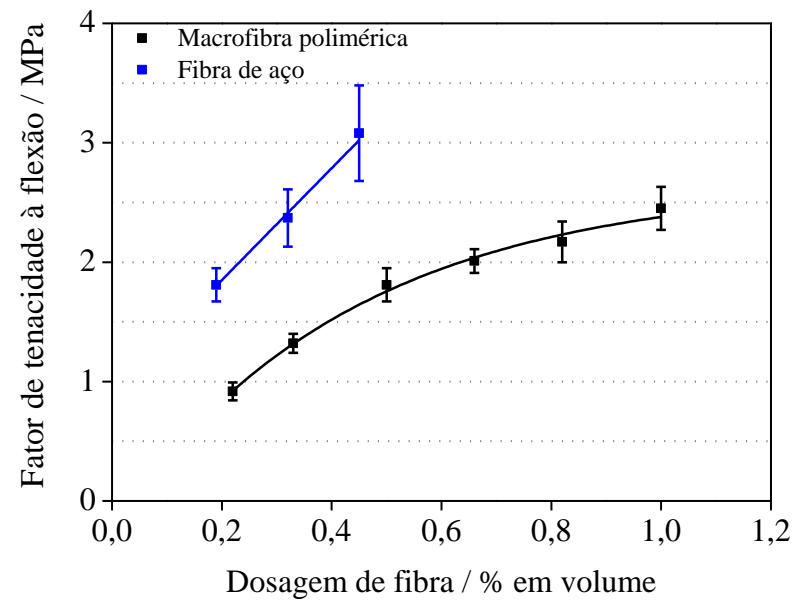

(c)

Gráfico 6.13 - Comparação entre a resistência residual em $0,75 \mathrm{~mm}$ (a), em 3,0mm (b) e o fator de tenacidade (c) para o para o concreto CRF 35 reforçado com a fibra de aço e com a polimérica.

Assim como nos resultados obtidos por Figueiredo et al (2012), quando se compara um mesmo teor em volume de fibra de aço e polimérica, a fibra de aço confere maiores resistências residuais, principalmente para baixos níveis de deformação, devido ao seu maior módulo de elasticidade. No entanto, quando a demanda de desempenho é adotada como o critério de comparação, verifica-se que a macrofibra pode atingir o mesmo desempenho que a fibra de aço, desde que respeitadas as equivalências entre os teores obtidas por estudo de dosagem. Daí, a escolha de determinado tipo de reforço se baseia no custo e nos aspectos executivos relacionados ao processo de sua utilização.

Para avaliação dos resultados, os valores das resistências residuais em 0,75 e 3,0mm de deslocamento vertical para o concreto reforçado com a fibra de aço foram comparados com os resultados obtidos por Bernard (2009). O autor estudou a mesma fibra de aço no teor de 
$25,0 \mathrm{~kg} / \mathrm{m}^{3}$ em um concreto com resistência média à compressão de 20MPa. Os dados estão apresentados na tabela 6.6.

Tabela 6.6 - Comparação de valores das resistências residuais em 0,75 e 3,0mm de deslocamento vertical com o concreto reforçado com a fibra de aço com os dados publicados por Bernard (2009).

\begin{tabular}{cccc}
\hline $\begin{array}{c}\text { Resistência } \\
\text { residual }\end{array}$ & $\begin{array}{c}\text { Valor obtido neste programa } \\
\text { experimental / Mpa }\end{array}$ & $\begin{array}{c}\text { Valor publicado por } \\
\text { Bernard (2009) / MPa }\end{array}$ & Diferença / \% \\
\hline $\mathrm{f}_{150,0.75}$ & 2,38 & 1,86 & $+28,0$ \\
\hline $\mathrm{f}_{150,3.0}$ & 2,23 & 2,03 & $+9,9$ \\
\hline
\end{tabular}

Pelos dados da tabela 6.6, pode ser observado que a diferença entre os valores médios das resistências residuais foi alta. Os resultados podem ser diferentes devido à composição do concreto, que apresentava resistência à compressão inferior à do concreto utilizado neste programa experimental. Em matrizes de maior resistência, maior será a aderência das fibras na matriz. Como este é um dos principais mecanismos que influenciam a tenacidade conferida por fibras de aço, quanto maior a resistência mecânica da matriz, maior será a tenacidade do compósito (FIGUEIREDO; MOURAD; CARVALHO, 2000).

\subsection{Resultados obtidos com o ensaio da norma ASTM C1399}

As curvas da primeira etapa desse ensaio, correspondentes ao rompimento do corpode-prova com o auxílio da chapa metálica, não são utilizadas para análise de resultados. Portanto, elas não estão apresentadas na discussão.

Os gráficos 6.14, 6.15 e 6.16 apresentam as curvas da segunda etapa do ensaio para os concretos CRF 30, CRF 35 e CRF 40, respectivamente, reforçados com a macrofibra polimérica nas dosagens de 2,0,3,0,4,5,6,0,7,5 e 9,0kg/m ${ }^{3}$. O gráfico 6.17 apresenta as curvas médias para os três traços de concreto reforçado com a macrofibra polimérica. 


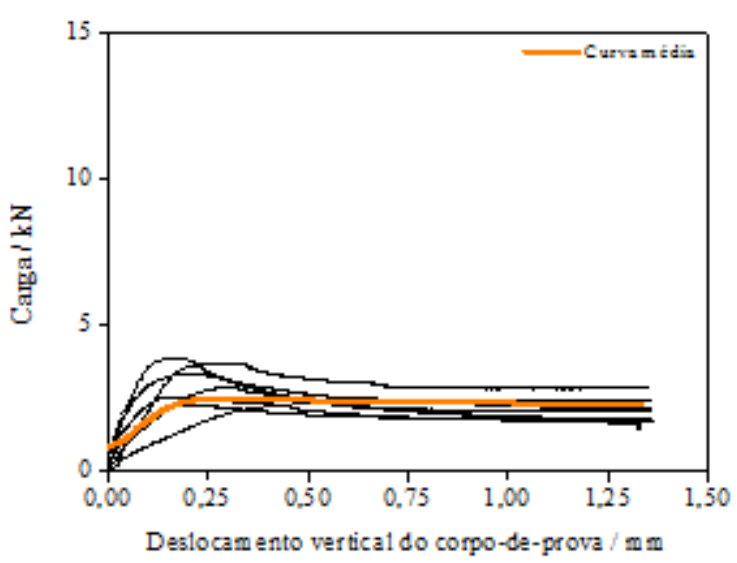

(a)

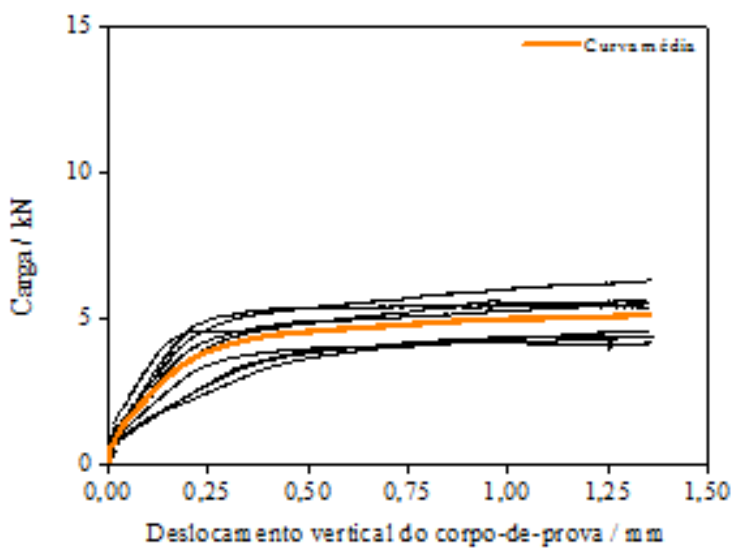

(c)

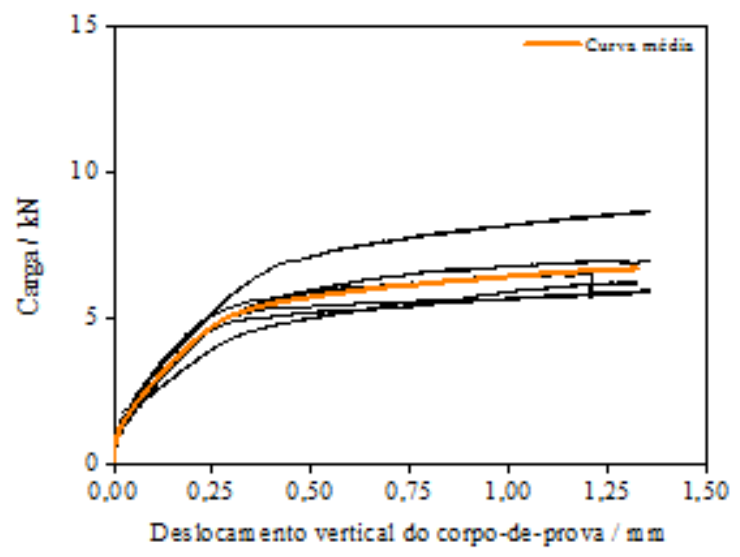

(e)

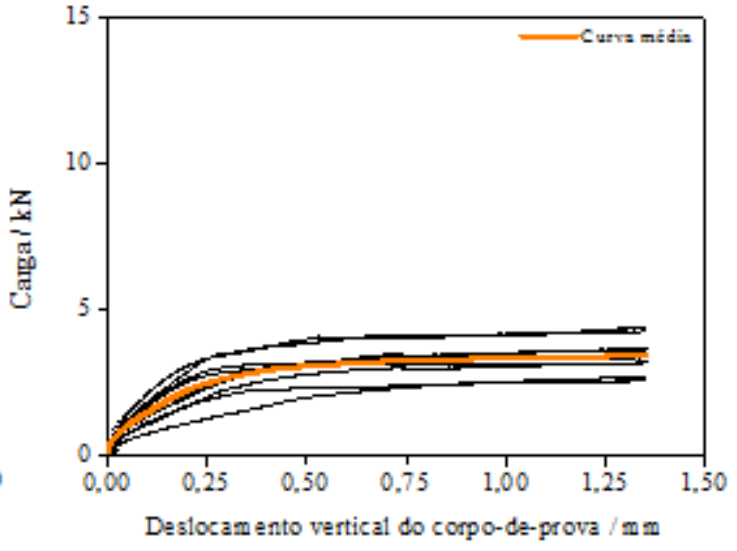

(b)

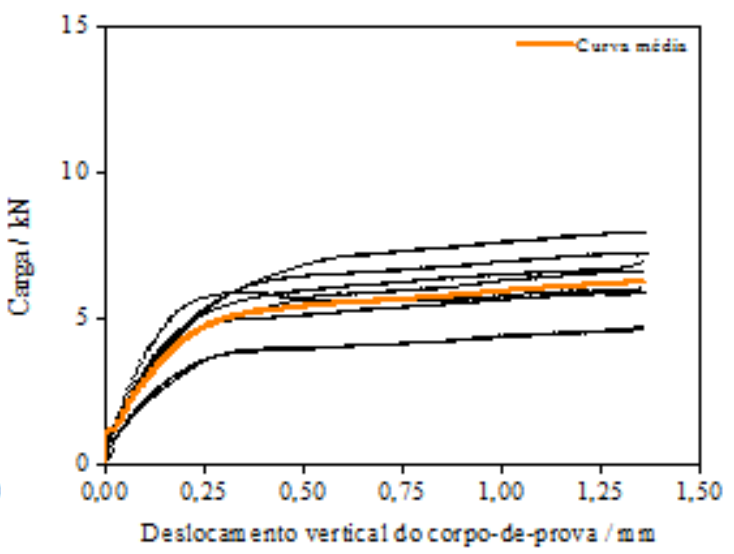

(d)

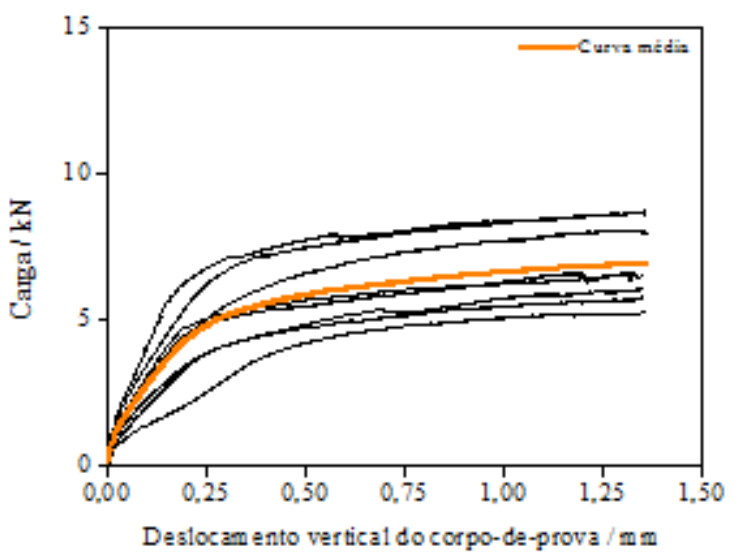

(f)

Gráfico 6.14 - Curvas de carga por deslocamento vertical referentes à segunda etapa do ensaio, obtidas com o traço CRF 30, utilizando-se a macrofibra polimérica, segundo ASTM C1399: (a) $2,0 \mathrm{~kg} / \mathrm{m}^{3} ;$ (b) $3,0 \mathrm{~kg} / \mathrm{m}^{3}$; (c) $4,5 \mathrm{~kg} / \mathrm{m}^{3} ;$ (d) $6,0 \mathrm{~kg} / \mathrm{m}^{3} ;$ (e) $7,5 \mathrm{~kg} / \mathrm{m}^{3} ;$ (f) $9,0 \mathrm{~kg} / \mathrm{m}^{3}$. 


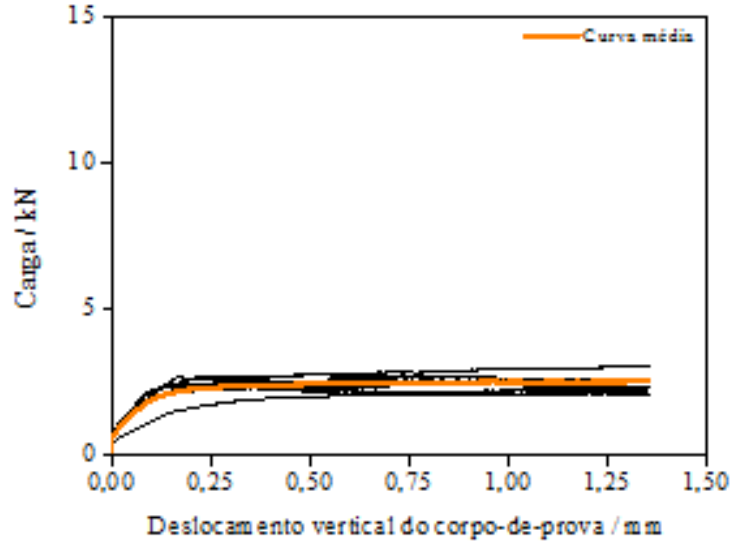

(a)

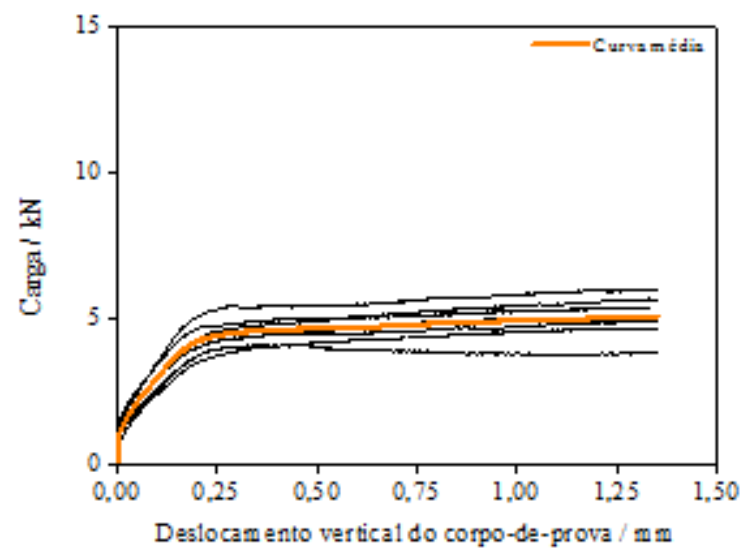

(c)

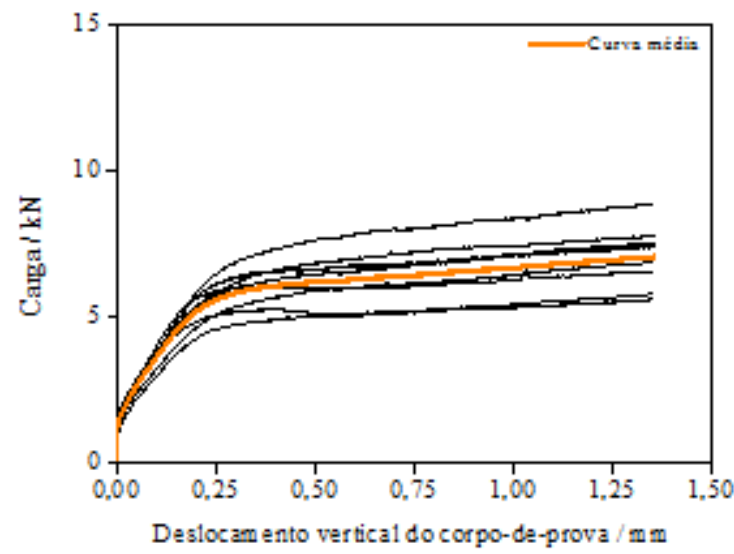

(e)

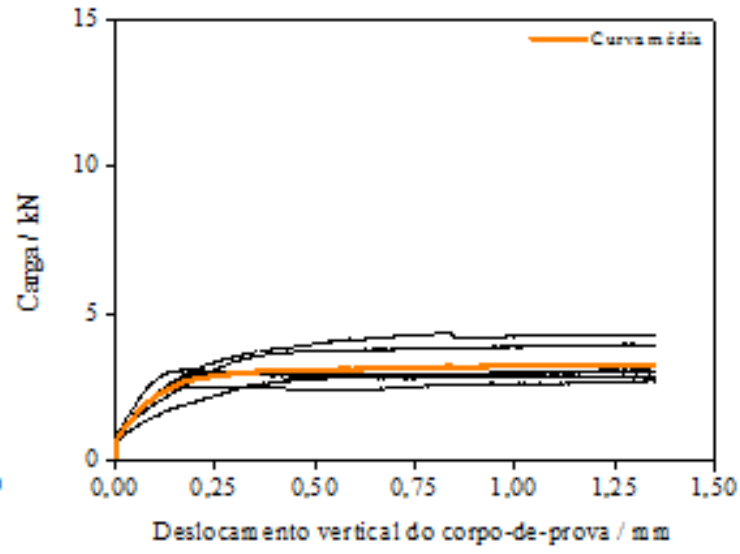

(b)

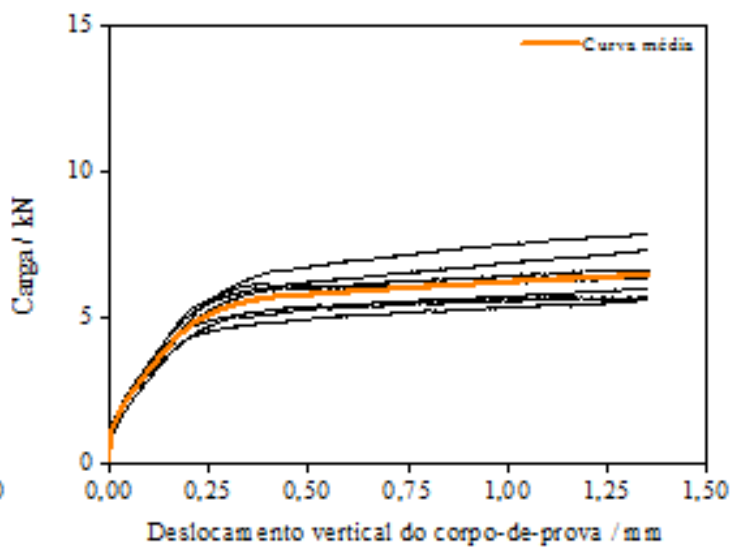

(d)

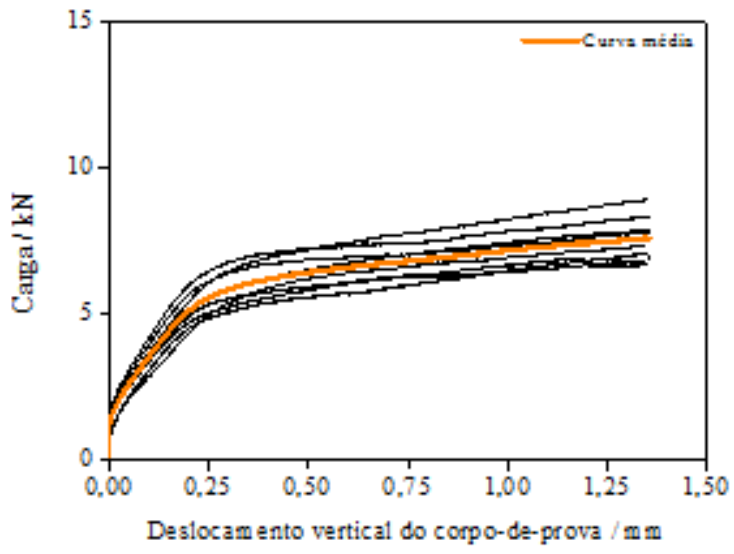

(f)

Gráfico 6.15 - Curvas de carga por deslocamento vertical referentes à segunda etapa do ensaio, obtidas com o traço CRF 35, utilizando-se a macrofibra polimérica, segundo ASTM C1399: (a) $2,0 \mathrm{~kg} / \mathrm{m}^{3} ;$ (b) $3,0 \mathrm{~kg} / \mathrm{m}^{3}$; (c) $4,5 \mathrm{~kg} / \mathrm{m}^{3}$; (d) $6,0 \mathrm{~kg} / \mathrm{m}^{3}$; (e) $7,5 \mathrm{~kg} / \mathrm{m}^{3}$; (f) $9,0 \mathrm{~kg} / \mathrm{m}^{3}$. 


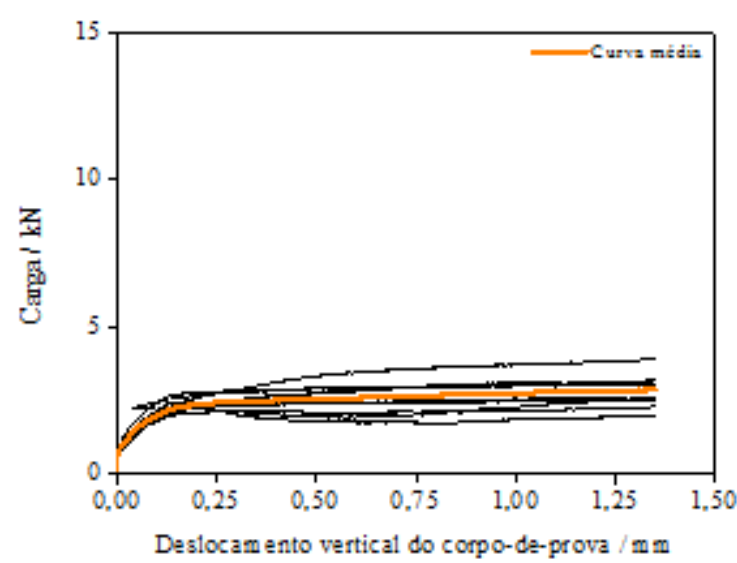

(a)

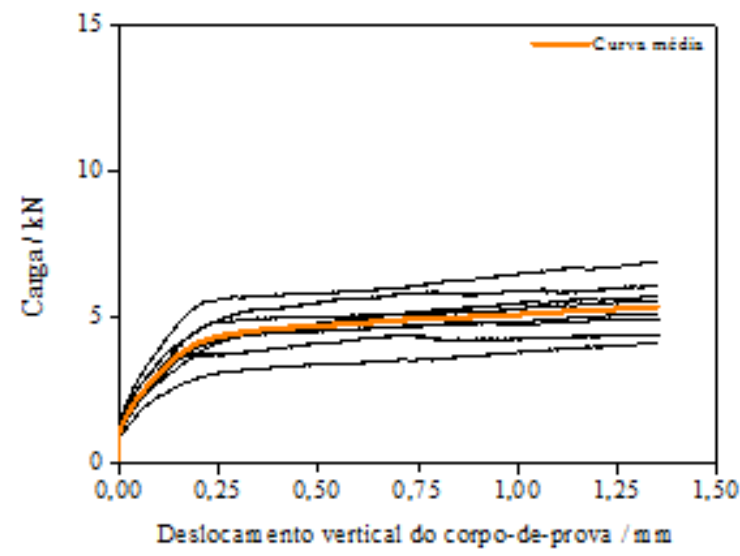

(c)

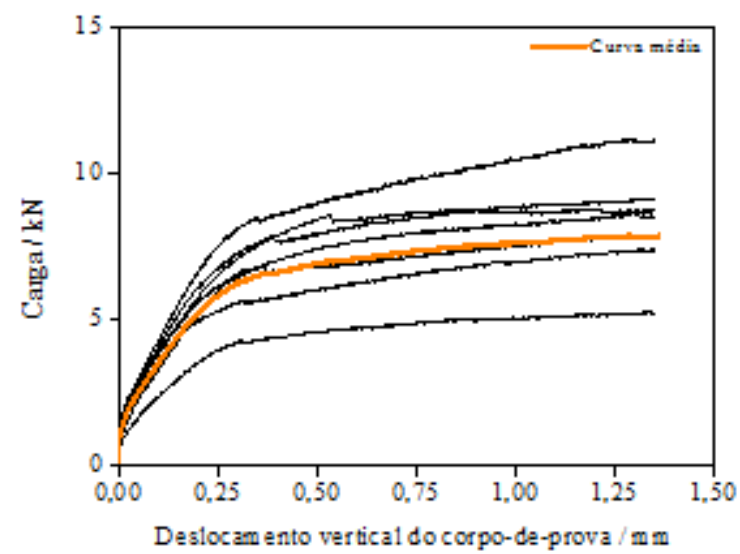

(e)

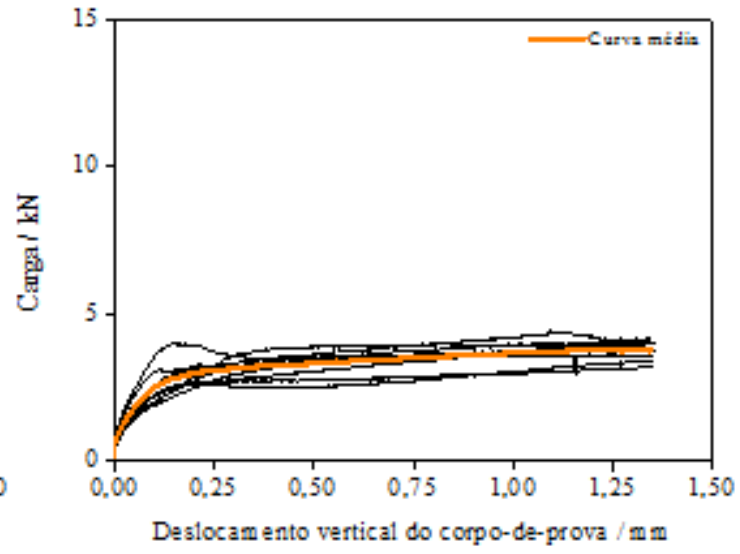

(b)

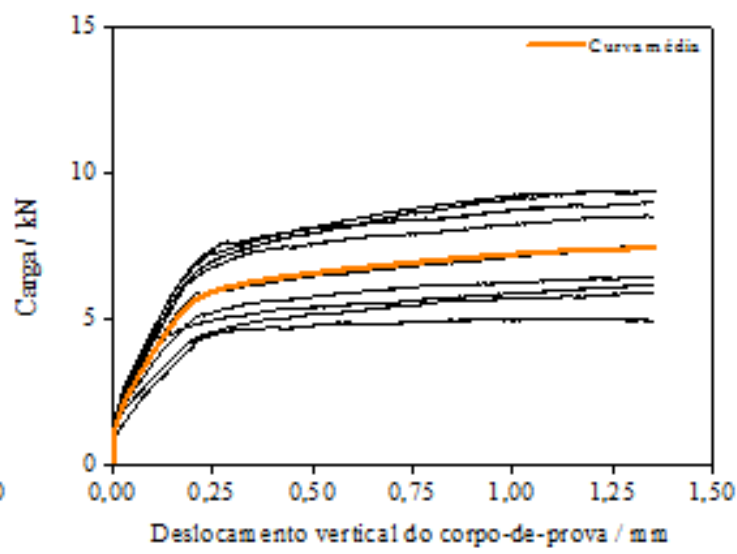

(d)

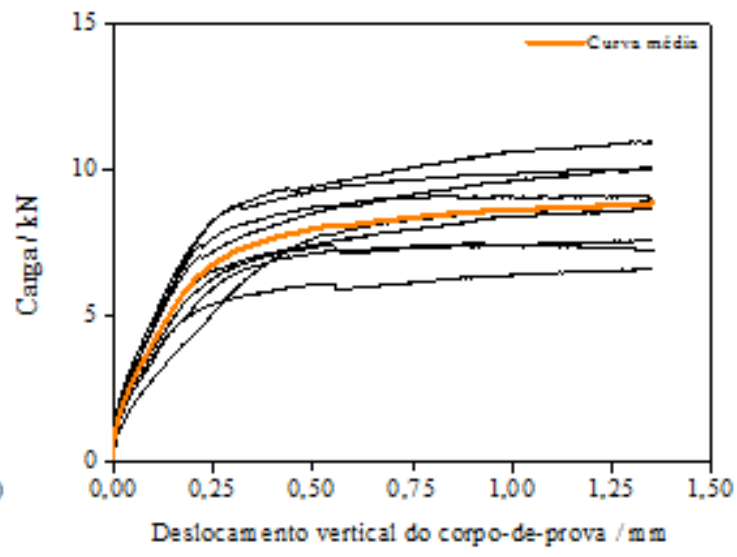

(f)

Gráfico 6.16 - Curvas de carga por deslocamento vertical referentes à segunda etapa do ensaio, obtidas com o traço CRF 40, utilizando-se a macrofibra polimérica, segundo ASTM C1399: (a) $2,0 \mathrm{~kg} / \mathrm{m}^{3} ;$ (b) $3,0 \mathrm{~kg} / \mathrm{m}^{3}$; (c) $4,5 \mathrm{~kg} / \mathrm{m}^{3}$; (d) $6,0 \mathrm{~kg} / \mathrm{m}^{3}$; (e) $7,5 \mathrm{~kg} / \mathrm{m}^{3}$; (f) $9,0 \mathrm{~kg} / \mathrm{m}^{3}$. 


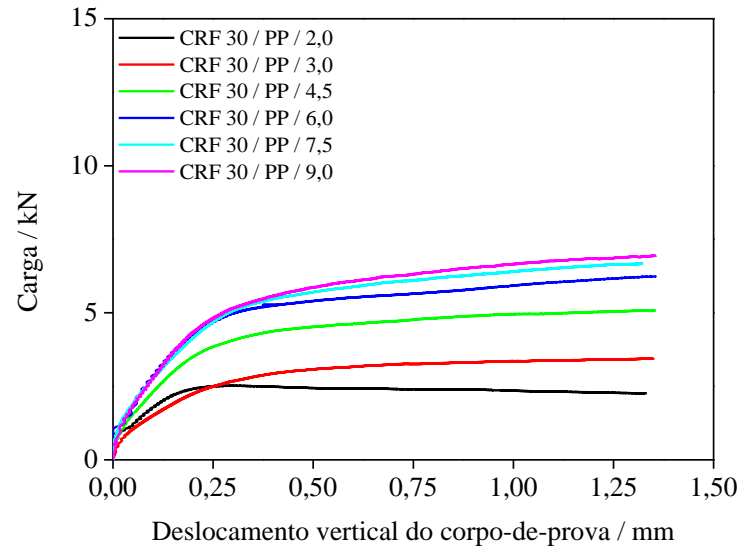

(a)

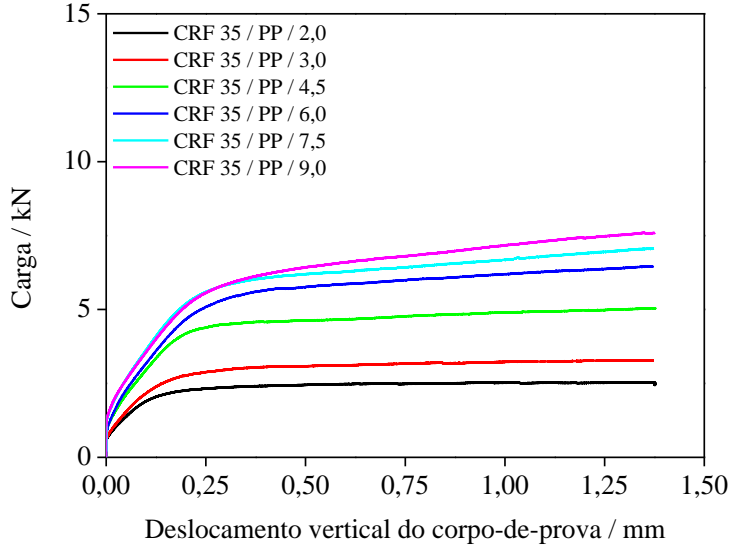

(b)

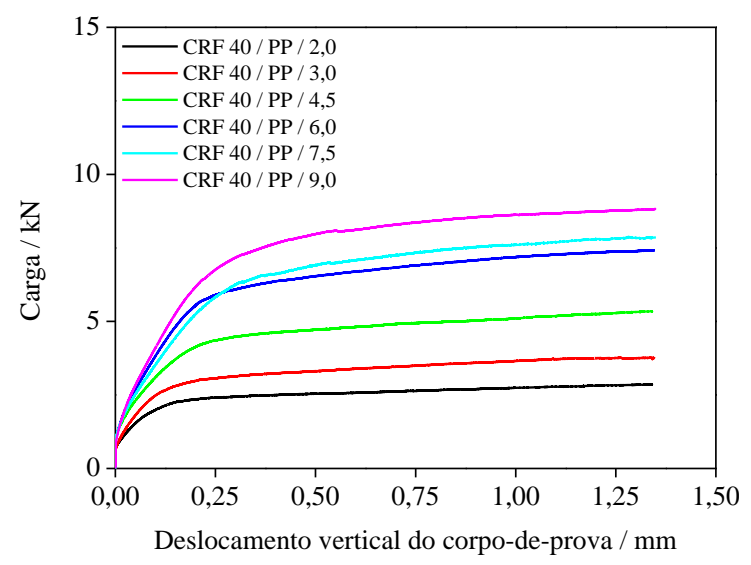

(c)

Gráfico 6.17 - Curvas médias obtidas segundo ASTM C1399: (a) CRF 30, (b) CRF 35 e (c) CRF 40, com a macrofibra polimérica.

Verifica-se que as curvas obtidas nesse procedimento de ensaio apresentam boa proximidade com as curvas obtidas pela norma ASTM C1609. Com o aumento da dosagem de fibras, a carga que o corpo-de-prova suporta é maior e, portanto, a resistência residual também. O comportamento de slip-hardening da fibra também pode ser observado. Os rompimentos também se deram pela formação de apenas uma fissura.

A partir da análise das curvas experimentais, foi calculada a resistência residual média (ARS), segundo a equação (4.6). Os resultados estão apresentados na tabela 6.7 e no gráfico 6.18 . 
Tabela 6.7 - Resultados obtidos com as curvas carga por deslocamento vertical dos traços CRF 30 / PP, CRF 35 / PP e CRF 40 / PP, segundo ASTM C1399.

\begin{tabular}{|c|c|c|}
\hline Traço & Dosagem de fibra $/ \mathrm{kg} / \mathrm{m}^{3}$ & ARS / MPa \\
\hline \multirow{6}{*}{ CRF 30 / PP } & 2,0 & $0,705 \pm 0,142$ \\
\hline & 3,0 & $0,980 \pm 0,182$ \\
\hline & 4,5 & $1,41 \pm 0,20$ \\
\hline & 6,0 & $1,66 \pm 0,35$ \\
\hline & 7,5 & $1,82 \pm 0,26$ \\
\hline & 9,0 & $2,00 \pm 0,43$ \\
\hline \multirow{6}{*}{ CRF 35 / PP } & 2,0 & $0,725 \pm 0,078$ \\
\hline & 3,0 & $0,961 \pm 0,168$ \\
\hline & 4,5 & $1,42 \pm 0,18$ \\
\hline & 6,0 & $1,79 \pm 0,21$ \\
\hline & 7,5 & $1,93 \pm 0,29$ \\
\hline & 9,0 & $2,04 \pm 0,19$ \\
\hline \multirow{6}{*}{ CRF 40 / PP } & 2,0 & $0,778 \pm 0,160$ \\
\hline & 3,0 & $1,04 \pm 0,16$ \\
\hline & 4,5 & $1,48 \pm 0,24$ \\
\hline & 6,0 & $2,07 \pm 0,45$ \\
\hline & 7,5 & $2,16 \pm 0,41$ \\
\hline & 9,0 & $2,46 \pm 0,37$ \\
\hline
\end{tabular}

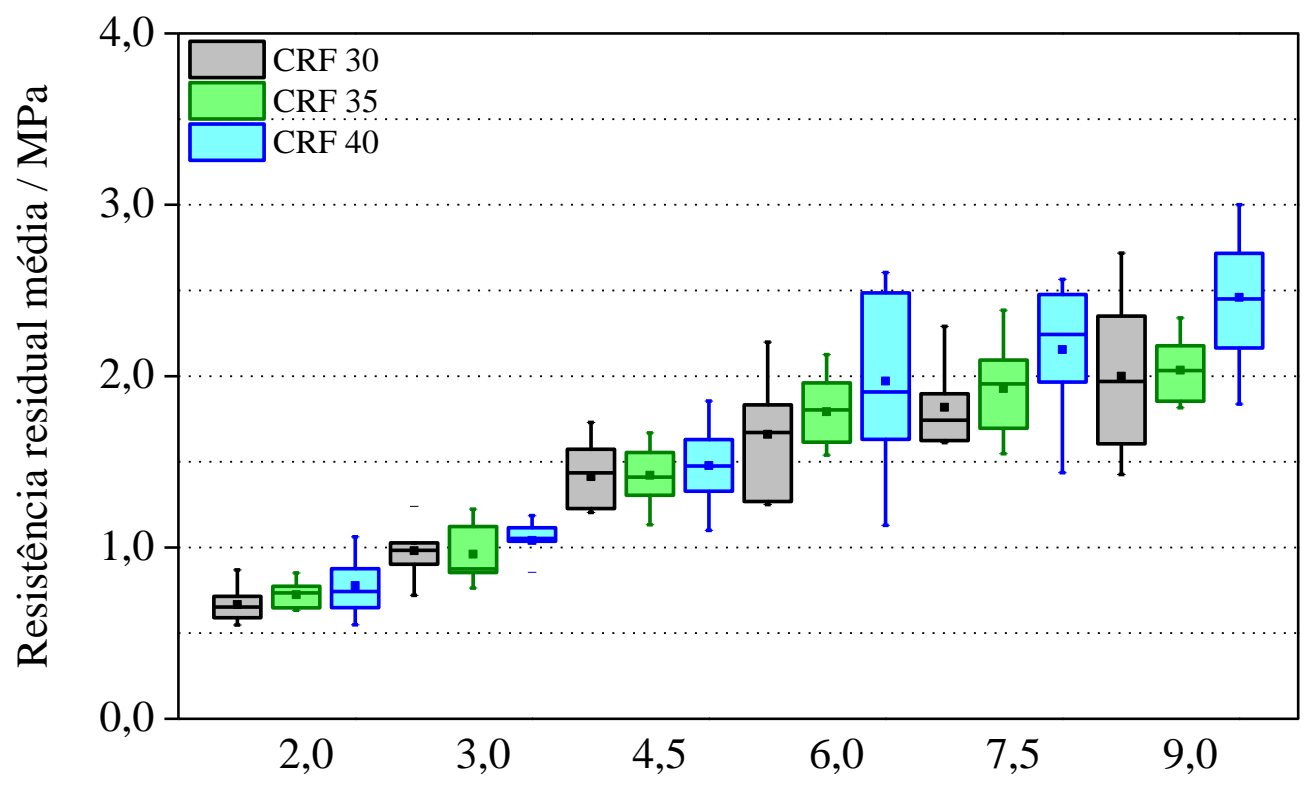

Dosagem de fibra $/ \mathrm{kg} / \mathrm{m}^{3}$

Gráfico 6.18 - Resistência residual média para os concretos CRF 30, CRF 35 e CRF 40 reforçados com a macrofibra polimérica, segundo ASTM C1399. 
Analisando os resultados obtidos, verifica-se que para todos os traços a resistência residual apresenta um comportamento assintótico para as dosagens utilizadas, corroborando com os resultados obtidos pelo ensaio da norma ASTM C1609 e com dados presentes na literatura (ARMELIN; BANTHIA, 1997; FIGUEIREDO; NUNES; TANESI, 2000). Também foi observada heterocedasticidade nos valores de resistência residual.

No geral, o coeficiente de variação para a resistência residual média obtida segundo a norma ASTM C1399 foi maior do que para os outros métodos. Tal fato pode ser devido às menores dimensões do corpo-de-prova. Como possuem seção menor, a presença ou a ausência de apenas um filamento na região onde ocorreu a ruptura pode levar a diferenças significativas entre os resultados. Além disso, o dano que cada corpo-de-prova sofre na primeira etapa do ensaio pode diferir entre os corpos-de-prova da mesma série, contribuindo para o maior desvio na resposta pós-fissuração.

\subsection{Resultados obtidos com o ensaio da norma EN 14651}

Para cada corpo-de-prova, foi obtida uma curva de carga por abertura de fissura e para cada conjunto de corpos-de-prova do mesmo traço, foi calculado seu valor médio. O gráfico 6.19 apresenta as curvas para o concreto CRF 35 reforçado com a macrofibra polimérica nas dosagens de $3,0,4,5$ e $6,0 \mathrm{~kg} / \mathrm{m}^{3}$. O gráfico 6.20 apresenta as curvas para o concreto CRF 35 reforçado com a fibra de aço nas dosagens de 15,0, 25,0 e $35,0 \mathrm{~kg} / \mathrm{m}^{3}$. O gráfico 6.21 apresenta as curvas médias para o traço de concreto reforçado com as duas fibras. 


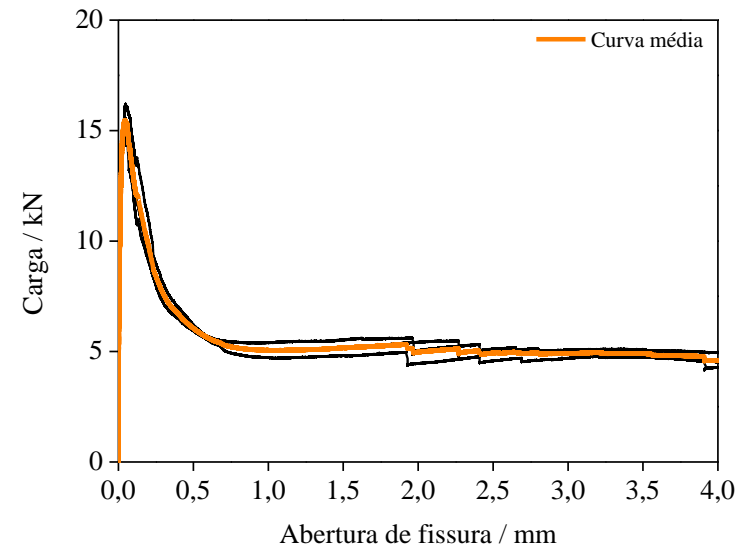

(a)

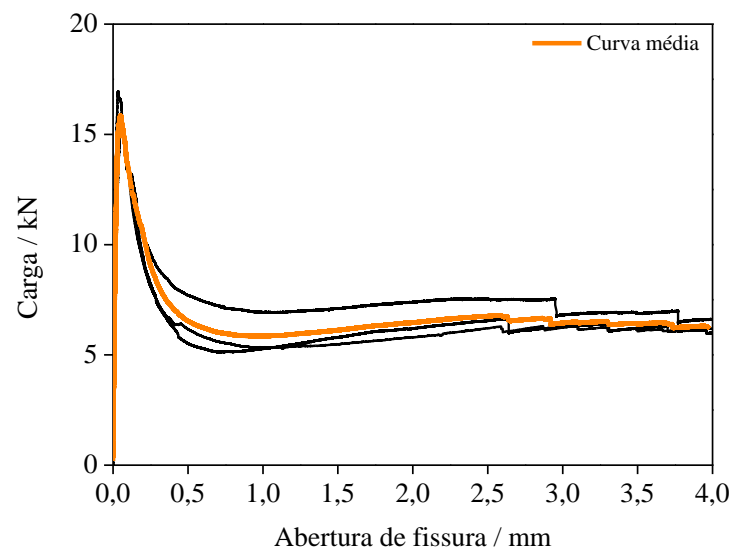

(b)

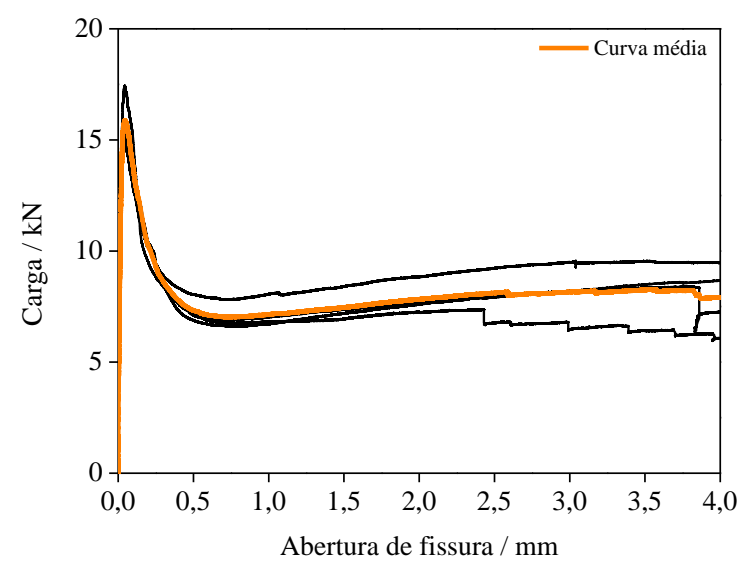

(c)

Gráfico 6.19 - Curvas de carga por abertura de fissura obtidas com o traço CRF 35, utilizando-se a macrofibra polimérica, segundo EN 14651: (a) $3,0 \mathrm{~kg} / \mathrm{m}^{3}$; (b) $4,5 \mathrm{~kg} / \mathrm{m}^{3}$; (c) $6,0 \mathrm{~kg} / \mathrm{m}^{3}$. 


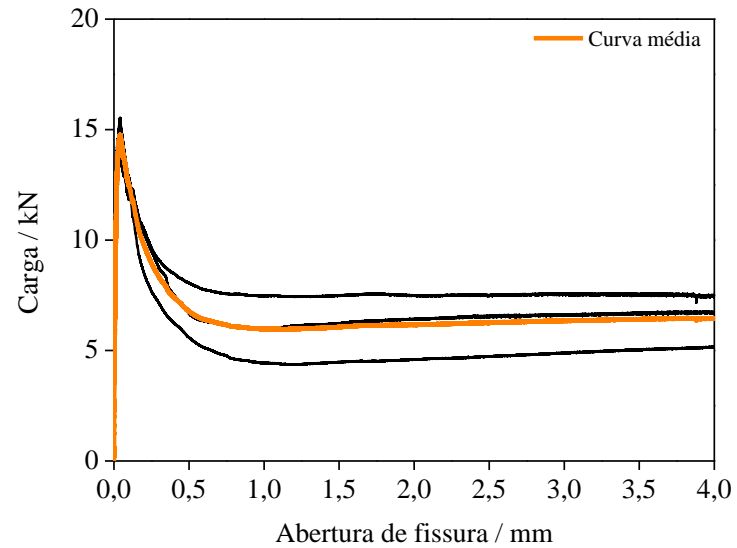

(a)

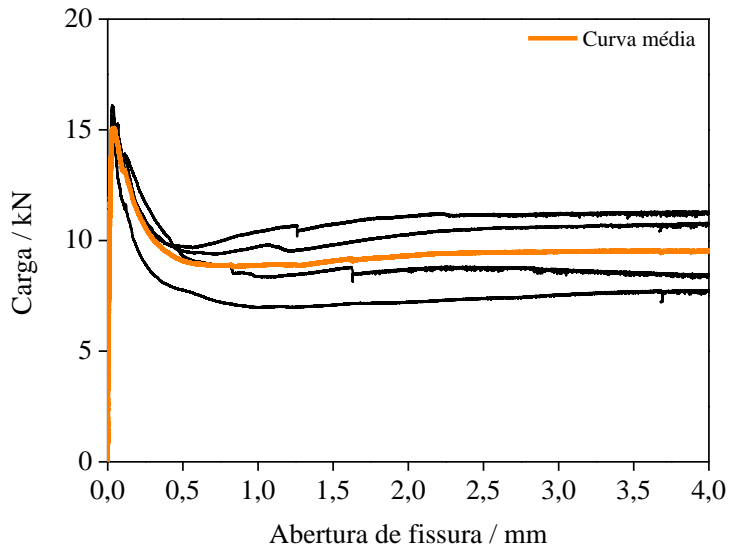

(b)

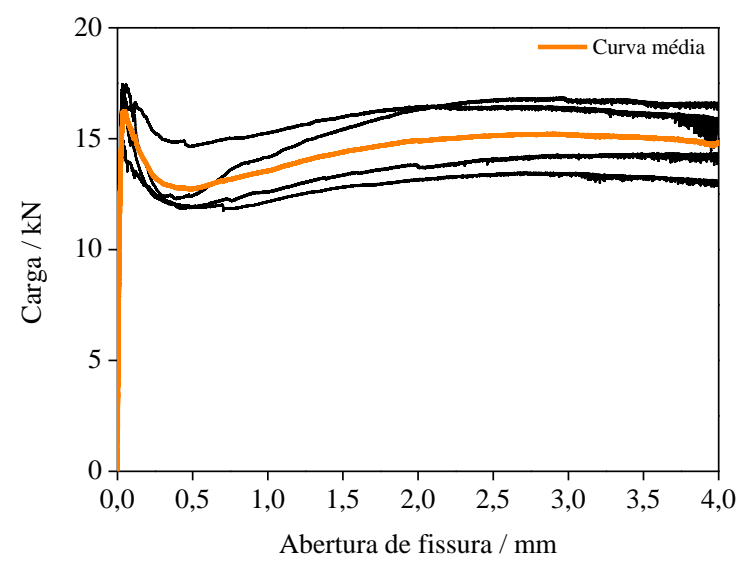

(c)

Gráfico 6.20 - Curvas de carga por abertura de fissura obtidas com o traço CRF 35, utilizando-se a fibra de aço, segundo EN 14651: (a) $15,0 \mathrm{~kg} / \mathrm{m}^{3}$; (b) $25,0 \mathrm{~kg} / \mathrm{m}^{3}$; (c) $35,0 \mathrm{~kg} / \mathrm{m}^{3}$.

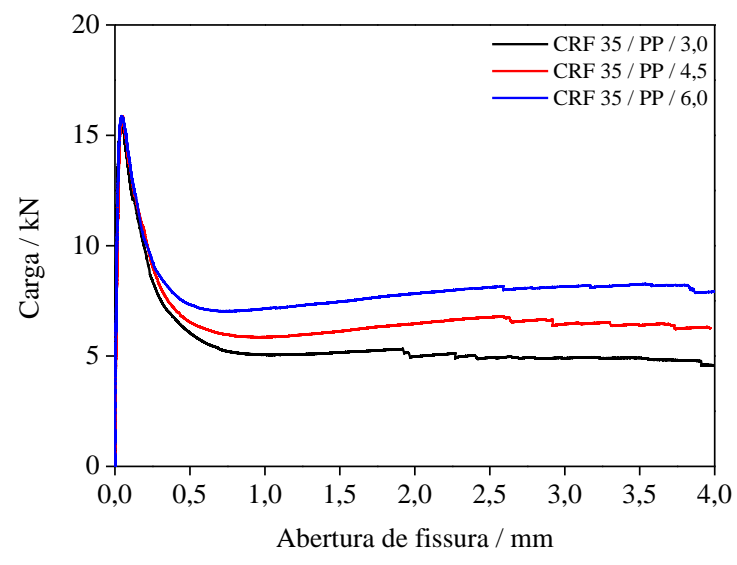

(a)

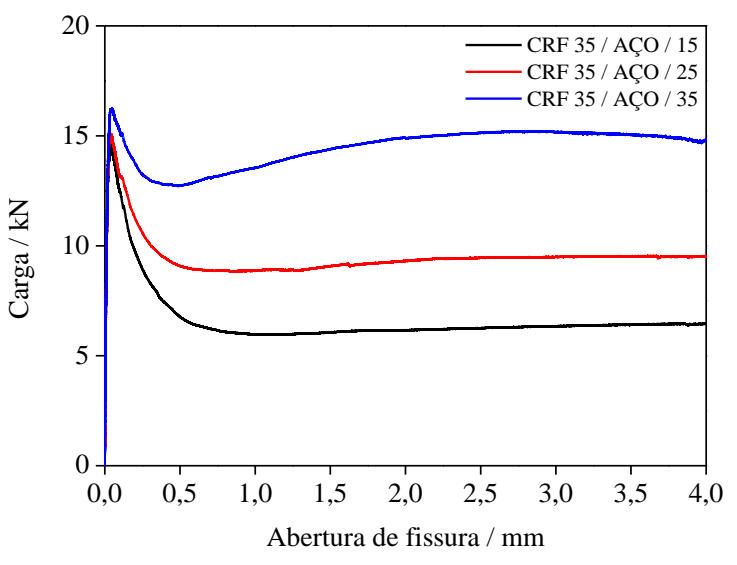

(b)

Gráfico 6.21 - Curvas médias de carga por abertura de fissura, segundo EN 14651, obtidas com o traço CRF 35 reforçado com a macrofibra polimérica (a) e com a fibra de aço (b). 
A partir da análise das curvas experimentais, foram calculados o limite de proporcionalidade e as resistências residuais em $0,50 \mathrm{~mm}$ e $2,5 \mathrm{~mm}$ de abertura de fissura utilizando as equações (4.7) e (4.8), além das relações $f_{R, 1} / L O P$ e $f_{R, 3} / f_{R, 1}$. Nos cálculos das razões entre as resistências residuais e a resistência referente ao limite de proporcionalidade foram utilizados os valores médios ao invés dos valores característicos como recomenda a norma. Isto ocorreu pelo fato da amostragem ser reduzida e não ser possível estabelecer valores característicos com precisão.

Os resultados obtidos estão mostrados na tabela 6.8 .

Tabela 6.8 - Resultados obtidos com as curvas carga por abertura de fissura dos traços CRF 35 / PP e CRF 35 / AÇO, segundo EN 14651.

\begin{tabular}{ccccccc}
\hline Traço & $\begin{array}{c}\text { Dosagem de fibra } / \\
\mathbf{k g} / \mathbf{m}^{\mathbf{3}} \text { (\% em volume) }\end{array}$ & $\mathbf{L O P} / \mathbf{M P a}$ & $\mathbf{f}_{\mathbf{R}, \mathbf{1}} / \mathbf{M P a}$ & $\mathbf{f}_{\mathbf{R}, \mathbf{3}} / \mathbf{M P a}$ & $\mathbf{R a z a ̃ o} \mathbf{f}_{\mathbf{R}, \mathbf{1}} / \mathbf{L O P}$ & $\mathbf{R a z a ̃ o} \mathbf{f}_{\mathbf{R}, \mathbf{3}} / \mathbf{f}_{\mathbf{R}, \mathbf{1}}$ \\
\hline \multirow{2}{*}{$\begin{array}{c}\text { CRF 35 / } \\
\text { PP }\end{array}$} & $3,0(0,33)$ & $4,46 \pm 0,12$ & $1,72 \pm 0,04$ & $1,41 \pm 0,08$ & $0,39 \pm 0,01$ & $0,82 \pm 0,04$ \\
\cline { 2 - 7 } & $4,5(0,50)$ & $4,70 \pm 0,23$ & $1,86 \pm 0,32$ & $1,94 \pm 0,19$ & $0,40 \pm 0,08$ & $1,06 \pm 0,12$ \\
\hline \multirow{2}{*}{$\begin{array}{c}\text { CRF 35 / } \\
\text { AÇO }\end{array}$} & $6,0(0,66)$ & $4,56 \pm 0,25$ & $2,08 \pm 0,14$ & $2,26 \pm 0,28$ & $0,46 \pm 0,04$ & $1,09 \pm 0,11$ \\
\cline { 2 - 7 } & $15,0(0,19)$ & $4,20 \pm 0,24$ & $1,92 \pm 0,36$ & $1,78 \pm 0,41$ & $0,45 \pm 0,06$ & $0,92 \pm 0,07$ \\
\hline
\end{tabular}

De acordo com os dados apresentados na tabela 6.8, pode ser observado que a macrofibra polimérica apresentou o comportamento de slip-hardening para os teores de 4,5 e $6,0 \mathrm{~kg} / \mathrm{m}^{3}$. A fibra de aço apresentou o mesmo comportamento para os teores de 25,0 e $35,0 \mathrm{~kg} / \mathrm{m}^{3}$.

Assim como nos resultados obtidos pela norma ASTM C1609, houve maior dispersão para as resistências residuais com a fibra de aço e os dados também apresentaram heterocedasticidade. Devido à pequena área da superfície de fratura (em relação ao comprimento da fibra), o número de fibras nessa posição é bastante diferente dentre os corpos-de-prova da mesma série. Outro fator que pode contribuir para a maior dispersão é a alta rigidez das fibras de aço, que pode dificultar sua homogeneização e orientação no momento da moldagem (di PRISCO; PLIZZARI; VANDEWALLE, 2009).

Os resultados apresentados na tabela 6.8 foram utilizados para a produção dos gráficos 6.22 e 6.23, que representam a correlação entre a resistência residual para abertura de fissura de $0,50 \mathrm{~mm}$ e $2,50 \mathrm{~mm}$ com o teor de fibra, respectivamente. Devido ao menor número de corpos-de-prova utilizados nesse ensaio, foram feitos gráficos de dispersão, ao invés de 
boxplots. As regressões foram obtidas a partir dos valores médios da resistência residual para cada teor de fibra e podem ser utilizadas somente para o intervalo de dosagens estudado.

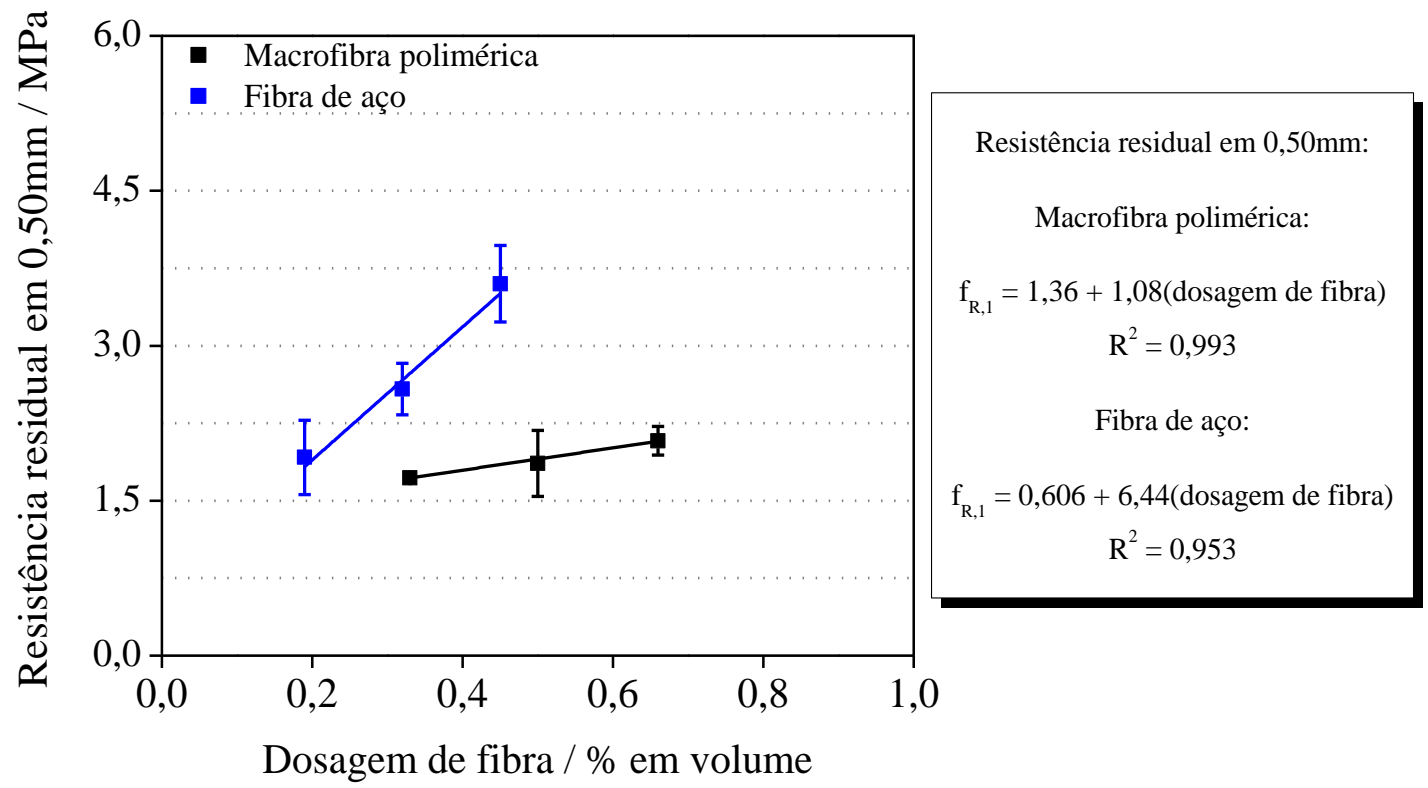

Gráfico 6.22 - Resistência residual para abertura de fissura de 0,50mm, para o concreto CRF 35 reforçado com a macrofibra polimérica e com a fibra de aço, segundo EN 14651.

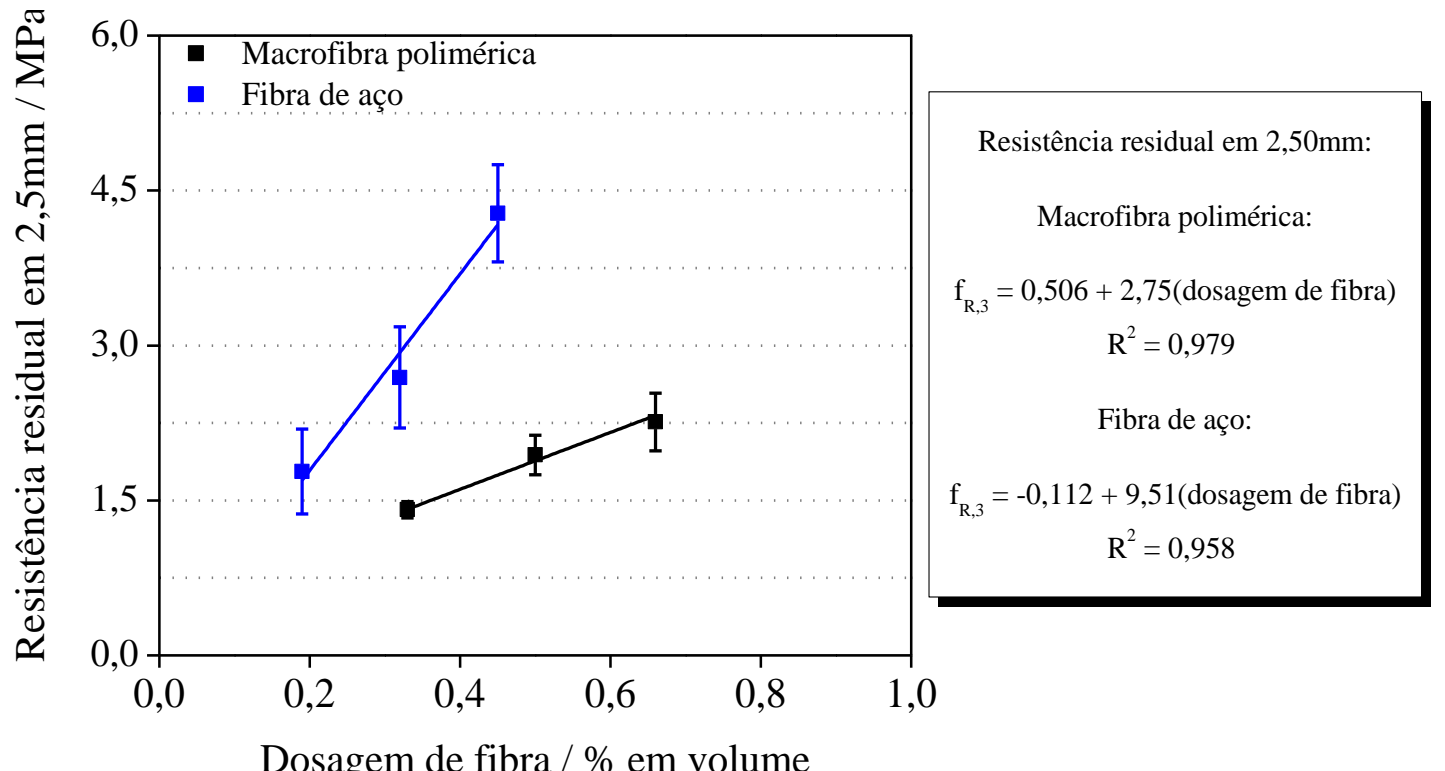

Gráfico 6.23 - Resistência residual para abertura de fissura de 2,50mm, para o concreto CRF 35 reforçado com a macrofibra polimérica e com a fibra de aço, segundo EN 14651. 
Como esperado, a fibra de aço proporciona maior resistência residual do que a macrofibra polimérica para teores equivalentes. Essa diferença é mais acentuada para a resistência na menor abertura de fissura $\left(f_{R, 1}\right)$ devido ao alto módulo da fibra de aço. Ambas as fibras atendem os critérios apresentados nas equações (4.9) e (4.10), com relações $f_{R, 1} /$ LOP e $f_{R, 3} / f_{R, 1}$ superiores a 0,4 e 0,5 , respectivamente.

Segundo os critérios apresentados na tabela 4.1, a macrofibra polimérica e a fibra de aço podem receber a classificação mostrada na tabela 6.9.

Tabela 6.9 - Classificação de desempenho segundo critérios apresentados no Model Code fib 2010.

\begin{tabular}{ccc}
\hline \multirow{2}{*}{ Fibra } & $\begin{array}{c}\text { Dosagem de fibra / } \\
\mathbf{k g} / \mathbf{m}^{\mathbf{3}} \mathbf{( \% \text { em volume } )}\end{array}$ & Classificação de desempenho \\
\hline \multirow{2}{*}{$\begin{array}{c}\text { Macrofibra } \\
\text { polimérica }\end{array}$} & $3,0(0,33)$ & $1,5 \mathrm{~b}$ \\
\cline { 2 - 3 } & $4,5(0,50)$ & $1,5 \mathrm{~b}$ \\
\hline \multirow{2}{*}{ Fibra de aço } & $6,0(0,66)$ & $2,0 \mathrm{~b}$ \\
\cline { 2 - 3 } & $15,0(0,19)$ & $1,5 \mathrm{~b}$ \\
\cline { 2 - 3 } & $25,0(0,32)$ & $2,5 \mathrm{~b}$ \\
\hline
\end{tabular}

Para avaliar os dados experimentais, os resultados de resistência residual obtidos com o concreto reforçado com a macrofibra polimérica foram comparados aos publicados por Buratti, Mazzotti e Savoia (2011), que estudaram a mesma macrofibra polimérica na dosagem de $4,8 \mathrm{~kg} / \mathrm{m}^{3}$ em um concreto com resistência média no LOP de 4,3MPa. Como a dosagem utilizada por esses autores é diferente da utilizada nesse plano experimental, por meio das regressões dos gráficos 6.22 e 6.23 foram obtidos os valores de $f_{R, 1}$ e $f_{R, 3}$ para a dosagem de $4,8 \mathrm{~kg} / \mathrm{m}^{3}$. Os valores estão comparados na tabela 6.10 .

Tabela 6.10 - Comparação de valores de resistência residual obtidos com o concreto reforçado a macrofibra polimérica no teor de $4,8 \mathrm{~kg} / \mathrm{m}^{3}$ com os valores publicados por Buratti, Mazzotti e Savoia (2011).

\begin{tabular}{cccc}
\hline $\begin{array}{c}\text { Resistência } \\
\text { residual }\end{array}$ & $\begin{array}{c}\text { Valor obtido por regressão } \\
\text { exponencial / MPa }\end{array}$ & $\begin{array}{c}\text { Valor publicado por Buratti, } \\
\text { Mazzotti e Savoia (2011) / MPa }\end{array}$ & Diferença / \% \\
\hline $\mathrm{f}_{\mathrm{R}, 1}$ & 1,93 & 1,49 & $+29,5$ \\
\hline $\mathrm{f}_{\mathrm{R}, 3}$ & 1,96 & 1,59 & $+23,2$ \\
\hline
\end{tabular}

As regressões mostradas nos gráficos 6.22 e 6.23 apresentaram alta aderência aos valores médios experimentais, dados os altos valores de $\mathrm{R}^{2}$. Comparando os valores calculados com os publicados pelos autores, foi obtido, aproximadamente, $30 \%$ de diferença entre os resultados. Essa alta diferença pode ser devida ao concreto utilizado, operador, tipo de equipamento e variáveis de ensaio. 
Os resultados de resistência residual obtidos com o concreto reforçado com a fibra de aço foram comparados aos publicados por Barros et al (2005), que estudaram a mesma fibra de aço nas dosagens 15,25 e $35 \mathrm{~kg} / \mathrm{m}^{3}$, em um concreto com resistência média à compressão de 40MPa. Nesse artigo, estão apenas os dados da resistência residual $\mathrm{f}_{\mathrm{R}, 1}$. A comparação está mostrada na tabela 6.11. Os resultados estão abaixo dos publicados por Barros et al (2005), podendo essa diferença ser devida à maior resistência da matriz utilizada pelos autores, o que proporcionaria maior resistência residual ao concreto reforçado com a fibra de aço.

Tabela 6.11 - Comparação de valores de resistência residual $f_{R, 1}$ obtidos com o concreto reforçado com a fibra de aço nos teores de 15,25 e $35 \mathrm{~kg} / \mathrm{m}^{3}$ publicados por Barros et al (2005).

\begin{tabular}{cccc}
\hline $\begin{array}{c}\text { Teor de fibra / } \\
\mathbf{k g} / \mathbf{m}^{\mathbf{3}}\end{array}$ & $\begin{array}{c}\text { Valor obtido neste programa } \\
\text { experimental / } \mathbf{M P a}\end{array}$ & $\begin{array}{c}\text { Valor publicado por } \\
\text { Barros et al (2005) / MPa }\end{array}$ & Diferença / \% \\
\hline 15 & 1,92 & 2,12 & $-9,4$ \\
\hline 25 & 2,58 & 3,06 & $-15,7$ \\
\hline 35 & 3,60 & 4,01 & $-10,2$ \\
\hline
\end{tabular}




\section{Comparação de métodos de ensaio}

Este capítulo trata da comparação dos métodos de ensaio utilizados nesse programa experimental, sendo subdivido nos seguintes itens:

a) Correlação entre os ensaios ASTM C1609 e ASTM C1399 para os concretos reforçados com a macrofibra polimérica, pois a amostragem para esses ensaios foi maior (três traços de concreto e seis teores de fibra);

b) Correlação entre os ensaios ASTM C1609 e EN 14651 para os concretos reforçados com a macrofibra polimérica e com a fibra de aço, pois as composições utilizadas para o segundo método foram reduzidas. Nessa comparação, foram analisadas as resistências residuais no estado limite de serviço e último, para ambos os métodos de ensaio;

c) Correlação entre JSCE-SF4 e ASTM C1609 para os concretos reforçados com a macrofibra polimérica e com a fibra de aço e entre JSCE-SF4 e ASTM C1399 para os concretos reforçados com a macrofibra polimérica.

Para todas as correlações, foi encontrada uma função para comparar as resistências residuais obtidas a partir de cada método. As variáveis utilizadas para as análises estão descritas no item 7.1. A comparação entre os métodos ASTM C1609 e ASTM C1399 está descrita no item 7.2, a comparação entre ASTM C1609 e EN 14651 no item 7.3 e a comparação entre JSCE-SF4 e as normas americanas no item 7.4.

A análise estatística contou com a grande colaboração dos alunos Leandro Ruiz Consentino e Rafael Ribeiro dos Santos (graduandos em Estatística), com a orientação do professor doutor Alexandre Galvão Patriota, do Centro de Estatística Aplicada do Instituto de Matemática e Estatística da Universidade de São Paulo. 


\subsection{Descrição das variáveis}

\subsubsection{Variáveis independentes}

As variáveis independentes, que estão sublinhadas em cada item, são:

a) Traço de concreto: $\underline{\mathrm{CRF} 30}, \underline{\mathrm{CRF} 35}$ e $\underline{\mathrm{CRF} 40}(30,35$ e 40MPa de resistência à compressão, respectivamente);

b) Tipo de fibra: $\underline{\mathrm{PP}}$ e $\underline{\mathrm{ACCO}}$ (macrofibra polimérica e fibra de aço). Fibra de aço somente utilizada no CRF 35;

c) Teor de fibra: $\underline{0,22}, \underline{0,33}, \underline{0,50}, \underline{0,66}, \underline{0,82}, \underline{1,0} \%$ em volume para a macrofibra polimérica e $\underline{0,19}, \underline{0,32}$ e $\underline{0,45} \%$ em volume para a fibra de aço.

\subsubsection{Variáveis dependentes}

As variáveis dependentes, que estão sublinhadas em cada item, são:

a) ASTM C1609: $\underline{\mathrm{f}}_{150,0.75}$ e $\underline{\mathrm{f}}_{150,3.0}$ (resistências residuais nos deslocamentos verticais de 0,75 e 3,0mm, correspondentes ao ELS e ao ELU, respectivamente, com a unidade de $\mathrm{MPa})$;

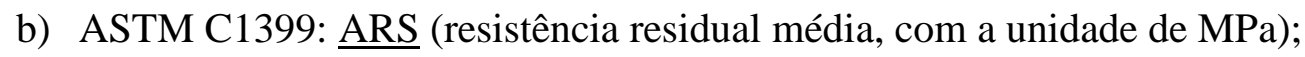

c) EN 14651: $\underline{f}_{R, 1}$ e $\underline{f}_{R, 3}$ (resistências residuais para abertura de fissura de 0,50 e 2,50mm, correspondentes ao ELS e ao ELU, respectivamente, com a unidade de MPa).

\subsection{Comparação entre os métodos ASTM C1609 e ASTM C1399}

Inicialmente, estão apresentados os gráficos 7.1, 7.2 e 7.3, com os valores das resistências residuais pelo teor de macrofibra polimérica, para ambos os métodos de ensaio, 
referentes aos traços CRF 30, CRF 35 e CRF 40. Pode ser observado que os valores de resistência residual não apresentam a mesma variância para todos dados amostrais e, portanto, são caracterizados como heterocedásticos. Quanto maior a resistência residual (maior teor de fibra), maior a dispersão entre os resultados.

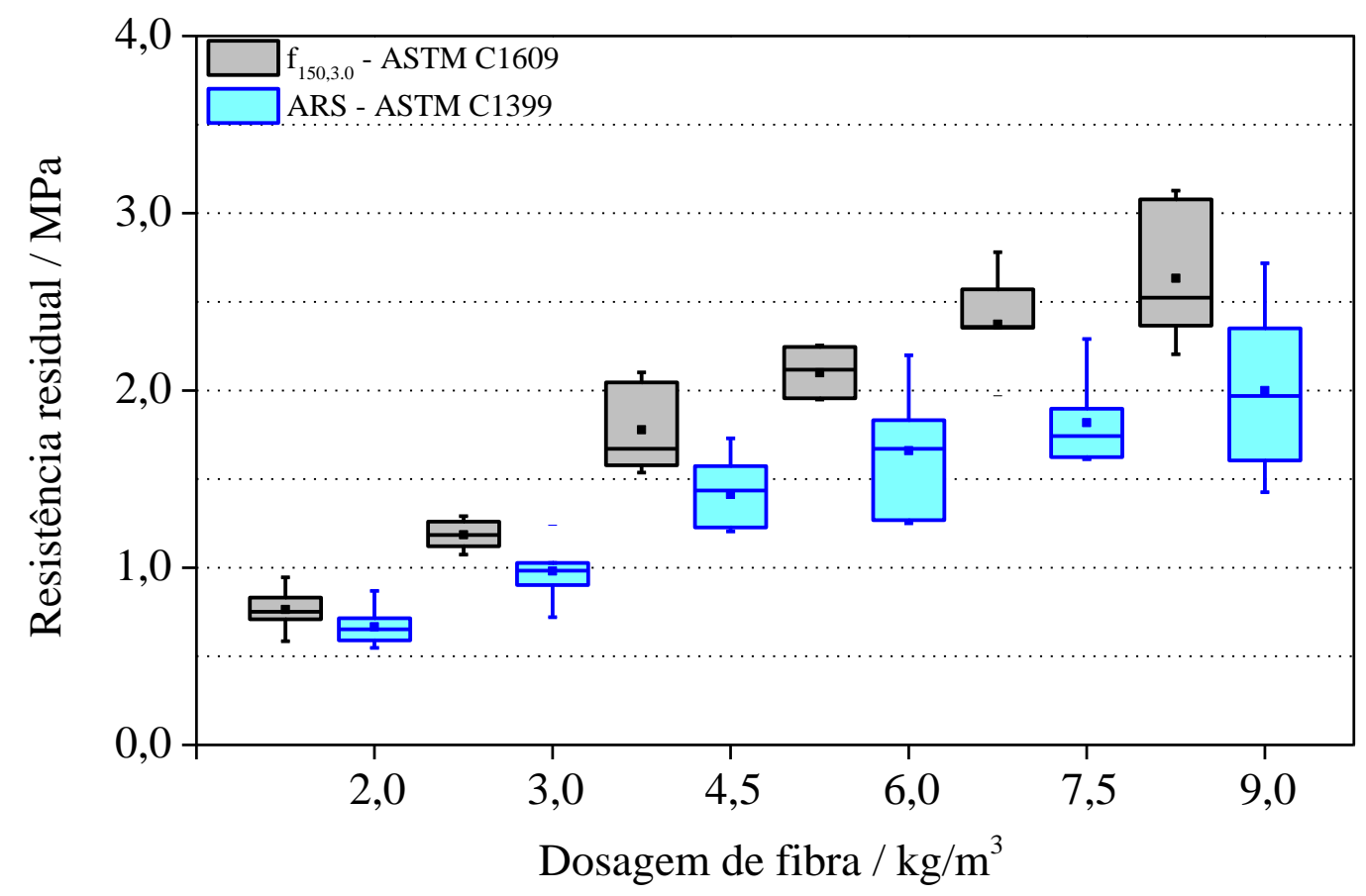

Gráfico 7.1 - Resistências residuais ( $\mathrm{f}_{150,3.0}$ e ARS) pelo teor de macrofibra polimérica, obtidas com o traço CRF 30. 


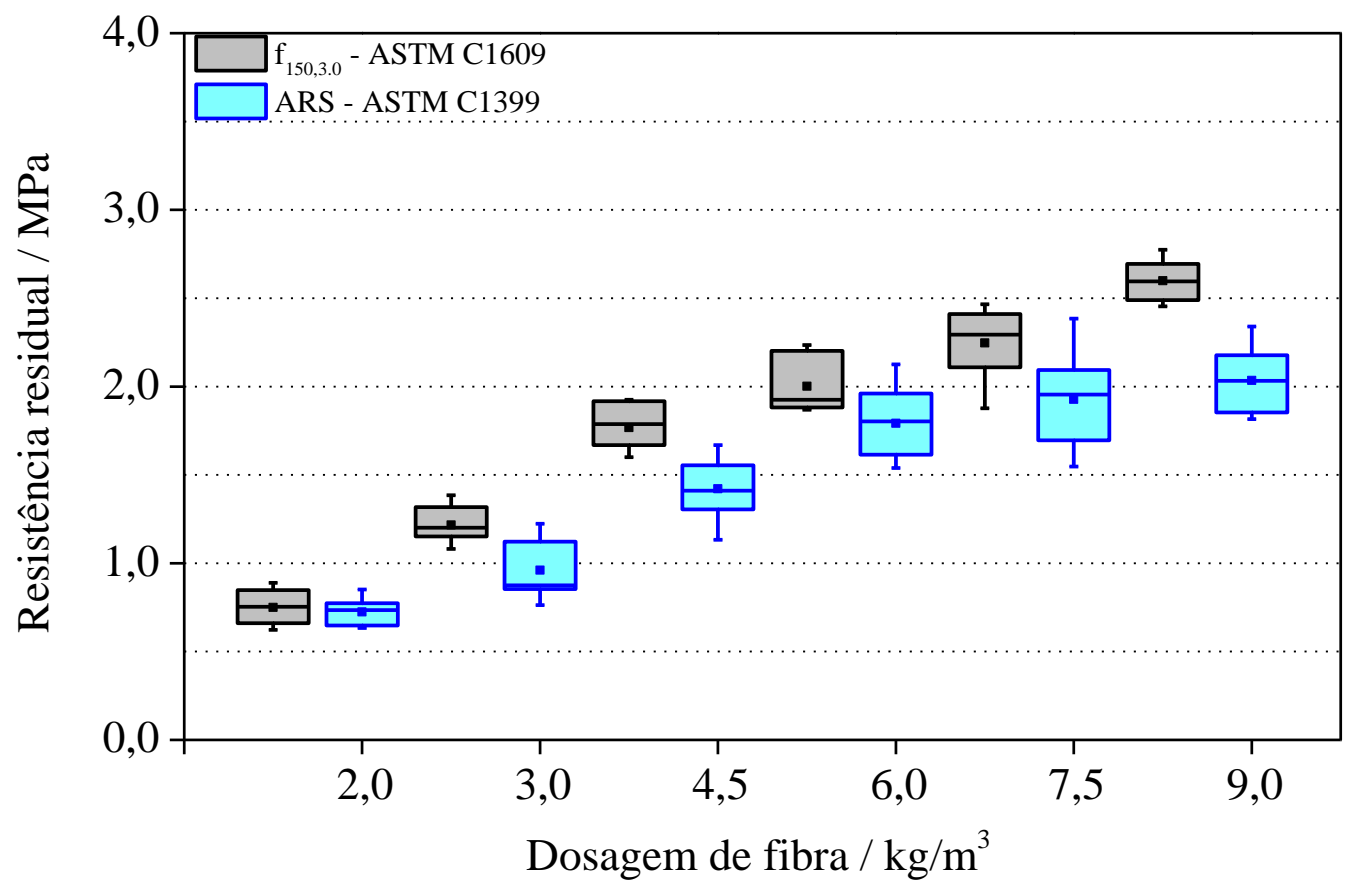

Gráfico 7.2 - Resistências residuais ( $f_{150,3.0}$ e ARS) pelo teor de macrofibra polimérica, obtidas com o traço CRF 35.

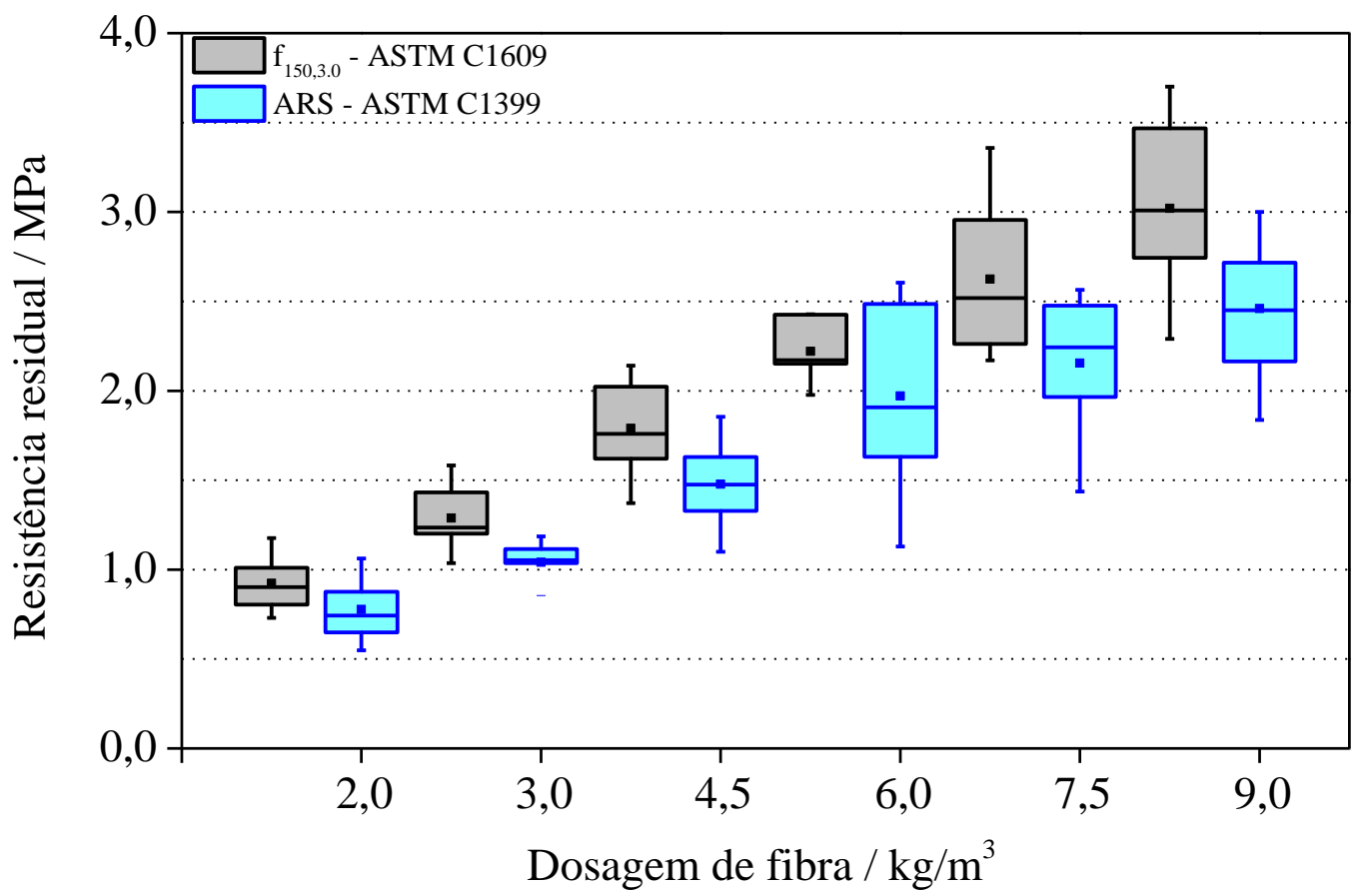

Gráfico 7.3 - Resistências residuais ( $\mathrm{f}_{150,3.0}$ e ARS) pelo teor de macrofibra polimérica, obtidas com o traço CRF 40.

Devido à heterocedasticidade dos dados experimentais, optou-se pela aplicação do modelo de regressão Gama para a modelagem dos resultados (PAULA, 2010). Esse tipo de 
regressão modela a média (esperança estatística) da resistência residual, segundo o método de ensaio (ASTM C1609 ou ASTM C1399), o traço de concreto (CRF 30, CRF 35 ou CRF 40) e o teor de fibra (em \% volume).

No gráfico 7.4, verifica-se que este modelo teve um excelente ajuste, pois os resíduos estão distribuídos aleatoriamente em torno de zero (gráfico 7.4 (a)), além de sua média também ser próxima de zero. Os resíduos padronizados não apresentaram nenhum tipo de tendência em relação aos valores preditos (gráfico 7.4 (b)). Esse modelo estabiliza a variância, ou seja, transforma os dados heterocedásticos em homocedásticos, deixando-os em uma distribuição normal.

Além disso, para reafirmar que o modelo gama tem excelente ajuste aos dados, no gráfico 7.5, que apresenta os percentis de probabilidades com envelopes gerados pelo modelo gama, não é observado nenhum ponto fora do envelope. Esse envelope foi gerado com uma banda de confiança de $95 \%$.

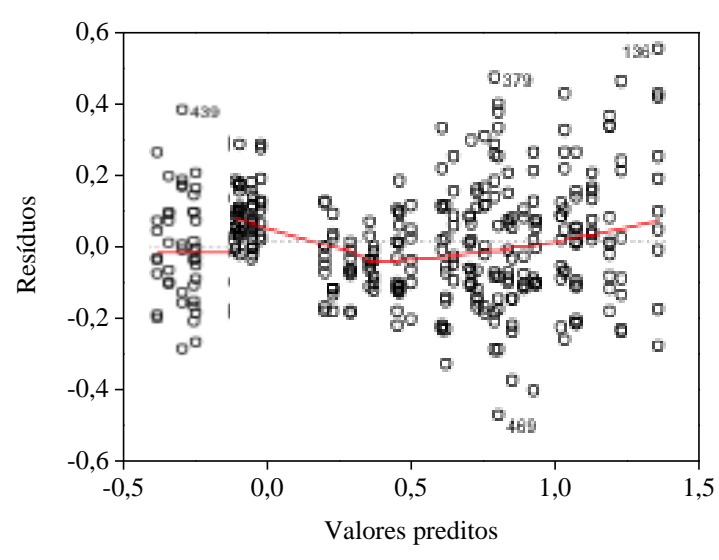

(a)

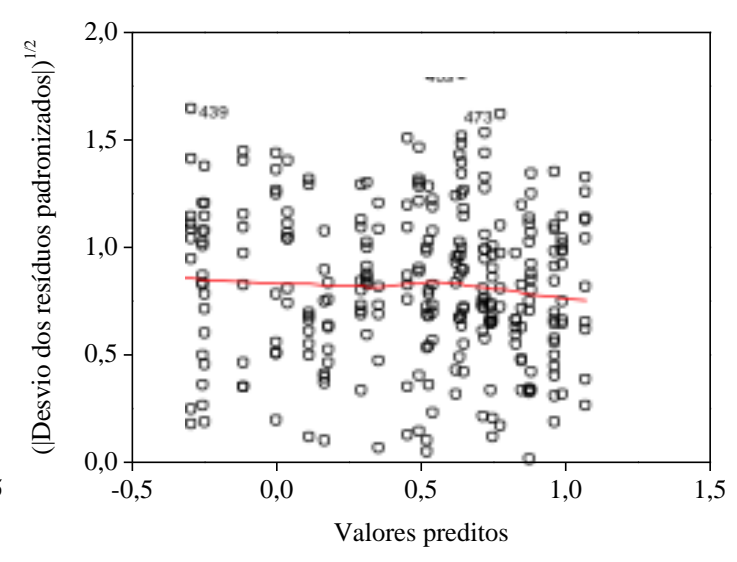

(b)

Gráfico 7.4 - Gráfico dos resíduos pelos valores preditos (a) e dos resíduos padronizados pelos valores preditos (b). 


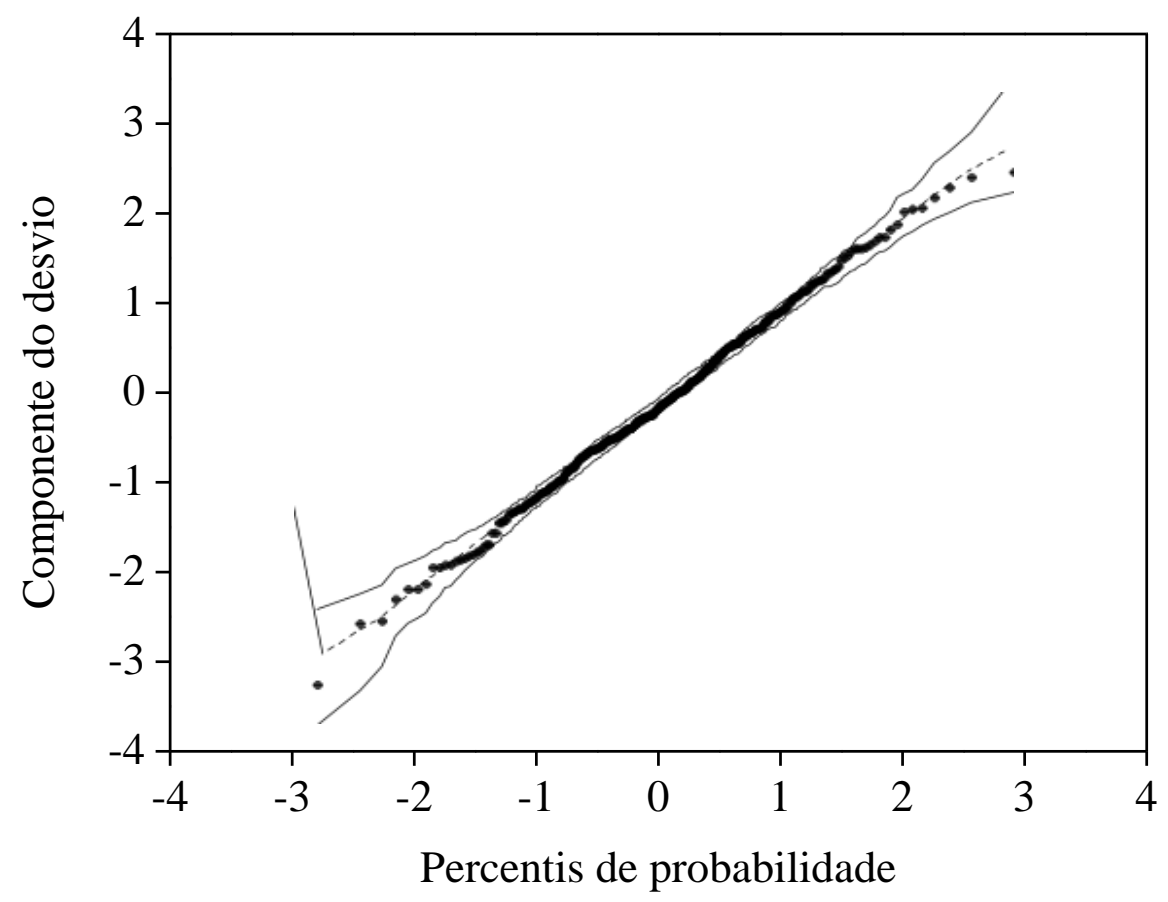

Gráfico 7.5 - Gráfico normal de probabilidades com envelope gerado pelo modelo gama, para a equação (7.3).

Inicialmente, foi utilizado o modelo gama com todos os fatores e interações (modelo saturado). Com o intuito de reduzir o modelo saturado, foi utilizado o algoritmo stepAIC do pacote MASS do programa $R$. O modelo linear generalizado reduzido obtido através deste software é dado na equação (7.1), onde foi adotado a resistência residual média $f_{150,3.0}$ para o concreto CRF 30 como referência. A partir dessa referência, foram calculadas as parcelas referentes ao tipo de concreto, ao método de ensaio e ao teor de fibra que alteram o valor dessa resistência.

$$
E(Y)=\exp \left[\left(\mu+\alpha_{1} X_{1}+\alpha_{2} X_{2}+\beta X_{3}+\left(\gamma+\sigma X_{3}\right) d^{-1 / 2}\right]\right.
$$

Onde,

E (Y): esperança do valor médio da resistência residual f f $_{150,3.0}$ (ASTM C1609) (MPa);

Y: resistência residual média;

$\mu$ : logaritmo da média da resistência residual $\mathrm{f}_{150,3.0}$ para o concreto CRF 30;

$\alpha_{1}$ : efeito do concreto CRF 35 no valor da resistência residual do concreto CRF 30;

$\alpha_{2}$ : efeito do concreto CRF 40 no valor da resistência residual do concreto CRF 30;

$\beta$ : efeito do método de ensaio ASTM C1399 no valor da resistência residual do concreto CRF 30 ; 
$\gamma$ : efeito do teor de fibra (no termo $1 / \sqrt{\text { dosagem }}$ ) sobre a resistência residual;

$\sigma:$ efeito do método de ensaio ASTM C1399 sobre o efeito do teor de fibra (no termo $1 / \sqrt{\text { dosagem }})$ sobre a resistência residual;

d: dosagem de fibra (\% em volume);

$\mathrm{X}_{1}$ : Concreto CRF 35 (1 para sim, 0 para o contrário);

$\mathrm{X}_{2}$ : Concreto CRF 40 (1 para sim, 0 para o contrário);

$\mathrm{X}_{3}$ : Método de ensaio ASTM C1399 (1 para sim, 0 para o contrário);

Foi utilizado o termo $1 / \sqrt{\text { dosagem }}$ no modelo de regressão, pois esse foi o termo encontrado por Figueiredo (1997), que relaciona o fator de tenacidade com a dosagem de fibra pela equação (7.2).

$$
\overline{\sigma_{\mathrm{b}}}=\frac{\mathrm{A}}{\mathrm{B}^{\wedge}(0,1 \sqrt{\text { dosagem }})}
$$

Onde:

A e B: constantes

Os valores estimados para os parâmetros da equação (7.1) estão apresentados na tabela 7.1. Substituindo esses valores na equação (7.1), obtém-se a equação (7.3). De acordo com os p-valores, pode ser observado que o termo $\alpha_{1}$ (efeito do concreto CRF 35) pode não ser significativo, pois apresenta p-valor superior a 0,05. Esse fator é o que representa menor interferência nos resultados de resistência residual do CRF 30. O fator $\sigma$ (efeito do método ASTM C1399) apresenta menor significância que os demais, mas deve ser levado em conta na equação para o melhor ajuste da curva aos dados experimentais. Todos os demais fatores apresentam o p-valor inferior a 0,05, sendo significativos para a banda de confiança de $95 \%$. 
Tabela 7.1 - Valores estimados para os parâmetros utilizados na equação (7.1).

\begin{tabular}{cccc}
\hline Parâmetro & Estimado & Desvio padrão & p-valor \\
\hline$\mu$ & 2,04 & 0,05 & $<0,001$ \\
\hline$\alpha_{1}$ & 0,01 & 0,02 & 0,695 \\
\hline$\alpha_{2}$ & 0,12 & 0,02 & $<0,001$ \\
\hline$\beta$ & $-0,30$ & 0,06 & $<0,001$ \\
\hline$\gamma$ & $-1,08$ & 0,03 & $<0,001$ \\
\hline$\sigma$ & 0,08 & 0,04 & 0,073 \\
\hline
\end{tabular}

$E(Y)=\exp \left[\left(2,04+0,01 X_{1}+0,12 X_{2}-0,30 X_{3}+\left(-1,08+0,08 X_{3}\right) d^{-1 / 2}\right]\right.$

A partir da equação (7.3) e do modelo proposto, pode-se- concluir o seguinte:

a) A resistência residual média para o concreto CRF 35 é cerca de $1,0 \%\left(\mathrm{e}^{\alpha}{ }_{1}=\mathrm{e}^{0,01}=\right.$ 1,01) maior que a resistência residual média para o concreto CRF 30. A diferença obtida nos valores de resistência residual não é significativa para os teores de fibra estudados e é independente do método de ensaio utilizado;

b) A resistência residual média para o concreto CRF 40 é cerca de $12,7 \%\left(\mathrm{e}^{\alpha}{ }_{2}=\mathrm{e}^{0,12}=\right.$ 1,127 ) maior do que resistência residual média para o concreto CRF 30, para qualquer teor de fibra ou método de ensaio. Como o valor de $\alpha_{2}$ é significativamente diferente de zero, é possível concluir que a resistência residual média para o CRF 40 é maior do que o valor médio para o CRF 30, fixando-se o teor de fibra e o método de ensaio;

c) A resistência residual média no ensaio ASTM C1399 corresponde a 74,1\% $\left(\mathrm{e}^{\beta}=\mathrm{e}^{-0,30}\right.$ $=0,741)$ da resistência residual média em 3,0mm no ensaio ASTM C1609, para um teor de fibra suficientemente grande.

A equação (7.3) pode ser utilizada para definir as equações que descrevem a resistência residual para cada traço de concreto de acordo com cada ensaio. As equações obtidas, (7.4) a (7.9), estão mostradas na tabela 7.2.

Tabela 7.2 - Equações para determinação da resistência residual média para os diferentes traços de concreto e ensaios realizados.

\begin{tabular}{cll}
\hline Traço & \multicolumn{1}{c}{ ASTM C1609 } & \multicolumn{1}{c}{ ASTM C1399 } \\
\hline CRF 30 & $\mathrm{E}(\mathrm{Y})=\exp \left(2,04-1,08 \mathrm{~d}^{-1 / 2}\right) \mathbf{( 7 . 4 )}$ & $\mathrm{E}(\mathrm{Y})=\exp \left(1,74-1,00 \mathrm{~d}^{-1 / 2}\right) \mathbf{( 7 . 7 )}$ \\
\hline CRF 35 & $\mathrm{E}(\mathrm{Y})=\exp \left(2,05-1,08 \mathrm{~d}^{-1 / 2}\right) \mathbf{( 7 . 5 )}$ & $\mathrm{E}(\mathrm{Y})=\exp \left(1,75-1,00 \mathrm{~d}^{-1 / 2}\right) \mathbf{( 7 . 8 )}$ \\
\hline CRF 40 & $\mathrm{E}(\mathrm{Y})=\exp \left(2,16-1,08 \mathrm{~d}^{-1 / 2}\right) \mathbf{( 7 . 6 )}$ & $\left.\mathrm{E}(\mathrm{Y})=\exp \left(1,86-1,00 \mathrm{~d}^{-1 / 2}\right) \mathbf{( 7 . 9}\right)$ \\
\hline
\end{tabular}


Os gráficos 7.6. 7.7 e 7.8 apresentam os ajustes das curvas segundo os modelos da tabela 7.2 para os diferentes teores de fibra e métodos de ensaio para os concretos CRF 30, CRF 35 e CRF 40, respectivamente. As curvas obtidas para cada método de ensaio (ASTM C1609 e ASTM C1399), sempre crescentes, se mostram próximas para baixos teores e distanciam-se conforme o aumento do teor. Esse comportamento é verificado para todos os diferentes traços de concreto (CRF 30, CRF 35 e CRF 40). Verifica-se excelente ajuste das curvas modelo aos dados experimentais.

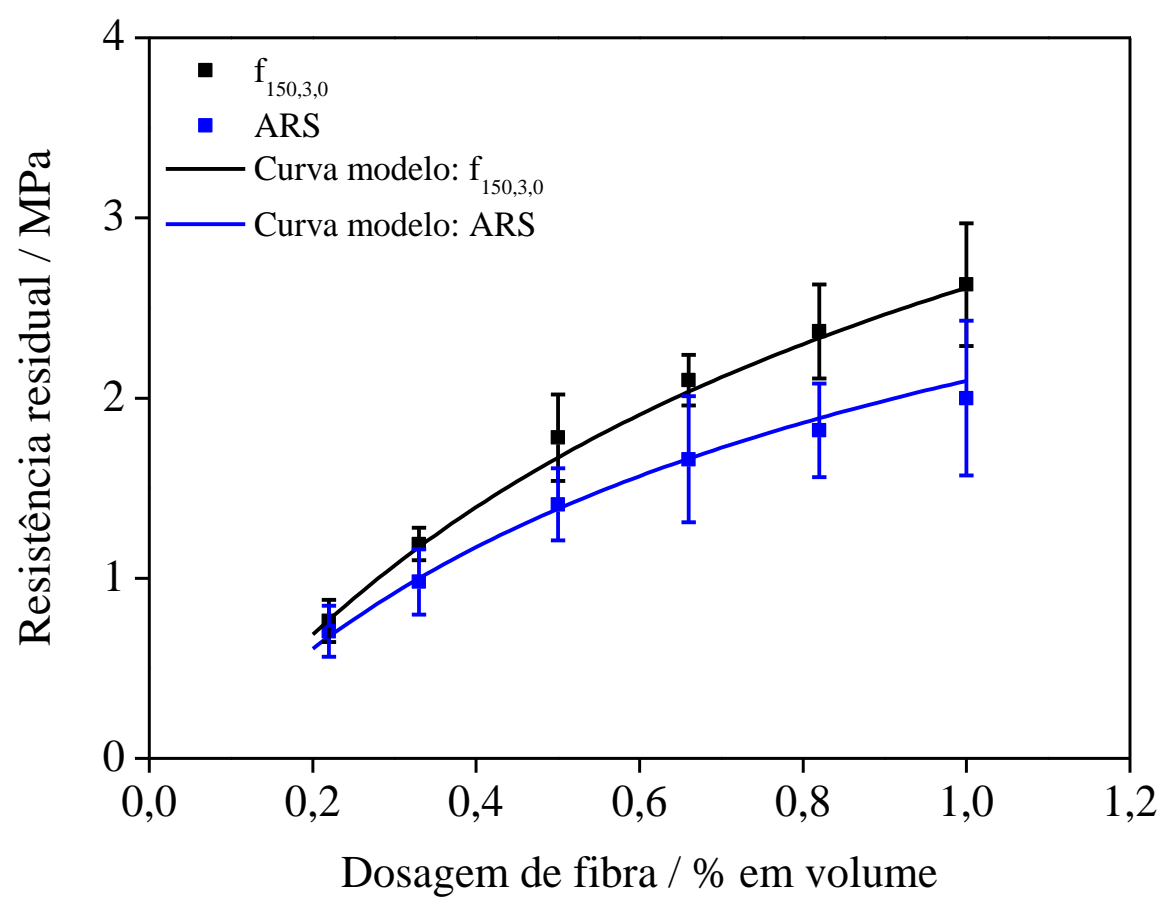

Gráfico 7.6 - Curvas de tendência entre os valores médios da resistência residual para os ensaios ASTM C1609 e ASTM C1399, para o traço CRF 30. 


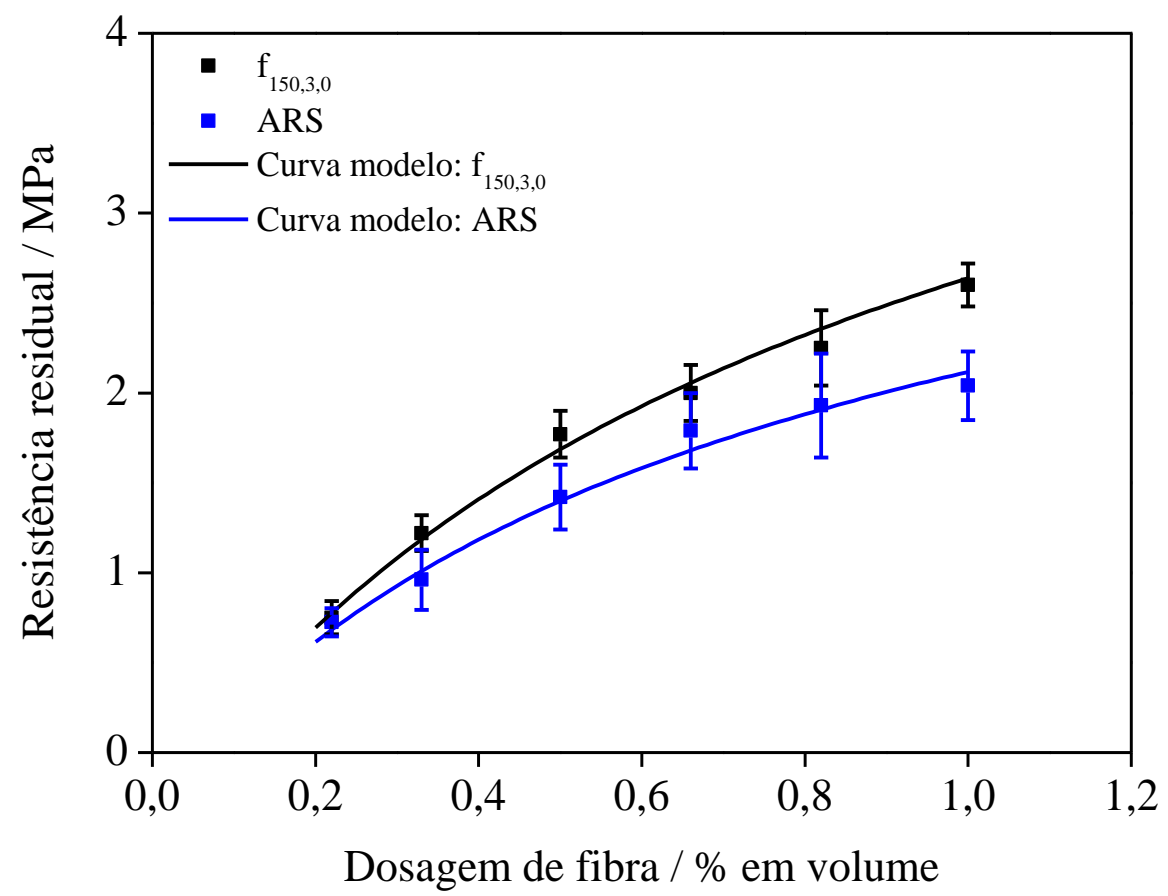

Gráfico 7.7 - Curvas de tendência entre os valores médios da resistência residual para os ensaios ASTM C1609 e ASTM C1399, para o traço CRF 35.

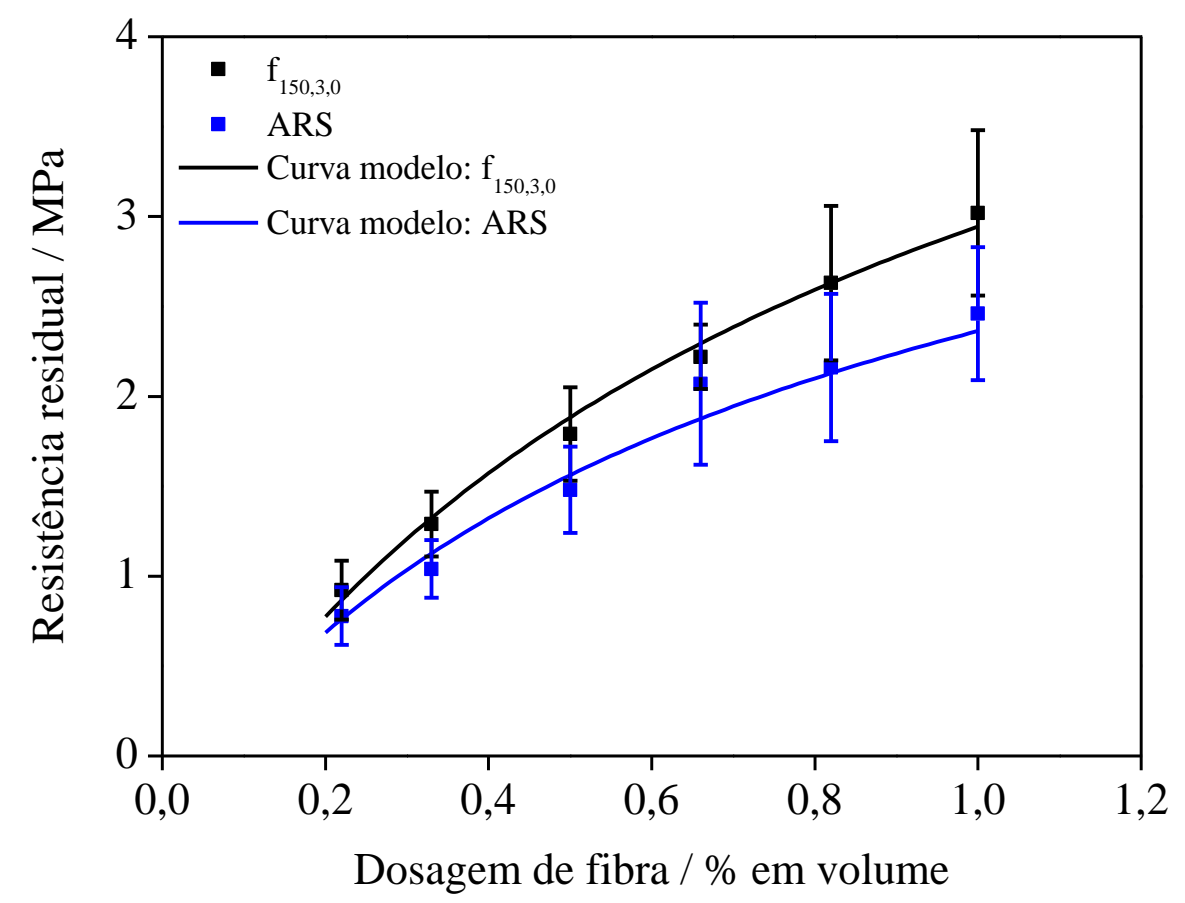

Gráfico 7.8 - Curvas de tendência entre os valores médios da resistência residual para os ensaios ASTM C1609 e ASTM C1399, para o traço CRF 40. 
Com o intuito de encontrar uma relação entre as resistências residuais médias segundo os ensaios ASTM C1609 e ASTM C1399, foi definida a razão entre as equações que descrevem as resistências residuais para os dois ensaios, ambas provenientes da equação (7.1), fixando-se o traço de concreto. As equações (7.10), (7.11) e (7.12), presentes na tabela 7.3, mostram o resultado encontrado.

Tabela 7.3 - Razões entre as equações dos modelos de resistência residual obtidas para os métodos ASTM C1609 e ASTM C1399.

\begin{tabular}{cc}
\hline Traço & Razão ASTM C1609 / ASTM C1399 \\
\hline CRF 30 & $\exp \left(0,30-0,08 \mathrm{~d}^{-1 / 2}\right)(\mathbf{7 . 1 0})$ \\
\hline CRF 35 & $\exp \left(0,30-0,08 \mathrm{~d}^{-1 / 2}\right)(\mathbf{7 . 1 1})$ \\
\hline CRF 40 & $\exp \left(0,30-0,08 \mathrm{~d}^{-1 / 2}\right)(\mathbf{7 . 1 2})$ \\
\hline
\end{tabular}

Pode ser observado que as razões obtidas dependem do teor de fibra, que possui uma interação com o método de ensaio. Além disso, as razões são idênticas entre si. Isso indica que a diferença entre os ensaios é a mesma, independentemente do traço de concreto.

Para melhor visualização, essa razão foi plotada no gráfico 7.9. Para baixos teores, a diferença entre os resultados é menor que com teores mais elevados, devido ao comportamento de slip-hardening ter sido mais pronunciado no ensaio realizado segundo a norma ASTM C1609.

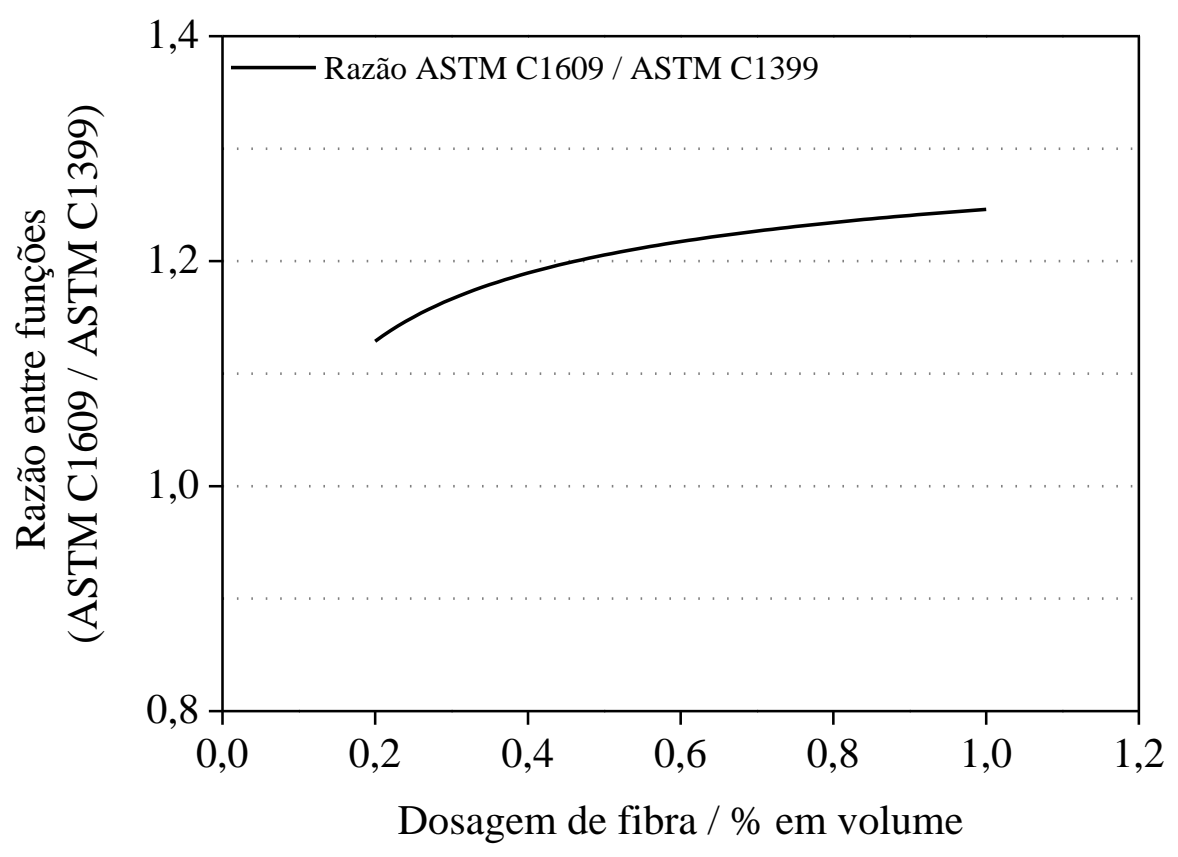

Gráfico 7.9 - Razão entre as funções obtidas para os traços CRF 30, CRF 35 e CRF 40. 


\subsection{Comparação entre os métodos ASTM C1609 e EN 14651}

Por meio dos mesmos métodos utilizados no item 7.2, a comparação entre os ensaios prescritos pelas normas ASTM C1609 e EN 14651 foi feita. Nesse caso, as resistências residuais correspondentes ao ELS $\left(f_{150,075}\right.$ e $\left.f_{R, 1}\right)$ e ao ELU $\left(f_{150,3.0}\right.$ e $\left.f_{R, 3}\right)$ estão diferenciadas nas fórmulas obtidas, sendo a resistência residual em $0,75 \mathrm{~mm}\left(\mathrm{f}_{150,075}\right)$, proveniente do ensaio ASTM C1609, utilizada como base para determinação da equação. A fórmula correspondente ao concreto reforçado com a macrofibra polimérica está mostrada na equação (7.13).

$E(Y)=\exp \left[\mu+\alpha_{1} X_{1}+\alpha_{2} X_{2}+\alpha_{12} X_{1} X_{2}+\left(\alpha_{3}+\alpha_{13} X_{1}+\alpha_{23} X_{2}+\alpha_{123} X_{1} X_{2}\right) d^{-1}\right]$

Onde,

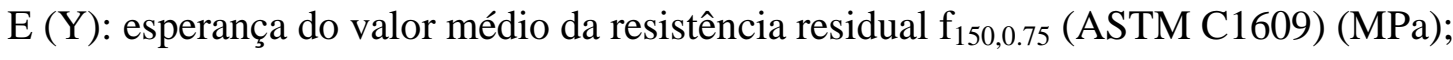

Y: resistência residual média;

$\mu$ : logaritmo da média da resistência residual $\mathrm{f}_{150,0.75}$;

$\alpha_{1}$ : efeito do método EN 14651 no valor da resistência residual $\mathrm{f}_{150,0.75}$. Utilizando-se esse termo e zerando-se os demais, obtém-se em $\mathrm{f}_{\mathrm{R}, 1}$;

$\alpha_{2}$ : efeito da medida no ELU no valor da resistência residual $\mathrm{f}_{150,0.75}$. Utilizando-se esse termo e zerando-se os demais, obtém-se em $\mathrm{f}_{150,3.0}$;

$\alpha_{12}$ : efeito da interação entre o método EN 14651 e a medida no ELU no valor da resistência residual $\mathrm{f}_{150,0.75}$;

$\alpha_{3}$ : efeito do teor de fibra (no termo $1 /$ dosagem) sobre a resistência residual $\mathrm{f}_{150,0.75}$;

$\alpha_{13}$ : efeito da interação entre o método EN 14651 e o teor de fibra no valor da resistência residual $\mathrm{f}_{150,0.75}$;

$\alpha_{23}$ : efeito da interação entre a medida no ELU e o teor de fibra no valor da resistência residual $\mathrm{f}_{150,0.75}$;

$\alpha_{123}$ : efeito da interação entre o método EN 14651, a medida no ELU e o teor de fibra no valor da resistência residual $\mathrm{f}_{150,0.75}$;

d: dosagem de fibra (\% em volume);

$\mathrm{X}_{1}$ : Método EN 14651 (1 para EN 14651, 0 para ASTM C1609);

$\mathrm{X}_{2}$ : Medida no ELU (1 para ELU, 0 para ELS); 
Os valores estimados para os parâmetros da equação (7.13) estão apresentados na tabela 7.4. Substituindo esses valores na equação (7.13), obtém-se a equação (7.14). De acordo com os p-valores, pode ser observado que os termos $\alpha_{1}$ e $\alpha_{12}$ (efeito do método EN 14651 e o efeito da interação desse método com a medida no ELU, respectivamente) podem não ser significativos, pois apresentam p-valores superiores a 0,05. Entretanto, como a amostragem desse ensaio foi baixa, esses fatores foram levados em conta na equação (7.14), pois, de acordo com os dados experimentais, foi verificada diferença em relação aos dados obtidos com o método ASTM C1609. Todos os demais fatores apresentam p-valor inferior a 0,05 , sendo significativos para a banda de confiança de $95 \%$.

Tabela 7.4 - Valores estimados para os parâmetros utilizados na equação (7.13), para o concreto reforçado com a macrofibra polimérica.

\begin{tabular}{cccc}
\hline Parâmetro & Estimado & Desvio padrão & p-valor \\
\hline$\mu$ & 1,04 & 0,03 & $<2 \times 10^{-16}$ \\
\hline$\alpha_{1}$ & $-0,15$ & 0,10 & 0,161 \\
\hline$\alpha_{2}$ & 0,20 & 0,04 & 0,000 \\
\hline$\alpha_{3}$ & $-0,28$ & 0,01 & $<2 \times 10^{-16}$ \\
\hline$\alpha_{12}$ & 0,19 & 0,15 & 0,191 \\
\hline$\alpha_{13}$ & 0,16 & 0,05 & 0,001 \\
\hline$\alpha_{23}$ & $-0,06$ & 0,01 & 0,000 \\
\hline$\alpha_{123}$ & $-0,13$ & 0,07 & 0,044
\end{tabular}

$$
\begin{aligned}
E(Y)= & \exp \left[\left(1,04-0,15 X_{1}+0,20 X_{2}+0,19 X_{1} X_{2}+\right.\right. \\
& \left.+\left(-0,28+0,16 X_{1}-0,06 X_{2}-0,13 X_{1} X_{2}\right) d^{-1}\right]
\end{aligned}
$$

No gráfico 7.10, são apresentados os percentis de probabilidades com envelopes gerados pelo modelo gama (PAULA, 2010), onde não é observado nenhum ponto fora da banda de confiança do envelope (95\%). Isso indica que o modelo utilizado foi adequado para estabelecer a comparação entre os dois métodos, para a macrofibra polimérica. 


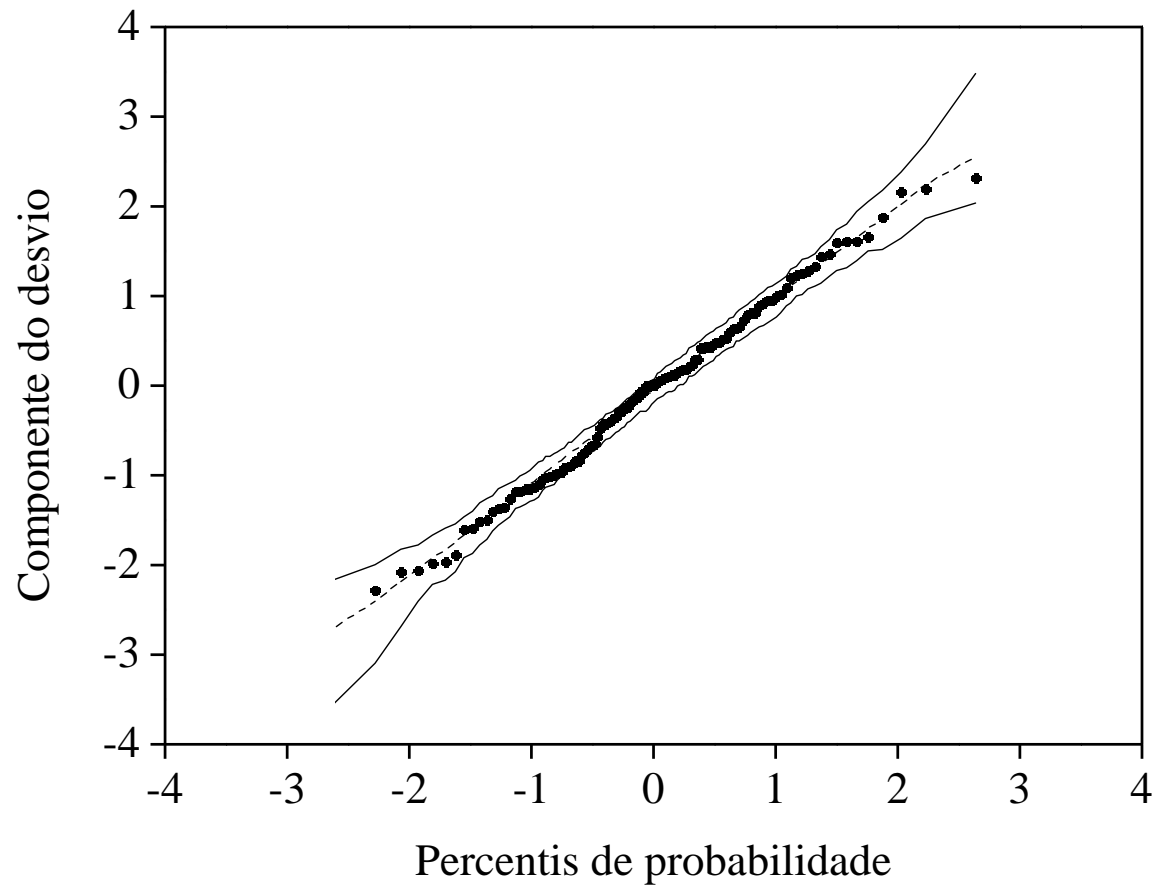

Gráfico 7.10 - Gráfico normal de probabilidades com envelope gerado pelo modelo gama, para a equação (7.14).

Para a fibra de aço, a equação (7.13) também se aplica. Entretanto, os valores estimados para os parâmetros dessa equação, listados na tabela 7.5, são diferentes. Substituindo-se esses valores na equação (7.13), obtém-se a equação (7.15). De acordo com os p-valores, pode ser observado que somente os termos $\mu$ e $\alpha_{3}$ (logaritmo da média da resistência residual $\mathrm{f}_{150,0.75}$ e efeito do teor de fibra no termo 1/dosagem, respectivamente) possuem valores inferiores a 0,05 . Entretanto, todos esses termos foram levados em conta na equação (7.15), devido melhor ajuste do modelo aos dados experimentais.

Tabela 7.5 - Valores estimados para os parâmetros utilizados na equação (7.15), para o concreto reforçado com a fibra de aço.

\begin{tabular}{cccc}
\hline Parâmetro & Estimado & Desvio padrão & p-valor \\
\hline$\mu$ & 1,50 & 0,09 & $<2 \times 10^{-16}$ \\
\hline$\alpha_{1}$ & 0,16 & 0,15 & 0,288 \\
\hline$\alpha_{2}$ & $-0,13$ & 0,13 & 0,318 \\
\hline$\alpha_{3}$ & $-0,18$ & 0,03 & $1 \times 10^{-9}$ \\
\hline$\alpha_{12}$ & 0,45 & 0,22 & 0,039 \\
\hline$\alpha_{13}$ & $-0,01$ & 0,04 & 0,738 \\
\hline$\alpha_{23}$ & 0,02 & 0,04 & 0,610 \\
\hline$\alpha_{123}$ & $-0,10$ & 0,06 & 0,112 \\
\hline
\end{tabular}




$$
\begin{aligned}
\mathrm{E}(\mathrm{Y})= & \exp \left[\left(1,50+0,16 \mathrm{X}_{1}-0,13 \mathrm{X}_{2}+0,45 \mathrm{X}_{1} \mathrm{X}_{2}+\right.\right. \\
& \left.+\left(-0,18-0,01 \mathrm{X}_{1}+0,02 \mathrm{X}_{2}-0,10 \mathrm{X}_{1} \mathrm{X}_{2}\right) \mathrm{d}^{-1}\right]
\end{aligned}
$$

No gráfico 7.11, são apresentados os percentis de probabilidades com envelopes gerados pelo modelo gama (PAULA, 2010), onde são observados poucos pontos fora da banda de confiança do envelope (95\%).

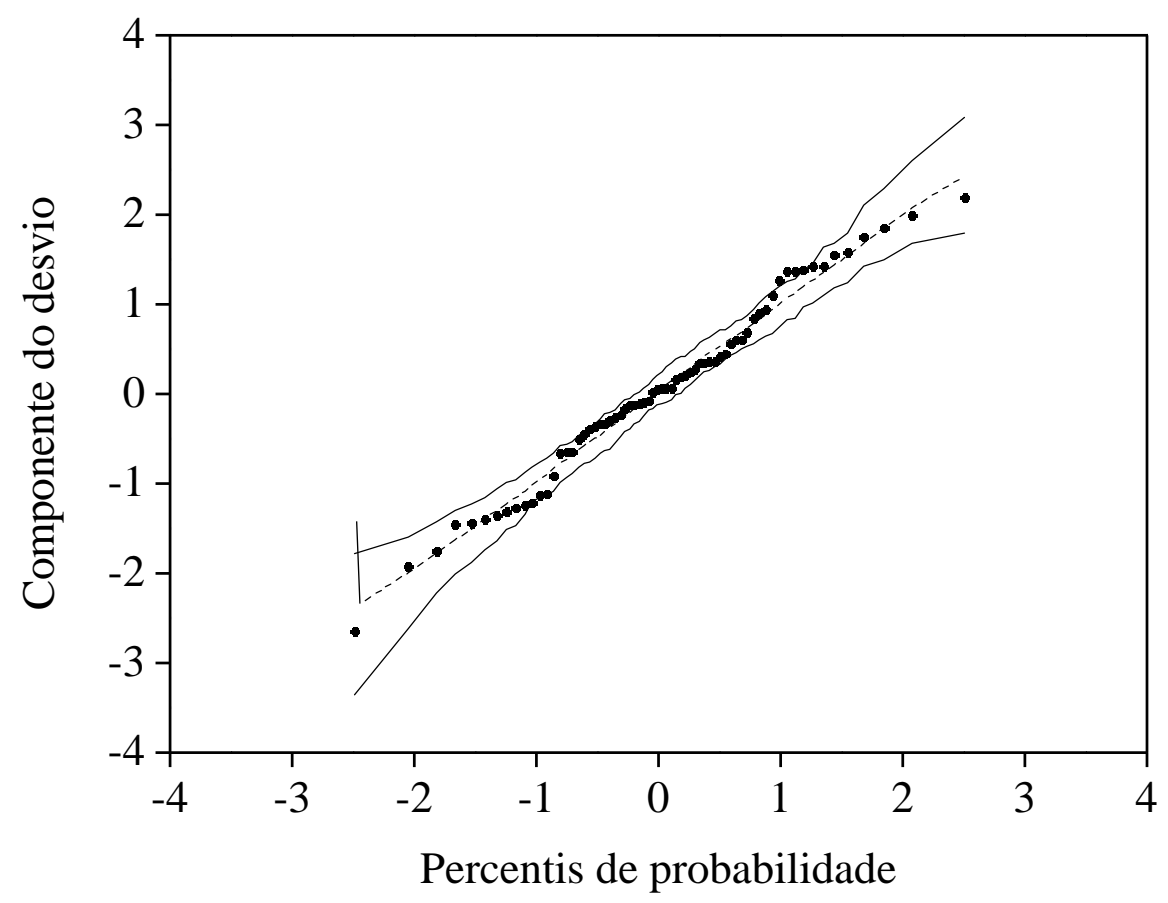

Gráfico 7.11 - Gráfico normal de probabilidades com envelope gerado pelo modelo gama, para a equação (7.15).

Como a equação (7.13) apresenta diversas interações entre os fatores multiplicantes do termo $\left(\right.$ dosagem $\left.^{-1}\right)$, é mais viável a comparação dos ensaios na forma gráfica. Para isso, foram definidas as equações para as resistências residuais obtidas pelas normas ASTM C1609 e EN 14651, derivadas da equação (7.13), tanto para a macrofibra polimérica quanto para a fibra de aço. As equações (7.16) a (7.23) estão mostradas na tabela 7.6.

Tabela 7.6 - Equações para determinação da resistência residual para as normas ASTM C1609 e EN 14651.

\begin{tabular}{cccc}
\hline Norma & Parâmetro & \multicolumn{1}{c}{ Macrofibra polimérica } & Fibra de aço \\
\hline \multirow{2}{*}{ ASTM C1609 } & $\mathrm{f}_{150,0.75}$ & $\mathrm{E}(\mathrm{Y})=\exp \left(1,04-0,28 \mathrm{~d}^{-1}\right) \mathbf{( 7 . 1 6 )}$ & $\mathrm{E}(\mathrm{Y})=\exp \left(1,50-0,18 \mathrm{~d}^{-1}\right)(\mathbf{7 . 2 0})$ \\
\cline { 2 - 4 } & $\mathrm{f}_{150,3.0}$ & $\left.\mathrm{E}(\mathrm{Y})=\exp \left(1,24-0,34 \mathrm{~d}^{-1}\right) \mathbf{( 7 . 1 7}\right)$ & $\mathrm{E}(\mathrm{Y})=\exp \left(1,37-0,16 \mathrm{~d}^{-1}\right)(\mathbf{7 . 2 1})$ \\
\hline \multirow{2}{*}{ EN 14651 } & $\mathrm{f}_{\mathrm{R}, 1}$ & $\left.\mathrm{E}(\mathrm{Y})=\exp \left(0,89-0,12 \mathrm{~d}^{-1}\right) \mathbf{( 7 . 1 8}\right)$ & $\mathrm{E}(\mathrm{Y})=\exp \left(1,66-0,19 \mathrm{~d}^{-1}\right)(\mathbf{7 . 2 2})$ \\
\cline { 2 - 4 } & $\mathrm{f}_{\mathrm{R}, 3}$ & $\mathrm{E}(\mathrm{Y})=\exp \left(1,28-0,31 \mathrm{~d}^{-1}\right) \mathbf{( 7 . 1 9 )}$ & $\mathrm{E}(\mathrm{Y})=\exp \left(1,98-0,27 \mathrm{~d}^{-1}\right)(\mathbf{7 . 2 3})$ \\
\hline
\end{tabular}


Para verificar a relação entre cada uma dessas medidas, foram feitas as seguintes relações, tanto para a fibra polimérica quanto para a de aço:

a) Razão entre as medidas no ELU e no ELS ( $f_{150,3.0}$ e $f_{150,0.75}$, respectivamente), para a norma ASTM C1609;

b) Razão entre as medidas no ELU e no ELS ( $f_{R, 3}$ e $f_{R, 1}$, respectivamente), para a norma EN 14651;

c) Razão entre a medida no ELU para as normas EN 14651 e ASTM C1609 $\left(f_{R, 3}\right.$ e $f_{150,3.0}$, respectivamente);

d) Razão entre a medida no ELS para as normas EN 14651 e ASTM C1609 $\left(\mathrm{f}_{\mathrm{R}, 1} \mathrm{e}\right.$ $\mathrm{f}_{150,0.75}$, respectivamente).

As razões obtidas, representadas pelas equações (7.24) a (7.31) estão mostradas na tabela 7.7. Para melhor visualização, essas funções foram plotadas nos gráficos 7.12 e 7.13, para a macrofibra polimérica, e nos gráficos 7.14 e 7.15, para a fibra de aço.

Tabela 7.7 - Razões entre as equações de determinação da resistência residual para as normas ASTM C1609 e EN 14651.

\begin{tabular}{ccc}
\hline Razão & Macrofibra polimérica & Fibra de aço \\
\hline $\mathrm{f}_{150,3.0} / \mathrm{f}_{150,0.75}$ & $\exp \left(0,20-0,06 \mathrm{~d}^{-1}\right)(\mathbf{7 . 2 4})$ & $\exp \left(-0,13+0,02 \mathrm{~d}^{-1}\right) \mathbf{( 7 . 2 8 )}$ \\
\hline $\mathrm{f}_{\mathrm{R}, 3} / \mathrm{f}_{\mathrm{R}, 1}$ & $\exp \left(0,39-0,19 \mathrm{~d}^{-1}\right)(\mathbf{7 . 2 5})$ & $\exp \left(0,32-0,08 \mathrm{~d}^{-1}\right)(\mathbf{7 . 2 9})$ \\
\hline $\mathrm{f}_{\mathrm{R}, 3} / \mathrm{f}_{150,3.0}$ & $\exp \left(0,04+0,03 \mathrm{~d}^{-1}\right)(\mathbf{7 . 2 6})$ & $\exp \left(0,61-0,11 \mathrm{~d}^{-1}\right)(\mathbf{7 . 3 0})$ \\
\hline $\mathrm{f}_{\mathrm{R}, 1} / \mathrm{f}_{150,0.75}$ & $\left.\exp \left(-0,15+0,16 \mathrm{~d}^{-1}\right) \mathbf{( 7 . 2 7}\right)$ & $\exp \left(0,16-0,01 \mathrm{~d}^{-1}\right)(\mathbf{7 . 3 1})$ \\
\hline
\end{tabular}




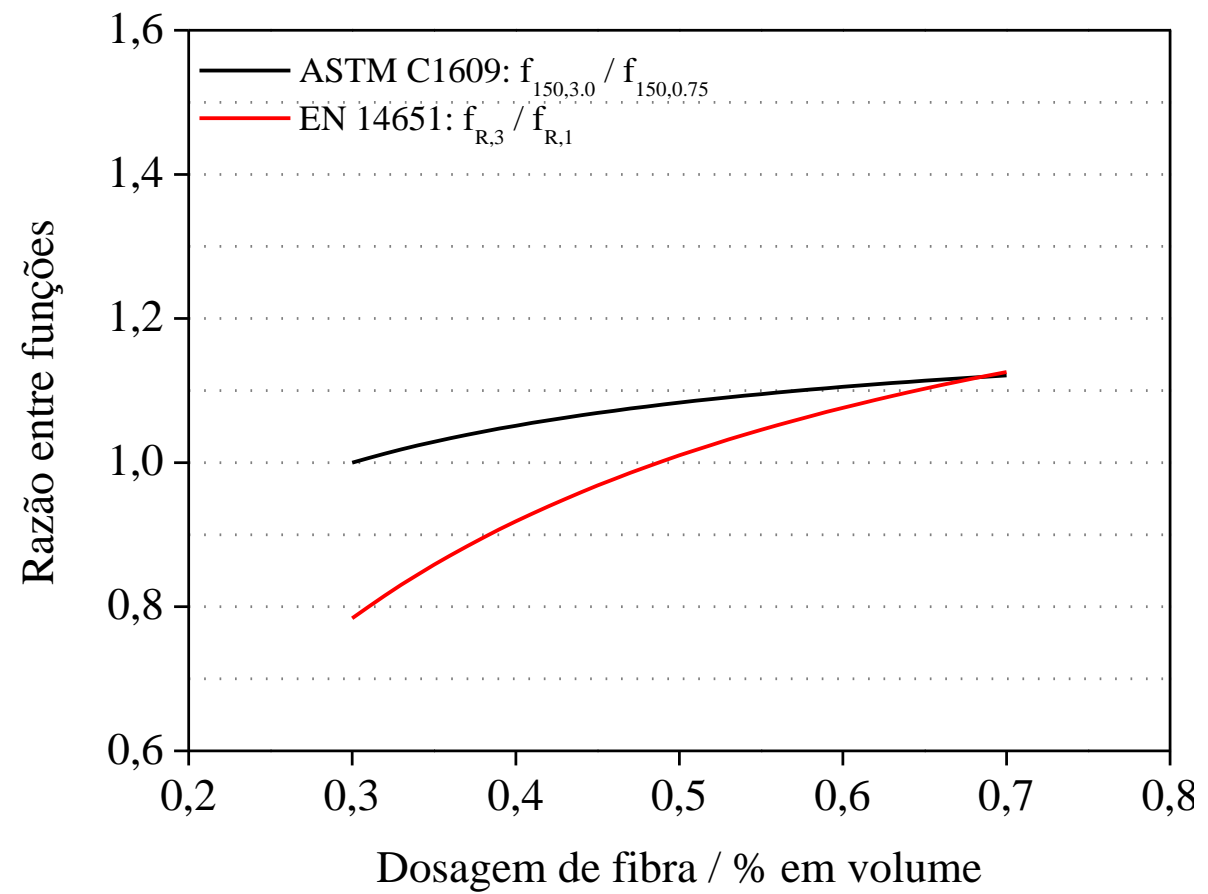

Gráfico 7.12 - Razão entre as resistências residuais no ELU e no ELS, feita a partir das funções obtidas para as normas ASTM C1609 e EN 14651, para a macrofibra polimérica.

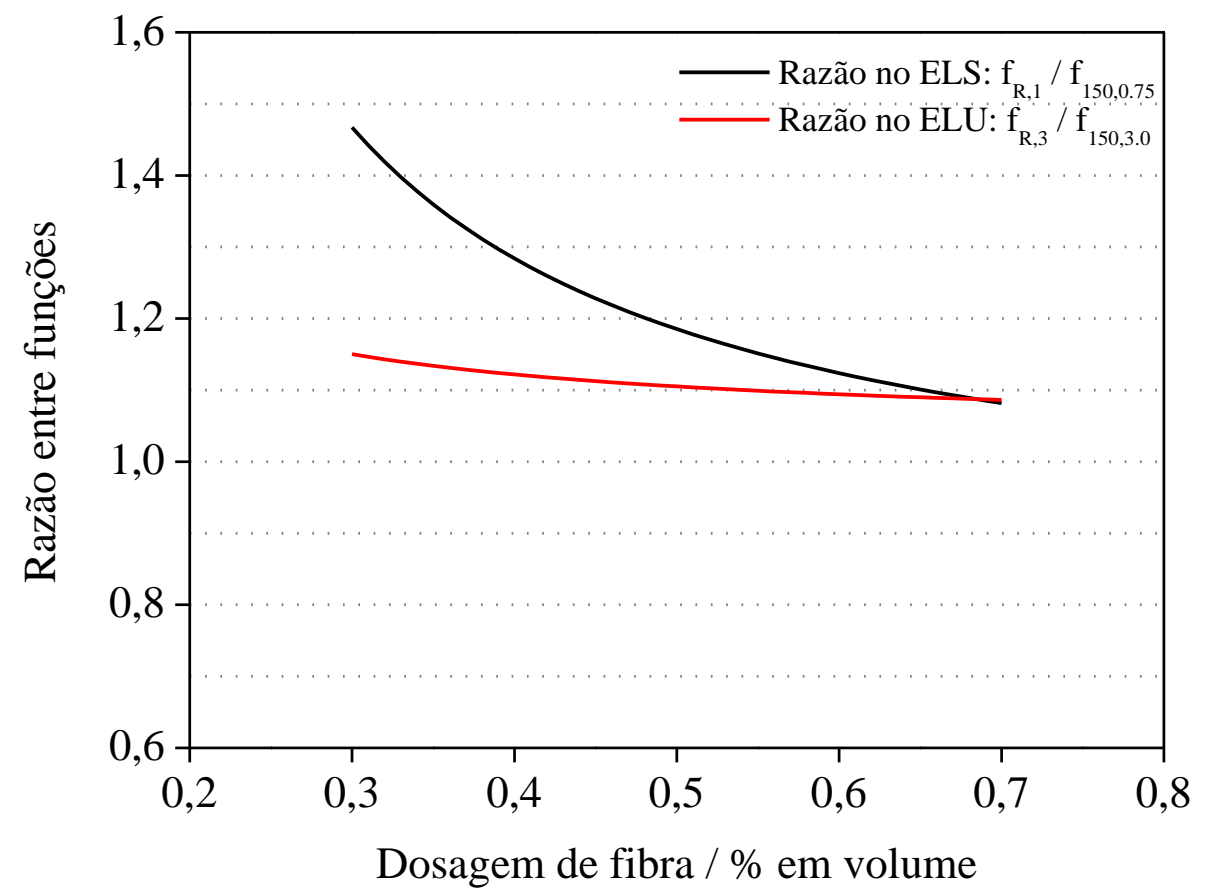

Gráfico 7.13 - Razão entre os métodos de ensaio, feita a partir das funções obtidas para as normas ASTM C1609 e EN 14651, para a macrofibra polimérica. 


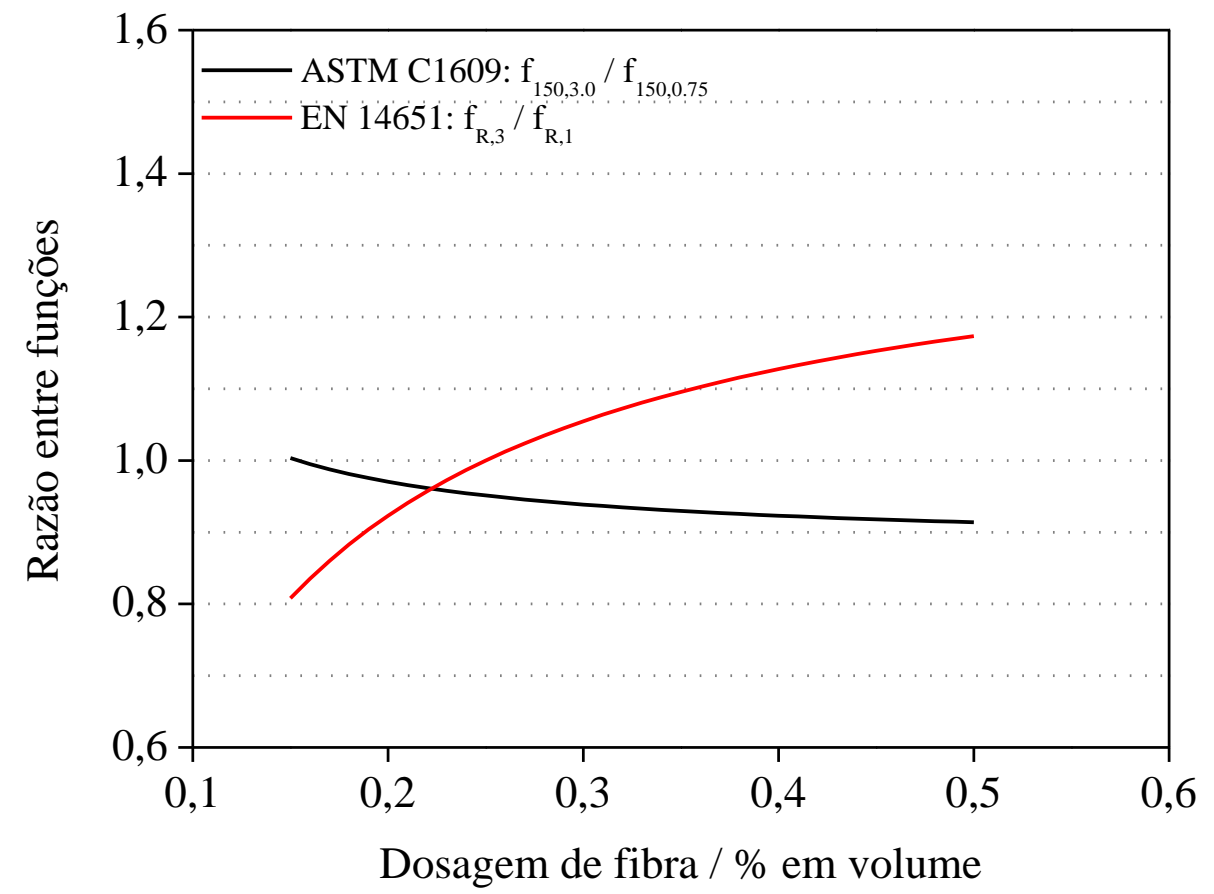

Gráfico 7.14 - Razão entre as resistências residuais no ELU e no ELS, feita a partir das funções obtidas para as normas ASTM C1609 e EN 14651, para a fibra de aço.

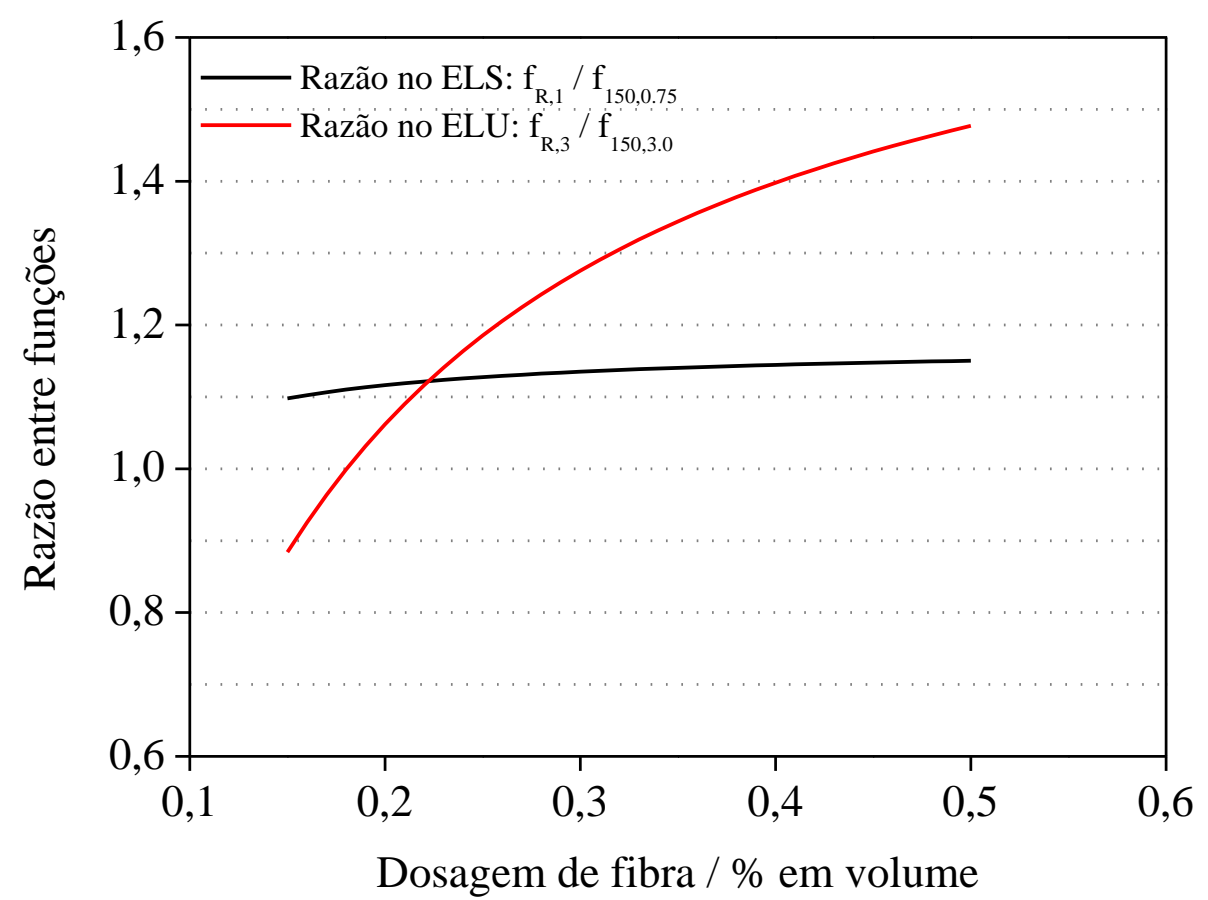

Gráfico 7.15 - Razão entre os métodos de ensaio, feita a partir das funções obtidas para as normas ASTM C1609 e EN 14651, para a fibra de aço.

Para a fibra polimérica, a relação $\mathrm{f}_{150,3.0} / \mathrm{f}_{150,0.75}$ é próxima de 1 para baixos teores e tende a aumentar com o aumento do teor. Essa diferença é devida ao comportamento de slip- 
hardening, que ocorre em maior intensidade em teores mais elevados. Já a relação $\mathrm{f}_{R, 3} / \mathrm{f}_{R, 1}$ só é maior que 1 para teores acima de $0,50 \%$ em volume.

Comparando-se os métodos de ensaio, a relação $\mathrm{f}_{\mathrm{R}, 1} / \mathrm{f}_{150,0.75}$ é alta para baixos teores, mas tende a diminuir com o aumento do teor. De acordo com os dados mostrados nas tabelas 6.5 e 6.8 , pode ser observado que o aumento do teor promove um aumento mais significativo na resistência residual $\mathrm{f}_{150,0.75}$, que é medida quando o corpo-de-prova apresenta deslocamento vertical de $0,75 \mathrm{~mm}$. Já a resistência residual $\mathrm{f}_{\mathrm{R}, 1}$, que é medida para abertura de fissura de $0,50 \mathrm{~mm}(0,46 \mathrm{~mm}$ de deslocamento vertical, aproximadamente), apresenta menor aumento com o acréscimo do teor, pois, para esse nível de deslocamento, há uma menor eficiência das fibras poliméricas, devido à sua baixa rigidez.

A relação $\mathrm{f}_{\mathrm{R}, 3} / \mathrm{f}_{150,3.0}$ é praticamente constante para todos os teores estudados, pois para altos níveis de deformação, o comportamento de slip-hardening é praticamente o mesmo para os dois ensaios.

Para a fibra de aço, a relação $\mathrm{f}_{150,3.0} / \mathrm{f}_{150,0.75}$ tende a diminuir com o aumento do teor, devido ao comportamento de slip-softening e à alta rigidez da fibra, que promove uma grande capacidade de absorção de energia para baixos níveis de deformação. Já a relação $f_{R, 3} / f_{R, 1}$ apresentou valor abaixo de 1 para baixos teores, devido à alta rigidez da fibra, assim como na relação anterior. Essa razão apresenta valor maior que 1 para teores mais elevados, pois para o ensaio EN 14651, com aplicação de carga por apenas um cutelo superior, centralizado em relação ao vão de ensaio, promoveu o comportamento de slip-hardening dessa fibra.

Além disso, outro fator que pode influenciar essas relações é o fato da distância entre a carga de pico e a carga residual no ELU ser maior para a norma ASTM C1609. Com isso, há um maior dano durante a fratura e, consequentemente, uma maior redução da resistência residual no ELU obtida a partir desse método de ensaio.

Tratando-se da diferença entre os ensaios, a relação $f_{R, 1} / f_{150,0.75}$ tende a ser praticamente constante para todos os teores estudados, pois, para baixos níveis de deformação, o aumento no teor promove aumento na resistência residual igualmente para os dois ensaios. A relação $\mathrm{f}_{\mathrm{R}, 3} / \mathrm{f}_{150,3.0}$ apresenta grande aumento com o aumento do teor, pois no ensaio EN 14651 foi verificado o comportamento de slip-hardening, enquanto para o ensaio ASTM C1609, o comportamento foi o oposto.

Para estabelecer uma correlação entre essas normas, que seja mais direta e de mais fácil entendimento, os valores médios das resistências residuais $\mathrm{f}_{\mathrm{R}, 1}$ e $\mathrm{f}_{150,0.75}$ foram plotados no gráfico 7.16. Os valores médios das resistências residuais $f_{R, 3}$ e $f_{150,3.0}$ foram plotados no 
gráfico 7.17. Foram utilizados os resultados obtidos com a macrofibra polimérica e com a fibra de aço para a elaboração desses gráficos.

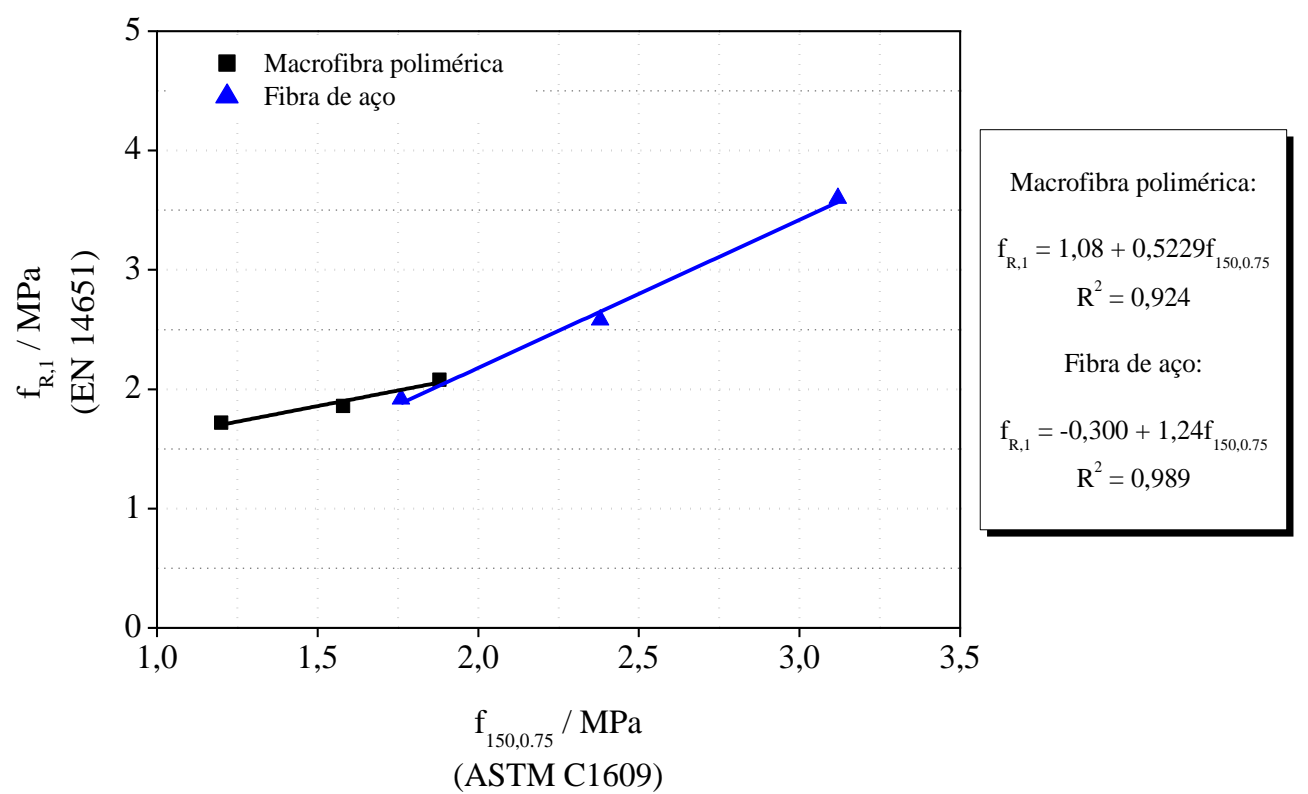

Gráfico 7.16 - Correlação entre as resistências residuais $f_{R, 1}$ e $f_{150,0.75}$ (EN 14651 e ASTM C1609, respectivamente).

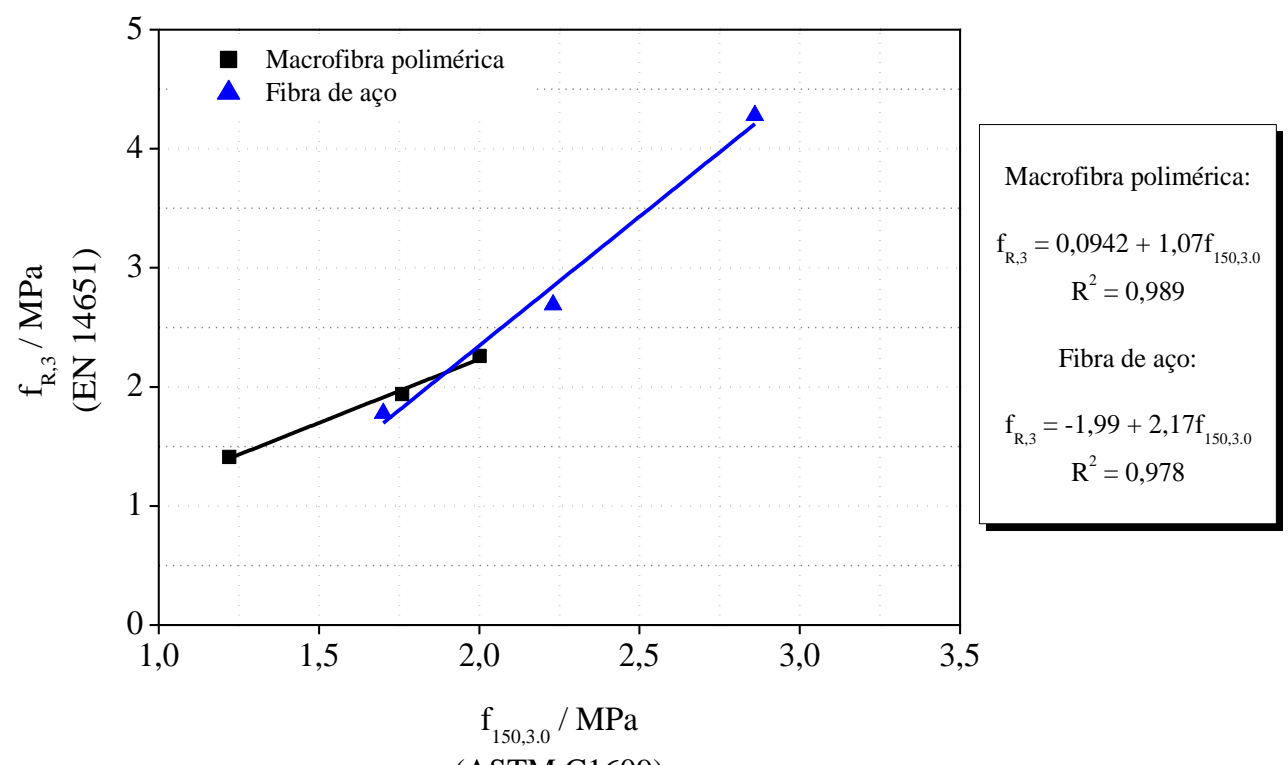

Gráfico 7.17 - Correlação entre as resistências residuais $\mathrm{f}_{\mathrm{R}, 3}$ e $\mathrm{f}_{150,3.0}$ (EN 14651 e ASTM C1609, respectivamente). 
Nas correlações mostradas nos gráficos 7.16 e 7.17, pode ser observado que as resistências residuais conferidas pela norma EN 14651 são sempre maiores que as resistências residuais conferidas pela norma ASTM C1609. Essas correlações não são muito precisas, visto que existe uma dependência das razões $f_{R, 1} / f_{150,0.75}$ e $f_{R, 3} / f_{150,3.0}$ com o teor de fibra, conforme mostrado nas equações (7.26) a (7.31).

Para aprimorar a análise dos resultados obtidos com a norma EN 14651 é fundamental que seja utilizado um maior número de corpos-de-prova e de teores de fibra. Assim é possível obter equações com maior aderência aos dados experimentais, proporcionando maior confiança nos resultados.

\subsection{Comparação entre os métodos JSCE SF4, ASTM C1609 e ASTM C1399}

Como os valores do fator de tenacidade e da resistência residual da norma ASTM C1609 foram calculados a partir das mesmas curvas carga-deslocamento vertical, essa análise foi mais simples, feita com regressões utilizando os valores médios de cada medida. Foram plotadas as resistências residuais em 0,75 e 3,0mm pelo fator de tenacidade, obtidos para o mesmo teor de fibras, presentes na tabela 6.5.

O gráfico 7.18 apresenta as correlações obtidas para os concretos reforçados com a macrofibra polimérica e com a fibra de aço. 


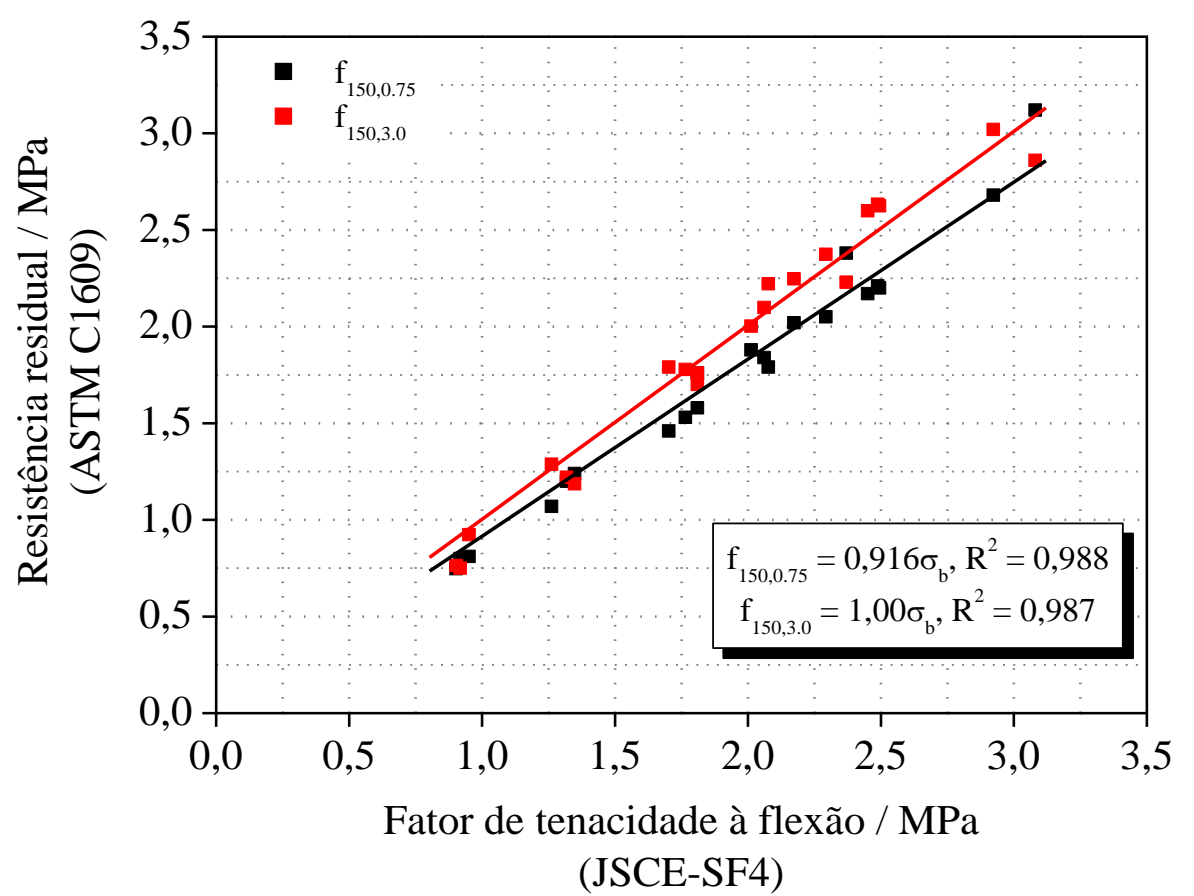

Gráfico 7.18 - Correlação entre as resistências residuais médias em 0,75 e 3,0mm (ASTM C1609) e o fator de tenacidade médio (JSCE-SF4).

Conforme discutido no item 6.4, a resistência residual em $3,0 \mathrm{~mm}$ e o fator de tenacidade são medidas muito similares, diferindo apenas no modo de leitura da curva cargadeslocamento vertical. A razão entre essas duas medidas é igual a 1,00, considerando todos os dados experimentais, com $\mathrm{R}^{2}$ igual a 0,987 , conforme mostrado no gráfico 7.18.

A razão obtida entre a resistência residual em $0,75 \mathrm{~mm}$ e o fator de tenacidade é inferior a 1, pois a carga resistida pela macrofibra polimérica em baixos níveis de deformação é mais baixa que em grandes aberturas de fissura. A carga resistida por essas fibras tende a aumentar com o decorrer do ensaio, devido ao seu comportamento de slip-hardening, ou seja, a carga no deslocamento de 3,0 mm é superior à carga no deslocamento de $0,75 \mathrm{~mm}$.

Da mesma forma, foram plotados os valores da resistência residual média (ASTM C1399) pelo fator de tenacidade. A correlação obtida está mostrada no gráfico 7.19. Nesse caso, foram utilizados apenas os resultados com a macrofibra polimérica, pois não foi realizado o ensaio da norma ASTM C1399 com a fibra de aço. 


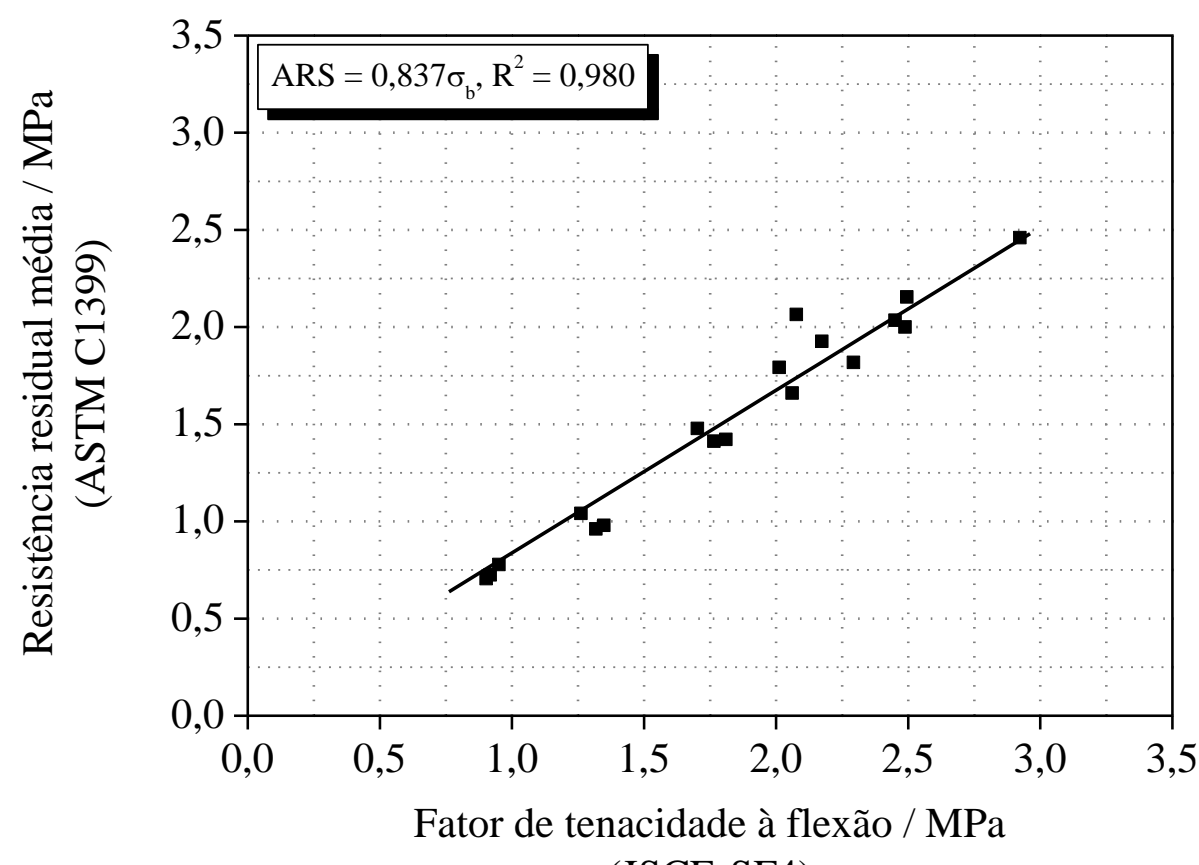

(JSCE-SF4)

Gráfico 7.19 - Correlação entre a resistência residual média (ASTM C1399) e o fator de tenacidade médio (JSCE-SF4).

Assim como mostrado no item 7.2, a resistência residual média, obtida pela norma ASTM C1399 é sempre menor que o fator de tenacidade. O valor da resistência residual média equivale a, aproximadamente, $83,7 \%$ do valor do fator de tenacidade, sendo que a regressão linear obtida possui $\mathrm{R}^{2}$ igual a 0,980 .

As correlações mostradas nos gráficos 7.16 e 7.17 são válidas somente para os ensaios realizados utilizando equipamento com sistema fechado de controle de velocidade de deslocamento (closed-loop), pois em equipamentos com sistema open-loop o valor do fator de tenacidade tende a ser aumentado pela área abaixo da região de instabilidade pós-pico, como mostrado em estudos realizados por Bernard (2009) e Tiguman (2004).

A análise feita nesse subcapítulo (item 7.4) é mais simples e mostra que os valores de resistência residual e o fator de tenacidade possuem uma correlação física. Entretanto, como as regressões mostradas nos gráficos 7.16 ao 7.19 são lineares, o valor dos coeficientes angulares são mostrados como constantes para o intervalo de teores de fibra avaliados. Tal fato não corresponde à realidade, pois, como mostrado na equação (7.1) e em estudos de Figueiredo (1997), as regressões são dependentes do teor de fibra.

Em suma, foi verificado que é possível a obtenção de uma correlação entre os métodos de ensaio e que as correlações são fortemente dependentes do comportamento padrão do 
material. Dependendo do tipo de fibra utilizado, pode ocorrer o comportamento de slipsoftening ou de slip-hardening, influenciando as correlações, pelo fato de ora serem utilizados os valores médios e ora os valores pontuais em diferentes níveis de abertura de fissura ou de deslocamento vertical, de acordo com cada método de ensaio. 


\section{Conclusões}

Este programa experimental investigou quatro diferentes métodos para a avaliação do comportamento mecânico de concreto reforçado com fibras. Os três ensaios prescreviam ensaios de flexão de corpos-de-prova prismáticos. Foi utilizado um equipamento dotado de sistema fechado de controle de velocidade de deslocamento. Foram analisadas uma macrofibra polimérica e uma fibra de aço em três matrizes de concreto. A partir dos resultados obtidos, os seguintes pontos podem ser concluídos:

a) Cada método de ensaio proporciona um resultado distinto. Então, a escolha de determinado método deve estar de acordo com o solicitado para a especificação de projetos de dimensionamento ou de controle de qualidade;

b) Os dados experimentais mostraram que existem diferenças significativas nos resultados quando são utilizadas diferentes configurações de ensaio. Portanto, foram determinadas equações que correlacionam cada método de ensaio;

c) É possível correlacionar os métodos de ensaio e as correlações são fortemente dependentes do tipo e do teor de fibra. Os comportamentos de slip-softening ou de slip-hardening, funções dessas variáveis, influenciam as correlações, sendo necessário estabelecer uma função de correlação para um determinado tipo de fibra;

d) A utilização de equipamento com sistema fechado de controle de velocidade de deslocamento, prescrito pela norma ASTM C1609, conferiu uma grande vantagem ao estudo: o comportamento pós-fissuração medido não foi afetado pela instabilidade pós-pico, mesmo quando utilizados baixos teores de fibra;

e) O ensaio ASTM C1399 é uma boa alternativa quando um equipamento com sistema fechado de controle de velocidade de deslocamento não estiver disponível. Apesar da maior variação nos resultados, este ensaio pode ser feito de maneira mais rotineira, como em controle tecnológico de obras que utilizam concretos reforçados com fibras, devido à maior simplicidade e rapidez de execução;

f) O ensaio EN 14651, que utiliza corpos-de-prova com entalhe, é um método interessante para determinação da tenacidade de concreto reforçado com fibras, pois a fissura sempre ocorre no plano do entalhe e se propaga de maneira estável. Os resultados podem ser relacionados a parâmetros de dimensionamento de estruturas; 
g) A dispersão dos resultados experimentais é uma consequência do método de ensaio utilizado. O desvio padrão dos dados obtidos nos ensaios de flexão em quatro pontos é maior que o obtido nos ensaios de flexão em três pontos;

h) Nos ensaios de flexão em quatro pontos, foram obtidos coeficientes de variação muito menores do que os esperados para esse tipo de ensaio, mas os resultados apresentaram heterocedasticidade em uma relação positiva com o teor de fibra. Isso significa que quanto maior o teor de fibra, maior foi o desvio padrão do valor da resistência residual. Por esse motivo, foi utilizado um modelo gama para análise e correlação dos resultados, pois foi possível transformar os dados heterocedásticos em homocedásticos;

i) A resistência residual média, calculada de acordo com a norma ASTM C1399, corresponde a, aproximadamente, $74 \%$ do valor da resistência residual em 3,0mm, calculada de acordo com a norma ASTM C1609, para os concretos reforçados com a macrofibra polimérica. Essa diferença permaneceu constante para os três diferentes traços de concreto utilizados e é dependente do teor de fibra;

j) Para as dosagens de fibra normalmente utilizadas em campo, esse tipo de reforço não apresenta influência nas propriedades elásticas do concreto. As fibras aprimoram somente a resposta pós-fissuração do compósito;

k) Os teores de fibras utilizados, que chegaram a 1,0\% em volume, não prejudicaram a capacidade de compactação do concreto, devido à utilização de mesa vibratória para o adensamento dos corpos-de-prova. Esse fato é corroborado pela uniformidade dos resultados do teor de ar incorporado e pela baixíssima variação dos resultados de resistência à compressão;

1) Dentre as duas fibras ensaiadas, comparando-as em um mesmo teor em volume, verifica-se que as fibras de aço conferem maiores resistências residuais, principalmente para baixos níveis de deformação, devido à sua maior rigidez. Adotando-se a resistência residual como critério de comparação, a macrofibra polimérica pode proporcionar o mesmo nível de desempenho que a fibra de aço, desde que os teores de desempenho equivalente de cada fibra sejam determinados em estudo de dosagem;

m) Correlacionando o desempenho da macrofibra com a resistência mecânica do traço de concreto, verifica-se que para matrizes de maior resistência, a resposta pós-fissuração conferida pela utilização da macrofibra estudada é melhor. 
Os resultados obtidos nesse trabalho não podem ser extrapolados para toda e qualquer aplicação e nem para qualquer tipo de fibra. Estudos específicos com diferentes elementos estruturais e outros compósitos devem ser realizados com o intuito de se obter a resposta do material para determinadas aplicações.

Para a realização de estudos futuros sobre o assunto, os seguintes temas são interessantes:

a) Comparação desses resultados com os obtidos por outros métodos de ensaio para a determinação da tenacidade, como o ensaio Barcelona e o ensaio em placas;

b) Utilização de sistemas de reforços que promovam uma variação no comportamento pós-fissuração do compósito, como os reforços híbridos, que são compostos por uma mescla de fibra de aço com micro ou macrofibras poliméricas;

c) Análise da influência da velocidade de aplicação de carga na resistência residual;

d) Influência das propriedades do concreto fresco, a partir de estudos de reologia, na resistência residual. 


\section{Referências bibliográficas}

AMERICAN CONCRETE INSTITUTE. Manual of concrete practice: part 5. ACI. Report on fiber-reinforced concrete (ACI 544.1R-96). ACI Committee 544. Detroit, USA, 2002.

AMERICAN SOCIETY FOR TESTING MATERIALS. ASTM C1609: Standard test method for flexural performance of fiber-reinforce concrete (using beam with third-point loading). Philadelphia, 2010a. 8 p.

ASTM C1399: Standard test method for obtaining average residual-strength of fiberreinforced concrete. Philadelphia, 2010b. 6 p.

ASTM D2256: Standard test method for tensile properties of yarns by the singlestrand method. Philadelphia, 2010c. 13 p.

ASTM D7508: Standard specification for polyolefin chopped strands for use in concrete. Philadelphia, 2010d. 4 p.

2012. 5 p.

ASTM D2257: Standard test method for extractable matter in textiles. Philadelphia,

ARAKAKI, D. H.; FIGUEIREDO, A. D. Avaliação da tenacidade de concretos reforçados com fibras de aço de alto e baixo teor de carbono. In: IV SIMPÓSIO EPUSP SOBRE ESTRUTURAS DE CONCRETO, 2000, São Paulo, 2000. p.1 - 15.

ARMELIN, H. S. Contribuição ao estudo do concreto projetado por via seca com fibras de aço destinado ao revestimento de túneis NATM. 1992. Dissertação (Mestrado) - Escola politécnica, Universidade de São Paulo, São Paulo, Brasil, 1992.

ARMELIN, H. S.; BANTHIA, N. Predicting the flexural post-cracking performance of steel fiber reinforced concrete from the pullout of single fibers. ACI Materials Journal. v. 94, n. 1, p.18-31, 1997.

ASSOCIAÇÃO BRASILEIRA DE NORMAS TÉCNICAS. NBR NM 67: Concreto: determinação da consistência pelo abatimento do tronco de cone. Rio de Janeiro, 1998. 8p.

NBR 7211: Agregados para concreto - Especificação. Rio de Janeiro, 2005a. 11p. 
NBR 9778: Argamassa e concreto endurecidos: determinação da absorção de água, índice de vazios e massa específica. Rio de Janeiro, 2005b. 4p.

NBR NM 47: Concreto: determinação do teor de ar incorporado em concreto fresco - método pressométrico. Rio de Janeiro, 2005c. 23p.

NBR 5739: Concreto: ensaio de compressão de corpos-de-prova cilíndricos. Rio de Janeiro, 2007a. 9p.

NBR 15530: Fibras de aço para concreto - Especificação. Rio de Janeiro, 2007b. 7p.

NBR 9833: Concreto fresco: determinação da massa específica, do rendimento e do teor de ar pelo método gravimétrico. Rio de Janeiro, 2008. 7p.

NBR 12142: Concreto: determinação da resistência à tração na flexão em corpos-deprova prismáticos. Rio de Janeiro, 2010. 3p.

ASUA, J.M. Polymer Reaction Engineering. USA: Blackwell Publishing, 2007.

AULIA, T. B. Effects of polypropylene fibers on the properties of high-strength concrete. Leipzig Annual Civil Engineering Report, v. 5, p. 43-59, 2002.

BANTHIA, N.; DUBEY, A. Measurement of flexural toughness of fiber-reinforced concrete using a novel technique - Part 1: Assessment and Calibration. ACI Materials Journal, v. 96, n. 6, p. 651-656, 1999.

Measurement of flexural toughness of fiber-reinforced concrete using a novel technique - Part 2: Performance of Various Composites. ACI Materials Journal, v. 97, n. 1, p. 3-11, 2000.

BANTHIA, N.; MINDESS, S. Toughness Characterization of Fiber-Reinforced Concrete: Which Standard to Use?. Journal of Testing and Evaluation, Vancouver, Canada, v. 32, n. 2, p.1-5, mar. 2004.

BANTHIA, N. Fiber reinforced concrete. The Canadian Society for Civil Engineers. 1998. 
BANTHIA, N., SAPPAKITTIPAKORN, M. Toughness enhancement in steel fiber reinforced concrete through fiber hybridization. Cement and Concrete Research, v. 37, p. 1366-1372, 2007.

BARCELOS, E. Braskem bate recorde de produção de polipropileno. Revista Exame, São Paulo, 19 de abril de 2012. Disponível em

http://exame.abril.com.br/negocios/empresas/noticias/braskem-bate-recorde-de-producao-depolipropileno-2/ > Acesso em: 05 de novembro de 2012.

BARR, B. et al. Toughness Measurement - the Need to Think Again. Cement and Concrete Composites, Barcelona, Spain., v. 18, p.281-297, 1996.

BARRAGÁN, B. E. Failure and toughness of steel fiber reinforced concrete under tension and shear. 2002. 151p. 1 v. Tese (Doutorado) - Universitat Politécnica de Catalunya, Barcelona. 2002.

BARROS, J. A. O. et al. Post-cracking behaviour of steel fibre reinforced concrete. Materials and Structures, v. 38, p. 47-56, 2005.

BENTUR, A.; MINDESS, S.; VONDRAN, G. Bonding in polypropylene fibre reinforced concretes. The International Journal Of Cement Composites And Lightweight Concrete, v. 11, n. 3, p.153-158, ago. 1989.

BENTUR, A.; PELED, A.; YANKELEVSKY, D. Enhanced bonding of low modulus polymer fibre-cement matrix by means of crimped geometry. Cement and Concrete Research. n. 27, p.1099-1111, 1997.

BENTUR, A.; MINDESS, S. Fibre reinforced cementitious composites. United Kingdom: Elsevier, 2007.

BERNARD, E. S. Influence of Test Machine Control Method on Flexural Performance of Fiber Reinforced Concrete Beams. Journal of ASTM International, v. 6, 2009.

BRINSON, H. F.; BRINSON, L. C. Polymer Engineering Science and Viscoelasticity. USA: Springer Science, 2008.

BRUICE, P.Y. Organic Chemistry. 6. ed. USA: Prentice Hall, 2010. 
BROWN, W.H. Introduction to Organic Chemistry. 2. ed. USA: Saunders College Publishing, 2002.

BURATTI, N.; MAZZOTTI, C.; SAVOIA, M. Post-cracking behavior of steel and macrosynthetic fibre-reinforced concretes. Construction and Building Materials, v. 25, p. 27132722, 2011.

CALDAS, A.; FIGUEIREDO, A. D.; BITTENCOURT, T. N. Propriedades do concreto reforçado com fibras de aço (CRFA): comparação entre métodos de medida. In: V SIMPÓSIO EPUSP SOBRE ESTRUTURAS DE CONCRETO, 2003, São Paulo. Anais. São Paulo, 2003.

CALLISTER, W.D. Ciência e engenharia de materiais: uma introdução. 5. ed., Rio de Janeiro: Livros Técnicos e Científicos, 2002.

CECCATO, M. R.; NUNES, N. L.; FIGUEIREDO, A. D. Estudo do controle da trabalhabilidade do concreto reforçado com fibras de aço. In: IV CONGRESSO IBEROAMERICANO DE PATOLOGIA DAS CONSTRUÇÕES E VI CONGRESSO DE CONTROLE DE QUALIDADE CONPAT, 1997, Porto Alegre, v. 2, p. 539-546.

CLAYDEN, J. et al. Organic Chemistry. USA: Oxford University Press, 2001.

di PRISCO, M.; PLIZZARI, G.; VANDEWALLE, L. Fibre reinforced concrete: new design perspectives. Material and Structures, v. 42, p. 1261-1281, 2009.

Fiber reinforced concrete in the new FIB model code. Proceedings of the Third International Congress and Exhibition Fib "Think Globally, Build locally". In: $3^{\circ}$ FIB INTERNATIONAL CONGRESS, 2010, Washington, p. 1-12.

EBEWELE, R.O. Polymer Science and Technology. Nigeria: CRC press LLC, 1996.

EUROPEAN COMMITTEE FOR STANDARDIZATION. EN 14651: Test method for metallic fiber-reinforced concrete - Measuring the flexural tensile strength (limit of proportionality (LOP), residual), CEN, London, 2007. 15p.

fib Bulletin 55, Model Code 2010. First complete draft, v. 1, 2010, 312p. 
FIGUEIREDO, A. D.; HELENE, P. R. L. Controle da tenacidade do concreto com fibras de aço. In: $39^{\mathrm{a}}$ Reunião do IBRACON - Instituto Brasileiro do Concreto, 1997, São Paulo. Anais. v.1. p. 357-372.

FIGUEIREDO, A. D. Parâmetros de Controle e Dosagem do Concreto Projetado com Fibras de Aço. 1997. 342p. Tese (Doutorado) - Escola Politécnica, Universidade de São Paulo, São Paulo, 1997.

Concreto com fibras de aço. Boletim Técnico (BT/PCC/260). São Paulo: Escola Politécnica da Universidade de São Paulo - Departamento de Engenharia de Construção Civil, 2000.

Concreto com fibras. Concreto: ciência e tecnologia. São Paulo: Instituto Brasileiro do Concreto (IBRACON), 2011a. 1902 p. cap. 37.

Concreto reforçado com fibras. 248p. Tese (Livre-Docência) - Escola Politécnica, Universidade de São Paulo, São Paulo, 2011b.

FIGUEIREDO, A. D.; MOURAD, F. A.; CARVALHO, J. L. C. Aspectos do controle do concreto reforçado com fibras de aço para pavimentos. In: $42^{\circ}$ CONGRESSO BRASILEIRO DO CONCRETO, 2000, Fortaleza. Anais. Instituto Brasileiro do Concreto (IBRACON), São Paulo, 2000.

FIGUEIREDO, A. D.; NUNES, N.L.; TANESI, J. Mix design analysis on steel fiber reinforced concrete. In: FIFTH INTERNATIONAL RILEM SYMPOSIUM ON FIBERREINFORCED CONCRETES (FRC), 2000, Lyon. Fibre-Reinforced Concretes (FRC). BEFIB, 2000. p. 103-118.

FIGUEIREDO, A. D. et al. Análise de viabilidade do uso de fibras metálicas em tubos de concreto. Parte 1: companha experimental. In $52^{\circ}$ CONGRESSO BRASILEIRO DO CONCRETO, Fortaleza-CE, 2010. Novas tecnologias do concreto para o crescimento sustentável. Anais. Instituto Brasileiro do Concreto (IBRACON). São Paulo, 2010.

FIGUEIREDO, A. D. et al. Fibras plásticas como reforço de tubos de concreto. Parte 1: caracterização tecnológica. In: $54^{\circ}$ CONGRESSO BRASILEIRO DO CONCRETO, 2012, Maceió. Anais. Instituto Brasileiro do Concreto (IBRACON). São Paulo, 2012.

GETTU, R. et al. Testing of concrete under closed-loop control. Advanced Cement Based Materials, v. 3, n. 2, p. 54-71, 1996. 
GOPALARATNAM, V. S.; GETTU, R. On the characterization of flexural toughness in fiber reinforced concretes. Cement \& Concrete Composites, v. 17, p. 239-254, 1995.

HANNANT, D.J. Fibre cements and fibre concretes. Chichester, John Wiley, 1978.

KIM, D. J.; NAAMAN, A. E.; EL-TAWIL, S. Comparative flexural behavior of four reinforced cementations composites. Cement \& Concrete Composites, v. 30, p. 917-928, 2008.

LI, V C.; WU, H; CHAN, Y. Effect of Plasma Treatment of Polyethylene Fibers on Interface and Cementitious Composite Properties. J. Am. Ceram. Soc., v. 03 , p. 700-704, 1996.

LIM, D. H.; OH, B. H. Experimental and theoretical investigation on the shear of steel fibre reinforced concrete beams. Engineering Structures, v. 21, p. 937-944, 1999.

LIN, Z.; LI, V. C. Crack bridging in fiber reinforced cementitious composites with sliphardening interfaces. J. Mech. Phys. Solids, USA, v. 45, n. 5, p.763-787, 1997.

MARK, J. E. Polymer Data Handbook. USA: Oxford University Press, 1998.

McGILL, R.; TUKEY, J. W.; LARSEN, W.A. Variations of Boxplots. The American Statistician. Vol. 32, n. 1, 1978, p. 12-16.

MEHTA, P. K.; MONTEIRO, P. J. M. Concreto. Microestrutura, propriedades e materiais. São Paulo: Instituto Brasileiro do Concreto (IBRACON), 2008. 674 p. Capítulo 12 , p $461-577$.

MINDESS, S.; CHEN, L.; MORGAN, D.R. Determination of the first-crack strength and flexural toughness of steel fiber-reinforced concrete. Advanced Cement Based Materials, v. 1, p. 201-208, 1994

MORGAN, D.R.; RICH, L.D. Polyolefin fibre reinforced wet-mix shotcrete. In: ACI/SCA International Conference on Sprayed Concrete/Shotcrete - "Sprayed Concrete Technology for the 21st Century", 10-11 sept. 1996. American Concrete Institute and Sprayed Concrete Association. Proceedings. P. 127-38

MORRISON, R.T.; BOYD, R.N. Organic Chemistry, USA: Prentice Hall, 2002. 
NAAMAN, A.E. Fiber reinforcements for concrete: looking back, looking ahead. In: RILEM Proceedings, PRO 15, RILEM Publications SARL, p. 65-86, 2000.

Toughness, ductility surface energy and deflection-hardening FRC composites. In: PREOCEEDINGS OF JCI WORKSHOP ON DUCTILE FIBER REINFORCE COMENTITIOUS COMPOSITES (DFRCC) - APPLICATION AND EVALUATION. 2002, Tokyo. Japan: Japan Concrete Institute, 2002. p. 33 - 57.

Engineered Steel Fibers with Optimal Properties for Reinforcement of Cement Composites. Journal Of Advanced Concrete Technology, v. 1, n. 3, p.241-252, Nov. 2003a.

High performance fiber reinforced cement composites: classification and applications. In: CBM-CI INTERNATIONAL WORKSHOP. Karachi, Pakistan, 2003b. p. $389-401$.

High performance fiber reinforced cement composites. In: RILEM Proceedings, PRO 30, RILEM Publications SARL, 2003c.

NANNI, A.; MEAMARIAN, N.. Distribution and Opening of Fibrillated Polypropylene Fibers in Concrete. Cement And Concrete Composites, Pennsylvania, v. 13, p.107-114, 1991.

NATARAJA, M. C.; DHANG, N.; GUPTA, A. P. Toughness characterization of steel fiberreinforced concrete by JSCE approach. Cement and Concrete Research, v. 30, p. 593-597, 2000 .

NUNES, N. L.; TANESI, J.; FIGUEIREDO, A. D. Aplicação do concreto reforçado com fibras de aço na recuperação de estruturas e pavimentos. In: CONGRESSO IBEROAMERICANO DE PATOLOGIA DAS CONSTRUÇÕES CON PAT, 4., 1997, Porto Alegre, RS: Anais, 1997. v. 2, p. 41 - 48.

NUNES, N. L. Contribuição para a aplicação do concreto reforçado com fibras de aço em elementos de superfície restringidos. 2006. 259 p. Tese (Doutorado) - Escola politécnica, Universidade de São Paulo, São Paulo, 2006.

OSSWALD, T.A., MENGER, G. Materials Science of polymers for engineers. USA: Hanser Gardener Publications, 2003. 
PAULA, G. A. Modelos de regressão com apoio computacional. São Paulo, Instituto de Matemática e Estatística, 2012, 427p.

PELED, A.; GUTTMAN, H.; BENTUR, A. Treatments of Polypropylene Fibres to Optimize their Reinforcing Efficiency in Cement Composites. Cement And Concrete Composites, Jerusalem, Israel, v. 14, p.277-285, 1992.

PERRY, R. H.; GREEN, D. W. Perry's Chemical Engineers' Handbook. USA: McGrawHill Professional, 1999.

PIETRA, I. Avaliação do concreto com agregados graúdos reciclados de resíduos de construção e demolição reforçado com fibras de aço., 2005.140p. Dissertação (Mestrado). Escola Politécnica, Universidade de São Paulo, São Paulo, 2005.

REQUENA, S. S. Ensayo de doble punzonamiento aplicado al hormigón reforzado con fibras (ensayo Barcelona). 2006. 338p. 1 v. Tese (Doutorado) - Universitat Politécnica de Catalunya, Barcelona. 2006.

RILEM TC 162. Final recommendation of RILEM TD 162-TDF: Test and design methods for steel fibre reinforced concrete $-\sigma-\varepsilon$ design method. Materials and Structures, v. 36, 2003, p. 560-657.

SHAH, S. P.; KUDER, K.G.; MU, B. Fiber-reinforced cement-based composites: a forty-year odyssey. In: RILEM SYMPOSIUM ON FIBRE-REINFORCED CONCRETE (FRC), 6. 2004, Verena, Italy. BEFIB, 2004. p. 3-30.

SILVA, J. C. Manual de elaboração de relatórios e tratamento de resultados experimentais. Universidade Nova de Lisboa, Portugal, 2001. 36p.

SPERLING, L.H. Introduction to physical polymer science. John Wiley \& Sons Inc., 4 ed., 2006.

TANESI, J. A influência das fibras de polipropileno no controle da fissuração por retração. 1999. 132p. Dissertação (Mestrado) - Universidade de São Paulo, São Paulo, 1999.

TIGUMAN, M. P. Estudo comparativo entre métodos de quantificação de tenacidade usando concreto reforçado com macrofibras de polipropileno. 2004. 85 p. Dissertação (Mestrado) - Universidade de São Paulo, São Paulo, 2004. 
TIGUMAN, M. P.; FIGUEIREDO, A. D. Nova técnica de determinação da tenacidade dos compósitos reforçados com fibras: ASTM C1399 (2002). Boletim Técnico (BT/PCC/398). São Paulo: Departamento de Engenharia de Construção Civil da EPUSP, 2005.

THE JAPAN SOCIETY OF CIVIL ENGINEERS. JSCE-SF1: Method of making steel fiber reinforced concrete in the laboratory. Concrete library of JSCE. Part III-2 Method of tests for steel fiber reinforced concrete. 1984. n. 3, p. 45-47.

JSCE-SF2: Method of making specimens for strength and toughness tests of steel fiber reinforced concrete. Concrete library of JSCE. Part III-2 Method of tests for steel fiber reinforced concrete.1984. n. 3, p. 48-55.

JSCE-SF4: Method of tests for flexural strength and flexural toughness of steel fiber reinforced concrete. Concrete library of JSCE. Part III-2 Method of tests for steel fiber reinforced concrete. 1984. n. 3, p. 58-61.

TROTIER, J-F.; MAHONEY, M. Innovative synthetic fibers. Concr. Int, v. 23, p. 23-28, 2001.

TU, L., KRUGER, D., CARSTENS, P.A.B. Effects of the increased surface wettability on the polypropylene-concrete interfacial bonding and the properties of the polypropylene fiber reinforced concrete". In: Y. Ohama and M. Puterman (eds) Adhesion between Polymers and Concrete, RILEM Proceedings PRO 9, RILEM Publications, Bagneux, 1999, p. 267-284.

VENABLES, W. N.; RIPLEY, B. D. Statistics and Computing. 4. ed. Springer, 2002. 512p.

ZHANDAROV, S.; MADER, E. Characterization of fiber/matrix interface strength: applicability of different tests, approaches and parameters. Composites Science And Technology, Germany, p.149-160, 2005.

ZHENG, Z.; FELDMAN, D. Synthetic fibre-reinforced concrete. Prog. Polym. Sci., Canada, v. 20, p. 185-210,1995.

ZOLLO, F. R. Fiber-reinforced Concrete: an overview after 30 years of development. Cement and Concrete Composites, 19, 1997, 107-122.

WIEBECK, H. HARADA, J. Plásticos de engenharia. Brasil. Artliber Editora, 2005. 


\section{Apêndice 1 - Critério de Chauvenet}

O critério de Chauvenet é um teste consistente para rejeição de resultados que fogem de uma determinada tendência dominante. Seu princípio é que os resultados obtidos devem estar aleatoriamente distribuídos em torno de um valor médio. Se a probabilidade de se obter um valor igual a $\mathrm{x}_{\text {susp }}$ em $\mathrm{n}$ medições for inferior a $1 / 2 \mathrm{n}$, o valor deve ser rejeitado (SILVA, 2001).

Para aplicá-lo, calcula-se o valor médio, $\mathrm{x}_{\text {médio, }}$ e o desvio padrão, $\sigma$, com todas as medições. Então, testa-se o valor de cada medida, $\mathrm{x}_{\mathrm{i}}$, calculando-se $\Delta \mathrm{x}$, segundo as equações abaixo:

$$
\begin{aligned}
\Delta \mathrm{x} & =\frac{\left|\mathrm{x}_{\mathrm{i}}-\mathrm{x}_{\text {médio }}\right|}{\sigma} \\
\Delta \mathrm{x}_{0} & =\frac{\left|\mathrm{x}_{\text {susp }}-\mathrm{x}_{\text {médio }}\right|}{\sigma}
\end{aligned}
$$

Se o valor de $\Delta \mathrm{x}$ for superior ao $\Delta \mathrm{x}_{0}$, indicado na tabela abaixo, o resultado $\mathrm{x}_{\mathrm{i}}$ deve ser descartado.

Tabela A1.1 - Valores de referência, segundo o critério de Chauvenet (SILVA, 2001).

\begin{tabular}{cc}
\hline Número de medições & $\mathbf{\Delta x}_{\mathbf{0}}$ \\
\hline 3 & 1,38 \\
\hline 4 & 1,54 \\
\hline 5 & 1,65 \\
\hline 6 & 1,73 \\
\hline 8 & 1,86 \\
\hline 10 & 1,96 \\
\hline 15 & 2,13 \\
\hline 20 & 2,24 \\
\hline 25 & 2,33 \\
\hline 30 & 2,39 \\
\hline 40 & 2,50 \\
\hline 50 & 2,58 \\
\hline 100 & 2,81 \\
\hline
\end{tabular}

